C O M F O R A B L E
CONTEMPLATION 


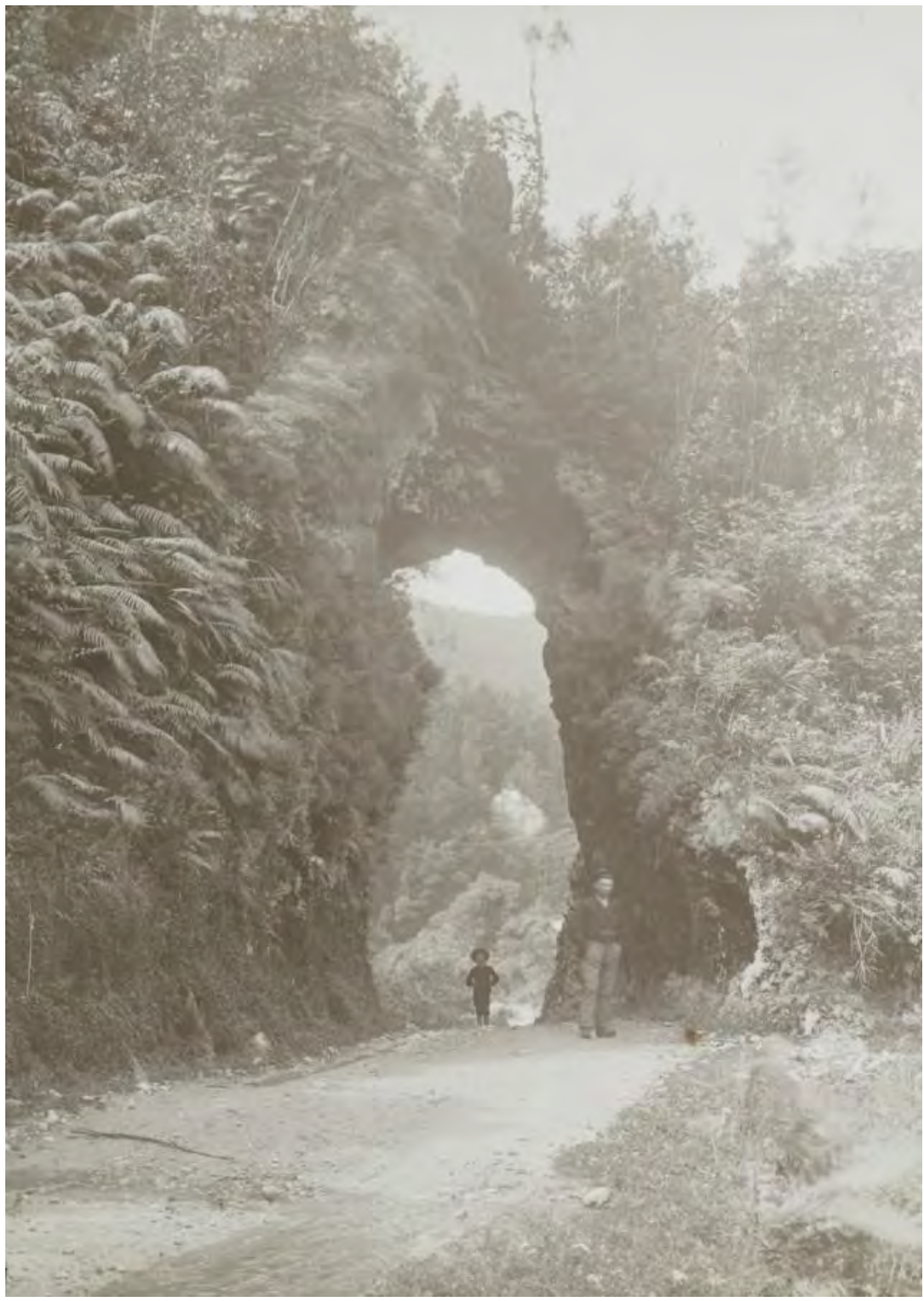




\title{
COMFORTABLE CONTEMPLATION
}

\author{
Joe Bolivar McEwan
}

A 120 point thesis submitted to the Victoria University of Wellington in partial fulfilment of the requirements of the degree of Master of Architecture (Professional).

Victoria University of Wellington, School of Architecture

February 2017 


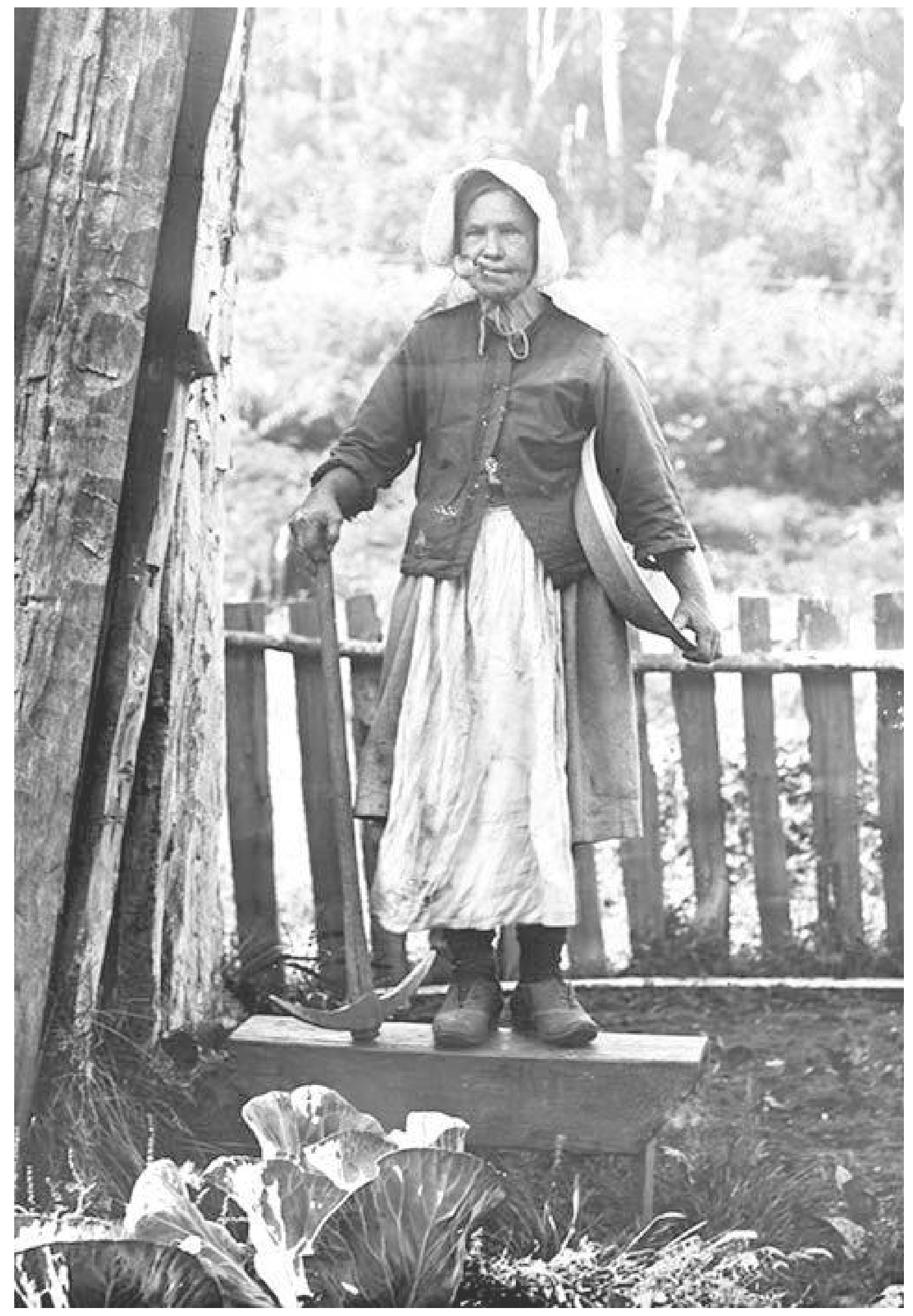




\section{ABSTRACT}

Through the design of memorial baths on the West Coast, this thesis proposes that through an increased understanding and interpretation of place identity, memorialisation can precipitate a process of understanding and healing. This process leads the visitor to gain a heightened level of mental wellbeing.

This research sheds light on, and provides an alternative to, the present state of memorials in New Zealand, identifying them as places to heal. It provides a solution of a memorial that connects people, their thoughts and memories to architecture. This is achieved through the application of the Kessler - Kübler-Ross model by facilitating participants' experience of grief through the bargaining, depression and acceptance stages.

This thesis proposes an architectural solution that sufficiently memorializes lost gold miners of the West Coast and their way of life. It also enquires into the somewhat aberrant architectural culture and identity of the West Coast and identifies methods of preserving this architectural regionalism before it is lost. This quickly disappearing West Coast identity and architectural regionalism becomes a further stimulant for memorialisation. The architectural form and composition respond to mining history and the miner's way of life.

This memorial, located deep within the Southern Alps hosts a series of natural thermal baths and contemplative spaces that prompt reflection and inner thought, transporting the visitor toward an improved level of mental wellbeing through a means of triggering memory, and providing spaces that prompt contemplation. 


\section{CONTENTS}

\begin{tabular}{|c|c|}
\hline Personal Statement .. & 008 \\
\hline Acknowledgements.... & $\ldots 009$ \\
\hline . Introduction .................... & $\ldots 011$ \\
\hline Background & 012 \\
\hline Research Question & 012 \\
\hline Research Proposition & 013 \\
\hline Methodology & 014 \\
\hline
\end{tabular}

Programme.

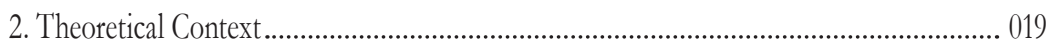

$\begin{array}{ll}\text { Introduction } & 021 \\ \text { Healing } & 022 \\ \text { Memory } & 025 \\ \text { Contemplation Space } & 028 \\ \text { Conclusion } & 034\end{array}$

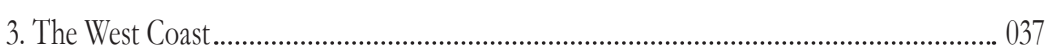

Introduction 039

Place Identity 039

Architectural Regionalism $\quad 057$

$\begin{array}{ll}\text { Conclusion } & 071\end{array}$ 


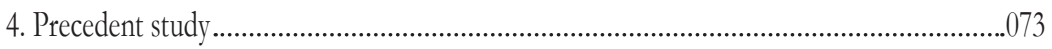

Introduction 074

Existing Precedents that outline the problem 077

Conclusion $\quad 088$

Precedents that are examples for a solution $\quad 091$

$\begin{array}{ll}\text { Conclusion } & 102\end{array}$

5. Physical Context …………………………………………………………………………....105

$\begin{array}{ll}\text { Site Selection } & 106\end{array}$

Environmental Factors 112

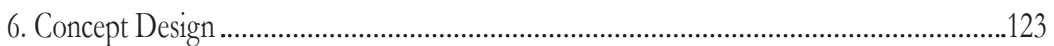

$\begin{array}{ll}\text { Preliminary Design } & 124\end{array}$

Concept Design 131

Arangement 148

Making it Work 159

$\begin{array}{ll}\text { Conclusion } & 167\end{array}$

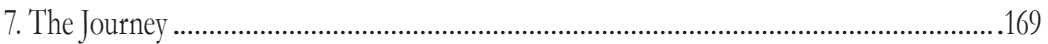

Walk In 171

Walk Out 177

8. Developed Design ...............................................................................................................183

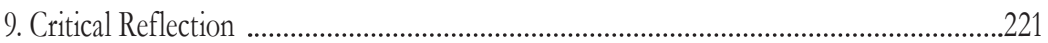

Works Cited

Figure List 


\section{PERSONAL STATEMENT}

Spending the early years of my life growing up on a farm on the West Coast I have always had a connection to the area. Living in a 'farm building' built by my father that skirted the building regulations I have grown an attachment to the more 'creative' sides of architecture, which is characteristic of West Coast architectural culture. Now, as a student of architecture my attachment to, and interest in, the uniqueness of the West Coast has grown. My belief in the importance of memorialising and preserving this idiosyncratic architecture underpins this project. 


\section{ACKNOWLEDGEMENTS}

To my supervisors Robin Skinner and Geoff Thomas, your much needed and readily given guidance, direction and knowledge has allowed me to learn a considerable amount over the course of the year, your supervision has been greatly appreciated.

To Jess for your guidance with some of the calculations. And to my family and friends, firstly sorry... But I thank you all for the little or large parts you played to help me pull this work together, your support, interest and humour has made this year much easier and enjoyable. I will forever be grateful. 
I Background

$\square$

. Introduction

Research Question

I Research Proposition

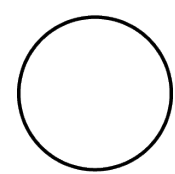

I Methodology
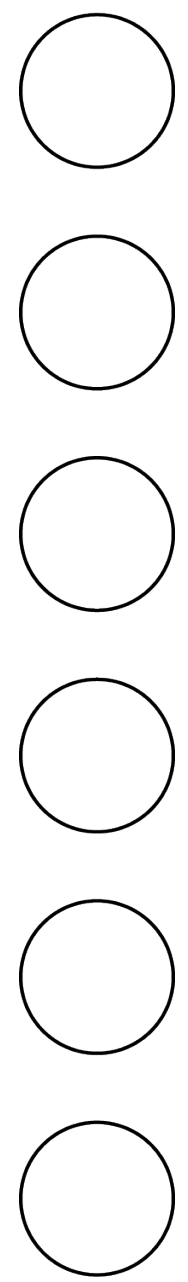
I N T RODUCTION

$/ / 1 / /$ 


\section{BACKGROUND}

The many gold miners killed in the gold rushes of the West Coast are largely unknown, unnamed people. These miners, their families and their way of life are being slowly forgotten, and descendants and friends of the lost have few places to remember. The memorials that do exist often fail to meet the basic requirements of a memorial. Furthermore the West Coast is a place with a specific, almost aberrant regional architecture that is coming under threat from economic growth and standardisation. This requires preserving.

\section{RESEARCH QUESTION}

How can architectural memorialisation of the universal and individual experience of loss through disaster provide a space for contemplation and healing, while celebrating place identity? 


\section{RESEARCH PROPOSITION}

Typically, memorials in New Zealand can be seen to have a commemorative function. This thesis aims to offer reflection on the present state of memorials in New Zealand, by providing a place to heal and where architecture connects people to their thoughts and memories. It proposes an architectural solution that sufficiently memorialises the lost gold miners of the West Coast and their way of life, and functions as a space for healing and contemplation. It also enquires into the idiosyncratic architectural culture and identity of the West Coast and offers a strategy for preserving and memorialising this architectural regionalism before it is lost.

The objectives of this thesis are to design a space that memorialises the experience of loss through disaster by providing a memorial which improves the mental wellbeing of its visitors while preserving place identity and architectural regionalism. To do this it seeks to explore the steps of grief, to prompt memory and to create a contemplation space. The preservation and reinterpretation of place identity will manifest through the design of a memorial that acknowledges the pristine landscape and context where the architecture itself memorialises the gold miners' way of life. The memorial will acknowledge an evergrowing list of mining deaths that have occurred and continue in the area. It will be thought provoking, will allow for education, reflection, contemplation and will facilitate healing. Memorials in both New Zealand and overseas contexts will be studied and the vernacular architecture of the West Coast will be explored. Theorists' writings on memory and places of contemplation will be interrogated to understand what makes a place one that triggers memory and prompts contemplation. Finally, the design solution will allow me to reflect on theorists' positions. 


\section{METHODOLOGY}

As someone who has lived on the West Coast and who operates as a designer I am in a privileged position to guide this thesis towards its outcome.

This design-led thesis undertakes research for design and research through design. Initially the linear process of research for design, gathers knowledge to support the design. The cyclic, research through design process follows. The 'problem': (How can architectural memorialisation of the universal and individual experience of loss through disaster provide a space for contemplation and healing, while celebrating place identity?) is addressed through this cyclic process. The third step, the critical analysis considers how the design responds to the questions posed by 'the problem'. Following adjustment of the 'problem', the design stage then again tries to answer the (potentially new) unaddressed questions that are identified. This cyclic process continues until the resolved design addresses all questions posed. This method parallels Murray Fraser's concept of design where:

It is vital that the design element and these other modes of research activity and research methodology operate together in an interactive and symbiotic manner, with each feeding into the others throughout the whole process from start to finish. In turn this raises an important point about temporality, in that design research should never be something that just happens at the beginning of a project... (2). 
The research through design methodology includes the use of analogue drawing and sketching for rapid diagramming and understanding of space, model making for improved understanding of scale and visual framing, visual representation to test experiential qualities and technical drawings to ensure the design solution meets the objectives.

Introduction of Design

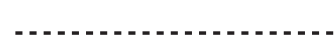

1 Introduction

Research for Design $\ldots$

2 Theoritical Context

3 The West Coast

$4 \quad$ Precedent Study

5 Physical Context

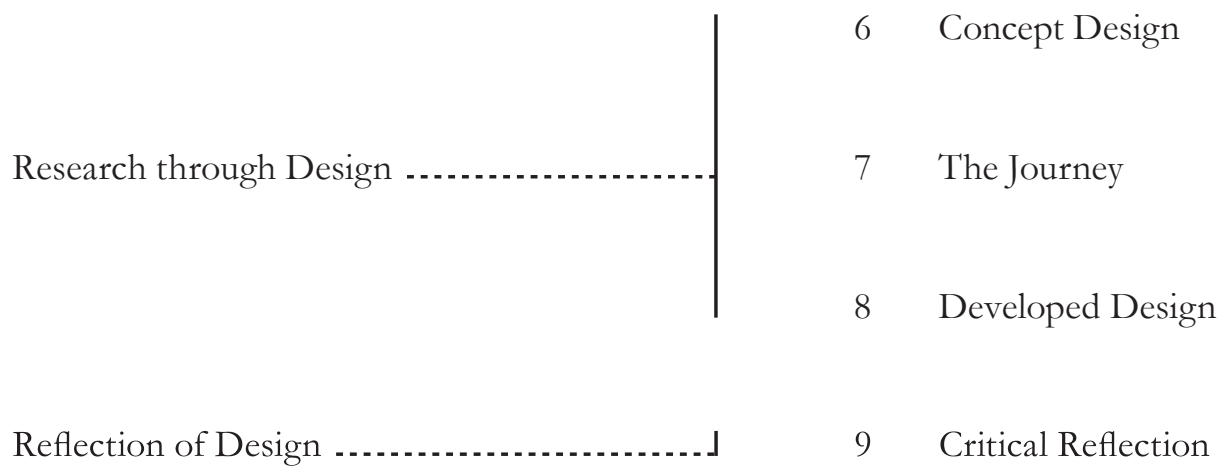

+Figure 1.03 Thesis Framework diagram. 


\section{PROGRAM ME}

The programme consists of a series of thermal baths that will be complemented by contemplation space. The baths will act as a catalyst for contemplation and improved mental wellbeing. Thermal baths were chosen to be a part of the programme for a number of reasons. Firstly, the fact the audibility of water and bathing in water has contemplative qualities as well as healing qualities (as discussed in chapter 2). Secondly, locality, there are areas of thermal activity in geographically relevant areas to that of the mining on the West Coast (as discussed in chapter 5). Finally, as the inhabitants of the West Coast expend a lot of energy protecting themselves against the - power of water - (as discussed in chapter 3), it seems paradoxical, yet appropriate that they should then find peace when it envelopes them.

People wanting to visit the memorial baths would have to bring their own food, cooking equipment and sleeping bags. Thirty bunks are provided. Two staff are stationed on site to make sure the baths run smoothly. This is a first-in-first-served facility on a regular day, however, there would be the opportunity for renting the memorial baths for a group. 

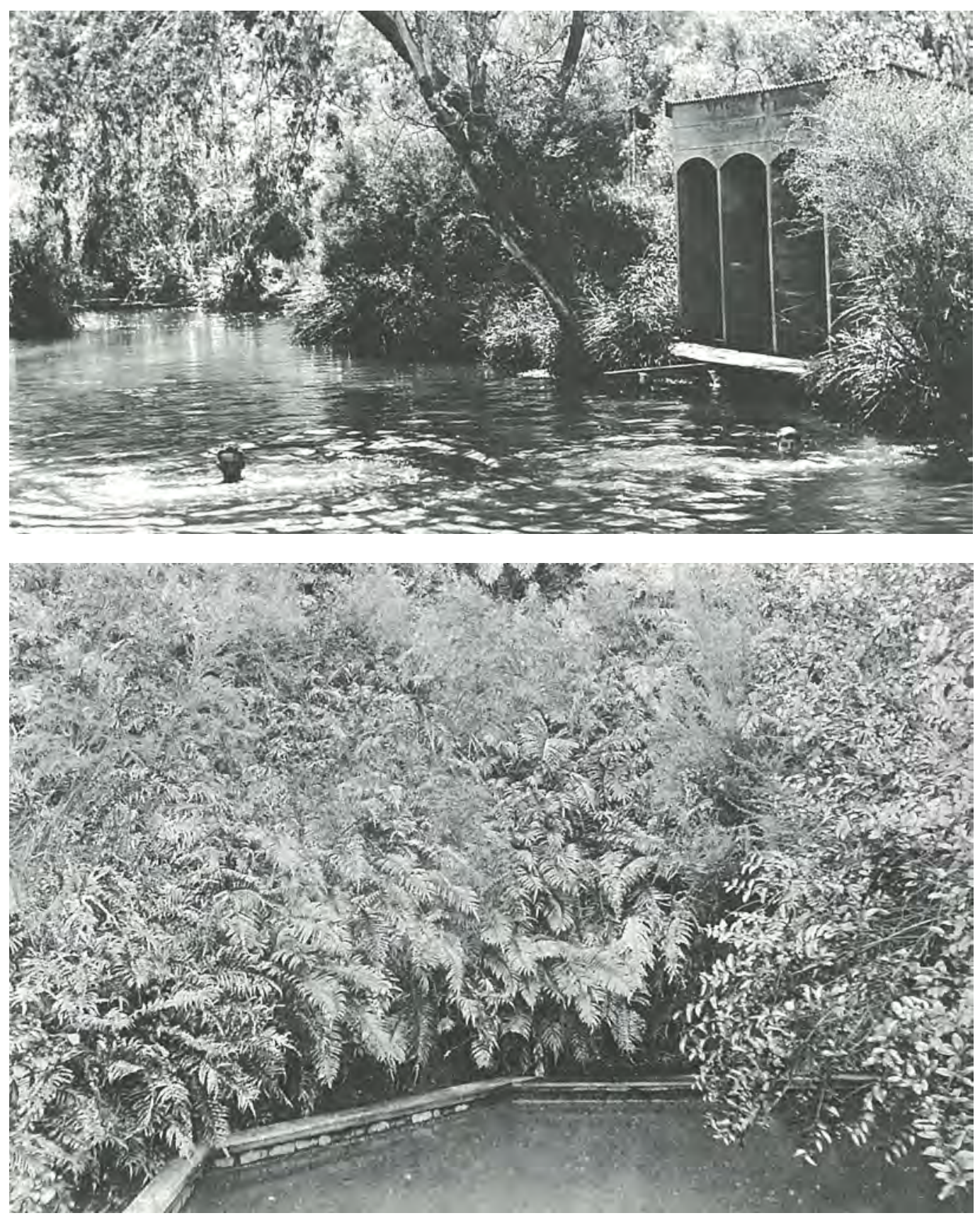

+Figure 1.04 The Crystal Springs, 1920, an early pool for batbing in New Zealand.

+Figure 1.05 The Fairy Bath, 1895, one of the most attractive early baths in New Zealand. 


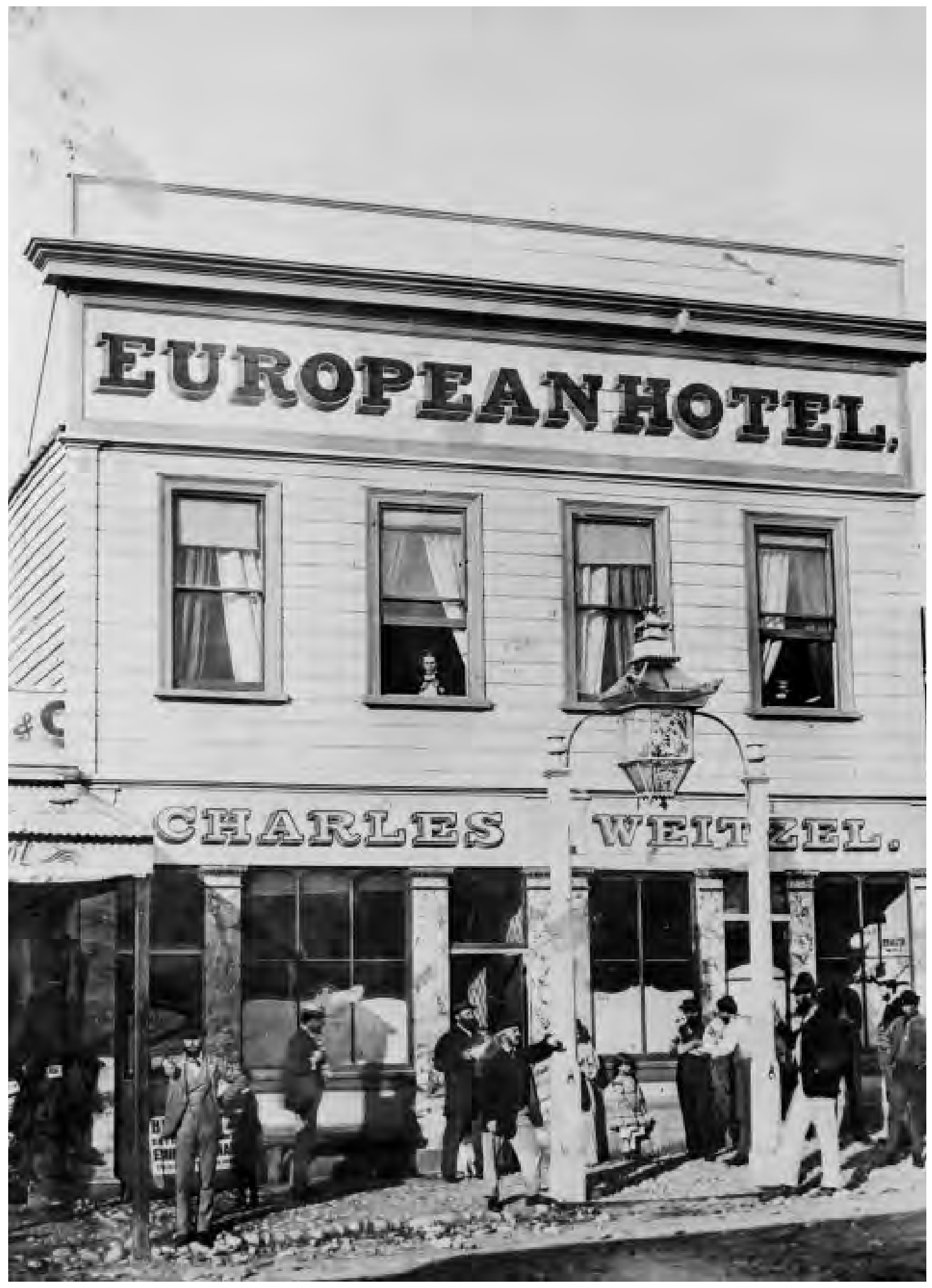

+Figure 2.01 European Hotel, Charleston, 1868, the traditional place for contemplation and healing. 
THEORETICAL CONTEXT

$/ / 2 / /$ 


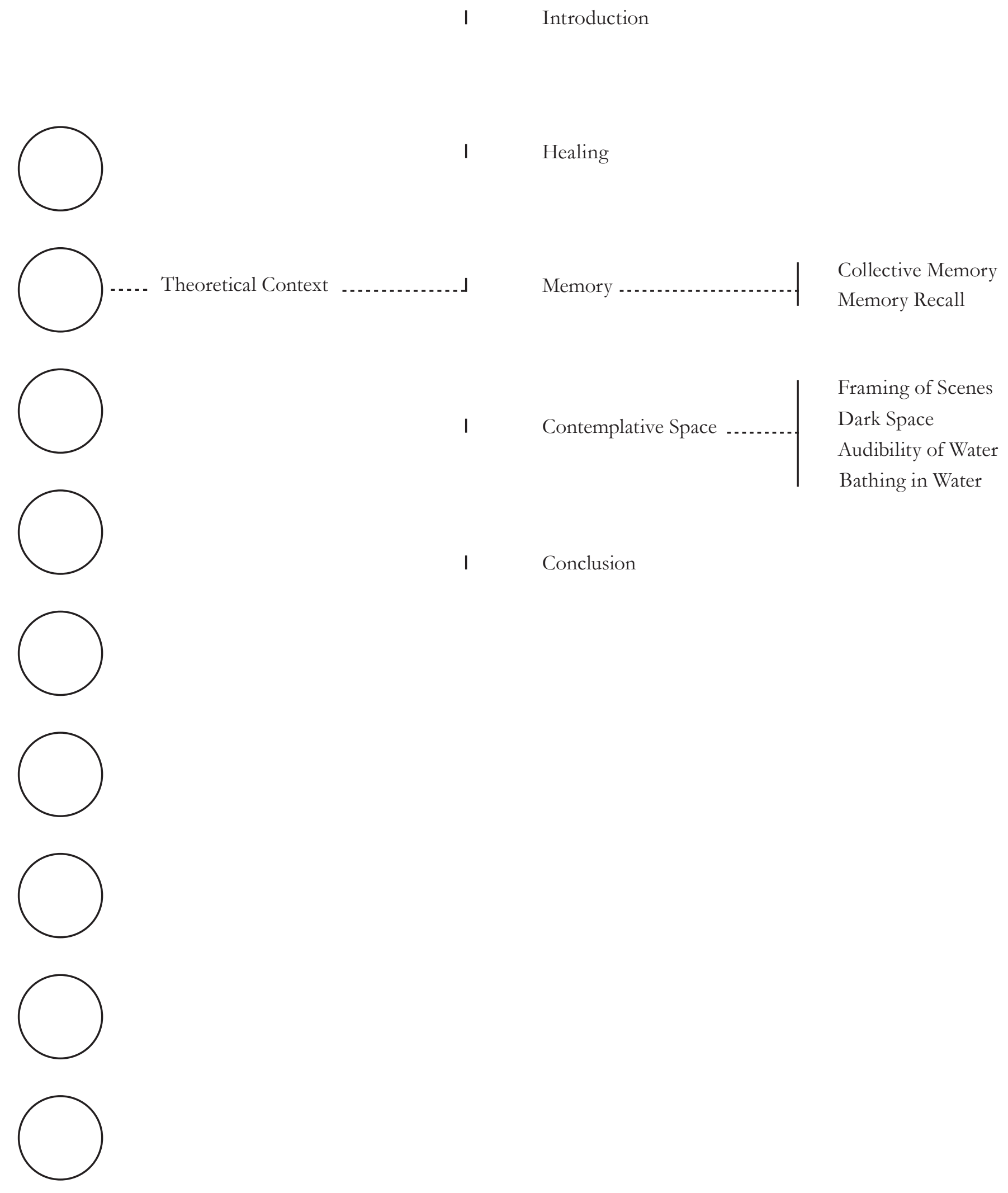




\section{INTRODUCTION}

This chapter outlines the theoretical context that this thesis fits within and discusses opportunities that can be taken forward into the design aspects of this thesis. This chapter comprises of three areas: health, memory, and contemplation spaces. All three are necessary to discuss as each provides insights into methods of designing space that improves the mental wellbeing of those who are grieving.

Grief is discussed through the writing of David Kessler and Elisabeth Kübler-Ross, the World Health Organisation (WHO), the UN High Commissioner for Human Rights (UNHCHR) and the International Covenant on Economic, Social and Cultural Rights (ICESCR). Memory is discussed through the writing of Maurice Halbwaches and Marcel Proust and contemplative space is discussed through the writing of Philip Kirke, Tadao Ando and Alev Croutier. I have chosen the writing of these people as throughout my research they proved to be the most relevant to my investigation. 


\section{HEA LING}

Edwin Heathcote argues that our deep-rooted fear of death is what drives our erection of monuments and memorials. We immortalise the dead, so they will never become forgotten, and hopefully, we will never be forgotten (8). Though this is likely true, in this thesis I argue that commemoration through memorialisation improves mental wellbeing, and we need these memorial spaces to reflect on who and what has been lost to provide paces to heal. After all "the victims are not the survivors but the friends and family of the deceased" (Collins and Opie 109).

In 1946 the World Health Organisation (WHO) defined health as "the state of complete physical, mental and social well-being, and not merely the absence of disease or infirmity" (1), further stating that: "The enjoyment of the highest attainable standard of health is one of the fundamental rights of every human being without distinction of race, religion, political belief, economic or social condition" (1). However, this was a non-legally binding document. In 1966 the UN High Commissioner for Human Rights (UNHCHR) adopted the International Covenant on Economic, Social and Cultural Rights (ICESCR), which is considered the principal document for the protection of the 'right to health'. Article 12 states: "The states parties to the present covenant recognise the right of everyone to the enjoyment of the highest attainable standard of physical and mental health" (ICESCR 20). It is important to note that the covenant gives both mental health and physical health equal consideration (UNHCHR 9). Individual states proceeded to ratify the ICESCR into their own human rights treaties. While in New Zealand law there is no expressly legislated 'right to health', by ratifying the ICESCR the state has accepted to follow the standards outlined in the Convention (Human Rights Commission 156). Grief is 
an experience that affects mental wellbeing. An aim of this thesis is to enable those experiencing grief to advance to better state of mental wellbeing. David Kessler and Elisabeth Kübler-Ross write about the five stages to grief and loss in On Grief and Grieving. They outline the stages as:

Denial - We try to find a way to simply get through each day. Denial and shock help us to cope and make survival possible. Denial helps us to pace our feelings of grief. As you accept the reality of loss and start to ask yourself questions, you are unknowingly beginning the healing process (Kessler and Kübler-Ross).

Anger - The more you feel and embrace it, the more it will begin to dissipate and the more you will heal. Underneath anger is pain. It is natural to feel pain, desertedness and abandonment. Anger is strength and it can be an anchor, giving temporary structure to the emptiness of loss (Kessler and Kübler-Ross).

Bargaining - The stage in which reflection begins, where you begin to question everything. Life becomes a series of "What if's...?" and "Why's...?" Your time is spent thinking of how things could have been different. In the bargaining stage guilt is present, you begin questioning your decisions. "What if I..." (Kessler and Kübler-Ross).

Depression - The depression stage sits squarely in the present. You have finally come to terms with the loss. You withdraw from life, wondering perhaps, if there is any point, you will also experience intense sadness. This step is often seen a form of mental illness, a state to be fixed. This is not the case (Kessler and Kübler-Ross). 
Acceptance - Where you come to terms with the fact that the lost have gone forever. Acceptance is often confused with being alright again. It's not. Acceptance is a form of readjustment, understanding that things are different from now on. We can never replace what has been lost, but we can invest in new friendships and in our relationship with ourselves. We begin to live again (Kessler and Kübler-Ross).

People often think of the stages as lasting weeks or months.

They forget that the stages are responses to feelings that can last for minutes or hours as we flip in and out of one and then another. We do not enter and leave each individual stage in a linear fashion. We may feel one, then another and back again to the first one (Kessler and Kübler-Ross).

This thesis aims to facilitate participants' experience of the bargaining, depression and acceptance stages. These stages involve internal thinking and reflection, unlike the denial and anger stages. This design project does not aim to distract the occupants from their thoughts of "what if?" or "why?" But rather, give space for this reflection to occur. Normal life does often not provide opportunity to stop and think, it does not provide adequate time to progress through the steps of grief. Utilising how people move through the bargaining, depression and acceptance stages as design drivers could enable an architectural solution. 


\section{MEMORY}

Advancement through the Kessler - Kübler-Ross model takes time: time to come to terms with what has happened and time to remember the lost. Thus an architecture that aims to confront people with their loss and triggers memory will aid the healing process.

Memorials are physical signifiers of the psychological concept of memory, and are a means of immortalising memories. The concept of memory is undoubtedly linked with memorials. Contemplative spaces facilitate space for memory recollection and therefore healing. The past and the present are connected via memory, to memorialise the past and remember the lost. Triggering of memory is then significant in the combating of grief. Triggering memory becomes a component of the theoretical foundation for this thesis. To understand methods of manipulating and triggering memory, the act of memory making must first be understood.

Memory retention, reactivation and reconstruction is a process where information is sensed via physical or chemical stimuli, encoded and stored in either the sensory memory, the short-term memory, or the long-term memory. Memories are then retrieved when stimulated by conscious thought or certain triggers.

Maurice Halbwachs' concept of 'collective memory' is well established by substantial testing and consequent theories (Brown 297 - 314; Assmann and Czaplicka 125 - 133; Dwyer and Alderman 165 - 178). It states that 'collective memory' is memory and knowledge that is shared and stored within the members of a group (Halbwachs 23). All memories are a collective experience as it is virtually impossible to have a purely individual experience. The social circles we identify with, the books we read and the songs we listen to all influence our memory. "In reality we are never alone. Other men need not be physically present, since we 
always carry with us and in us a number of distinct persons" (23). Pure individualistic memory cannot be possible due to the level of sociability we have as people.

Now that memory forming has been outlined the remainder of this chapter will take an interpretive look at the memory retrieval theories of Maurice Halbwachs and Marcel Proust. These two writers are considered because they have quite differing views, both of which are very relevant to this research. Halbwachs believed memory is made through a collective group, consequently, the triggering of memory is achieved through a purely collective experience also. Only through the presence of people that an individual shares their memory with, (be it psychological presence or physical presence) can it be consciously remembered. Marcel Proust's approach, 'Proustian memory' differs, as he understood memory retrieval as a sensual experience. Where an individual can still experience the memories as much as a group but though involuntary memory retrieval such as visual, auditory, haptic, olfactory or gustatory cues instead.

Conscious memory retrieval is a more powerful means of remembering than involuntary memory recall, a collective group of people remember a greater amount of information. A collective remembers more than a single individual because each individual in the group has their own unique background, experiences and personalities. However, due to 'free-riding' (Delton et al. 1252-1270) and 'social loafing' (Ringelmann 1-40) an individual in a group situation will remember less than an individual in an individual situation. An individual experiencing an event on their own will remember more; they unconsciously understand no one else can contribute and duly compensate. Conversely, a person in a group knows they are surrounded by people sharing that exact experience and consciously or unconsciously rely on the others in the group for information and memory. Although a collective memory is broader than an individual's memory, it also leads to 'collaborative inhibition' (Basden et al. 1176-1189) where a group experience can become generic and restricted by 
the collective information of the group. Basden et al. found that pressures toward conformity can influence collaborative group performance and unique experience can be over-shadowed (1187). The assemblage of collective memory can mean a group member with a louder voice, or a better story teller, may have a higher degree of sway in the combined collective memory. Thus collective memory can be highly malleable and subject to change over time (Stone and Hirst 320).

Marcel Proust believes, the past and present are connected neither by collective memories nor by conscious memory recall, but by individual acts of involuntary memory triggered by the senses (Proust 48 - 50). Involuntary memory triggered by the senses recalls unique memories that the individual can only have experienced themselves (Smith 38). The memory may have been forgotten by the individual, but the specifics of that memory were imprinted and the triggering of certain stimuli returns the memory. As these are memories that cannot be consciously retrieved or recalled, the surrounding space must provide the sensuous stimulation.

The vast majority of victims who have experienced loss in their family would remember through a collective memory process, therefore we should design a building that facilitates conscious, collective memory recall. However, the smaller proportion of people who have first-hand experience with the loss of family members or friends to gold mining, could experience triggers for involuntary memories, 'Proustian memory'. Unlike collective memory, 'Proustian' memory is a very unique and intimate experience. To situate memory recollection in this thesis would be to align it with both Halbwachs and Proust. Both are important methods of recall that will drive the design portion of this thesis forward. This design strategy leads to a more achievable outcome in relation to healing and remembering. 


\section{CONTEMPLATION SPACE}

Extended time in a comfortable contemplative space for the recollection of memory is as important in the process of healing as the triggering of memory itself. This chapter reviews existing knowledge on architecture for healing, drawing from the design of spiritual contemplative spaces. The spiritual, contemplative approach to gain a heightened level of mental wellbeing will often lead to healing through a means of transcendence and inner peace.

Here I am confronted with the problem of designing a physical space that expresses something intangible. A number of architectural interventions facilitate transcendence to a place of contemplation where sensual experiences can be evoked. These can be visual interventions through the concept of evoking the infinite through formal extension and the framing of specific scenes, or through the darkness of space. They could be experienced haptically through the act of bathing in water or audibly through the use of moving water.

Experiencing or viewing the infinite is one means of transcending to a place of contemplation. Philip Kirke outlines methods of overcoming issues regarding the design of the intangible. He states that to design an architecture that triggers awakening, enlightenment and facilitates contemplation, two fundamental elements must be understood. Firstly: "How architecture impacts upon and directs conscious experience"; and secondly: "Potential conscious preconditions and triggers to conscious awakenings, such that might precede Enlightenment" (8). Kirke then provides us with a possible means of joining these seemingly disparate statements through the dictum, 'to love one's neighbour'. Love is something infinite and transcendent, something intangible. A neighbour, however, is something very tangible, with proximity. Architecture then, could also seek the union of such a paradox, 
the intangible and the tangible, the infinite and the intimate, to be prompted toward contemplation by physical form (Kirke 12). Firstly, when dealing with the infinite we must understand that infinity can never physically be reached or captured. Lyle Massey puts is well:

\footnotetext{
It would be fallacious to claim, either that the infinite can be stopped, frozen, and spacialised in pictorial terms, or that is possible to represent a centre to infinite space.... The mathematical concept of infinity requires that access to the continum be imagined in terms of a constantly displaced de-centred point (15).
}

\section{FRAMING OF SCENES}

The framing of scenes and evoking the infinite is an important aspect of contemplative space. "In architecture, the infinite may be inferred by directional extension beyond itself" (Kirke 23). This extension, or the gesture toward the infinite draws the viewers' focal point. This extension could be capturing and framing a subject and thus drawing the viewer into it. Inevitably there will conversely be the drawing of this subject toward the viewer. Kirke writes of a perfect, framed view he glimpsed from a suburban setting. You were transported into it, or rather, it to you, "it was inserted into suburban normality like a revelation" (32 - 33). The horizontal extension of the frame transported you into the scene, not physically, but spiritually. These formal 
cues gesture toward an extent less infinite, they prompt the gazer to search, to dwell and to contemplate.

Similarly, when the framing of pictorial art cuts off significantedges or geographical features, the qualities within become seemingly limitless. This is simple enough to achieve in pictorial art, as the artist has to decide what will be included. While photography positively includes things, here we passively include things and have to explicitly exclude things. This is where architectural composition has to emulate photography and explicitly exclude things. Through careful consideration concerning what is present and absent in the architecture, or the glimpses the architecture is allowing its visitor to gaze upon, architectural spaces can be manipulated into spaces of contemplation. "Meditation is the discipline of consciousness. Architecture may direct the contents of consciousness by gathering or excluding views, sounds, visual and sensory stimuli" (Kirke 63). When an architecture is simple and calculated it can remove some sensory stimulation from the visitor. In doing this, it can express others and begin to encourage enlightenment. "What architecture may welcome or exclude from its spaces, it welcomes or excludes from the minds of its occupants" (64). It is understood that humans have a genetic tendency to respond positively to nature (Wilson 1 - 176) and views of nature have the power to speed the rate of recovery and better emotional our well-being (Ulrich 420 - 421). When Kirke writes about the framing of scenes he often refers to the framing of purely natural scenes.

I should emphasise that it is not only the framing of the scene that has the power to encourage contemplation, but it is also how we interact with that framing at an intimate level. For instance, when an occupant gets an intimate, unique view of something that directly engages his or her actual needs or desires that is perfectly framed, it has the power to prompt an emotional response (Kirke 49). It is not only the viewed scene that is important, but under what condition the scene is viewed from and how does the viewer's window or opening reflect the human scale? Finally, if 
the correctly framed scene presents itself as a 'surprise' this can also elicit a mental response. When the opening could have been 'normal' from an oblique angle, where it is in actual fact framing a very specific scene and only when in the desired location does the opening fully reveal itself to the viewer can 'surprise' be gained.

\section{DARK SPACE}

Darker spaces can have the power to prompt a mental response from occupants. They can prompt contemplation and take the visitor to places of memory. Tadao Ando acknowledges how darker environments can elicit a powerful spiritual sense. He believes there are two types of comfort, 'spiritual comfort' and 'physical comfort'. Where physical comfort can be sought in light, spiritual comfort is sought in darkness (Blackwood). He believes darkness enriches your soul but modern architecture has eliminated this through the design of bright spaces (Blackwood). Darker spaces with shafts of penetrating light can have a profound effect on viewers. They are often cast into places of deep inner reflection. Ando uses this uncontrollable human impulse to elicit contemplation in his architecture. The Church of Light (1989) is a good example of this. John Eberhard also comments on the need of both dark and light space. He suggests that architectural spaces with both light and dark areas will elicit higher emotional responses compared to similar spaces with no dark areas (98). Kirke's writing aligns with both Eberhard's and Ando's: "Such 
unexpected and unfamiliar luminosity might evoke powerful recollections of things not yet seen" (Kirke 34). Kirke further attempts to explain that irregular, unique lighting surprises you and could prompt the occupant toward enlightenment. Darker spaces elicit comfort, so with no one watching, you can be yourself, be confident and be comfortable. This confidence and comfort allows for a moment of rest.

\section{THE AUDIBILITY OF WATER}

The sound of moving water, of water over river boulders or rain falling in a forest has an inherently calming and soothing effect on people. Water is very important to our spiritual wellbeing. It is often a person's deepest sanctuary, their place of spiritual wellbeing will be near a place of water. "The most fundamental need of the body is water. And with body and spirit so intimately one, perhaps it is a case of spiritual need understanding physical need" (Kirke 53 - 54). Water then is such a physiological need, that it becomes a requirement of our spiritual, psychological health. Tadao Ando understands the movement of water in a similar manner. Water is infused throughout the body of his works. He links the act of contemplation to water through works: the Church on the Water (1988) and the Pulitzer Foundation for the Arts (2001). Ando manipulates water to "create a space for the contemplation of art and the cultivation of spirit" (Ando 154). In the Meditation Space (1995) Ando manipulates the audibility of water as means of calming, and thus creating spaces for contemplation (53). 


\section{BATHING IN WATER}

For centuries folksongs and poems have claimed that hot springs could cure many ailments (Croutier 111-112). The euphoria felt and the therapeutic qualities of thermal water has long been appreciated. For at least seven hundred years the Maori have utilised the qualities of thermal water for bathing, therapy and rituals (Jackson 10). Bathing culture has gone through countless phases. From rudimentary mineral springs that offered both spiritual and physical cures (Croutier 108), to locations for erotic rituals to take place, to sites of rigorous cleansing and finally to our present time with our scientific understanding that recognises the abilities of hot water to expand blood capillaries and act as a catalyst in muscle recovery. There is no longer the need to search for healing waters to alleviate aches and pains with modern medicine so easily accessed (Rockel 182). However, the spiritual, therapeutic qualities of water must still be acknowledged as mineral thermal water has un-quantitative positives. Baths force you to sit and contemplate; "There is magic in it. Let the most absent-minded of men be plunged in his deepest reveries... as everyone knows, meditation and water are wedded forever" (Croutier 61). In a bath a person is very restricted to what they can do, there are few distractions. You are compelled to look inwards, the ability to compel a person into contemplation is very important to this thesis. 


\section{CONCLUSION}

The three sections to this chapter: Health, Memory and Contemplative spaces work together very closely. To progress through the bargaining, depression and acceptance stages of the Kessler - Kübler-Ross model you need to confront your grief. This involves the recall of memories and design that prompts memory recall through either 'Proustian memory' or Halbwaches' 'collective memory recall'. To provide space to remember, a space that facilitates inner thought, prompts contemplation and stimulates the senses is required. Thus contemplative spaces that exhibit these aspects are essential to facilitate healing and gaining a heightened level of mental wellbeing. Across the design the three areas of research, health, memory and contemplation spaces together will provide space for improvement of mental wellbeing. The intertwining of these aspects are fundamental as they are so interconnected and the inclusion of one aspect with another results in a more powerful experience for the visitor. The Kessler - Kübler-Ross model will be explored and tested through the circulation and the programme of the design. Theories on memory will be explored through the tactility of surfaces, the audibility of spaces and the scale of spaces. Contemplative space will be explored through the light qualities, the connections between spaces and landscape and the use of water throughout the design. Finally, reflection on the architectural solution in light of the writers' texts can be made. 


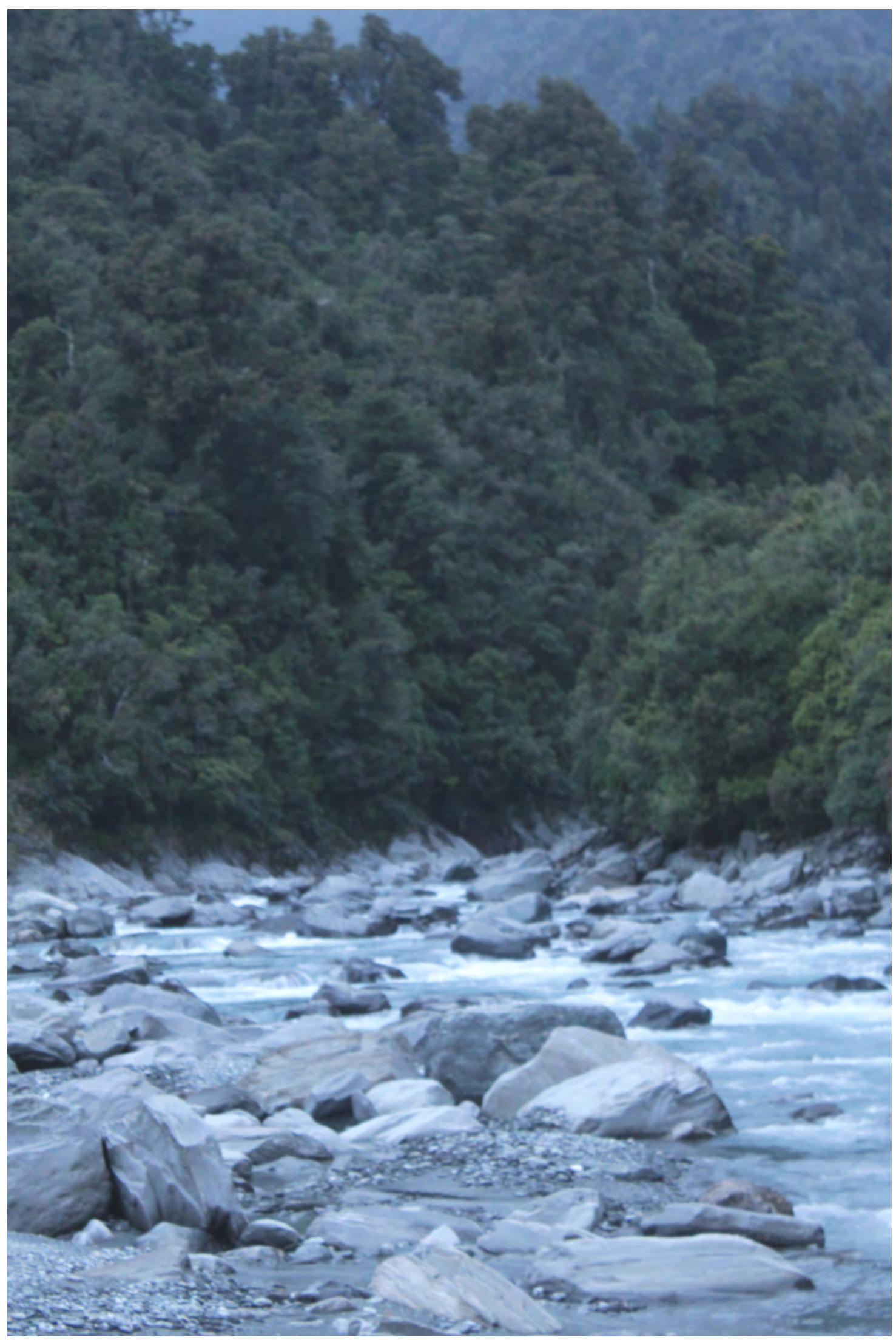




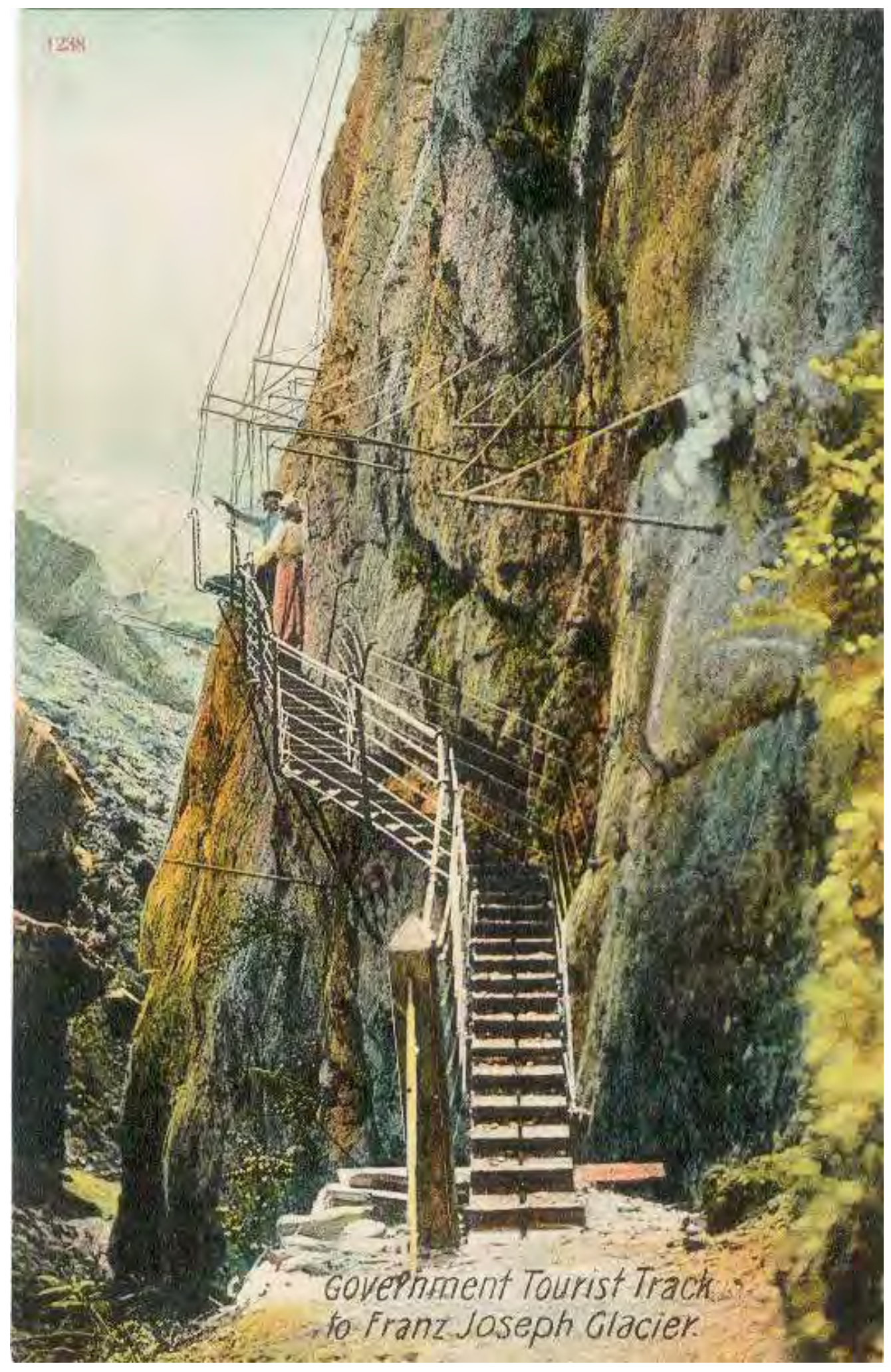




\section{THE WEST COAST}

$/ / 3$ // 

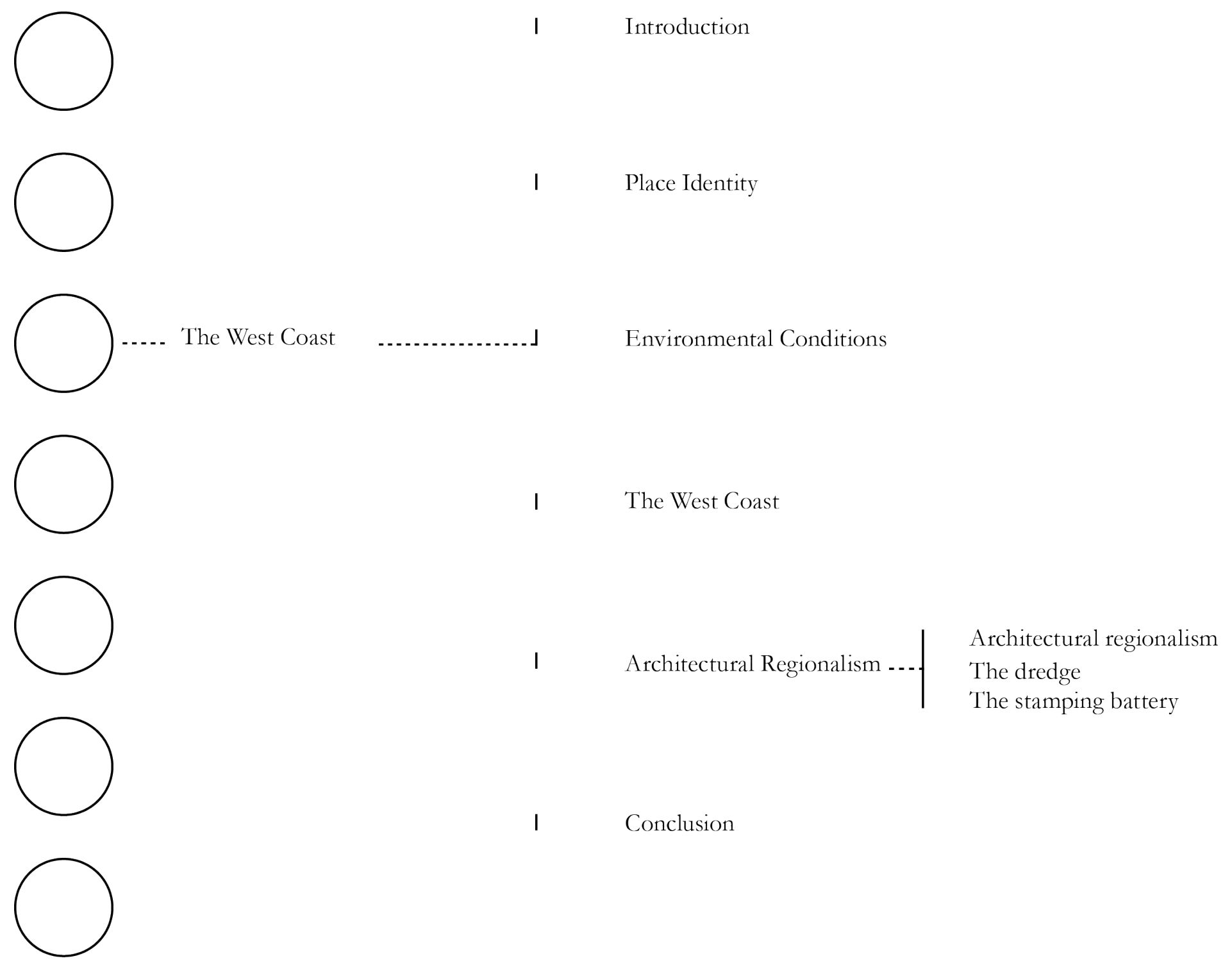

Conclusion
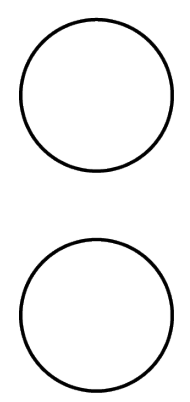


\section{INTRODUCTION}

This chapter serves to define place identity and architectural regionalism and then identify what these are on the West Coast. The chapter begins with a broad analysis of environmental conditions and finishes with research and analysis of the place identity and architectural regionalism.

\section{PLACE IDENTITY}

Place has a different meaning to that of space, location or territory. 'Places' are an intertwining of specific landscapes, activities, meanings and human habitation (Relph 3). 'Places' are 'spaces' that have been imbedded with memory, meanings and feeling; as opposed to territories which are a political construct to control geographical boundaries (Hague and Jenkins 4). 'Place' is also different from location. 'Place' is a mix of history, sensory experience and interpretation rather than a set of coordinates. Place identity is intrinsically linked with geography, cultural factors and historical factors. Identity is a non-static portrayal of a locality that is built through connection, "we do not have our beings and then go out and interact, but that to a disputed but none-the-less significant extent our beings, our identities are constituted in and through those engagements" (Massey 5). It is about being able to identify yourself, or a group of people from all other people, to reinforce the fact that we are all, too some extent, unique. In this globalising world a sense of grounded-ness, a sense of connection to 'place' becomes all the more important. There needs to be place-to-place differentiation. The global is associated with space, capital and history; while the local, conversely, is often linked to place, labour, women, and the poor (11). It would seem, then, that 'place' is inevitably the victim of globalisation. However, this is not always the case, for places are also the moment through which the global is invented (11). 


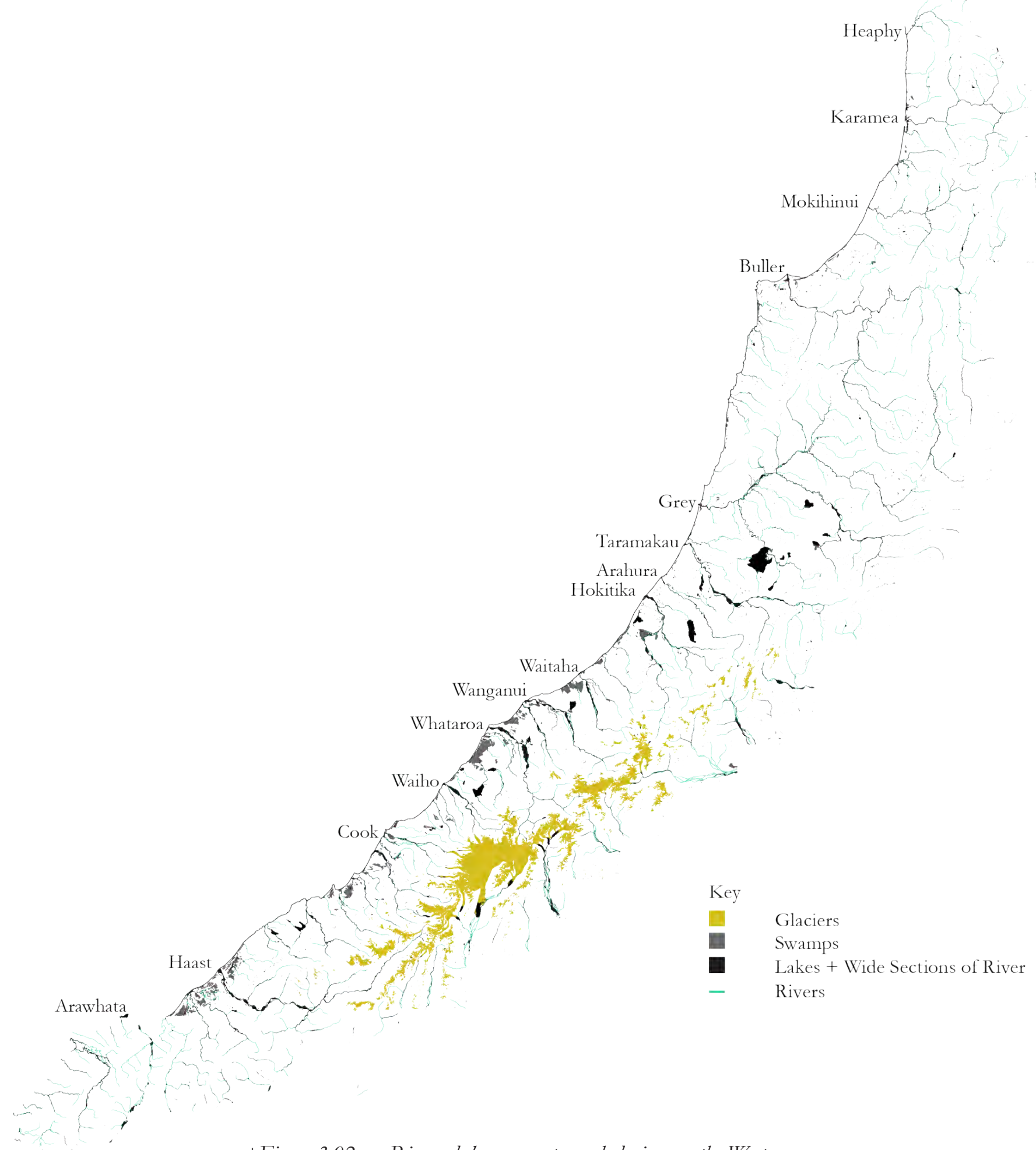

+Figure 3.02 Rivers, lakes, swamps and glaciers on the West

Coast. 


\section{ENVIRONMENTAL CONDITIONS}
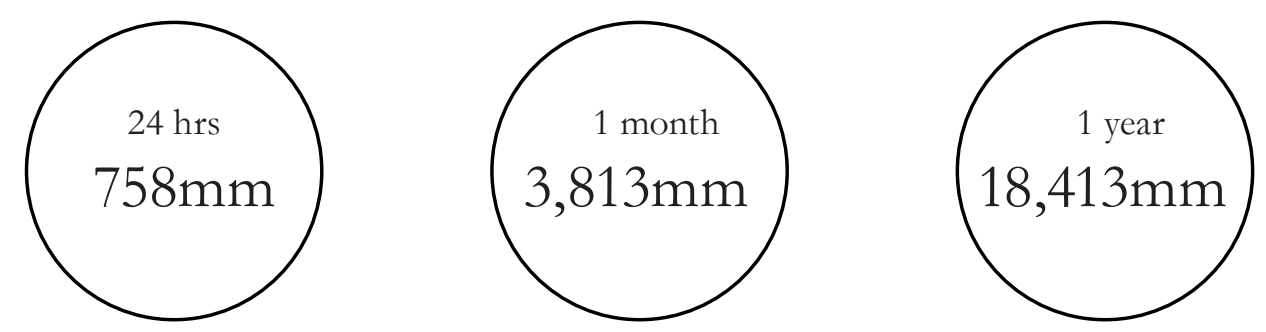

+Figure 3.03 Maximum rainfall statistics for New Zealand data recorded at Cropp River waterfall (NIWA).

The many large rivers are fed by excessive rainfall and stay swollen throughout winter. In the spring when temperatures warm, these rivers see no respite as the sun causes the glacier fed rivers to stay high. Water is such a barrier for the people of the West Coast: it is so involved in their lives, it controls when and how they can do things. 


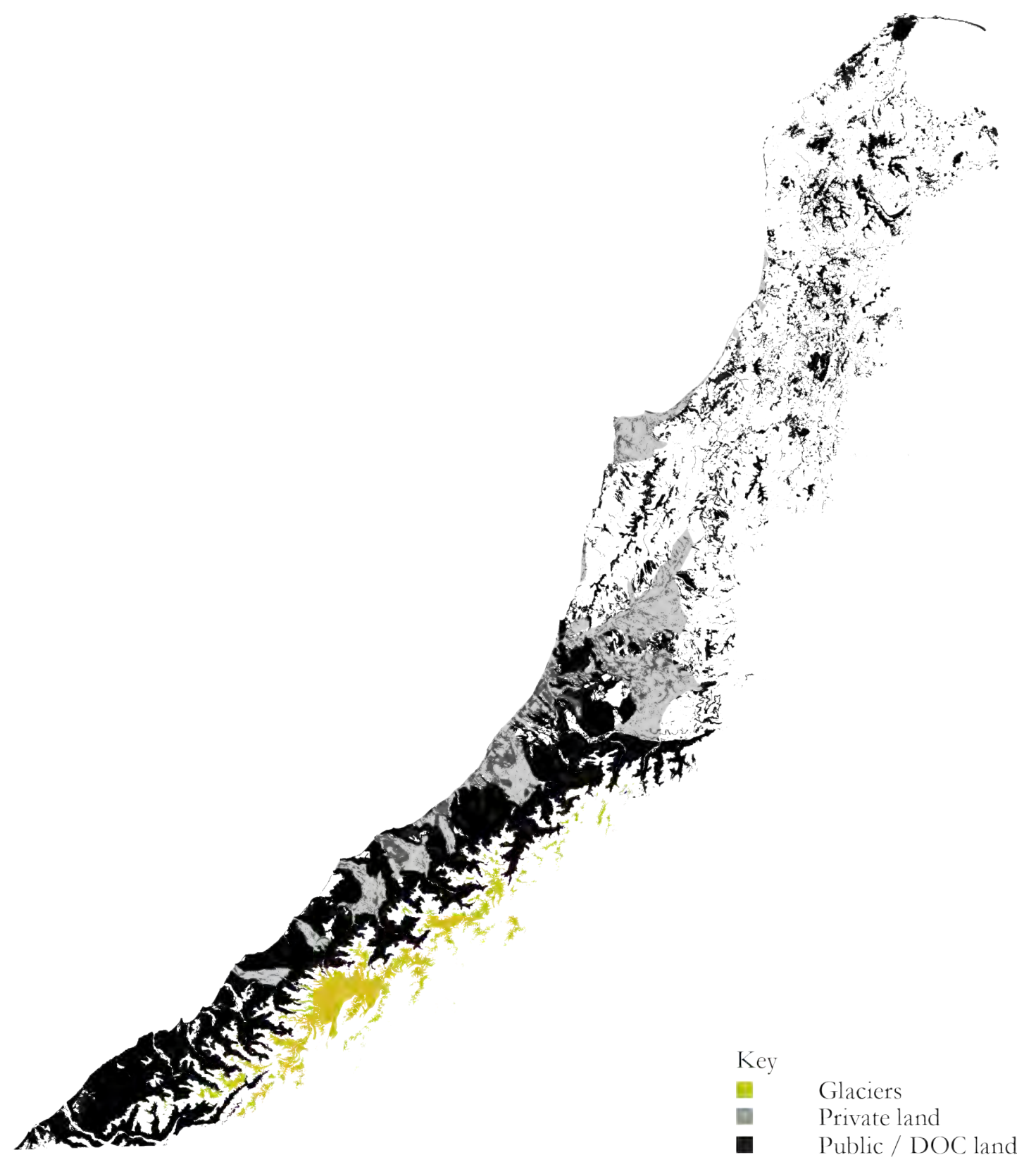

+Figure 3.04 Forested areas + public and private land. 


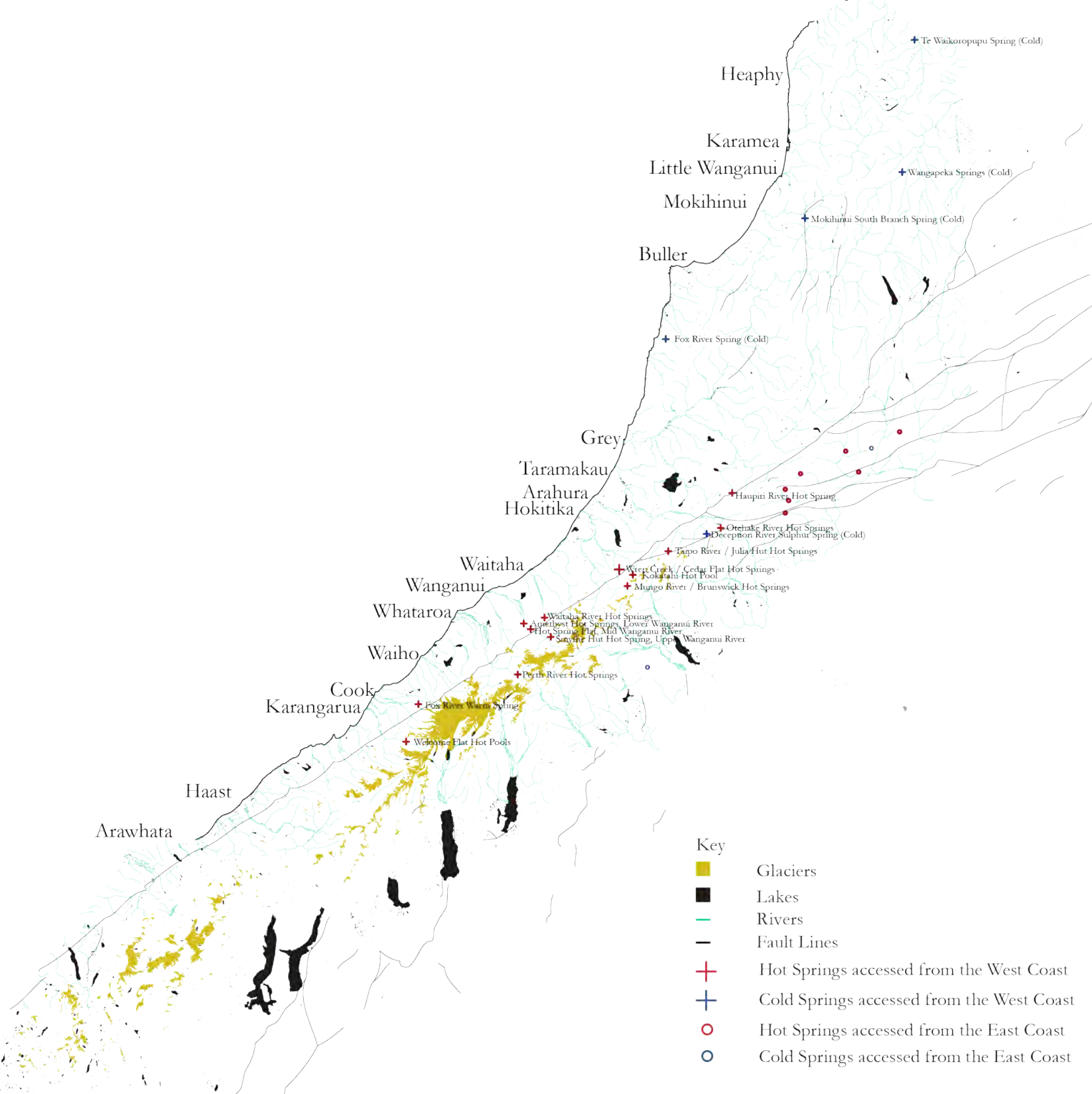

+Figure 3.05 Fault lines and thermal areas on the West Coast. 


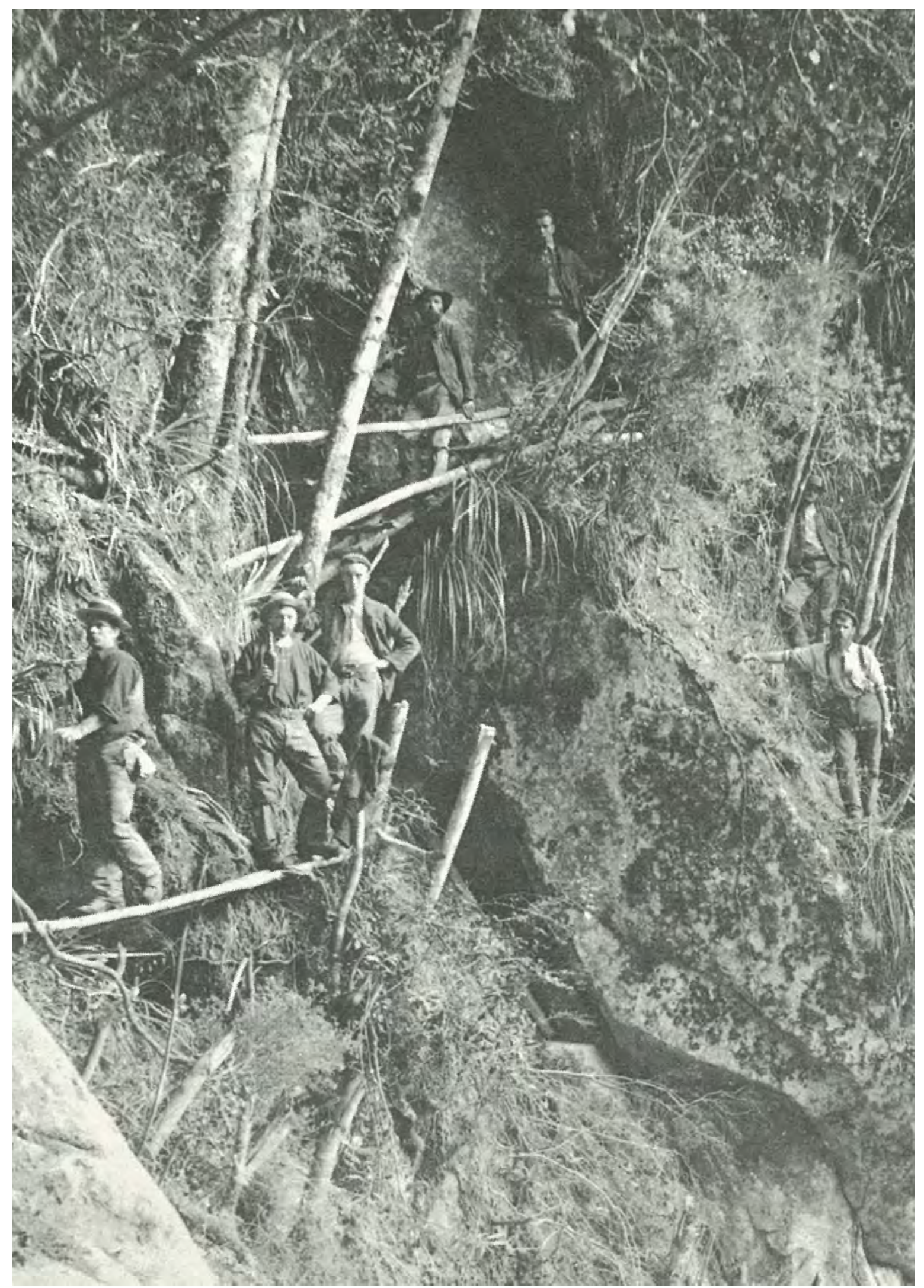




\section{THE WEST COAST}

In 1846 Thomas Brunner and Charles Heaphy led the first European exhibition to the western coast of the South Island, they referred to it as the 'West Coast'. Due to the place identity assigned to the area by the locals and the distinctive landscape the West Coast hardly necessitates the addition, 'of the South Island' to give it context.

Access to the West Coast was originally limited as the Southern Alps presented a huge barrier. There were few Maori living on the West Coast with visitors only venturing down to retrieve greenstone. The Maori were forced to go either by canoe around the top of the island, or over alpine passes. The climate was not conducive to large populations, thus there were few Maori settlements along this coastline. When Brunner explored the West Coast in 1846 he found it extremely isolated with access and travel made difficult by high rainfall and numerous swollen rivers (Brunner 31).

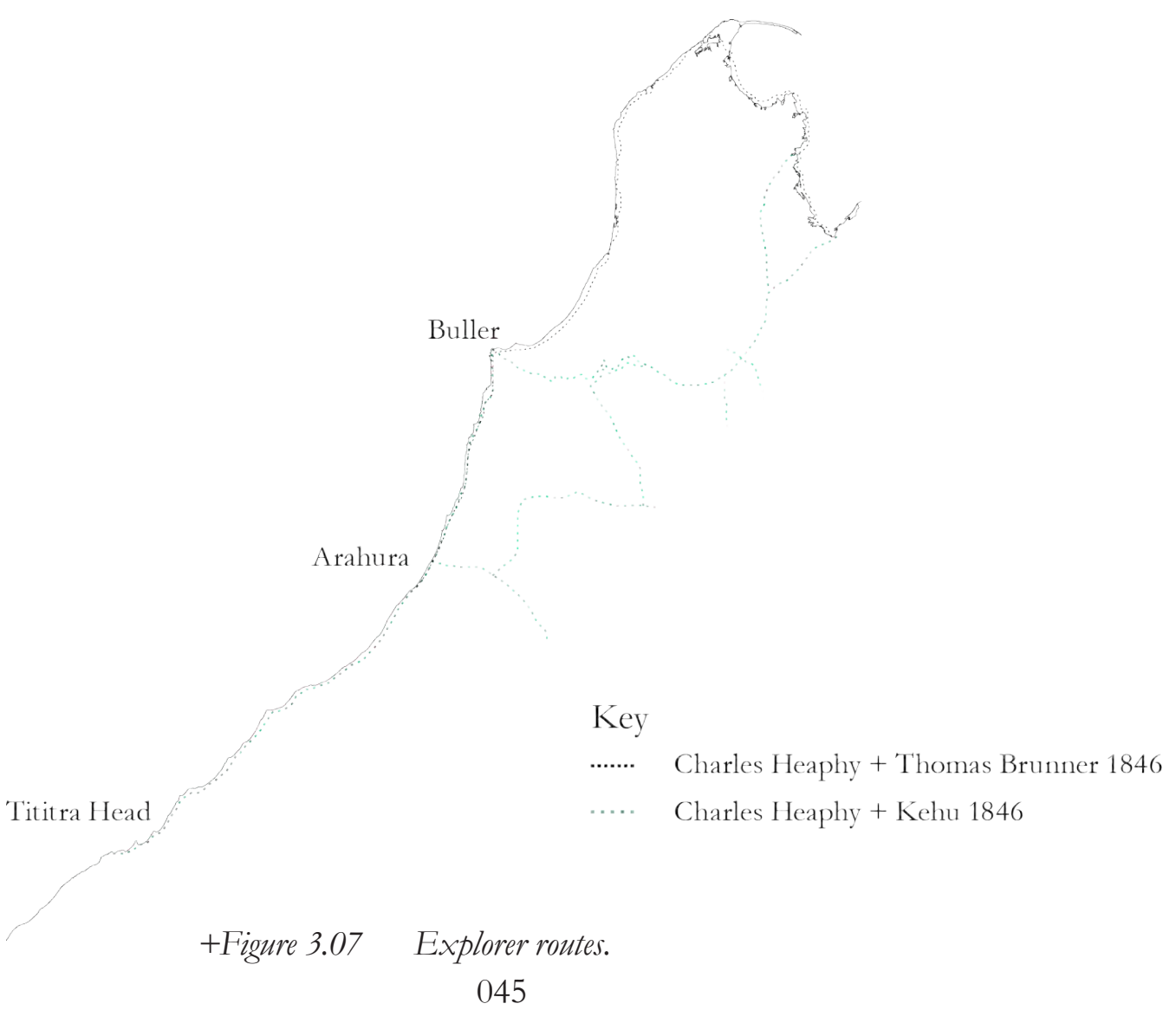




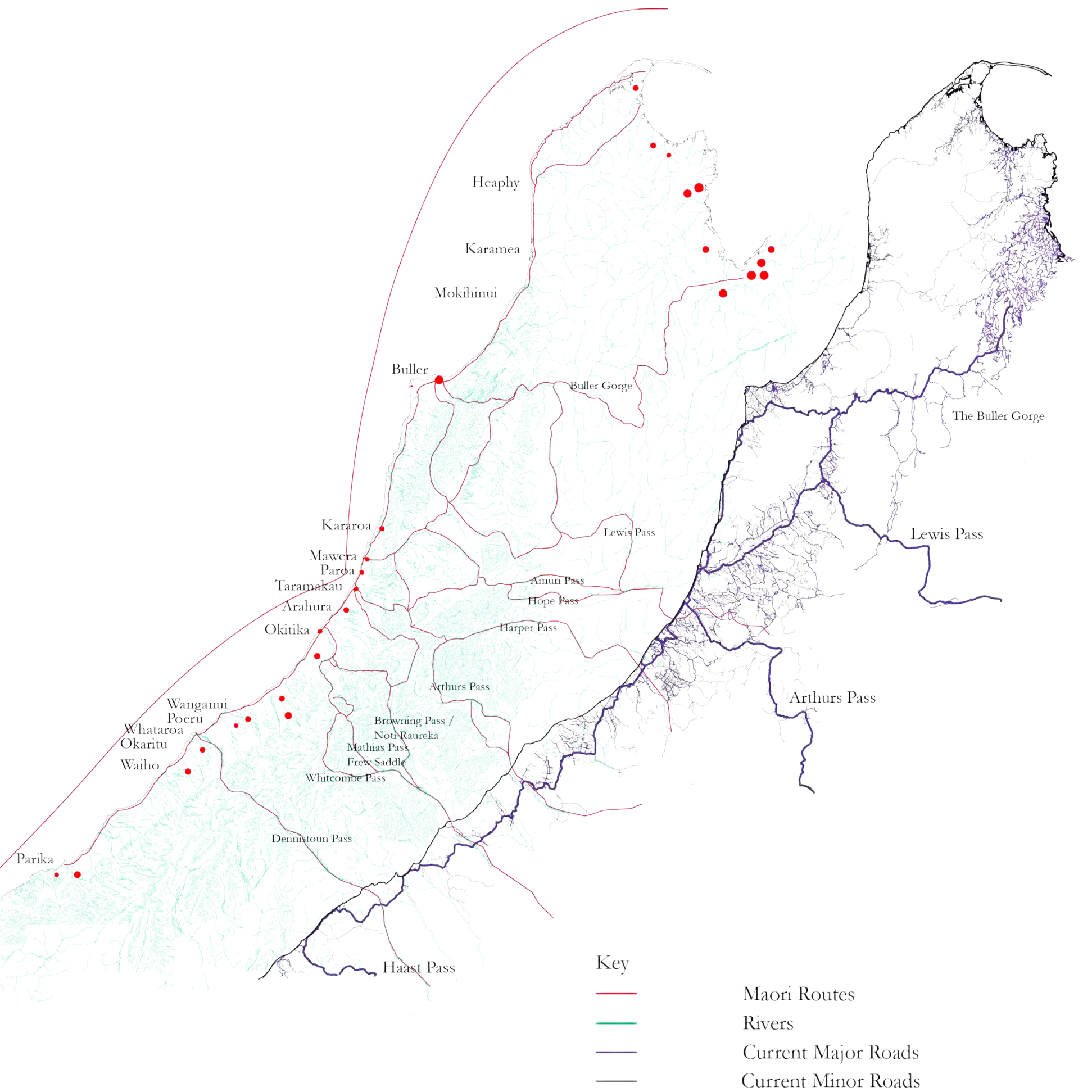

+Figure 3.08 Maori access routes.

+Figure 3.09 Current access routes. 


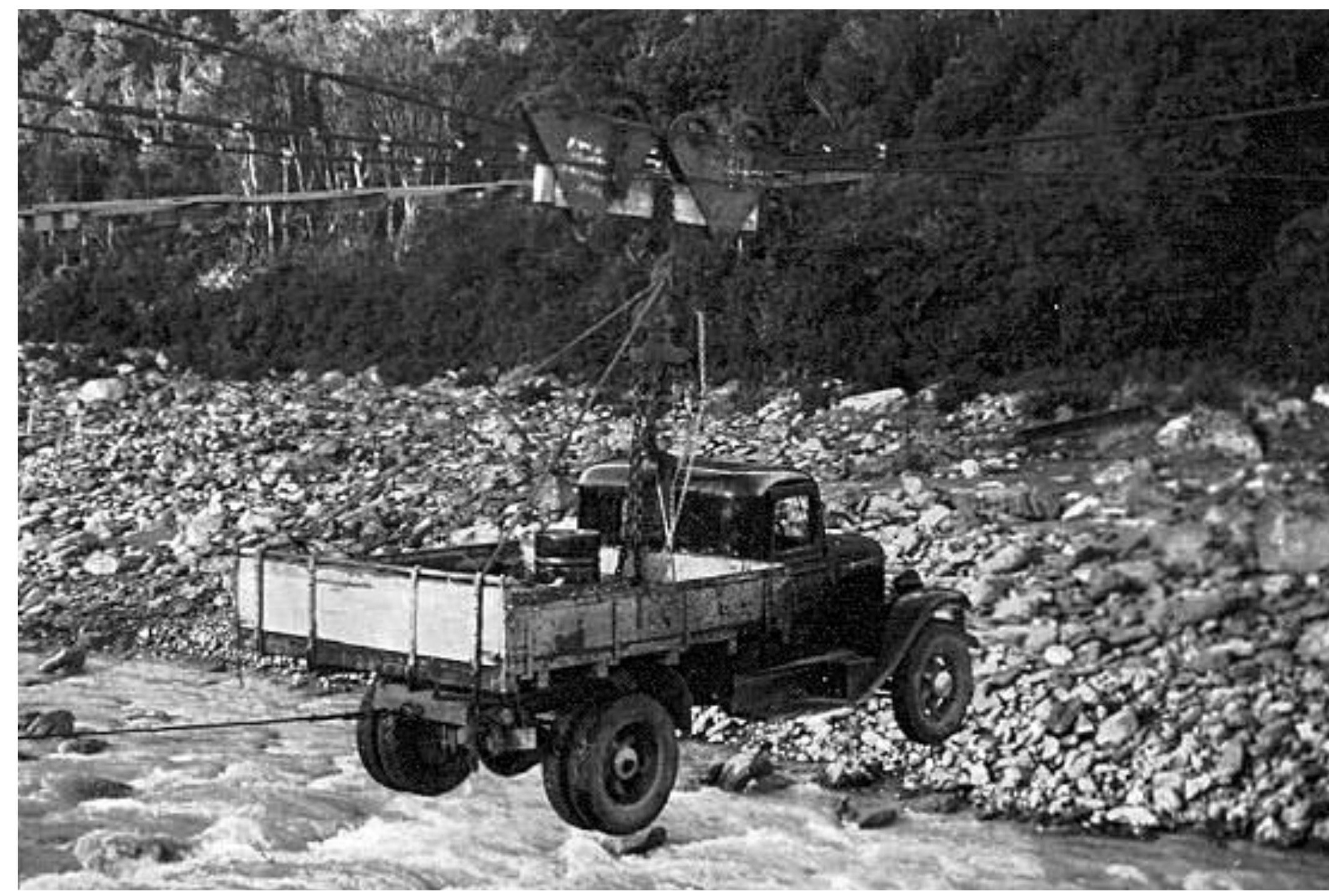

+Figure 3.10 Fox River bridge South Westland, before more permanent infrastructure. 


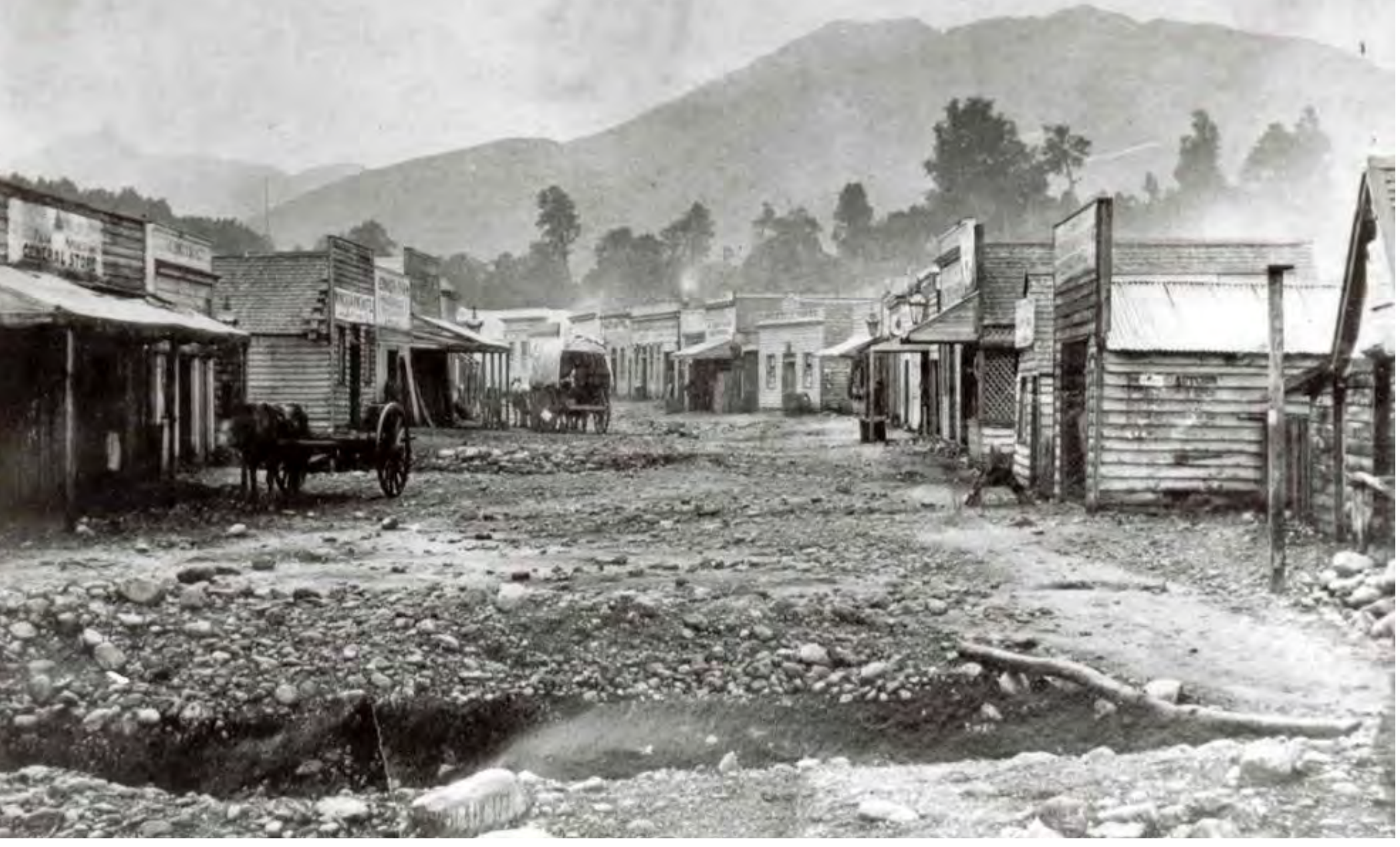

+Figure 3.11 Greenstone 1866.
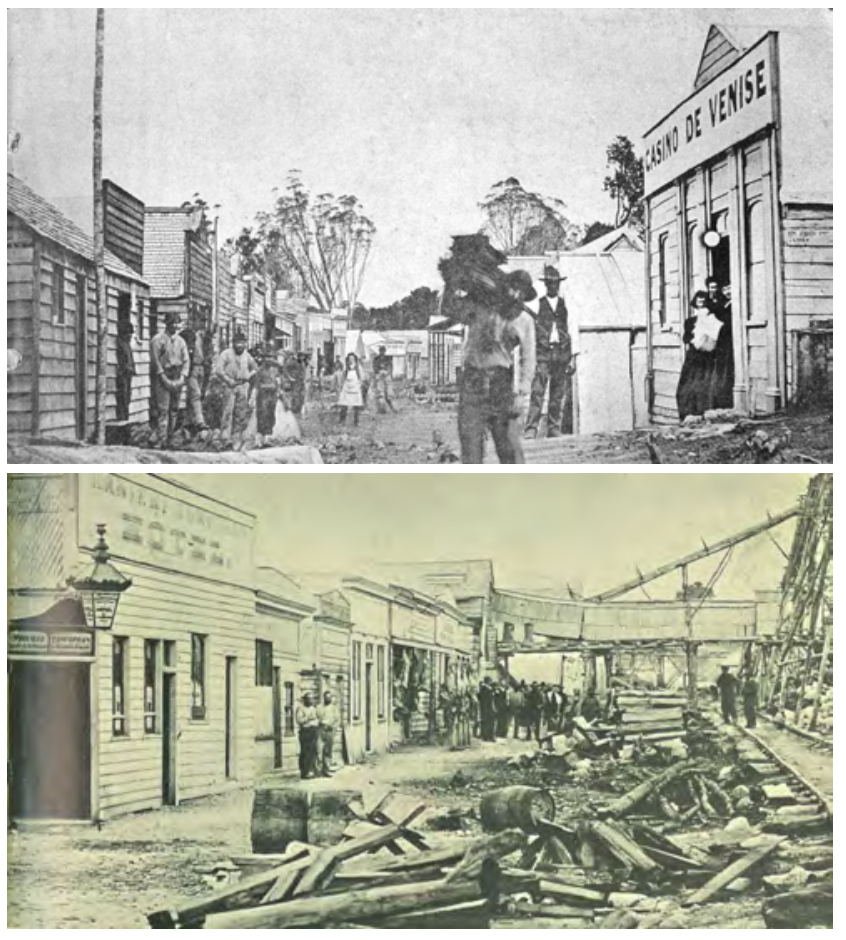

+Figure 3.12 Napoleon's Hill, about 1869.

+Figure 3.13 Kaniere, about 1869. 
Today's 'Coaster' comes from generations of people whose livelihood has been largely derived from the land, first by way of mining, then farming and forestry, and later tourism (Bishop and Walker 4).

This idiosyncratic identity has arisen through years of isolation, hardship and little money. It's a region of very self-reliant people. "In a geographically difficult region, privations have helped to make the independent and resourceful men and woman who live here today" (Sullivan 4).

"I doubt if such a wilderness will ever be colonised except through the discovery of gold", Henry Harper wrote of Westland in 1861 (Bishop and Walker 6). So was the case. Before gold was found at Greenstone in 1864 very few Europeans or Maori had been down this coast. With the population rapidly expanding, the West Coast packed twenty five years of history and colonisation in the three years following the initial discovery of gold (May 13).

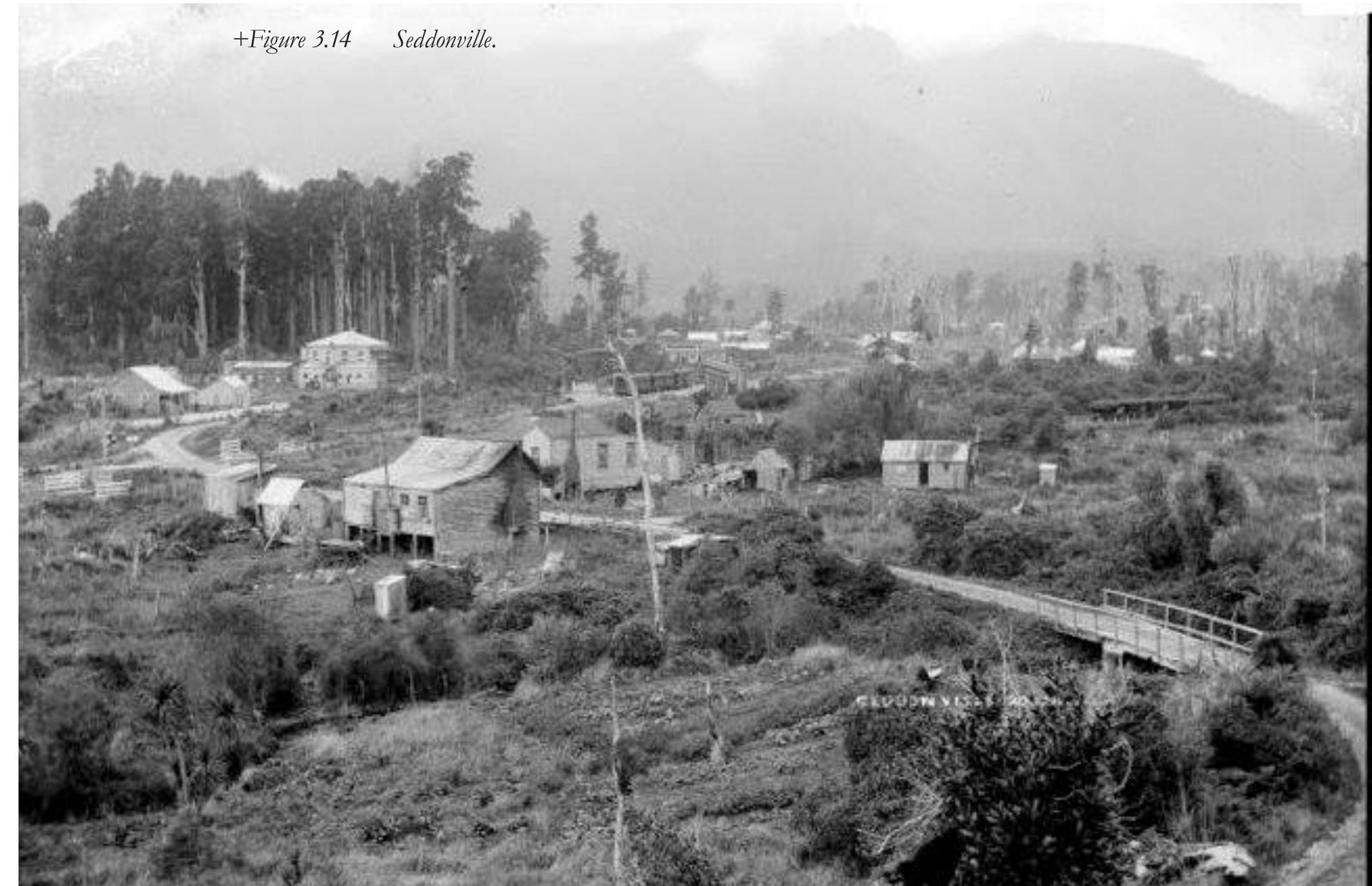




\begin{abstract}
At this time the road from the beach up to the township Iof Waimea], a distance of twelve miles, passing, as it did, the whole way through heavy bush and thick undergrowth, and crossing and re-crossing the creek-bed every hundred yards, was in a condition perfectly unconceivable to those who have not been to a great gold rush on the West Coast diggings in New Zealand. Roots of all sizes, torn and mangled when small into a sort of macaroni squash, and when large remaining a dead hindrance to both horse and man, caused the mud ploughed by cattle and pack horses to assume the appearance of a torrent; so bad was it that the whole distance was marked by the bones of dead animals (Bishop and Walker 29).
\end{abstract}

With so many people flowing into the West Coast for the gold new settlements appeared overnight. Charles Money records the birth of Waimea:

... An eager mob - lighting fires, pitching tents, drinking, fighting, cursing, and shouting all at once. By eleven o'clock, in the heart of a dense and almost untrodden bush, a street had arisen as if created by the magic wand of an enchanter. Swift as the walls of Aladdin's palace, stores, shanties, public houses, butchers, bakers and doctors' shops were to be found on every side...

(May 149). 

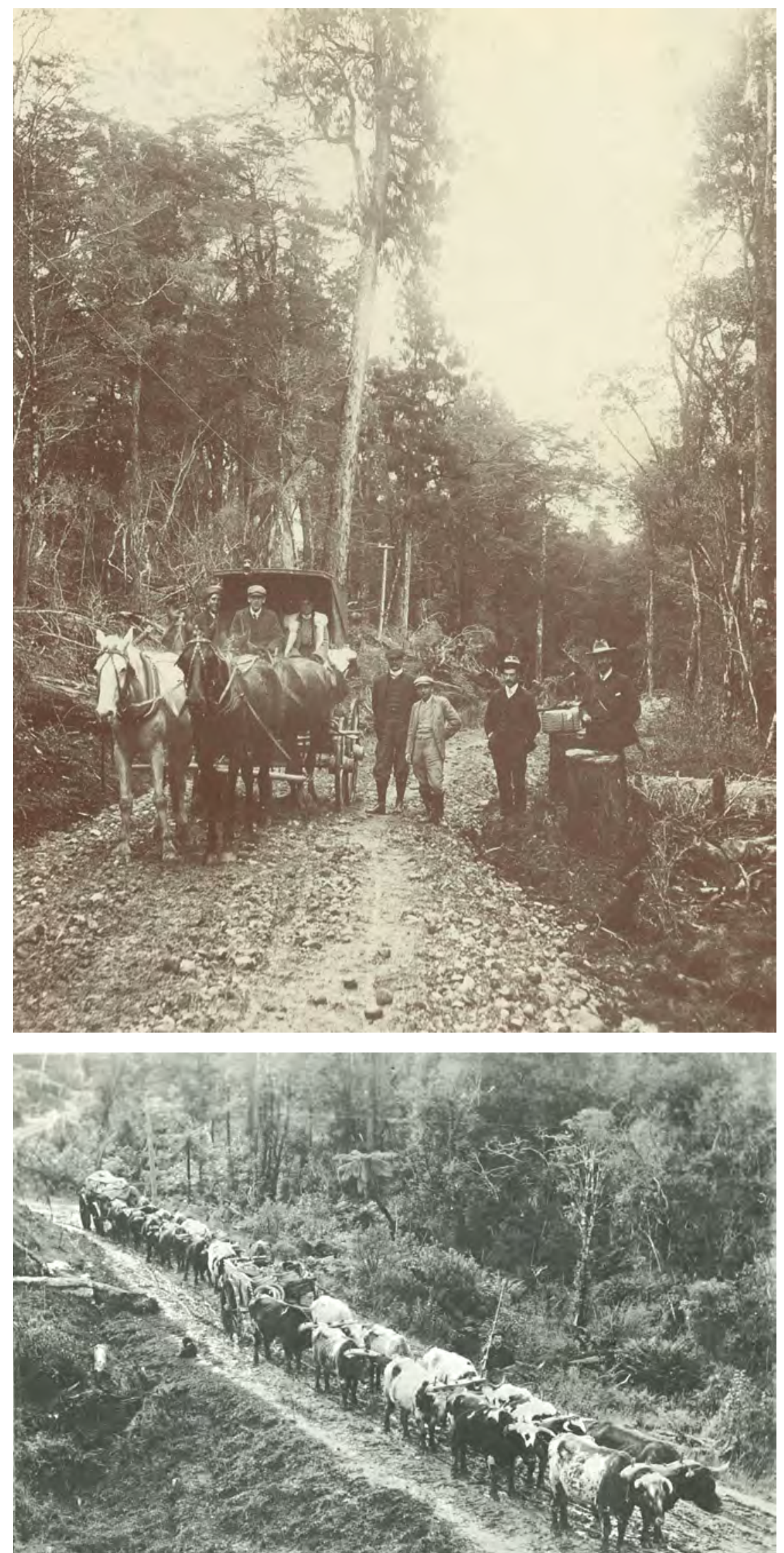

+Figure 3.15 The Road to Waiuta, 1909.

+Figure 3.16 This is a North Island scene but similar views

would have been common on the West Coast. 


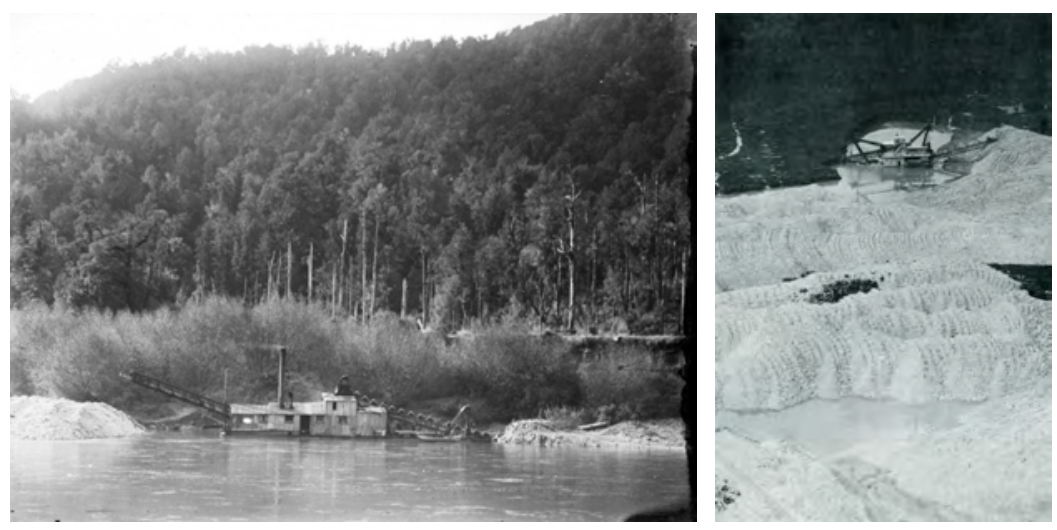

+Figure 3.19 Gold dredge on the Buller River.

+Figure 3.20 Rimu gold dredge and its tailings.

Dredging also became a viable means of extracting gold after the original alluvial rushes fell into decline. Dredges consumed and filtered through millions of cubic metres of gravel (Bishop and Walker 85). By 1902 there were 58 dredges in the West Coast region (84). Today a single remaining dredge operates in the Grey River, functioning in a very similar way to the original dredges (Carroll). Dredges have become iconic piece of machinery within the West Coast landscape.

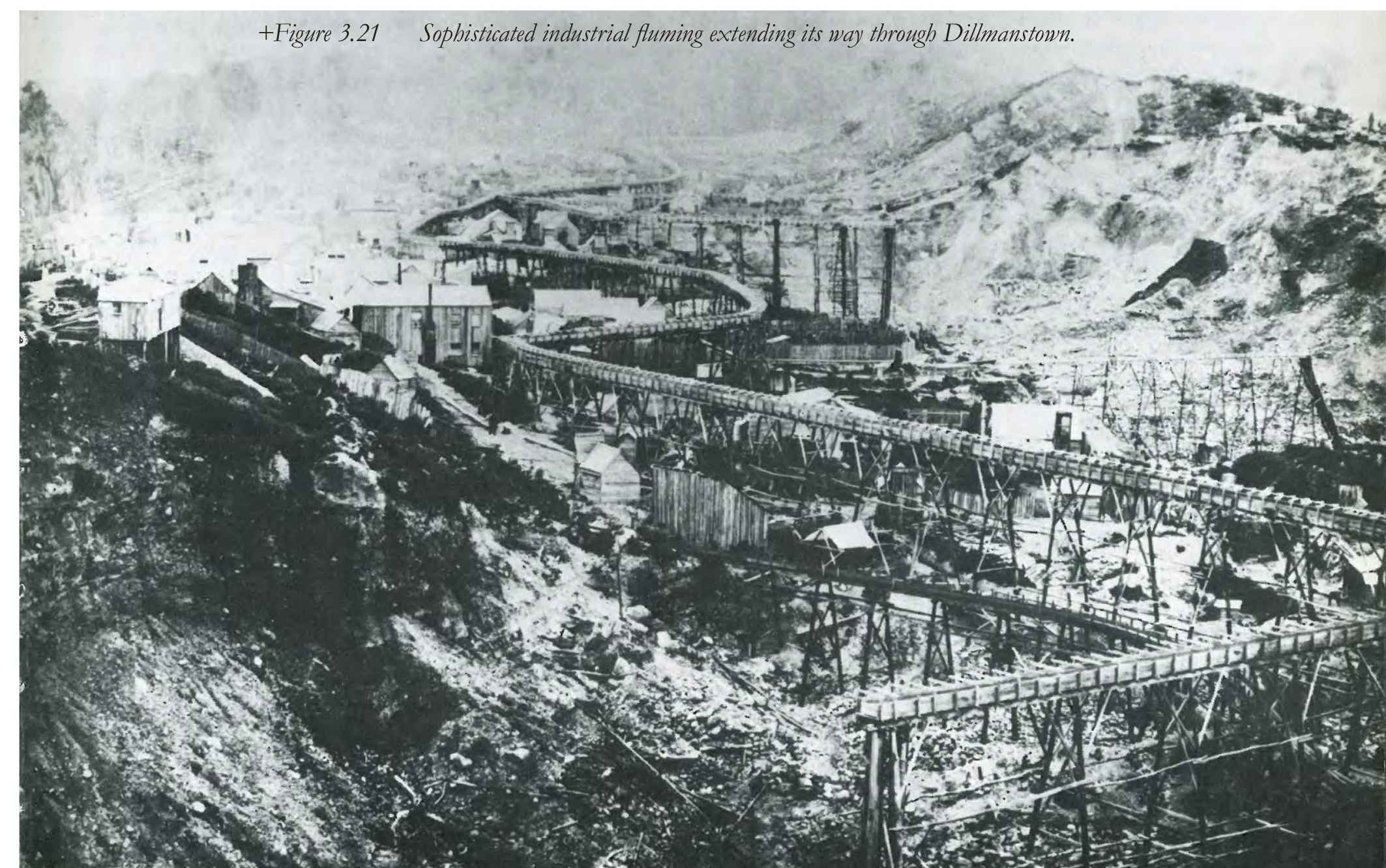


Westland forests were often said to be 'inexhaustible' (Bishop and Walker 100). The miners moved like locusts across the land felling huge swaths of bush to build settlements and infrastructure. However, as claims ran out of gold, towns began to fail and people left as quickly as they arrived. In the Hokitika area the mining towns of Chesterfield, Stafford, Goldsborough, Blue Spur Township, Rutherglen and Greenstone are all but gone. There were many more in the Reefton, Grey and Inangahua districts. Most have now undergone complete regeneration back to beech forest.
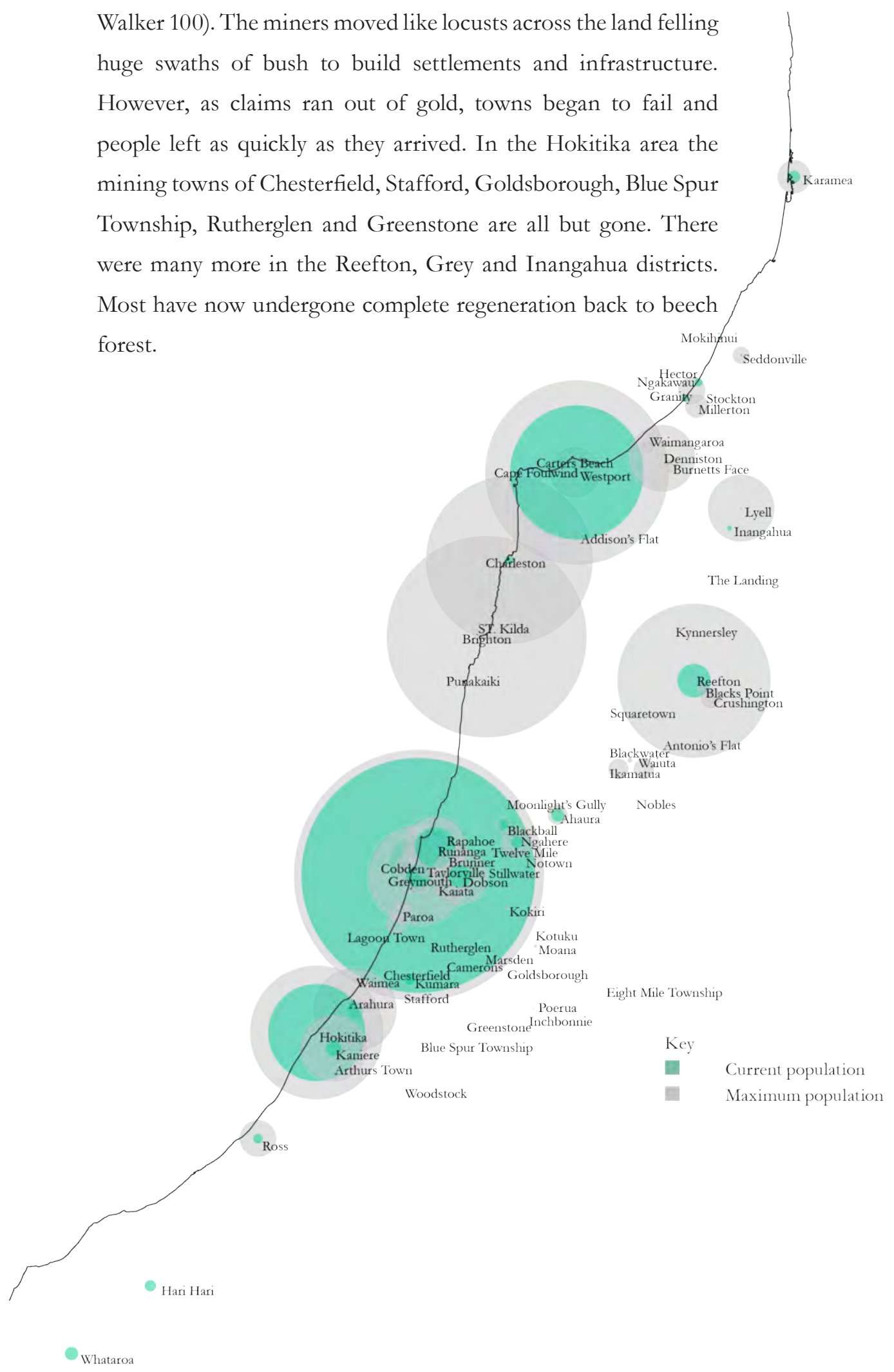

+Figure 3.22 The rise and fall of settlements. 
West Coast culture was further characterised by the writing of:

Len Richardson, Samuel Hurst Seager, Janny Hammond, David Magill, David Allan Hamer, Robert Paulin, Irwin Faris, Vaughan Yarwood and Allen Uren.

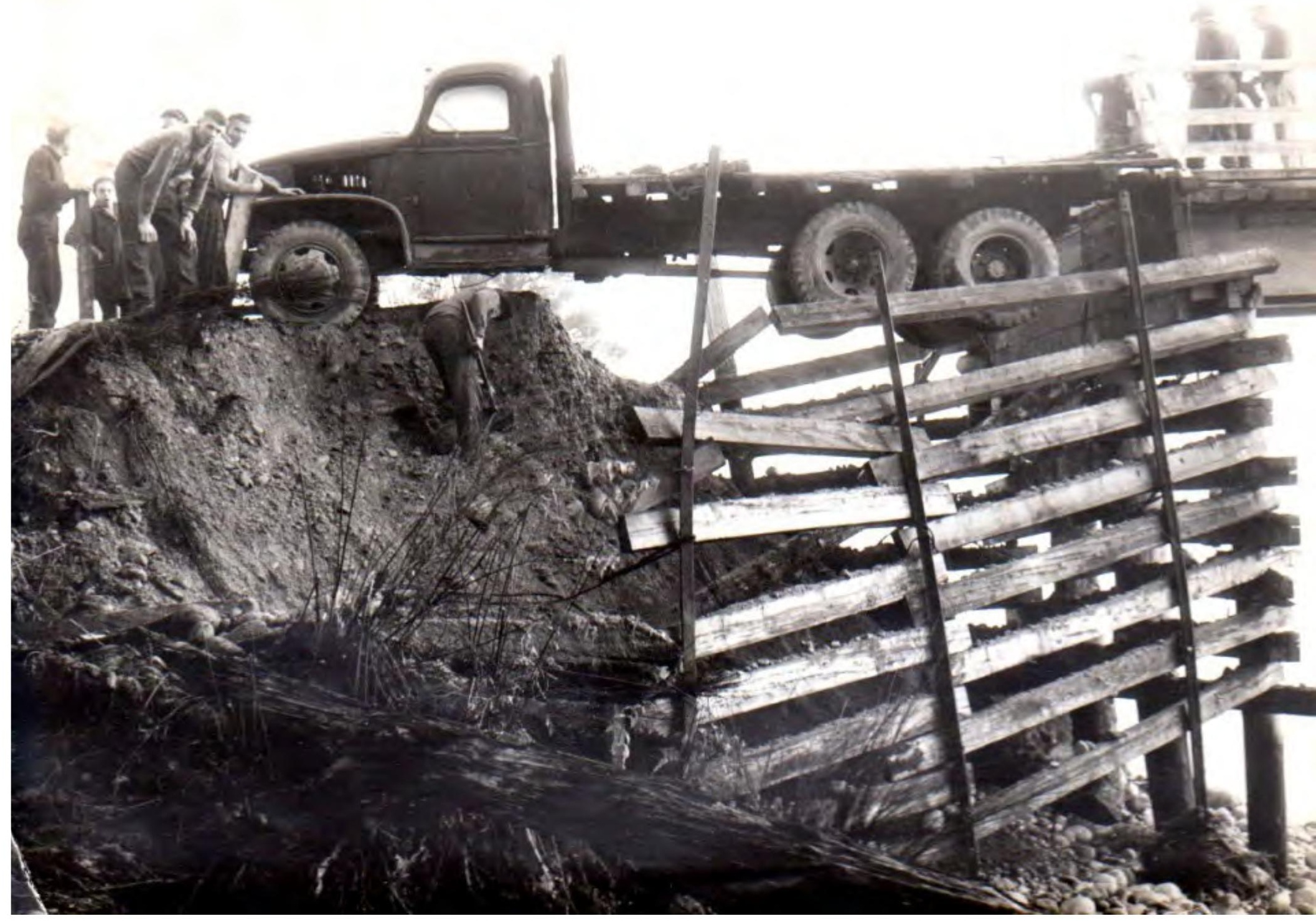

+Figure 3.23 Truck on Perserverence Bridge after a washout, ca early 1960s. 


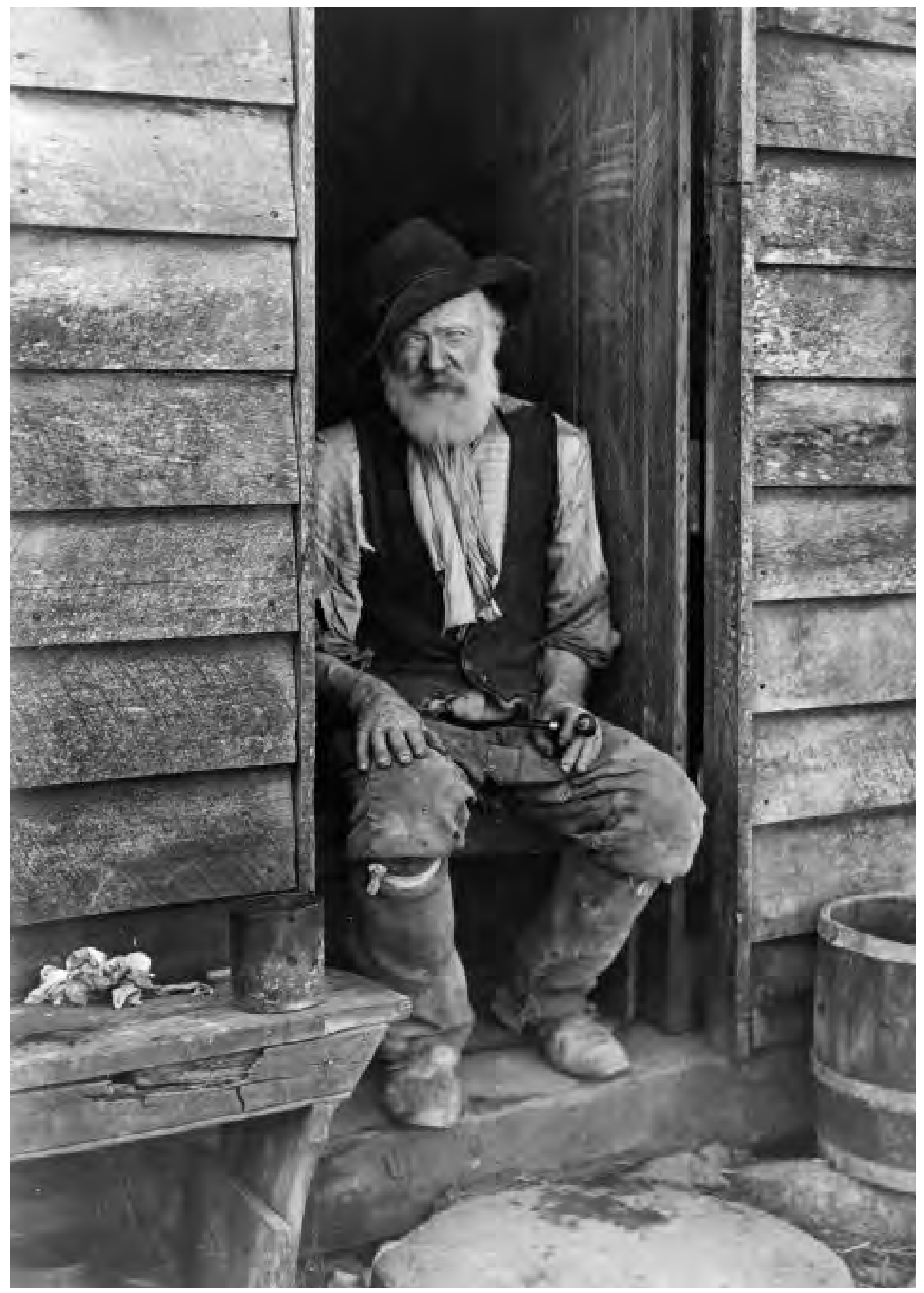




\section{ARCHITECTURAL REGIONALISM}

Stemming from place identity, architectural regionalism is the specific architectural identity of the 'place'. Regionalism is shaped by physical environmental factors and human cultural factors. Loss of architectural regionalism can lead to a homogenous architectural culture. Architectural regionalism can be understood through the folkloric approach, this is the specific architecture of a place through time. "Folk artefacts are thought to exhibit major variation over space and minor variation through time" (Pavlides 158). Architecture is also intrinsically linked with its context. "Frequently has architecture been divorced from its environment and considered apart from that environment. This is most unfortunate, for architecture, if it is anything, is a function of environment and, like other expressions of human life, cannot be fully understood outside that context" (Newcomb 81). 
In recent years there have been only four resident registered architects based on the West Coast (NZRAB). This has helped contribute too few buildings being architecturally designed, which has made for a very unique 'regionalism'. Although buildings constructed on a bigger budget have had imported architectural input, most residential dwellings have only had builder and owner input.

The regional architecture has also been shaped by the hard lifestyle and low income of the residents. The original isolation meant all materials were transported on horseback which heavily restricted the material palate. The buildings had nothing but the bare essentials. This has led towards a utilitarian architecture, with little or no ornamentation.

+Figure 3.25 Early miners camp near Buller, use of local materials, note corrugated iron or tin on the chimney only.

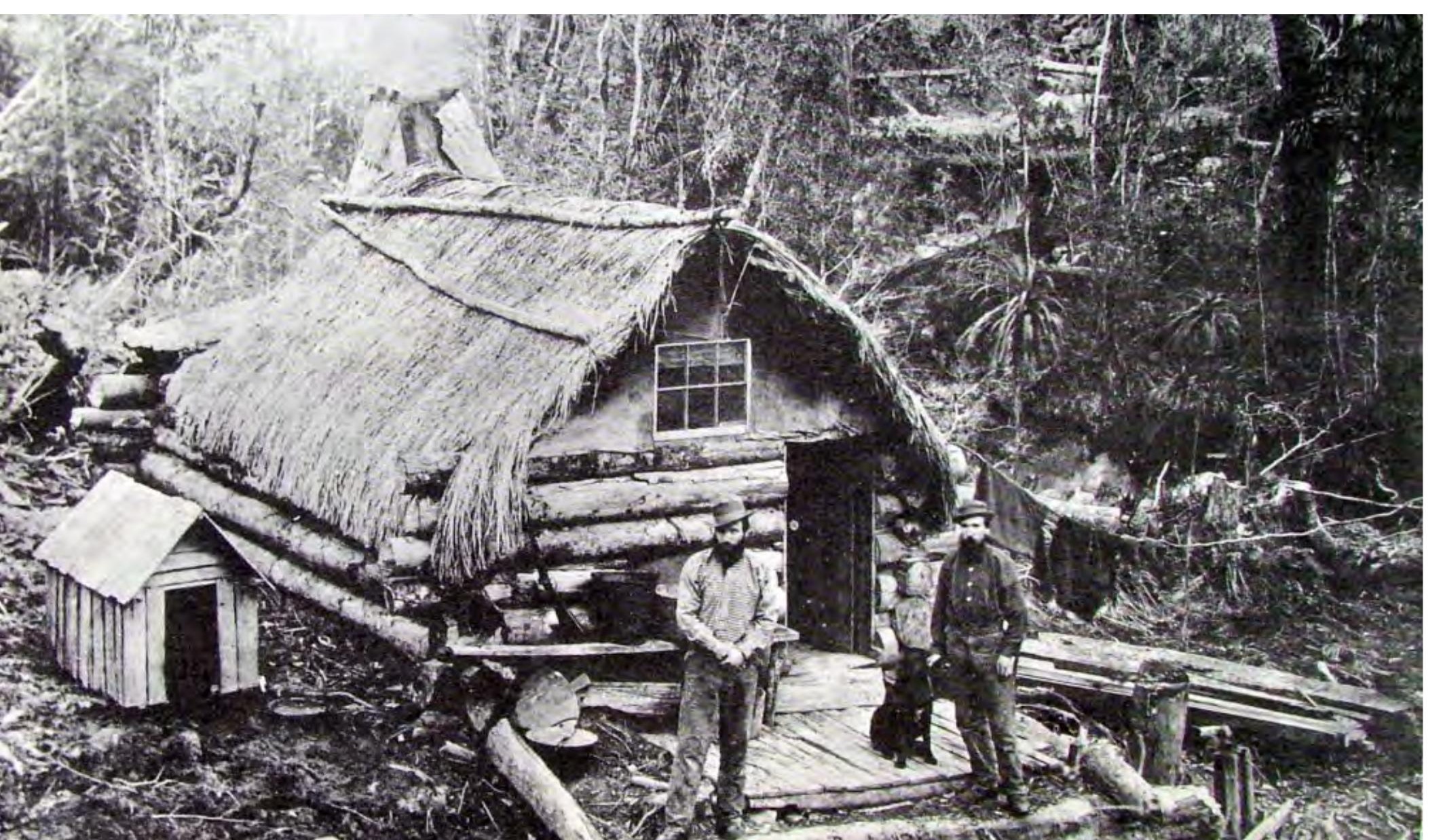




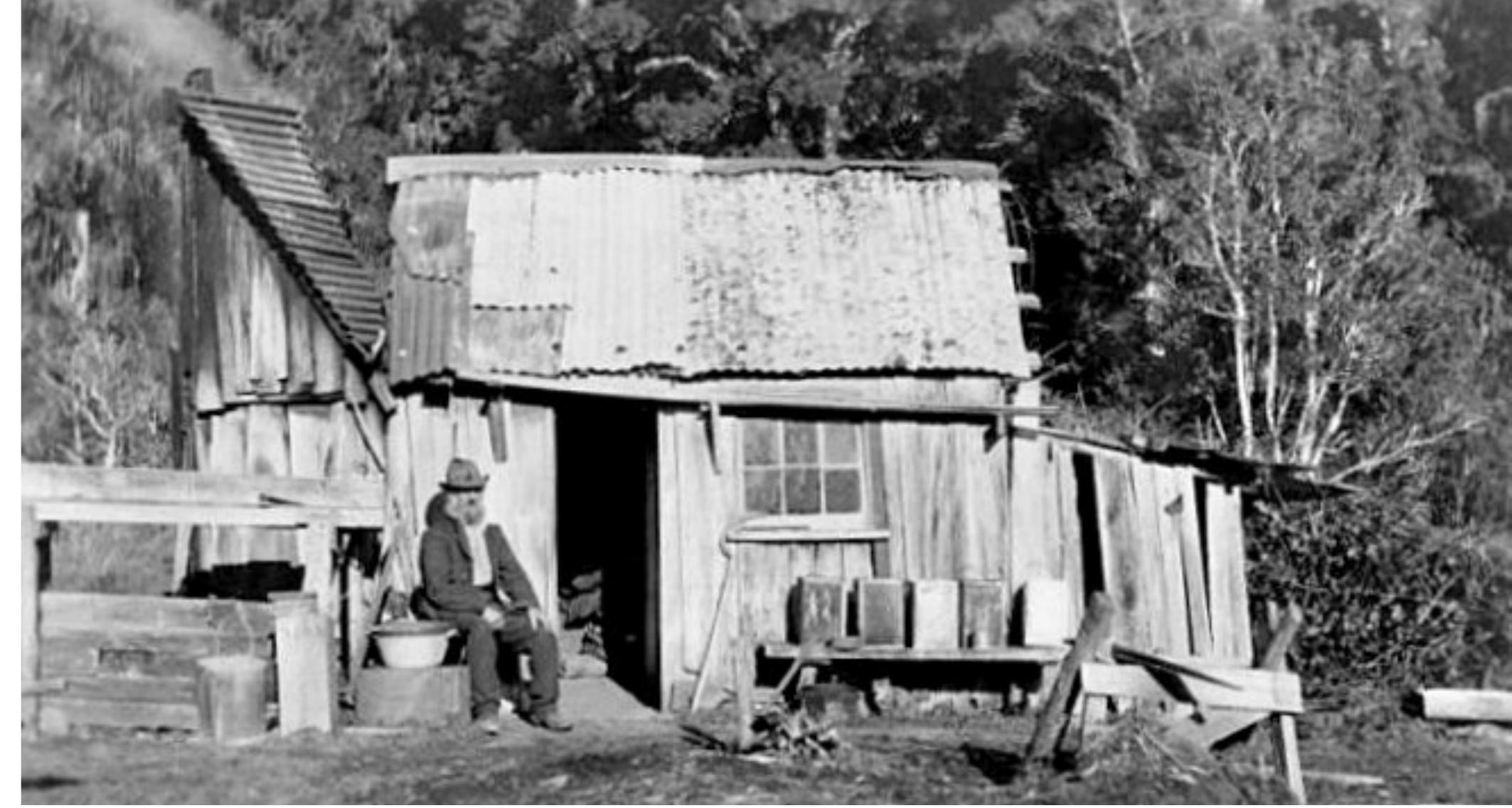

+Figure 3.26 Geordie Wiltshire outside his slab hut. Locally sourced timber was the most common building material on the West Coast. Corrugated iron or tin was used on the roof and chimney only.

This unique regionalism however, is coming under pressure. The growth of industry on the West Coast has brought in large amounts of money to the area and with money has come standardization and the development of a mono-culture, both in terms of architecture and way of life. Now to view regional architecture and cultural identity we must travel to places that have been dropped in time, places that have stayed still while the outside world has moved on.

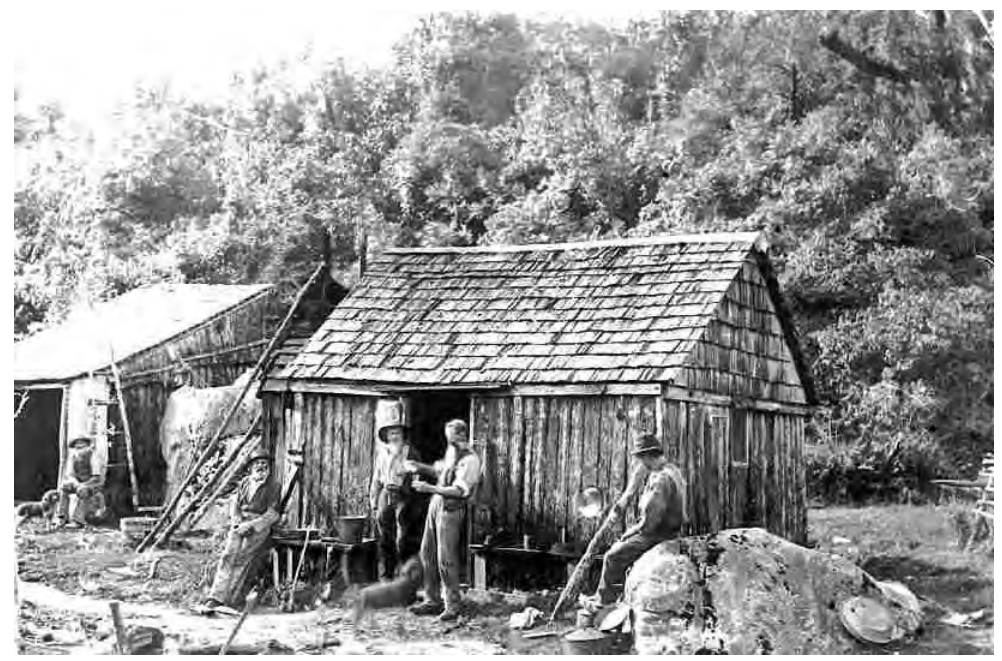

+Figure 3.27 Goldminers but South Westland. 
Deep eaves and verandas became common here as they did across New Zealand, the high level of rainfall required a covered outdoor space and adequate protection from water penetration for the walls, the wall to roof junctions, the windows and the soffits. The veranda was and still is a key architectural feature while also providing adequate rainfall collection for the selfsufficient residents.

The buildings have been a direct response to the landscape and environment. To gain a heightened level of shelter from the prevailing westerly wind and rain, dwellings had low roofs, roof lines that mimic the slope of the landscape they sit upon and roof lines that sit below the line of the canopy. The low roof has little visual impact, so these dwellings merge into the surrounding landscape. Many of the buildings are backed onto a hill as this allows for another level of protection. Buildings have also been orientated to the west/ north for maximum thermal gains. These architectural characteristics have been consistent through the years and have been utilised throughout the West Coast. Large industrial scale buildings including the dredge and the stamping battery also exhibit these characteristics. 


\section{THE DREDGE}

This process of gold retrieval consisted of dredging up gravels from the river bed and washing it through a series of wash-beds, extracting gold and discharging the waste rock behind.

Dredges have become historical icons on the West Coast with their simple gable forms atop a floating barge crisscrossing haphazardly. Nevertheless, the end result is a form and building typology that efficiently performs its purpose.

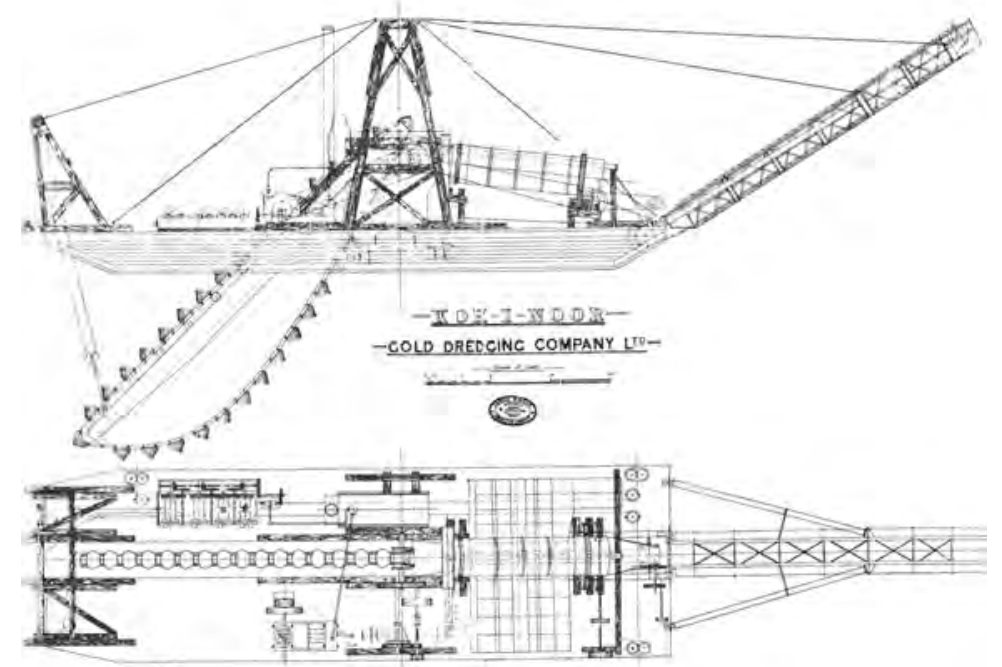

+Figure 3.32 Koh-i-noor gold dredge. 
The dredge construction was a process of accretion, a method of design that is evident across a lot of West Coast architecture. New sections were built on or up as required. Pieces of machinery, bigger than that of the floor area could, at times, cantilever over the water. Little thought was given to form, scale or proportion. The tight floor area induced a tight conglomeration of individual forms assembled according to what was physically possible. Figures $3.33-3.37$ show a spatial, formal and circulation analysis of the Kaniere dredge.
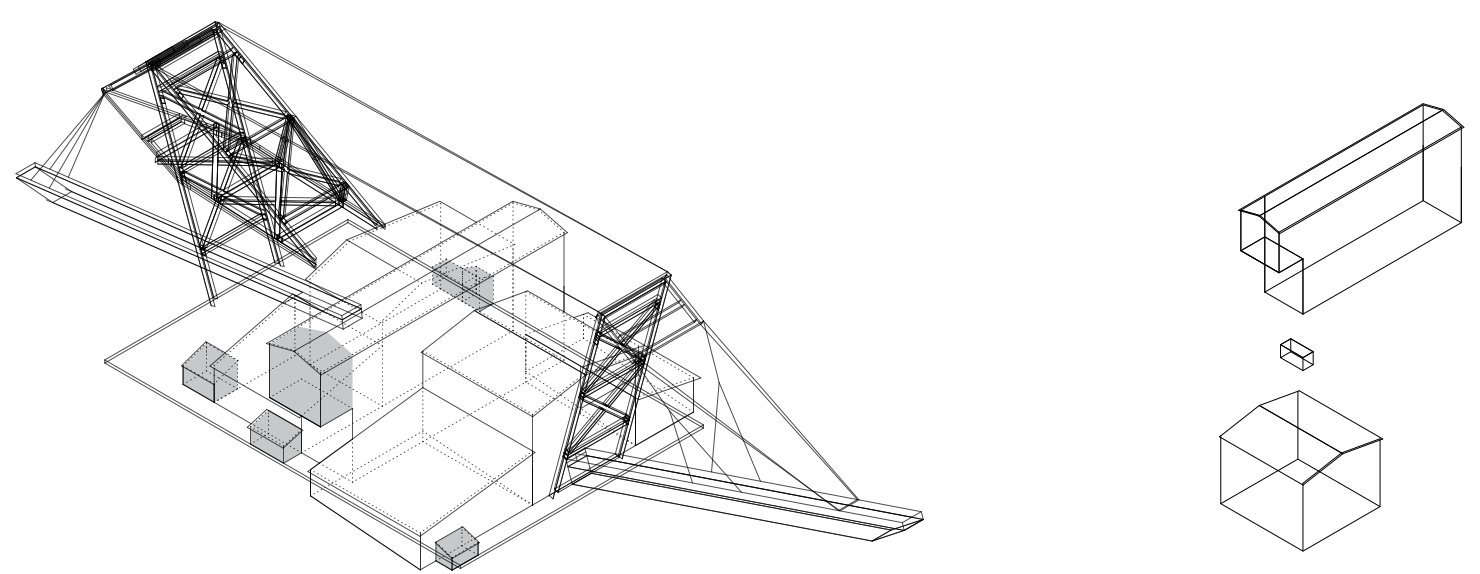

+Figure 3.33 Cantilevering additions to the Kaniere dredge.
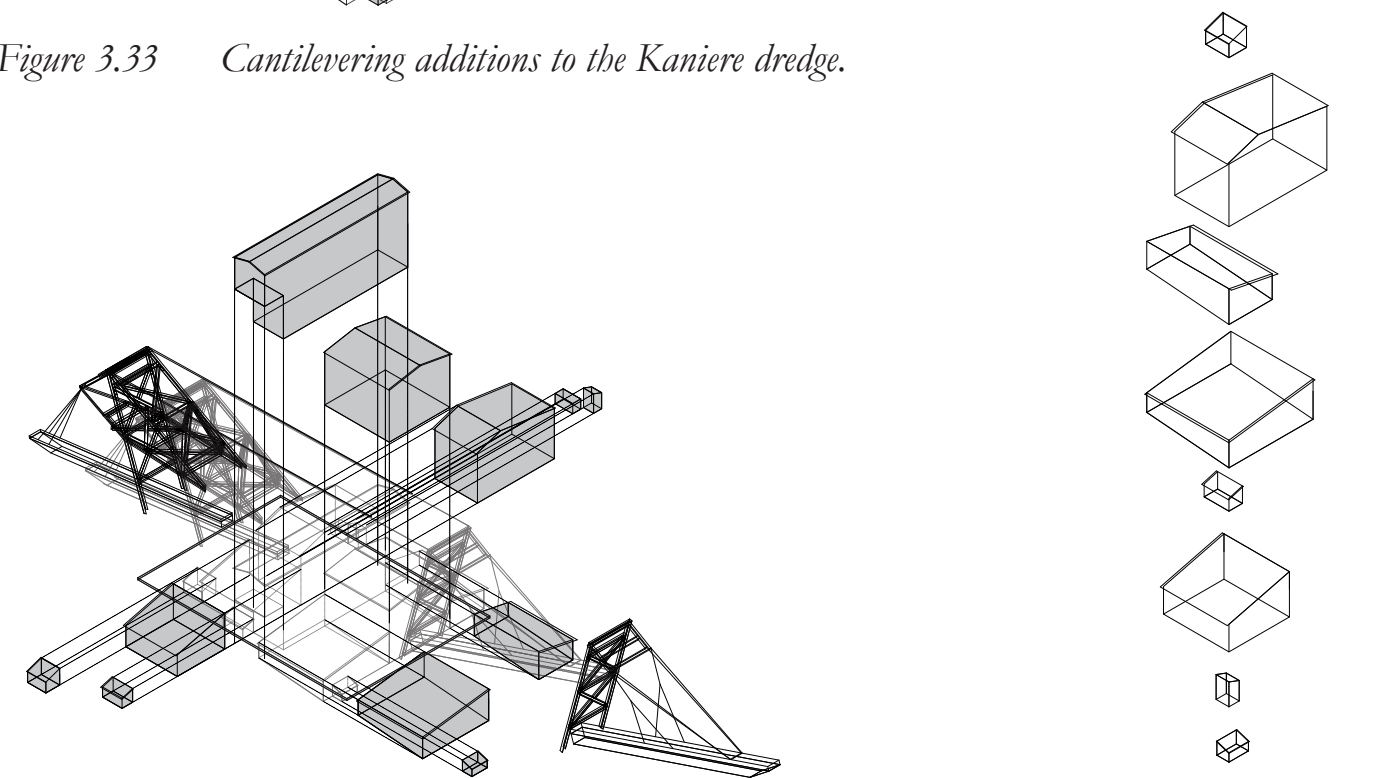

+Figure 3.34 Exploded axonometric of Kaniere dredge.

+Figure 3.35 Exploded axonometric of indervidual forms. 


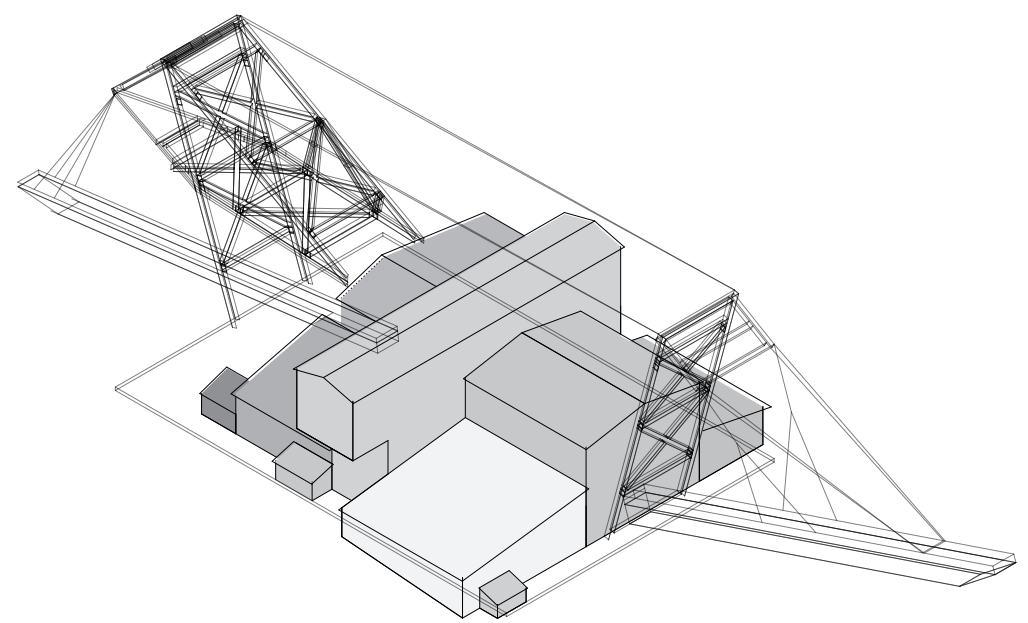

+Figure 3.36 Tight collection of closed intersecting forms.

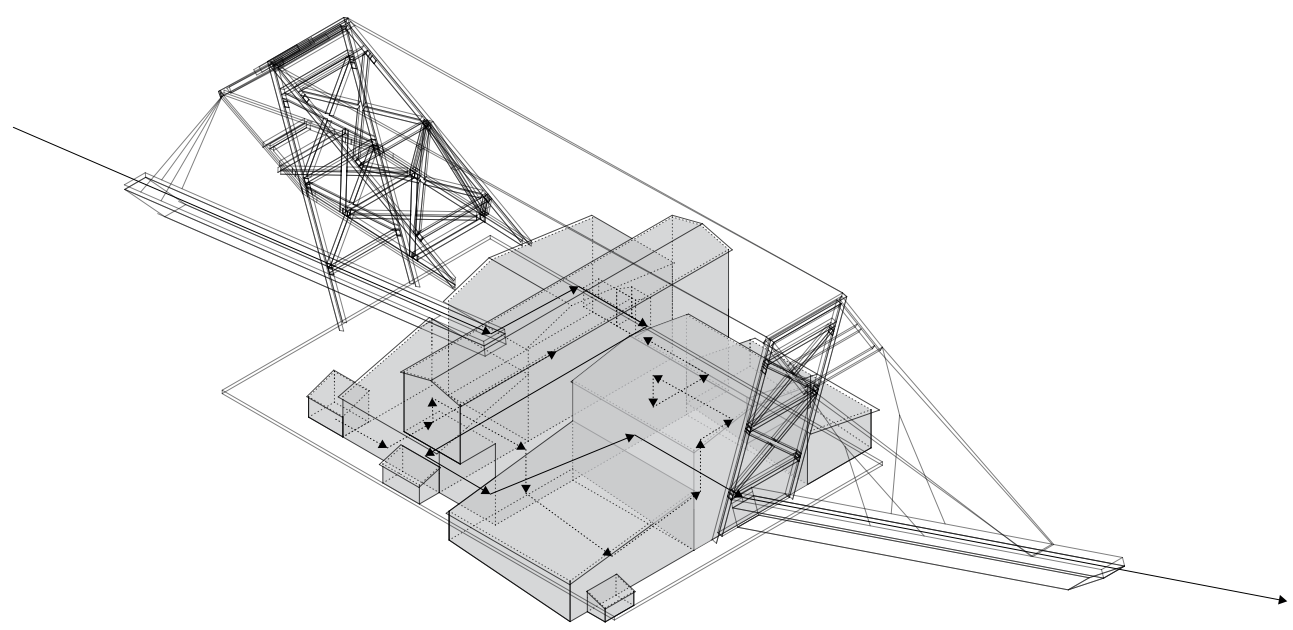

+Figure 3.37 Complex internal passages differing between staff, rock and water. 


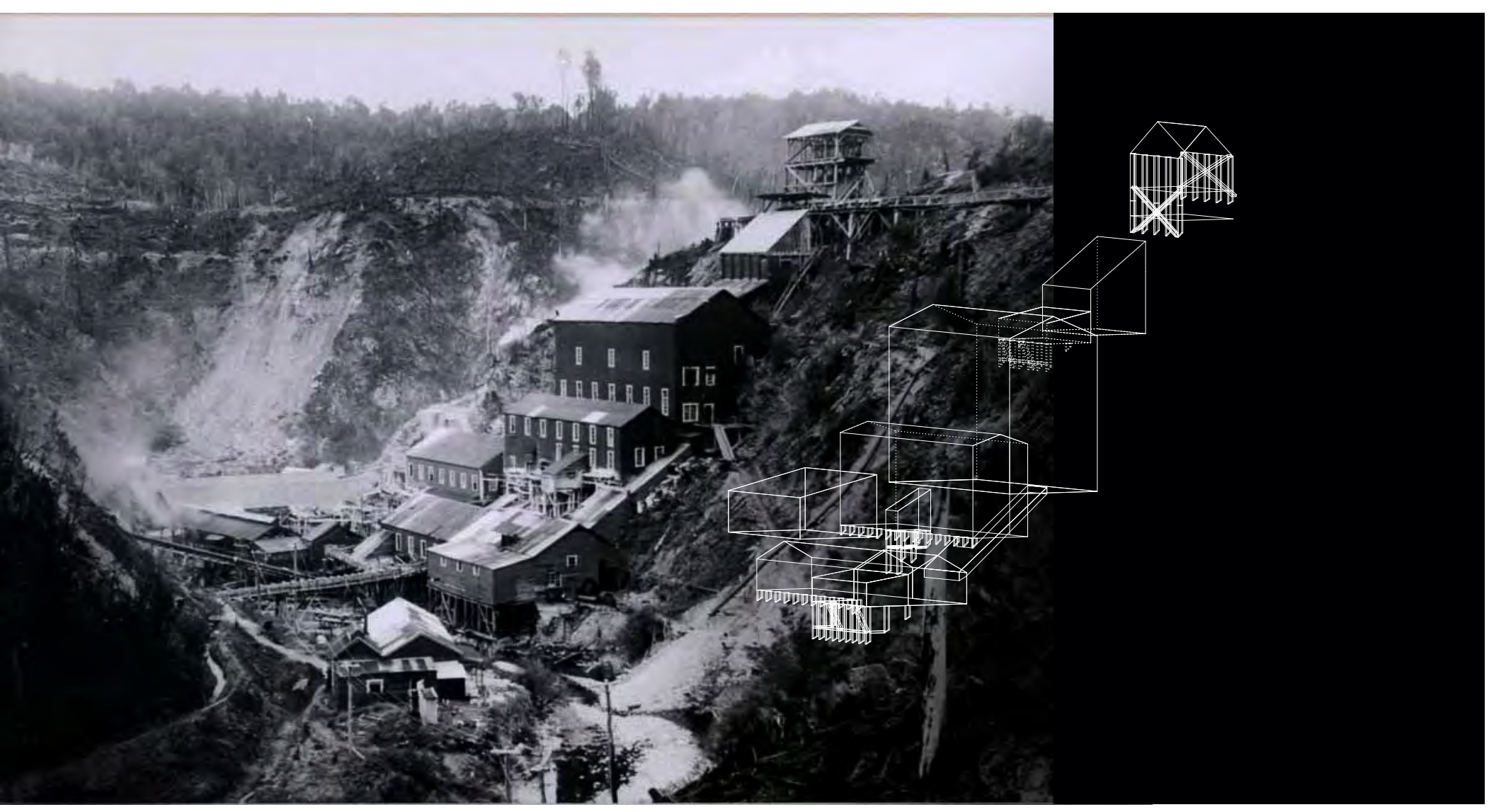

+Figure 3.38 The Snowy River Battery at Waiuta. 


\section{THE STAMPING BATTERY}

Stamping batteries were used to crush gold bearing quartz to extract gold. It was an intensive process of crushing, washing and refining the rock until only concentrated gold remained. Stamping batteries unlike dredges did not become such historical icons. However, they have kept their unique form through time and thus exhibit an architectural regionalism via the folkloric approach. They were a combination of gable and mono-pitch forms that stepped down a hill adjacent to the adit. Steep sites were chosen deliberately so ore could be moved through the various recovery processes by gravity, aided by high-pressure water. Figures 3.39-3.45 show a spatial, functional and formal analysis of the Snowy River Battery.

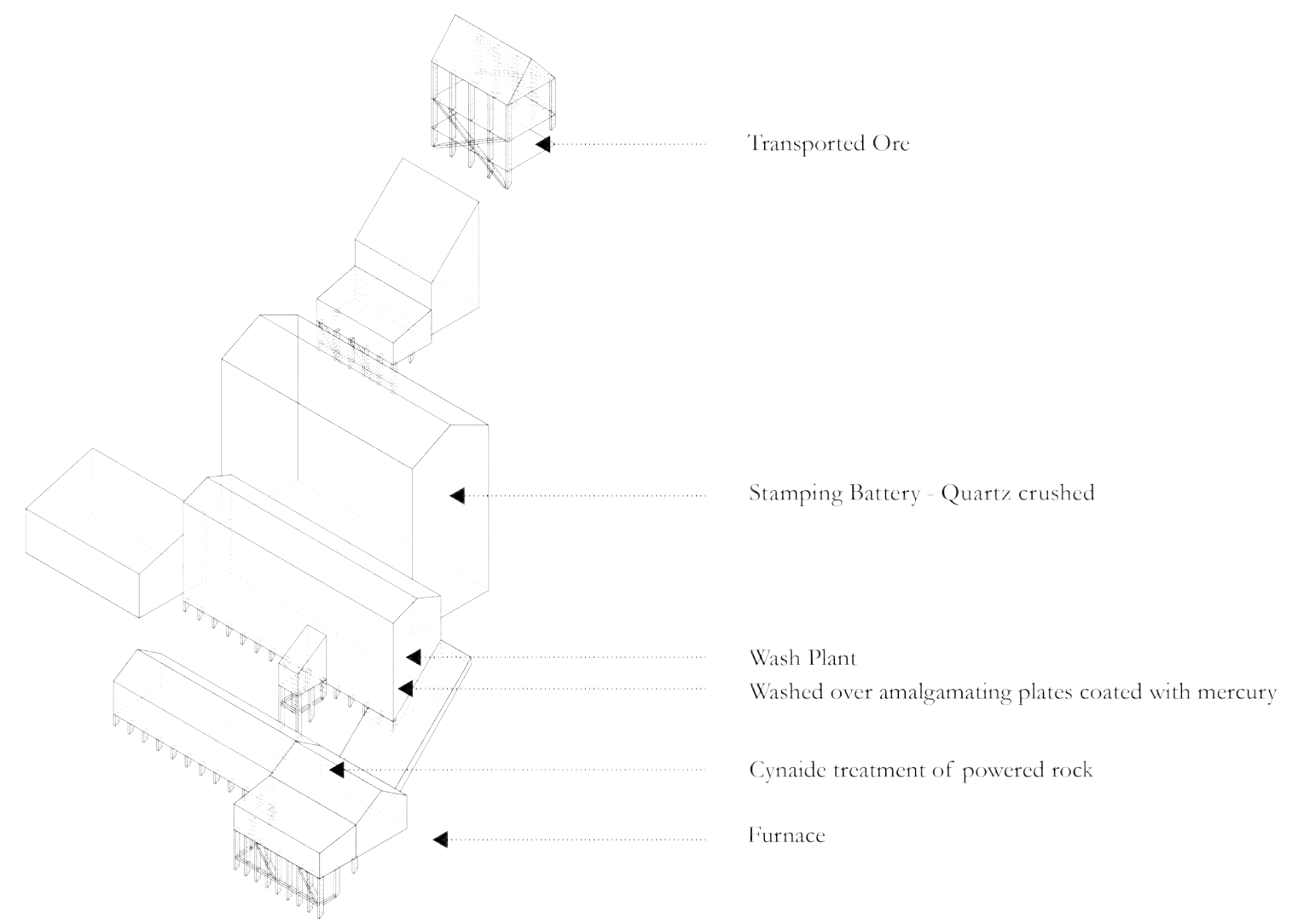

+Figure 3.39 Axonometric diagram of Waiuta Stamping Battery arrangement. 


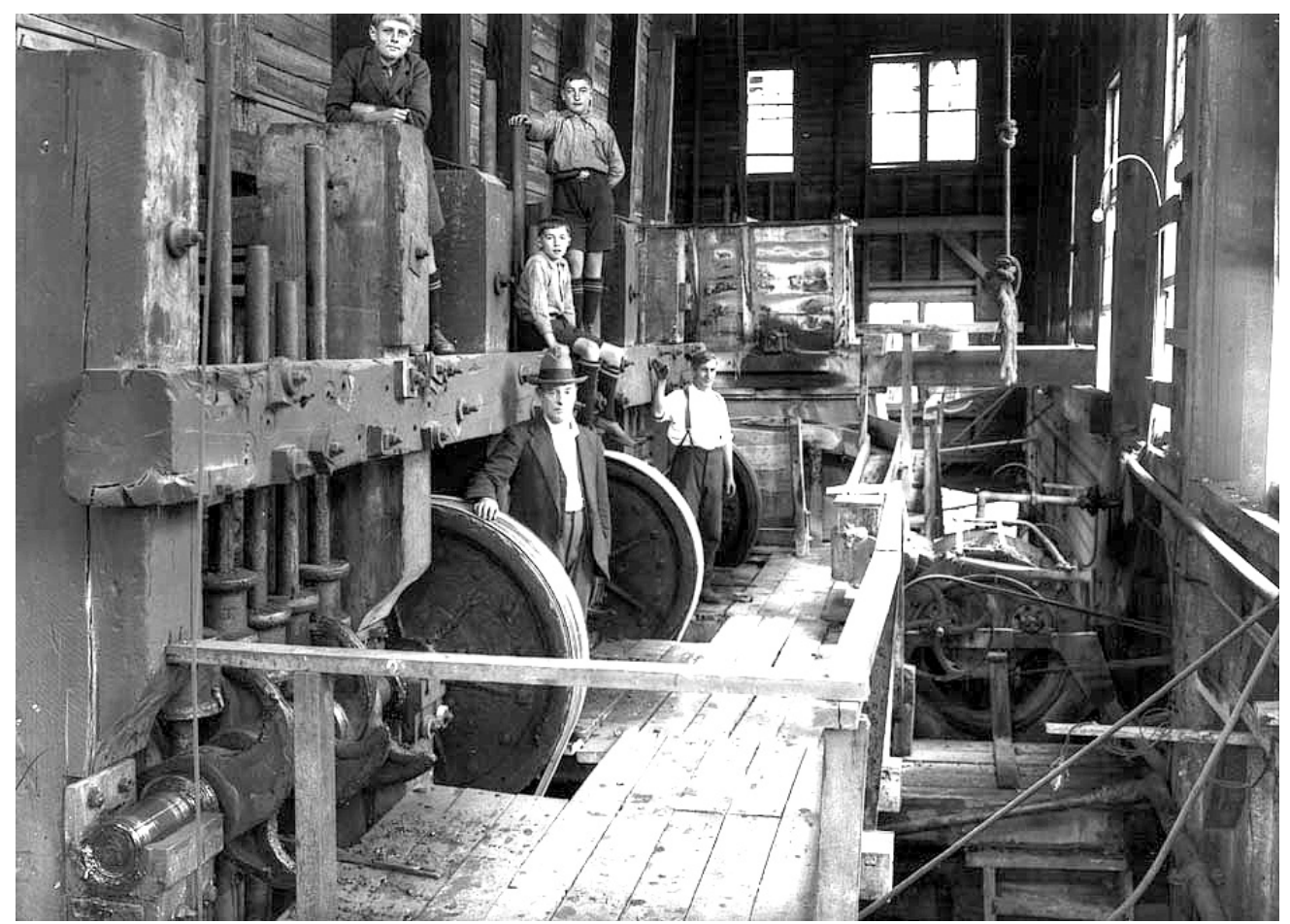

+Figure 3.40 The stamping battery at the Snowy River Battery.

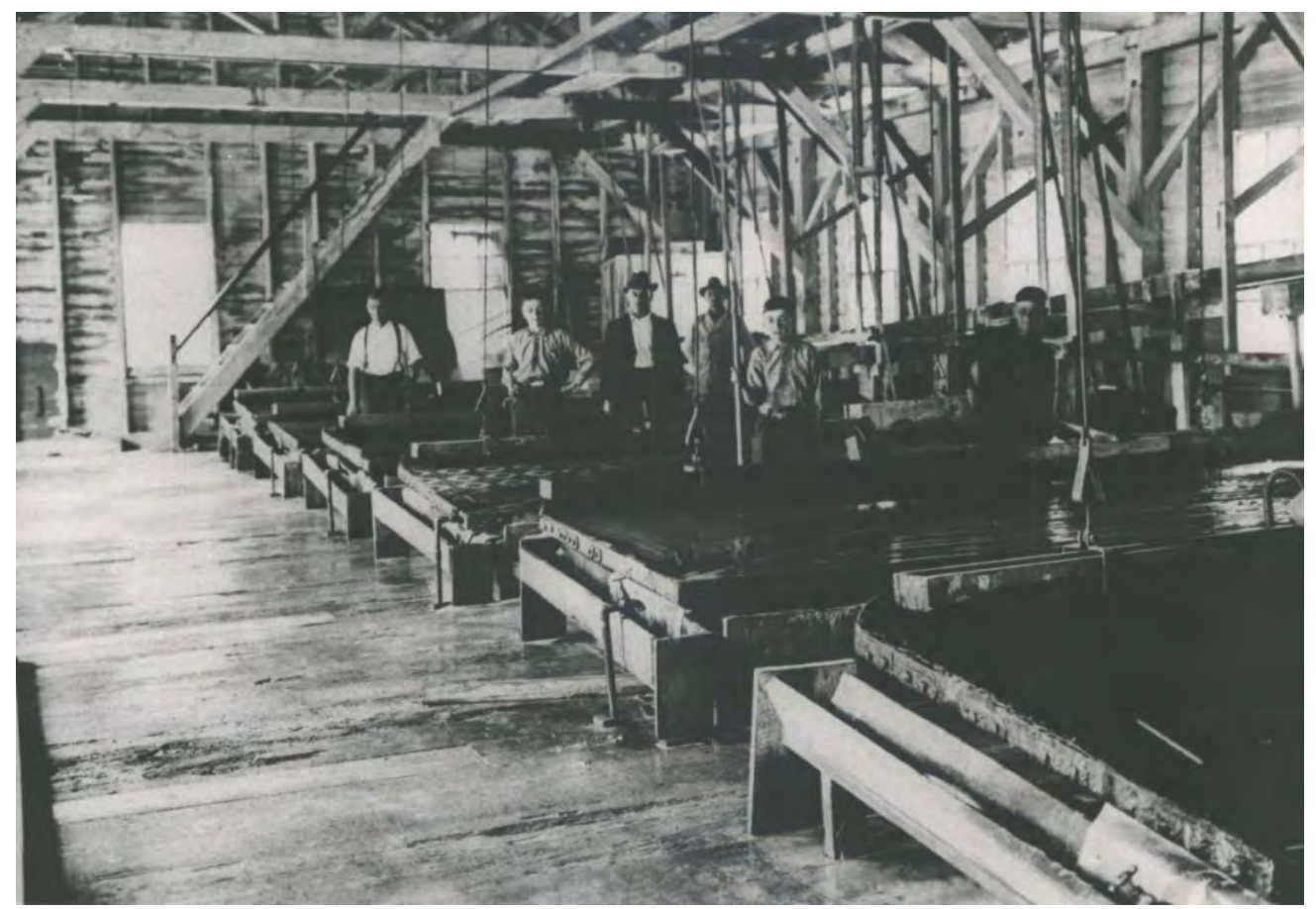

+Figure 3.41 The washroom at the Snowy River Battery. 


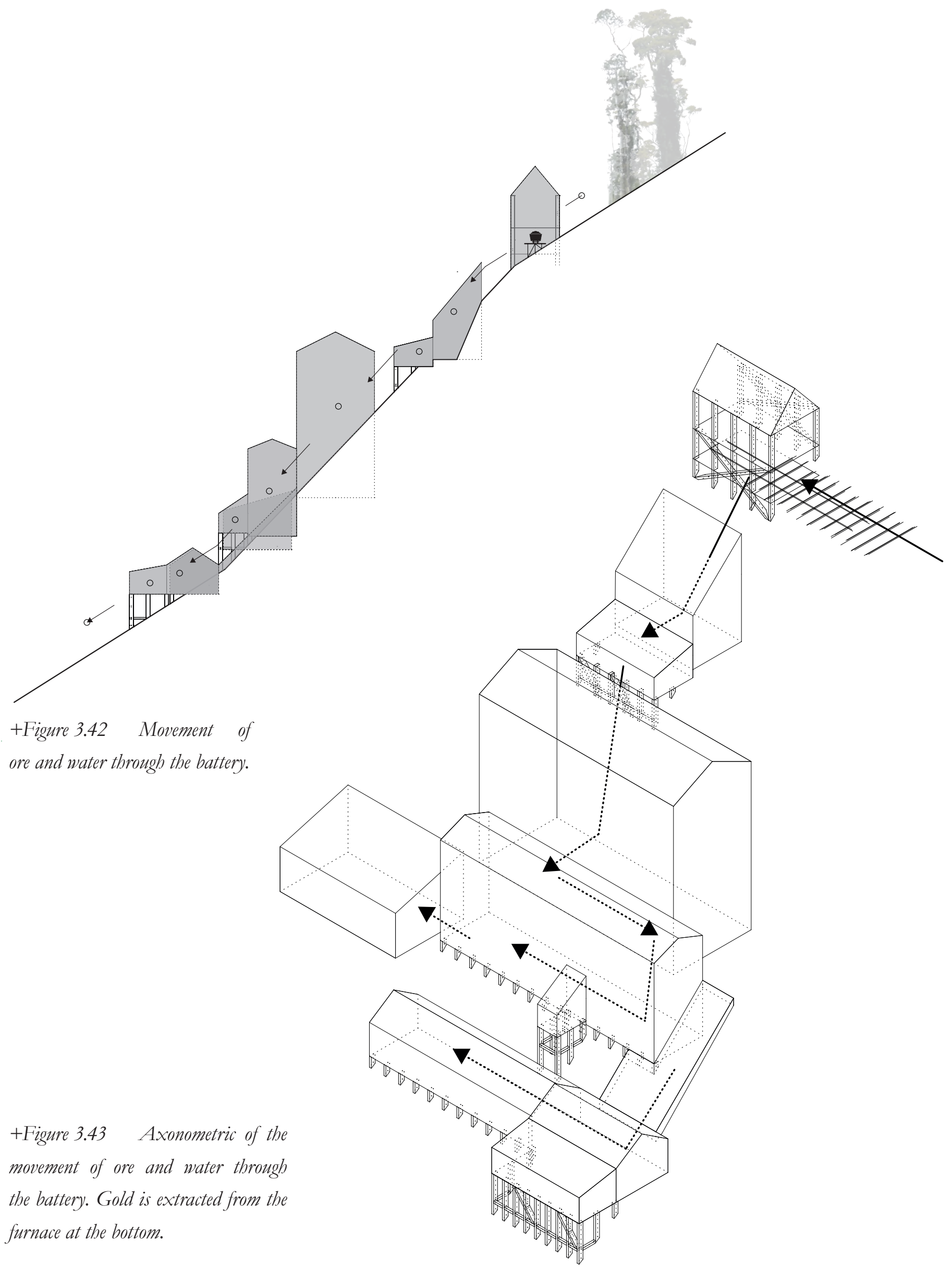




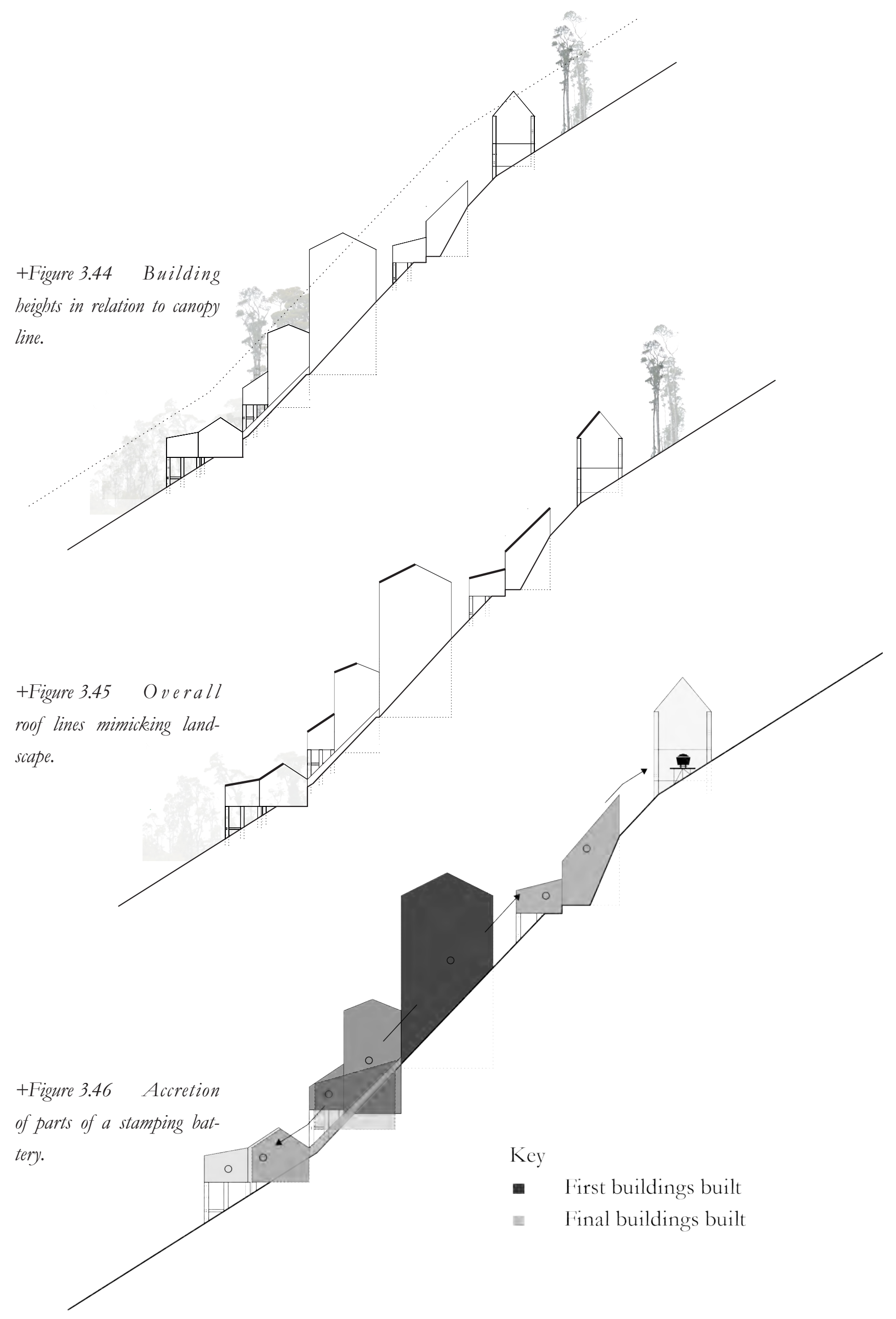




\section{CONCLUSION}

The West Coast's characteristic extreme isolation, extreme weather, highly industrial background and small population have shaped a local culture of self-reliance and enduring productivity. The relationship between working class individuals and the built form of their settlements has resulted in a clear place identity. The dredge, the stamping battery and the dwelling are three architectural typologies that exhibit many of the key principles in the West Coast regionalism.

Loss of this West Coast identity would also erase a very unique part of a wider New Zealand identity.

Form, scale, circulation, proportion and function which are fundamental and defining elements of the dwelling, stamping battery and the dredge will be critical to the design of my architectural solution. 

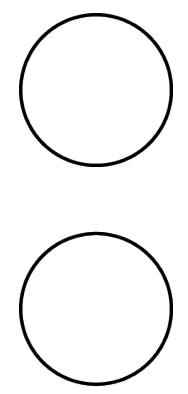

I Introduction

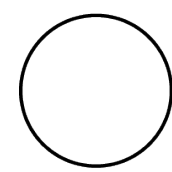

Precedents that Outline the ......
Problem

Locator memorials

Sculptural memorials

Functional memorials

Conclusion

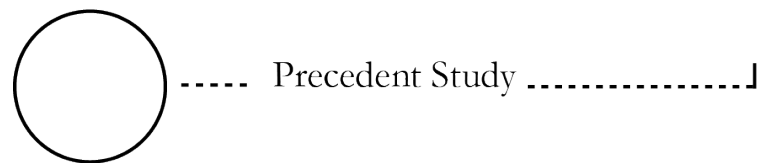

Precedents that Offer a ...........
Solution

The sZteilneset Memorial Therme Vals

Memorial des Martyrs

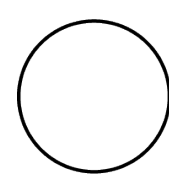

I Conclusion
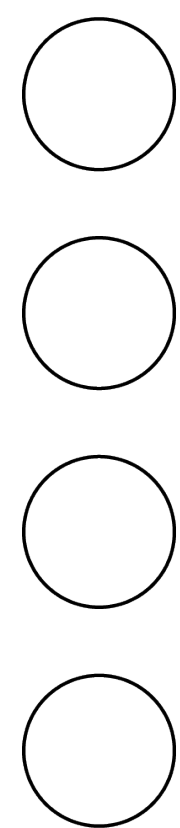


\section{PRECEDENT STUDY}

$/ / 4$ // 


\section{INTRODUCTION}

This chapter serves two purposes: to outline the current issues surrounding memorials in New Zealand and to identify successful memorials (and some non-memorials) overseas and in New Zealand. Insights from the successful memorials may be taken forward to my own architectural solution.

In this chapter there are six different precedents, three relating to memorial types that represent the current scene in New Zealand and three that represent possible methods for solution. The problem precedents are Locator memorials, Interpretative sculptural memorials and Functional memorials. Precedents to offer a solution are:

Steilnset Memorial - This memorial precedent outlines that enveloped space is required for physical comfort and that design, through education can preserve place identity.

Memorial des Martyrs - This memorial precedent outlines the use of specific framing to reach a place of contemplation.

Therme Vals - This spa precedent outlines the use of light and shadow, the sound of water, the use of local materials to achieve contextuality and the use of framing to ensure or deny views.

Each of the precedents are evaluated against the following criteria to critically assess whether or not the memorial is achieving the desired outcomes. These criteria have been developed through the knowledge gained in the previous two chapters. The theoretical context chapter outlined certain points that make a space for healing, memory and contemplation important in a memorial. The criteria are each accompanied by a small paragraph describing an aspect of the memorial to provide quick understanding of 
the memorials degree of success. I have refrained from adding a quantitative points system, as this would be naïve in emotionally driven spaces. This method of visual analysis can then be applied to the developed outcome of this thesis to gauge the success of my design in terms of memorializing and healing.

The memorial provides adequate space for and facilitates contemplation

Contemplative

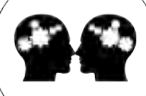
(

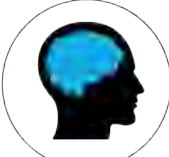

Memory Provoking

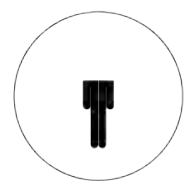

Transcendent

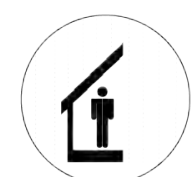

Physical Comfort

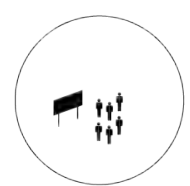

Education

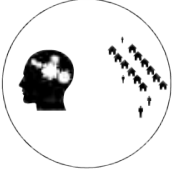

Distractionless

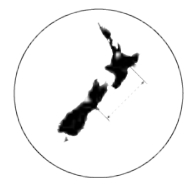

Geographical Relevance
Memorial provides adequate space for and facilitates inner reflection

Provokes memory through triggers and features representative of event

Architecture and space has a sense of transcendence

Users of the memorial have a level of comfort and are sheltered from weather and wind

The memorial sheds light on the event that occurred

The memorial provides adequate space for the user to fully experience the memorial minimising external distractions

The memorial is geographically relevant to the event that occurred

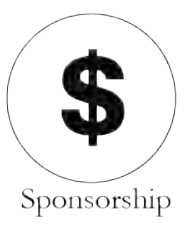

Who sponsored the memorial? Were there ulterior motives when constructing the memorial?

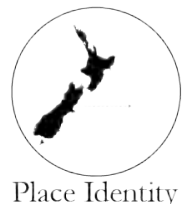

The identity if the place is represented in the design

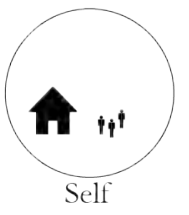

Sufficiency

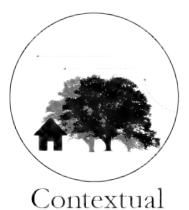

The memorial allows for self sufficiency or is it designed in a self sufficient manner. People do not want to be told how to heal

The memorial responds to its surroundings and is well integrated into the landscape

The memorial provides space for the uniqueness of people and the different ways in which they heal

Variation in Healing

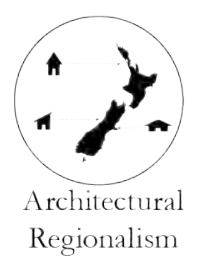

The architecture of the memorial is representative of the local architecture

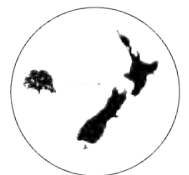

The materials are from local sources and manufacturers 


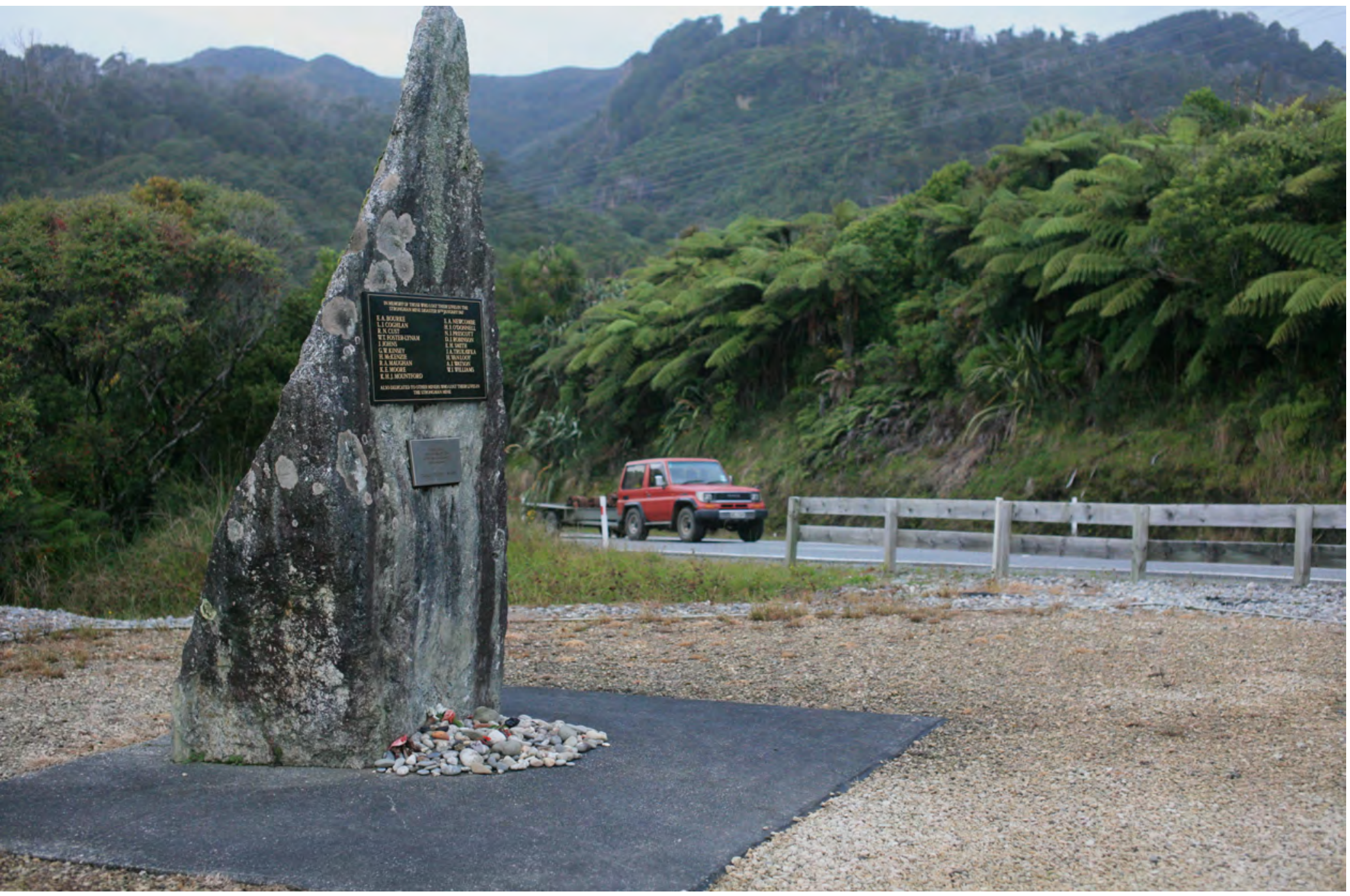

+Figure 4.01 Strongman Memorial. 


\section{EXISTING PRECEDENTS THAT OUTLINE THE PROBLEM}

In New Zealand the problem precedents can be fit into three main types: locator memorials, sculptural interpretative memorials and functional memorials. Examples of these types are analysed in the following chapter.

\section{LOCATOR MEMORIALS}

Many memorials in New Zealand reveal a belief that placing a plaque on a stone serves to create an adequate site for commemoration. The plaques act as a locator for tragedy and loss with the stones often being sourced locally. The majority of these 'stones' sit on the shoulder of the road; in places that are not respectful spaces to commemorate. Memorials function to provide a place to remember and to heal, these stones rarely achieve this. Memorials also serve to educate the public on the history of the site and provide insight to uninformed visitors; more often than not the stone only provides the names of the lost. As these plaques could be slapped onto any rock, anywhere, identity becomes lost. This method of memorialisation is common throughout New Zealand.

On the West Coast this is evident at the sites of the Strongman mine disaster, the Pike River mine disaster, the Cave Creek disaster, the memorial to Brunner in the Buller Gorge, and the memorial to Leonard John Kearton Holmes which are all memorialized by a stone. 


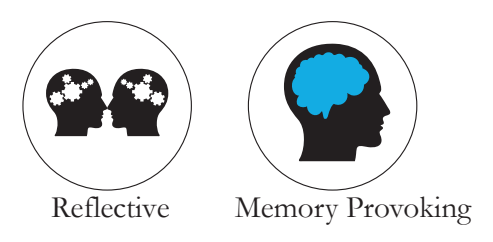

The simple nature of locator memorials lends them to provoke reflection and memory. A well-placed stone can also induce a reflective response.

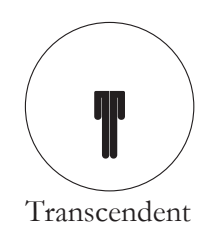

Due to their simple rudimentary nature and their poorly considered location these memorials fail to reach a level of transcendence. The Pike River memorial, for example, sits adjacent to a power substation that diminishes the experience of a transcendent space.

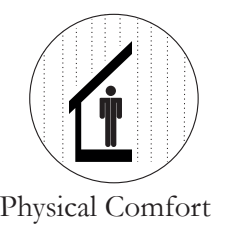

A safe, comfortable 'space' rather than a 'place' is required for successful healing to take place and locator memorials are generally unprotected from the weather.

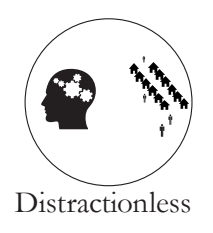

Locator memorials are generally arranged on the closest road adjacent to the site of the tragedy. There is an area to park your car with a place for standing to read the names on the memorial. Cars travelling past at $100 \mathrm{~km} / \mathrm{hr}$ are not conducive to a process of healing or reflection. 

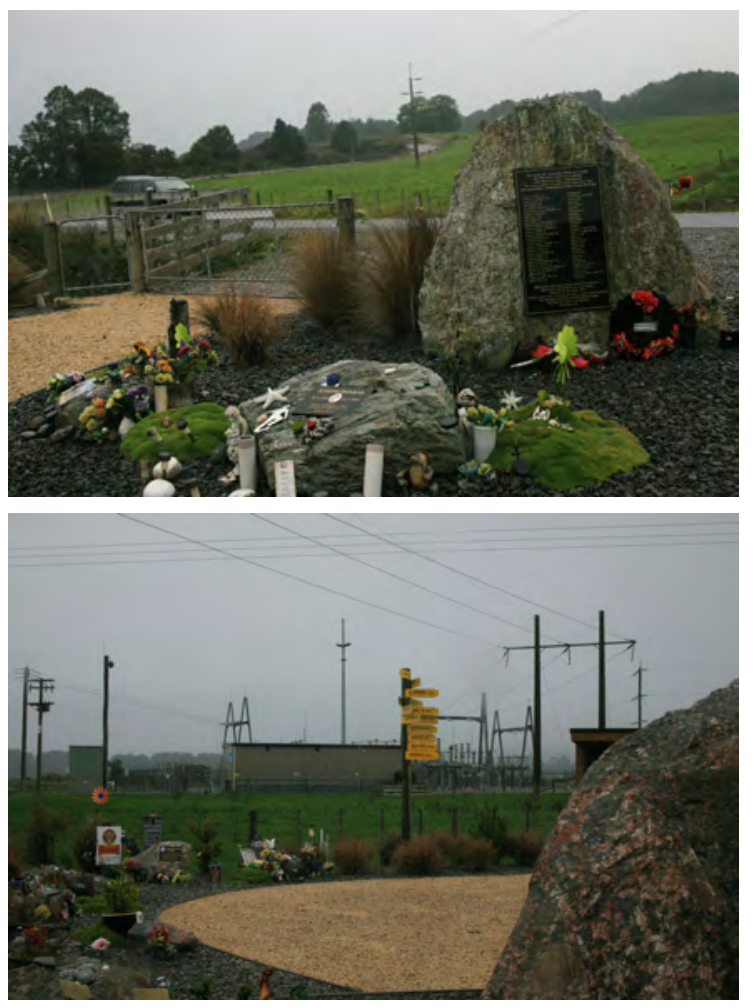

+Figure 4.02 Pike River Memorial.

+Figure 4.06 Pike River Memorial Substation.
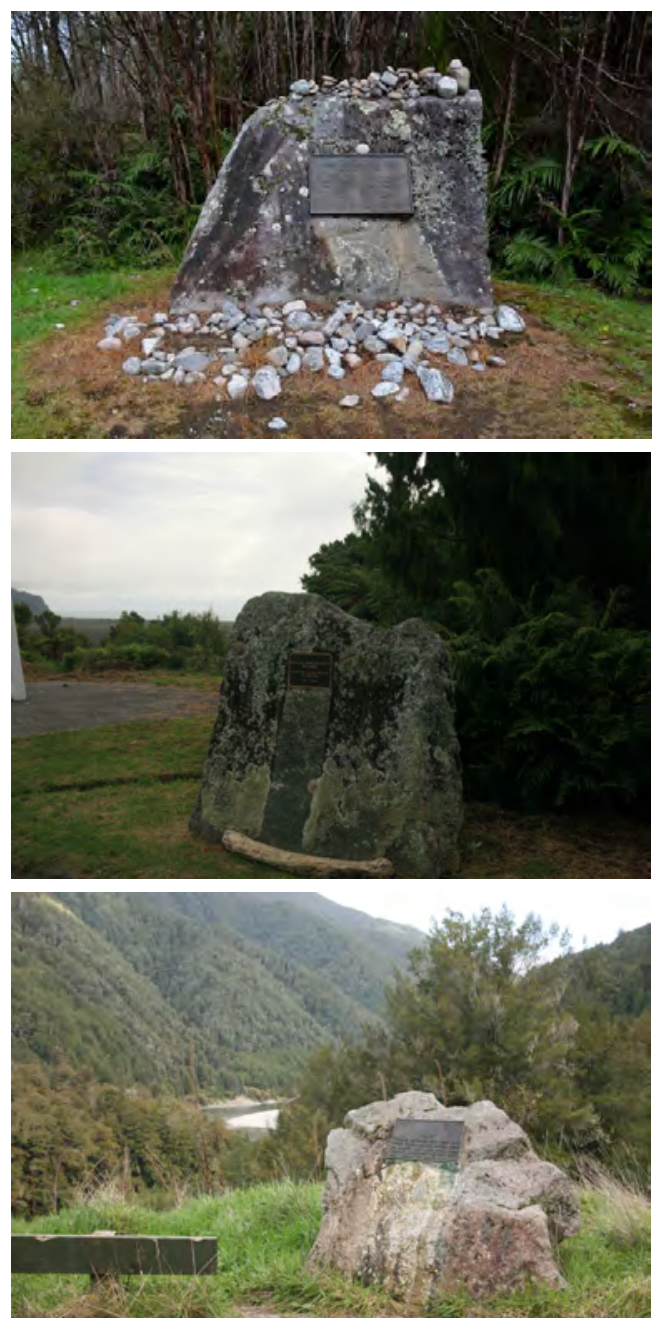

+Figure 4.03 Cave Creek Memorial.

+Figure 4.04 Kearton Holmes Memorial.

+Figure 4.05 Brunner Memorial (Buller Gorge).

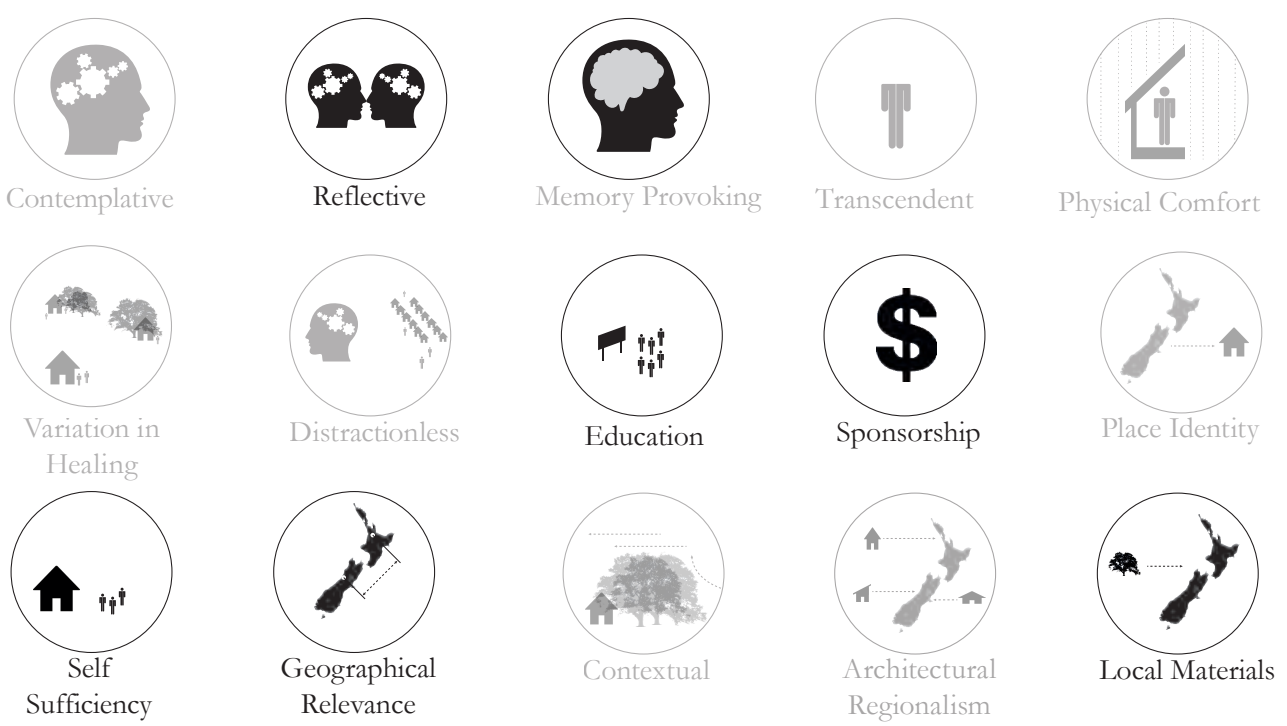




\section{SCULPTURAL MEMORIALS}

The majority of war memorials in New Zealand are reproductions of previous colonial works. The New Zealand government preferred monumental, ornamental memorials over functional memorials. Now, these often heroic figures have made the memorials irrelevant and out of context. Chris Maclean and Jock Phillips state that James Allen, William Montgomery and Samuel Hurst Seager campaigned for all war memorials to be purely ornamental after the First World War (78). They were supposed to communicate an idealistic and heroic view of war; a celebration of war. They were to reflect the country's loyalty and colonial status (82). These interpretative memorials were to encourage the next generation of men to strive to be like the sculpted heroes. This idea of celebration of a hero does not relate with the overly modest New Zealand culture. We do not identify well with war memorials that celebrate a heroic figure.

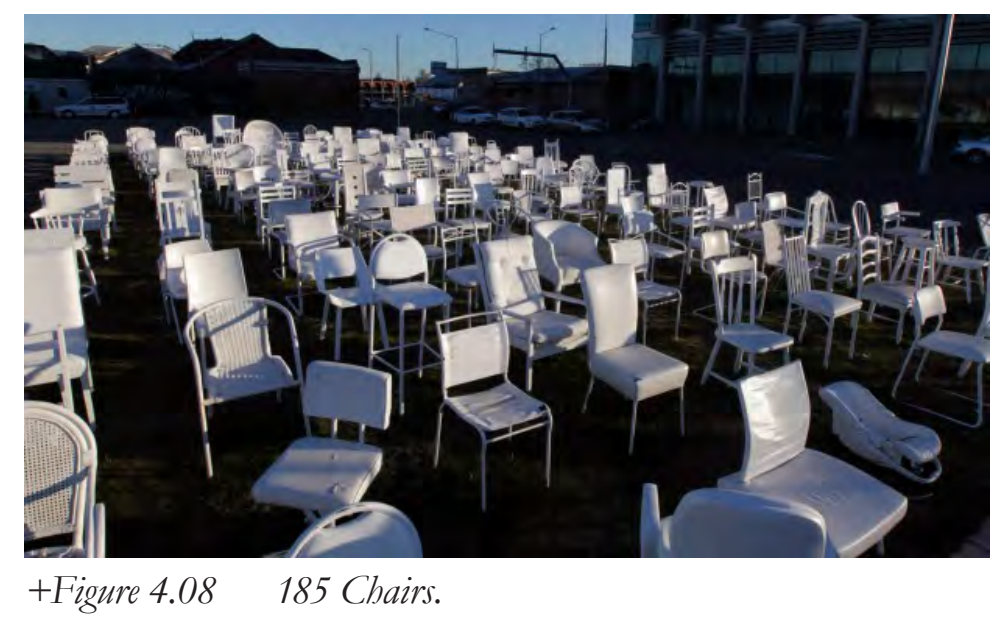




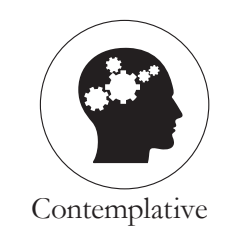

The sculpture can become the focal point. It can detract from a space for contemplation taking attention from the vast infinite view, where the viewer can lose themselves to thought.

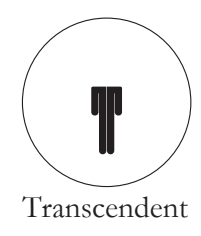

The 185 chairs for the Christchurch earthquake memorial is a sculptural memorial to the lost rather than a celebration of a heroic figure. This has cemented the memorial with gravitas. This weight allows for transcendence.

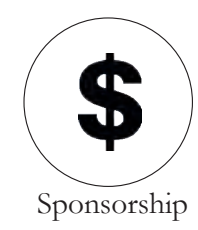

Government sponsorship sometimes has ulterior motives. This could have been electorally motivated, or reminding the public to they too are a part of the colony and they should not forget their role in it. Memorials erected by individuals are often more sincerely motivated.

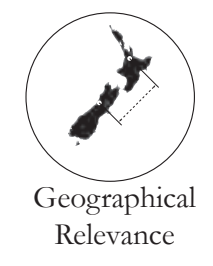

Often geographically relevant as they function as a memorial to the lost in that local area. The memorial is generally in a central park of the town, with the names of the fallen in the area engraved. 


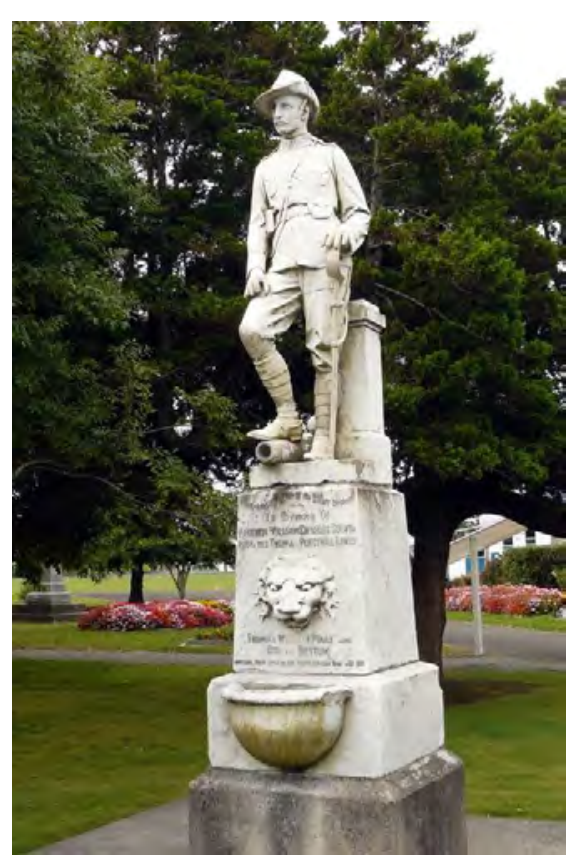

+Figure 4.09 South African War Memorial (Westport).

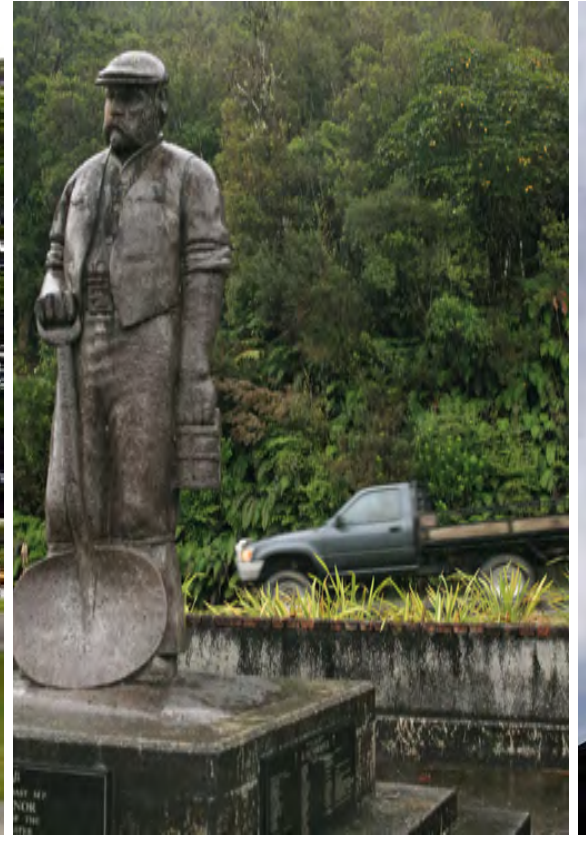

+Figure 4.10 (Grey River).

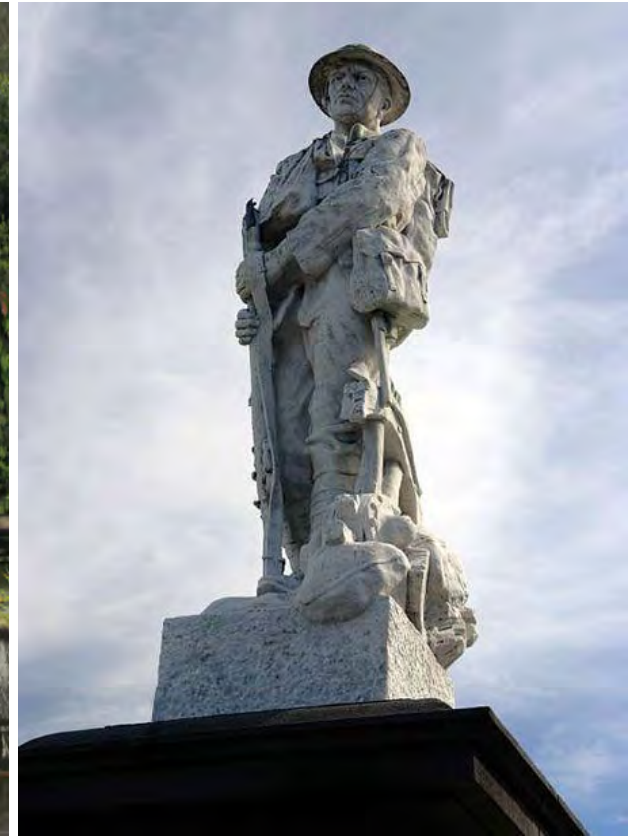

+Figure 4.11 Kaiapoi War Memorial.

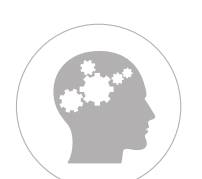

Contemplative

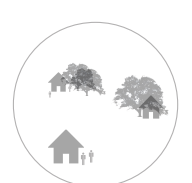

Variation in

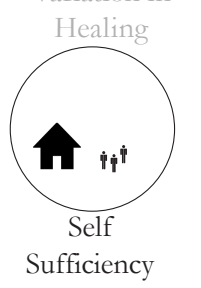

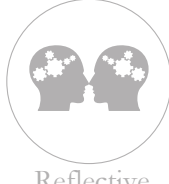

Reflective
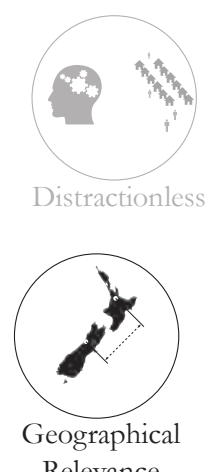

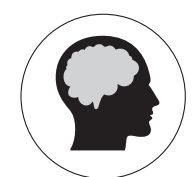

Memory Provoking

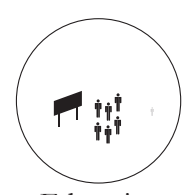

Education

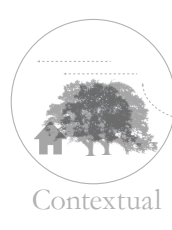

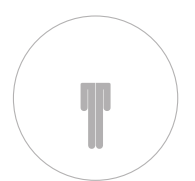

Transcendent

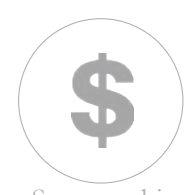

Sponsorship

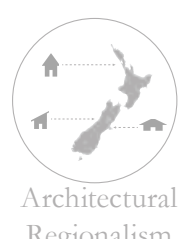

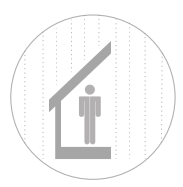

Physical Comfort

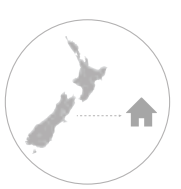

Place Identity

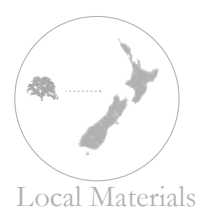




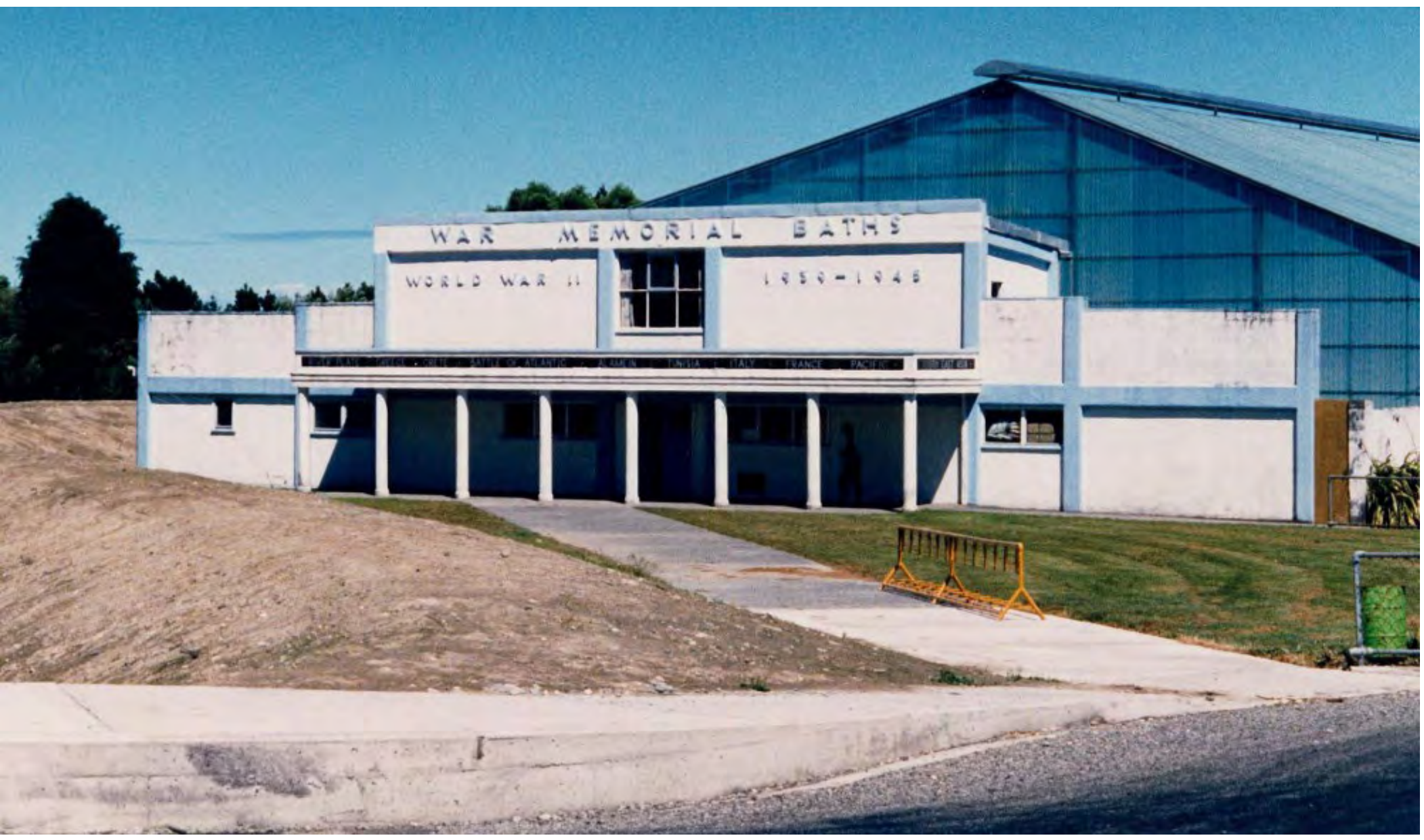

+Figure 4.12 Greymouth War Memorial Baths. 


\section{FUNCTIONAL MEMORIALS}

Functional memorials have usually taken the form of Plunket rooms, pools or community-centres with the Auckland War Memorial museum and the parliamentary debating chamber being obvious exceptions to this. Functional memorials were not favoured after the First World War as Allen and Montgomery firmly supported sculptural memorials (Maclean and Phillips 139). However, by the centennial memorials in 1940 living memorials fell into favour and after the Second World War the New Zealand Government supported 'living memorials', functional memorials. The stone soldiers "were merely reminders of war which had pitted the workers of the world against each other" (139). These living memorials provided space for recreation. At the time before television, and the transition of population from country to city, these buildings were the focal point for both rural and urban communities (147). 

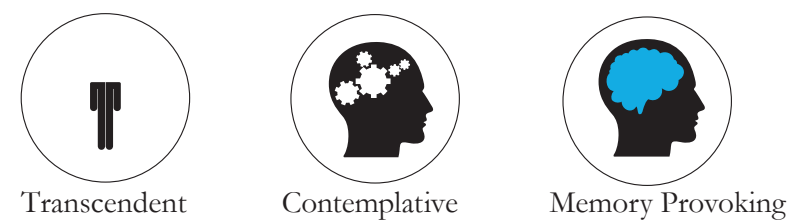

Memorial buildings often fail to achieve a transcendent experience. The buildings were designed to be purely functional. They were often built within a tight budget and this has led to spaces of a lower quality and spaces that are unlikely to provoke a visitor to reflect or transcend.

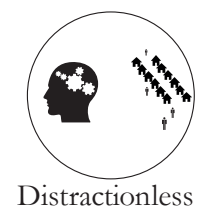

Memorial buildings are successful insofar as they offer a distraction from everyday life. They are designed to give the viewer / experiencer respite from hardship and grief found in their day-to-day existence.

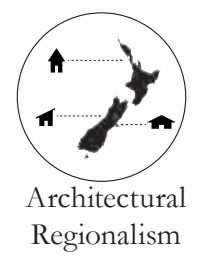

These spaces were usually budget-driven designs designed by a government employee. Little consideration was given to context, or vernacular architectural culture. 


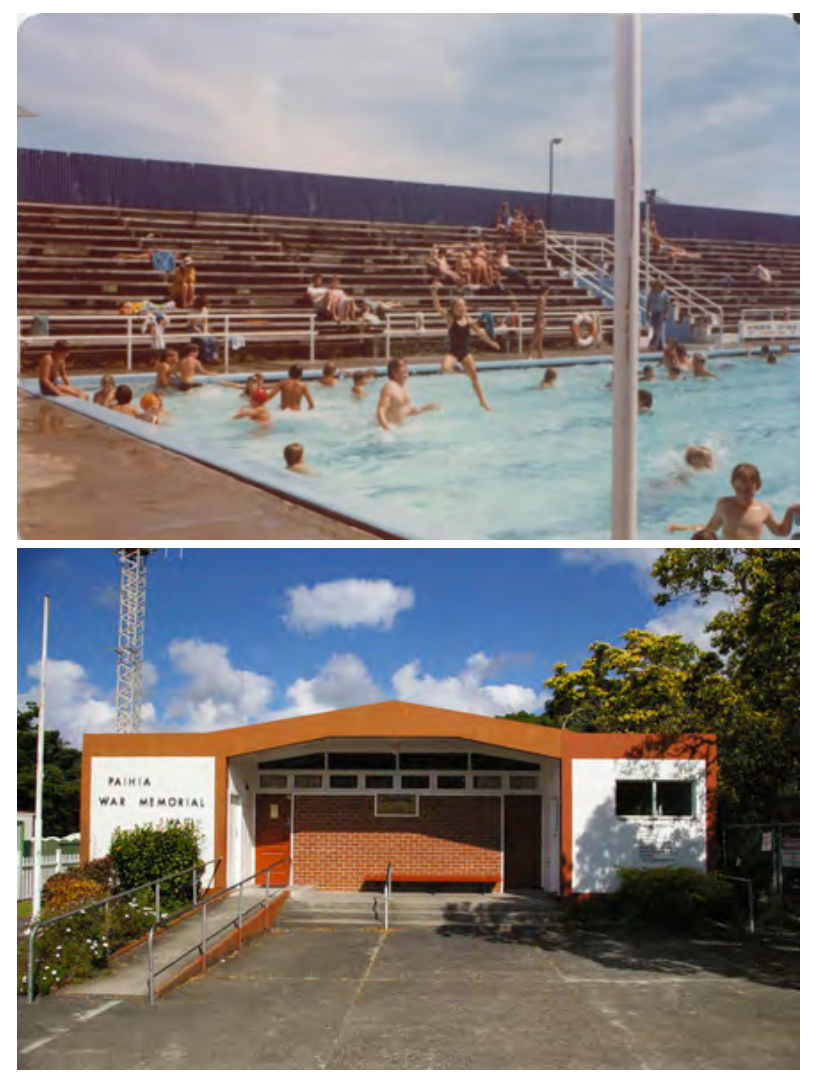

+Figure 4.13 Greymouth War Memorial Baths.

+Figure 4.14 Paibia War Memorial Hall.
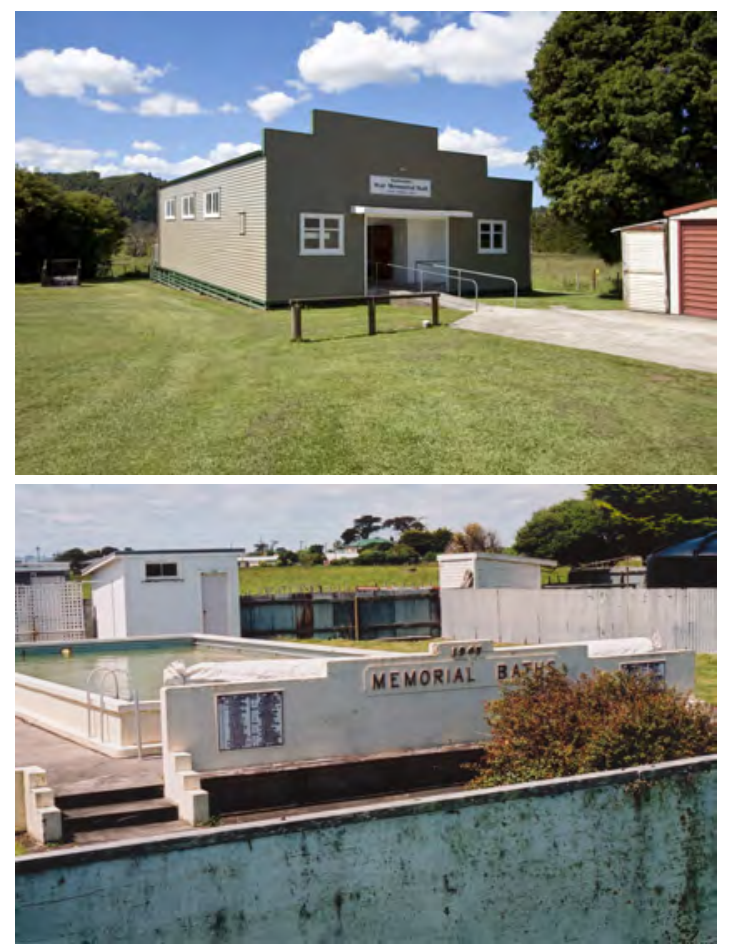

+Figure 4.15 Waitawheta War Memorial Hall.

+Figure 4.16 Memorial Baths at Manutabi School.
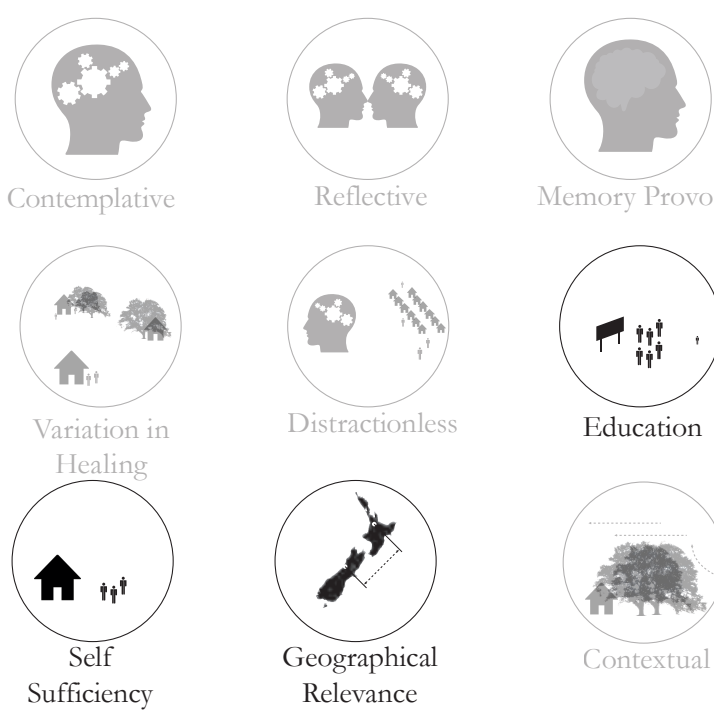

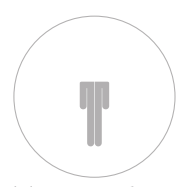

Transcendent
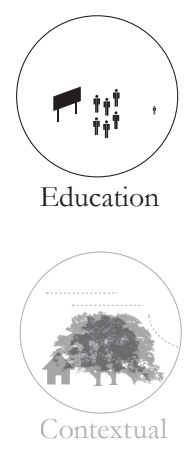
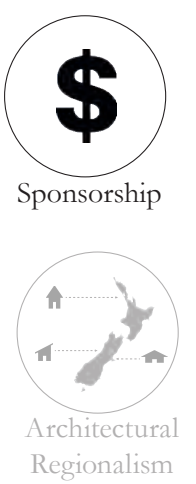

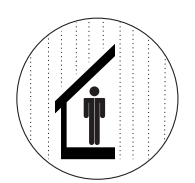

Physical Comfort
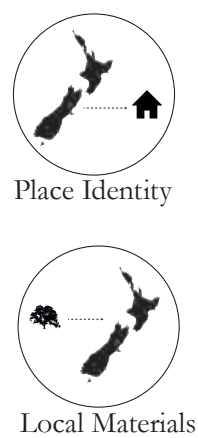


\section{CONCLUSION}

The criteria have highlighted that New Zealand memorials are often unsuccessful. Firstly, with only one of the three types of memorials 'reflective', two of the three 'memory provoking', and none 'contemplative' or 'transcendent', existing memorials were not found to be adequate places to think.

Secondly, none of the three precedent types achieve 'contextual' or 'architectural regionalism', with only the functional memorials exhibiting 'place identity'. This leaves memorials context-less. Due to the decreasing place identity and architectural regionalism of the West Coast and the fact that connection to place is very important for my architectural solution, architectural regionalism and place identity will be given more importance in my design solution.

Functional memorials are the most similar type to my proposed architectural solution. Functional memorials function as a place for distraction, a place to get away from problems. Whereas the memorial that I am proposing is a place to induce you to remember, a place of focus. It will be a more confrontational memorial. This focus rather than distraction is a more successful method of memorialisation and strengthens my decision for an activity-based memorial. 


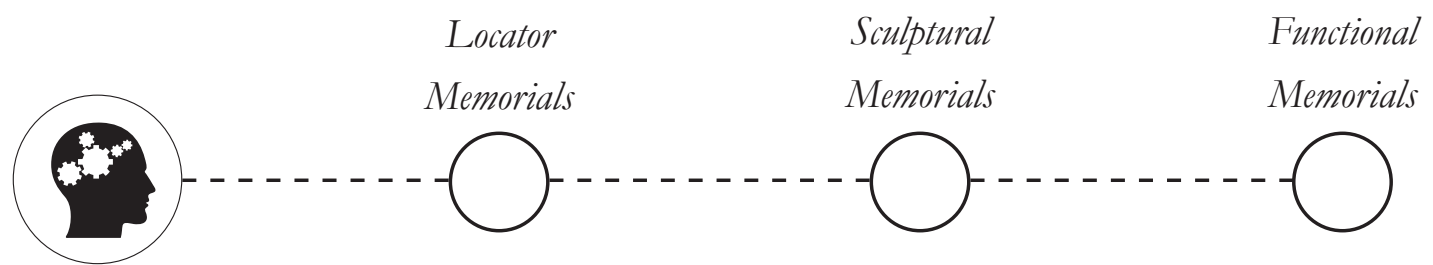

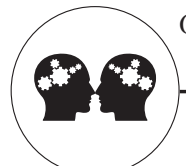

Contemplative

Reflective
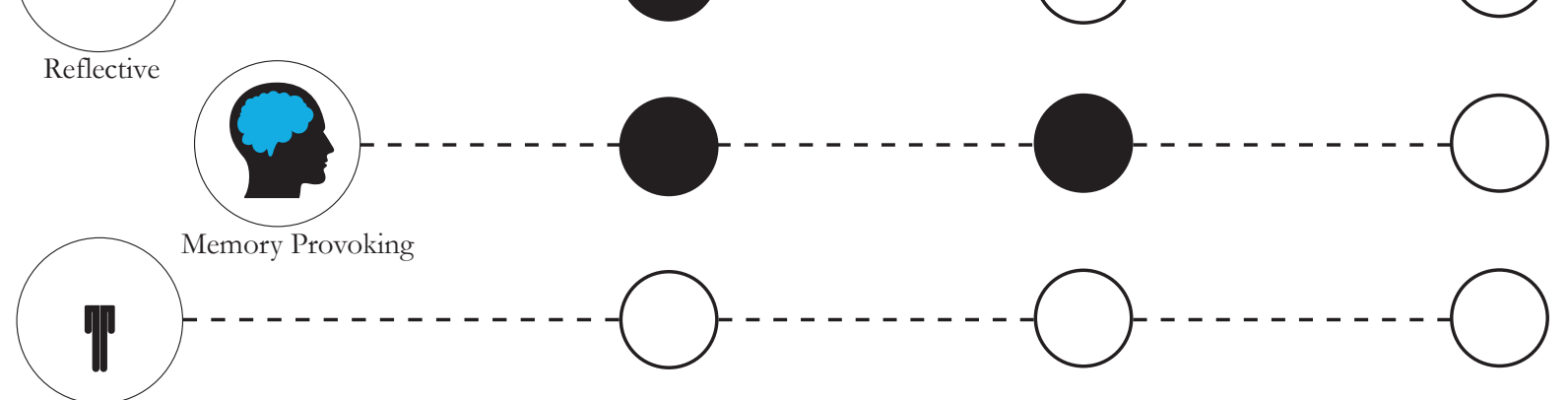

$\longrightarrow \cdots \cdots-\cdots-\cdots-\cdots$

Transcendent
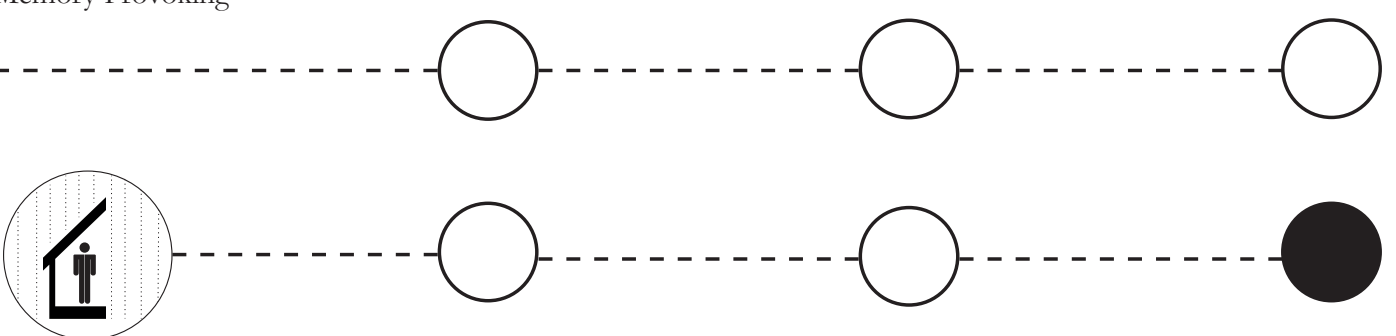

(

(

P

$\longrightarrow$

Education

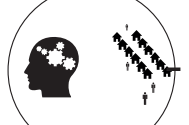<smiles>C1CCCCC1</smiles>

$(3$

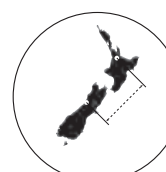

Distractionless

Geographical

Relevance

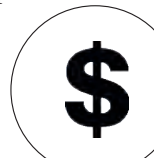

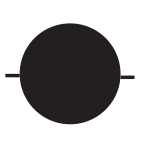

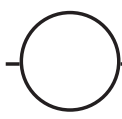

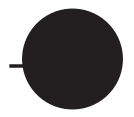

- - - - - - - - - - - - -
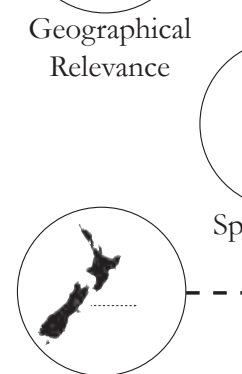

Sponsorship

Place Identity
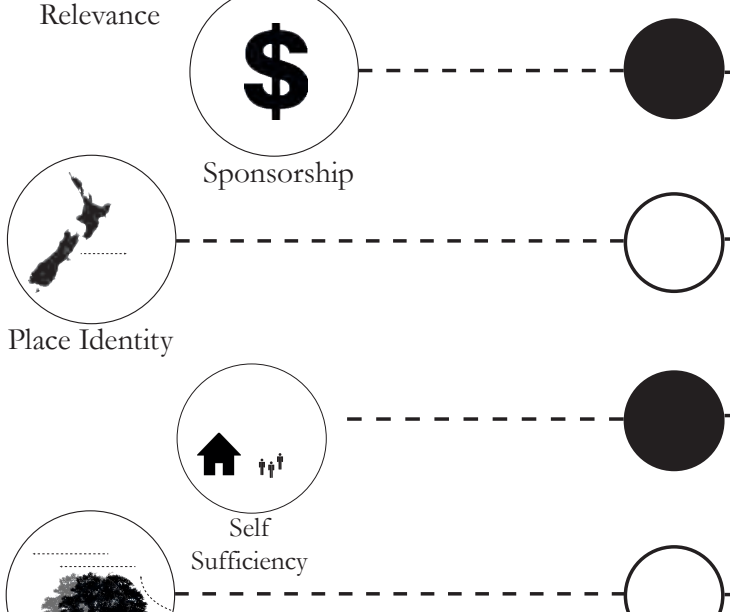

$\longrightarrow$

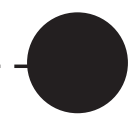

- - - - - . - . - -

$(3$
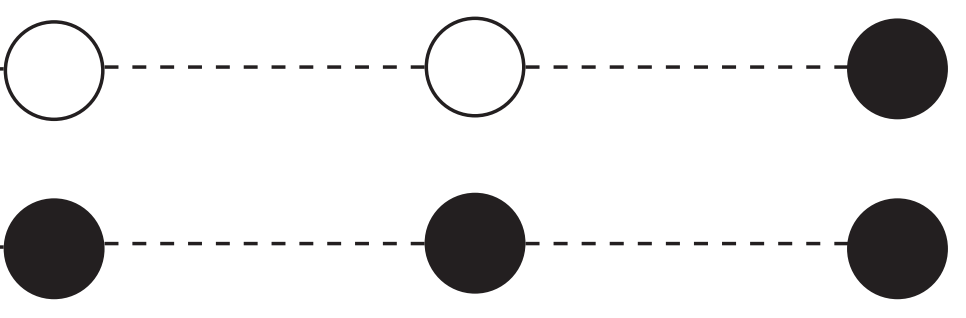

$\bigcirc$

$-(-\cdots \cdots \cdots$

Contextual

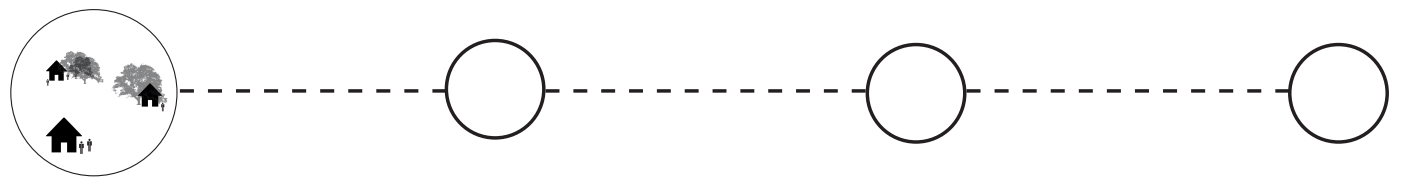

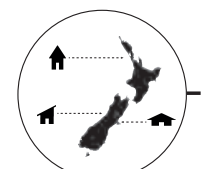

Variation in

Healing

Architectural
Regionalism

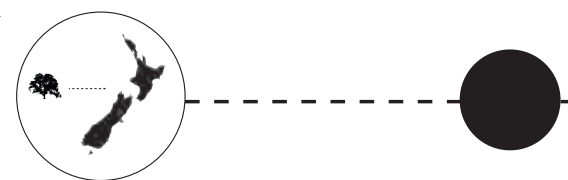

$-(-\cdots \cdots-\cdots$

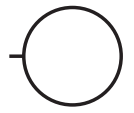

Local Materials

$-\cdots-\cdots--\square$

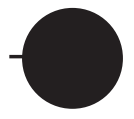




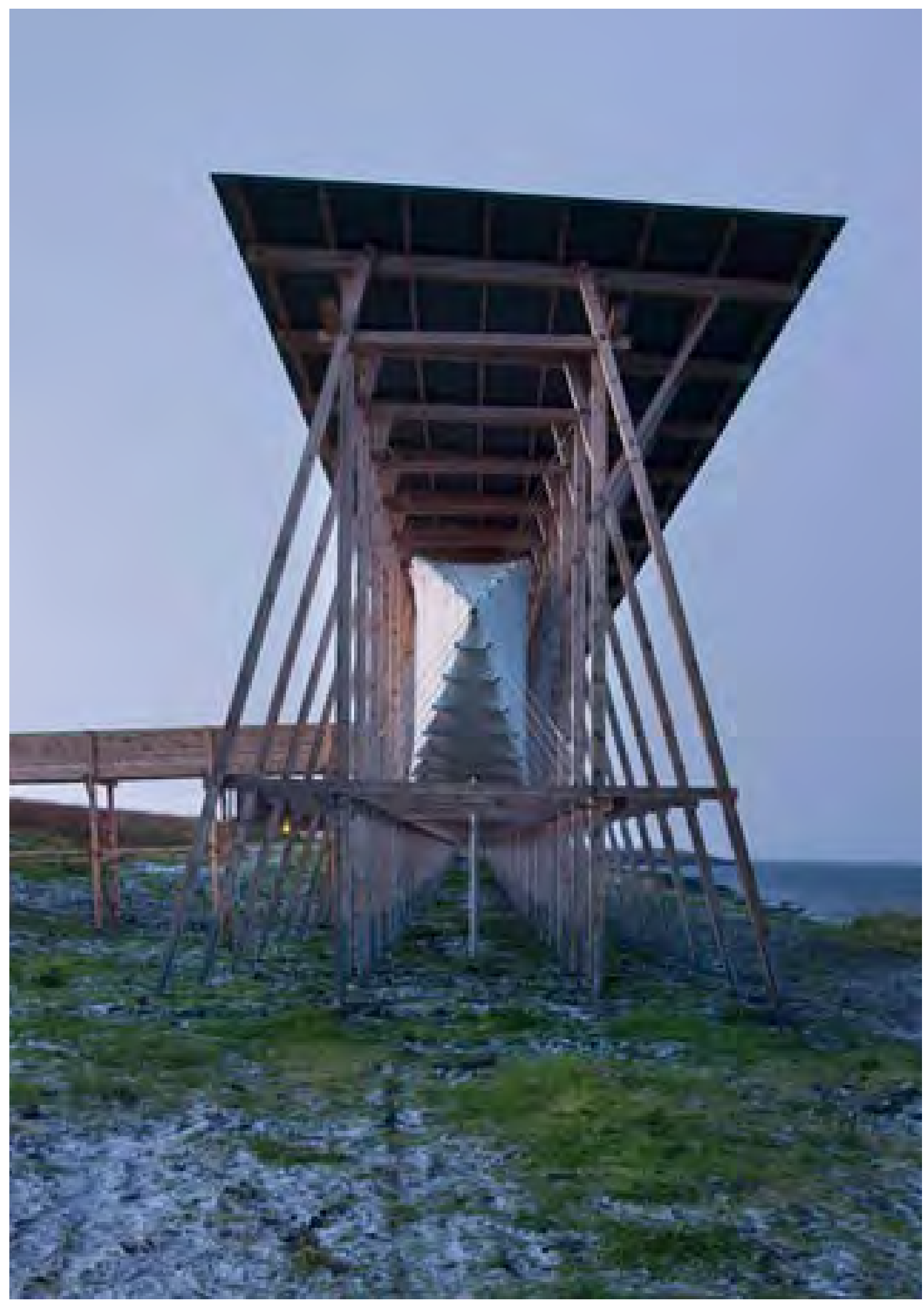




\section{PRECEDENTS THAT ARE EXAMPLES FOR A SOLUTION}

Three examples of memorials around the world that provide successful, contextual memorial space.

\section{THE STEILNESET MEMORIAL}

Architect: Peter Zumthor and Louise Bourgeois

Location: Vardø, Norway

Date of construction: 2011

In response to 91 people who were tried and burnt in the 17th century for witchcraft, Zumthor and Bourgeois designed the Steilneset Memorial. It is composed of two separate buildings, the long house designed by Zumthor which is a taut wood-frame and polytetrafluoroethylene structure. The 91 burnt are represented by 91 lightbulbs suspended within randomly spaced openings. Accompanying each of these openings is an information panel. The second part is Bourgeois's piece of art, a single chair with flames burning from the seat. The burning chair is reflected by mirrors placed around the perimeter of the seat, these are to symbolise judges surrounding the condemned. 


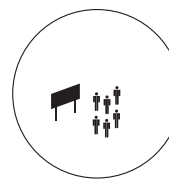

Education

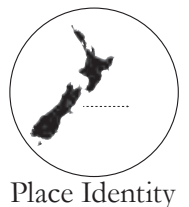

Place Identity

Responding to 'place' through both culturally sensitive design and education, the memorial acknowledges the witch burning as an important aspect of their identity. Though it does belatedly bring up past events, continued suppression would be insensitive to those who were burned. Here, education is a powerful method of protecting place identity.

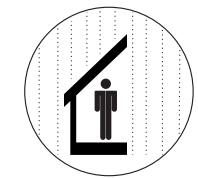

Physical Comfort

The Steilneset memorial can be inhabited and explored. Parts of it are protected from the elements, but others not so. Bourgeois' piece has been designed so the visitor experiences the wind and the cold. Comfort here has been considered.
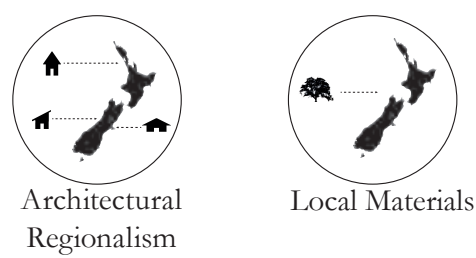

Wood is scarce in this region, thus, the entire wooden structure was sourced and fabricated off-site. The membrane was fabricated in Germany so despite this memorial's vernacular aesthetic it is not so.

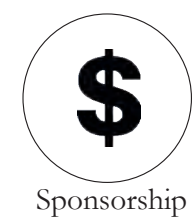

The Steilneset memorial was sponsored by the town of Vardø, Varanger Museum, and the Norwegian Public Roads Administration. The memorial is to remind us of the ongoing danger of collectively creating scapegoats. However, there is speculation it was also to attract more tourists by the Norwegian Public Roads Administration (Stephens 36). 


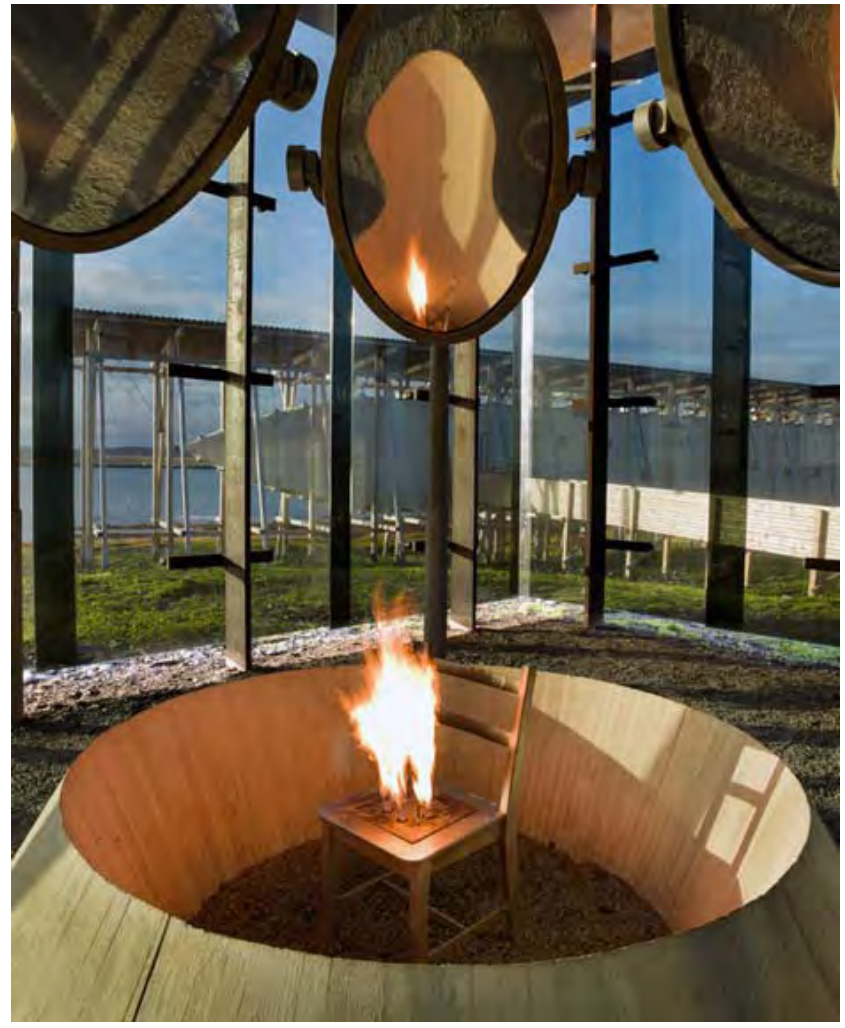

+Figure 4.18 Lonise Bourgeois, piece.

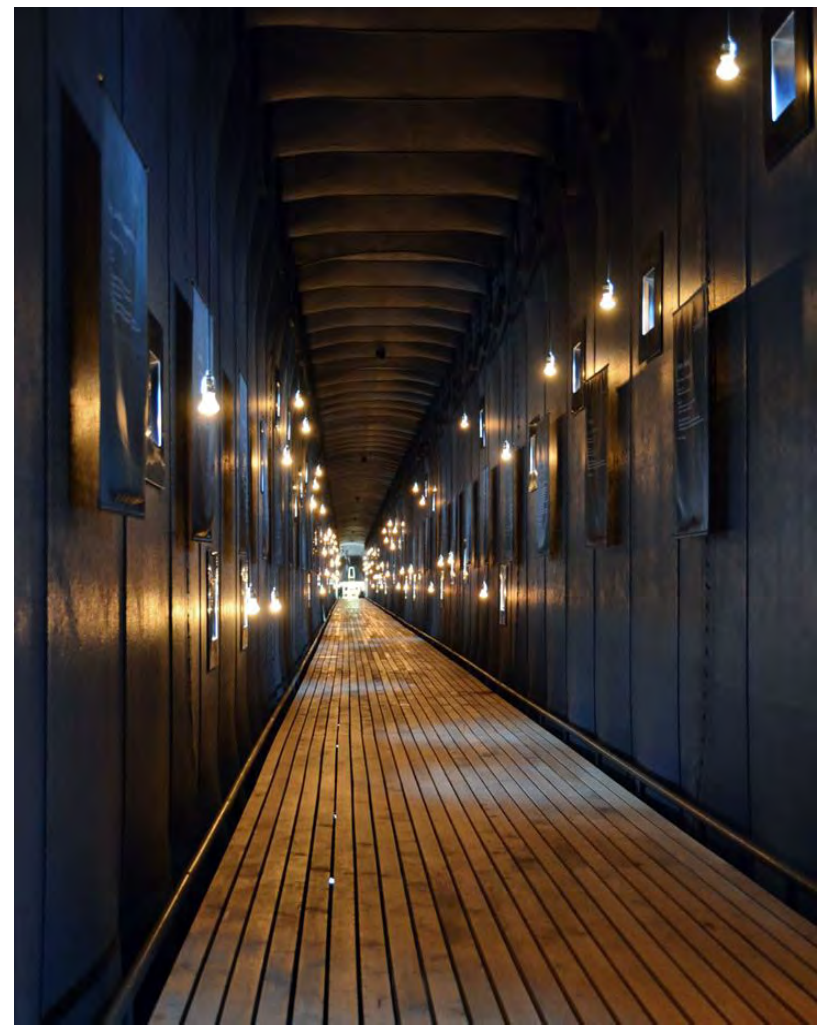

+Figure 4.19 Peter Zumthor's memorial (interior).
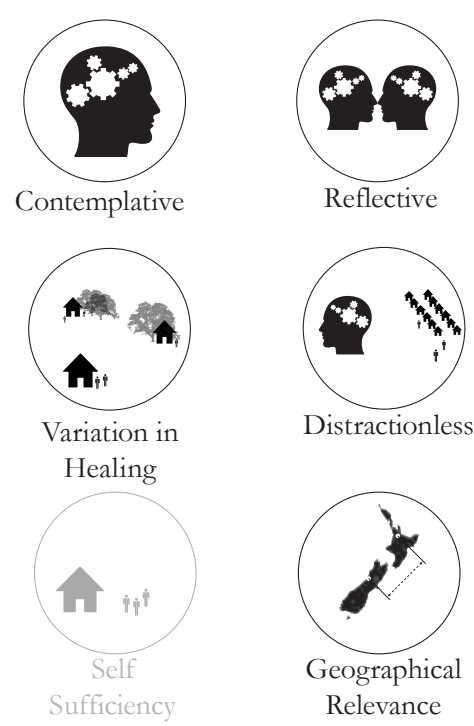
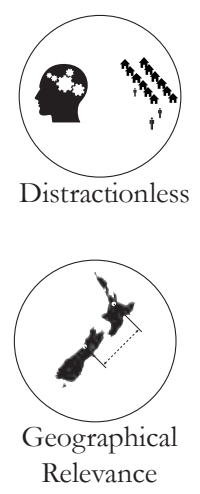

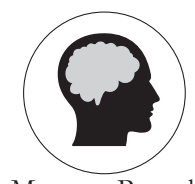

Memory Provoking
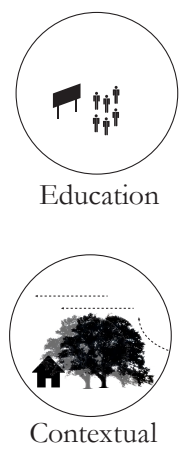

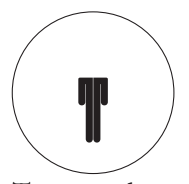

Transcendent
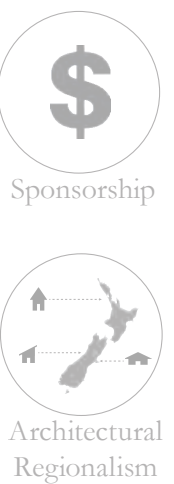

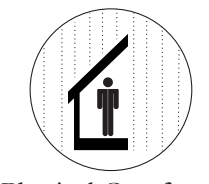

Physical Comfort
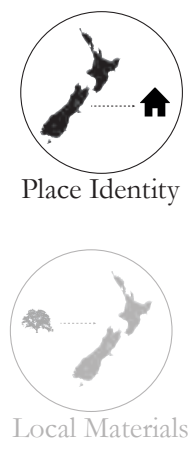


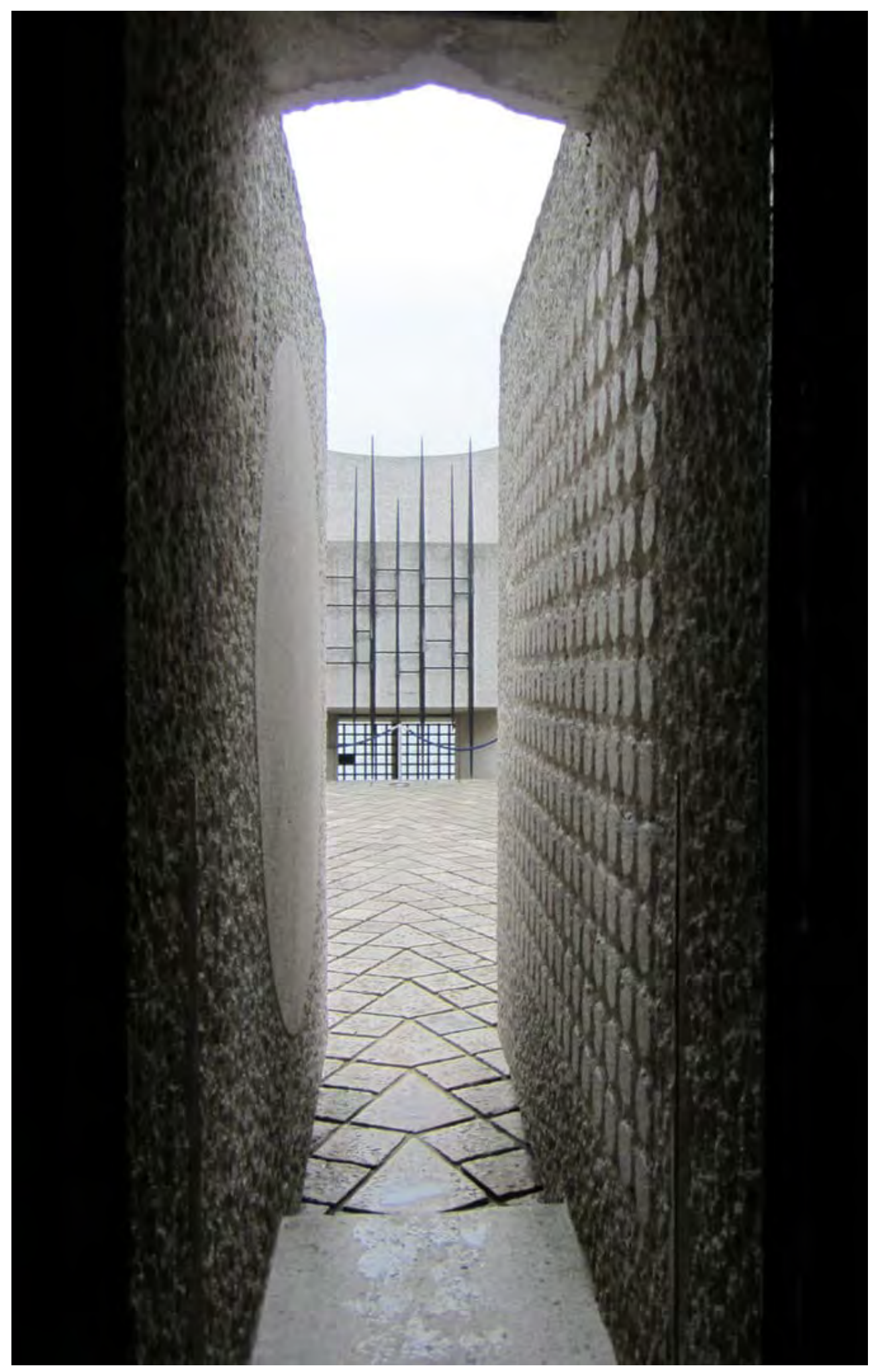

+Figure 4.20 Memorial des Martyrs de la Deportation. 


\title{
MEMORIAL DES MARTYRS DE LA DEPORTATION
}

\author{
Architect: Georges-Henri Pingusson \\ Location: : Île de la Cité, Paris, France \\ Date of Construction: 1962
}

Memorial des Martyrs de la Deportation is dedicated to the 200,000 people who were deported from Vichy France to Nazi concentration camps. The memorial is made entirely of pick hammered concrete to express the roughness and violence of the Holocaust.

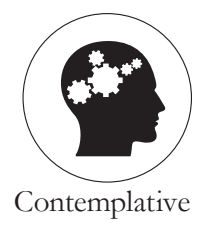

Access via a narrow passage leads to a space open only to the sky and a small barred opening that provides a glimpse of the Seine River. This intimately, individual framing focuses the senses and gives the viewer a specific view, enabling only sight and sound of the moving water. In the memorial you are removed from everything, you are alone.

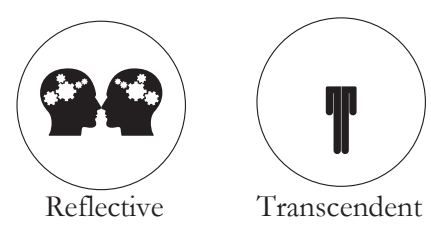

This memorial inverts the conventional form of the monument, rather void as opposed to protrusion. This concept of experiencing void is reflective of the experience of loss. This memorial is in a central part of Paris. Although, when experiencing the memorial there is a powerful disconnection from the city, all you can hear is the flow of water and all you can look at, is the sky, the water and yourself. 


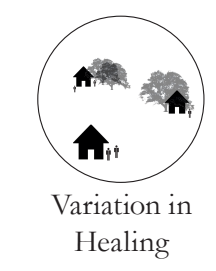

Stretching from the bright courtyard to an underground crypt with the remains of an unknown deportee, a corridor is dimly lit with 200,000 glass crystals that symbolise the dead. The dark entrance between the two blocks of concrete intrigues and draws in the viewer. The experience of being in a dimly lit corridor prompts feelings of comfort and safety. Exiting the dark corridor a similar experience is felt, you are drawn to the bright courtyard, out of the dark space.

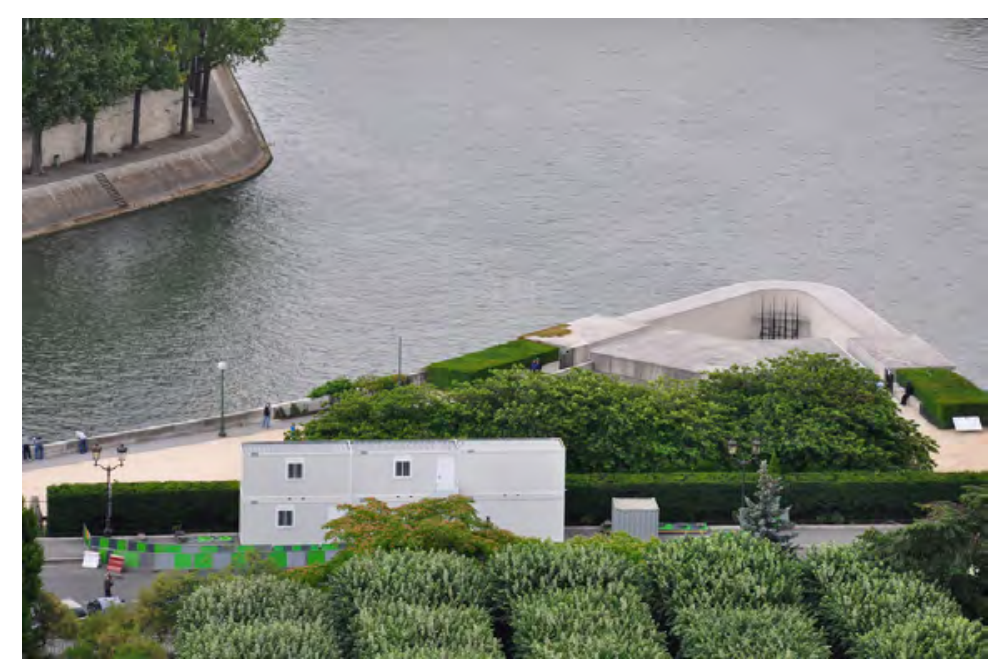

+Figure 4.21 Memorial des Martyrs de la Deportation. 


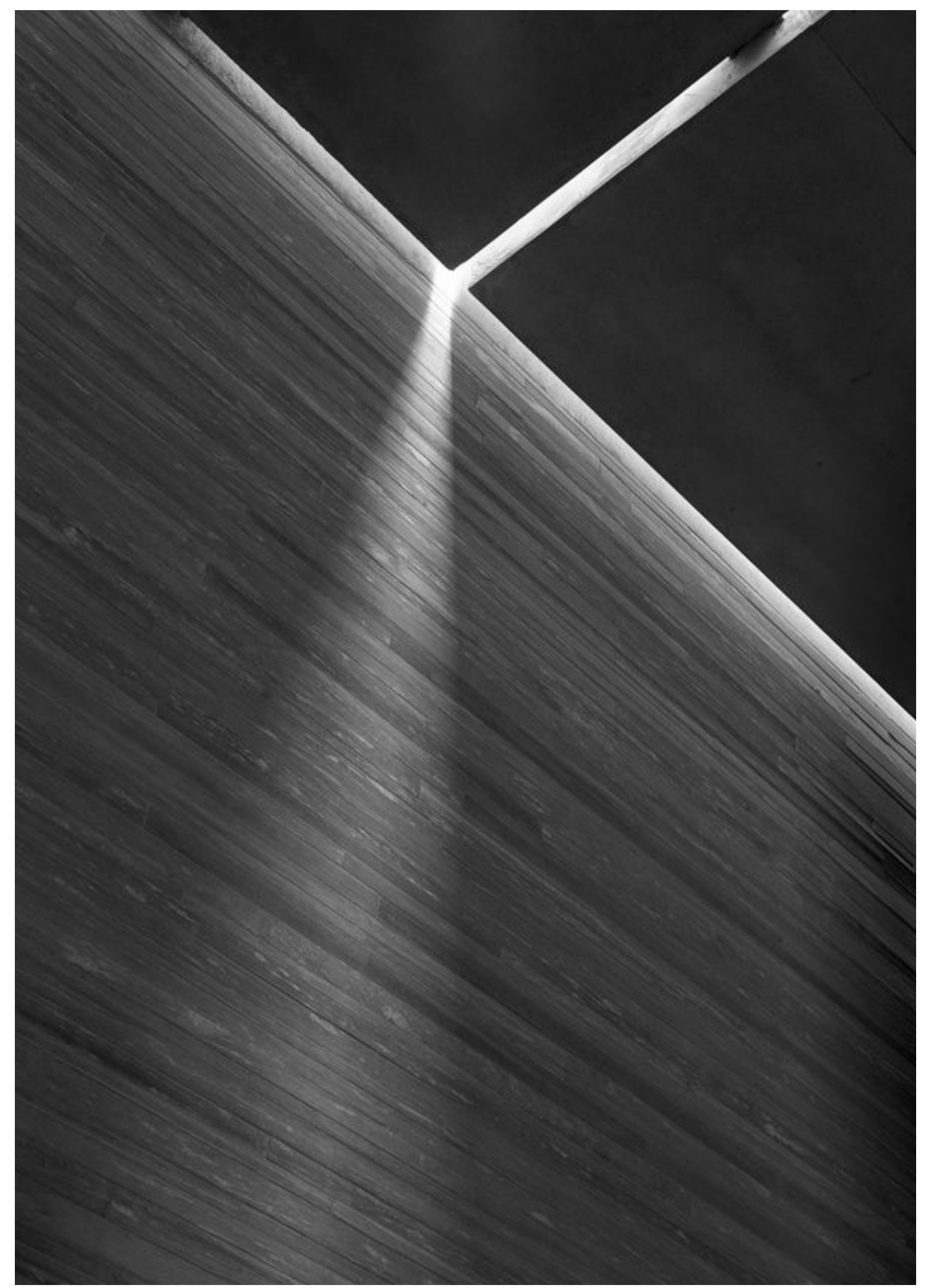




\title{
THE THERME VALS
}

This precedent study is of a bath, not a memorial

\author{
Architect: Peter Zumthor \\ Location: Graubünden, Switzerland
}

Date of Construction: 1996

The Therme Vals were designed for visitors to rediscover the ancient benefits of bathing. Programme is composed through a series of thermal baths in the mountains of Switzerland. The building protrudes both into the sky and ground, forcing the threshold of ground to be blurred. The thermal baths are designed as an experiential journey. The underlying layout of internal space is a carefully modelled path of circulation which leads bathers to certain predetermined points while also letting them explore other areas for themselves. The perspective is always controlled. It either permits or denies a view. 


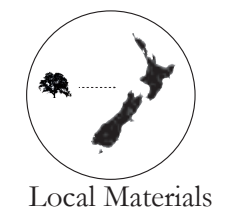

All baths are constructed of layers of Valser Quarzite slabs quarried from the surrounding mountains. This use of local material has meant the baths are contextual despite the form not being vernacular. The stone rooms were designed not to compete with the body, but to flatter the human form.

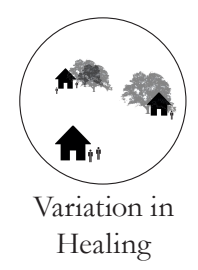

Zumthor uses darker and lighter spaces to draw people through space. Spaces of darkness are often quiet, solitary spaces for being alone with oneself. Whereas lighter spaces are often more communal, variation in lighting levels is used as a method of invoking the senses.

Water flows throughout the building, splashing and echoing off the stone. The sound of varies throughout the building. Areas of solitude and serenity have a quieter level of sound, while other more communicative areas exhibit a louder level of sound 


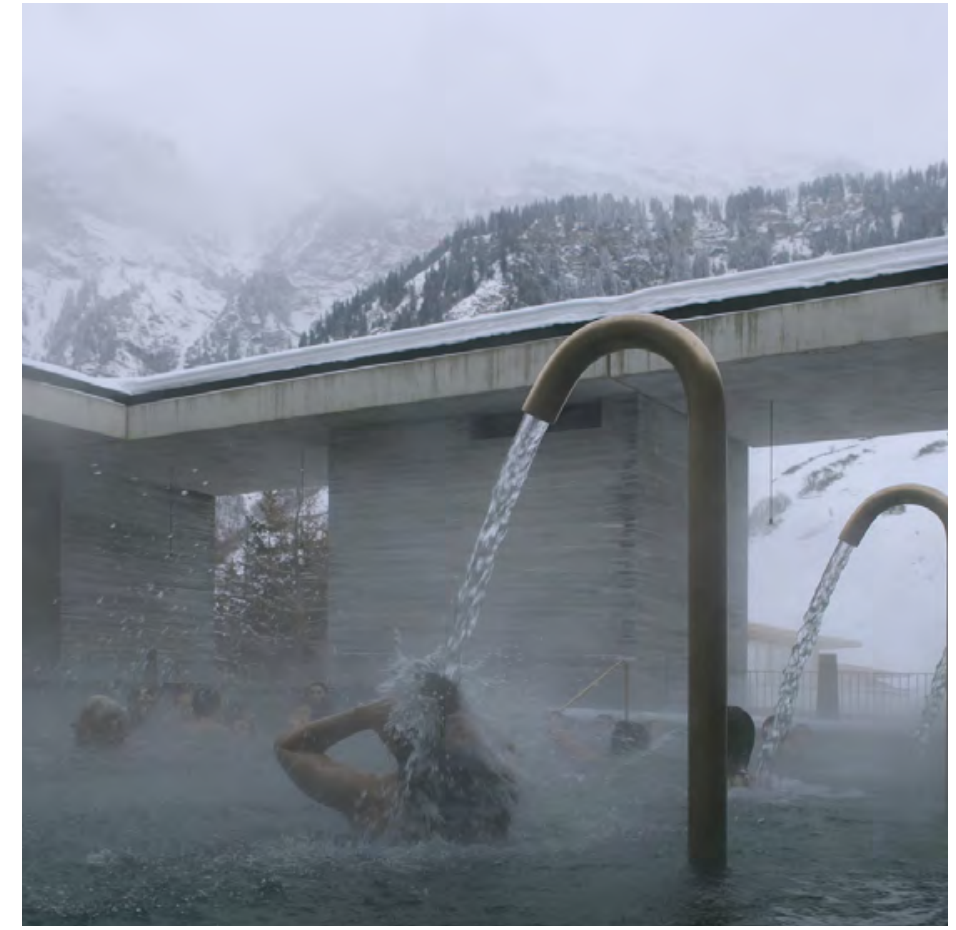

+Figure 4.25 Outdoor Baths.

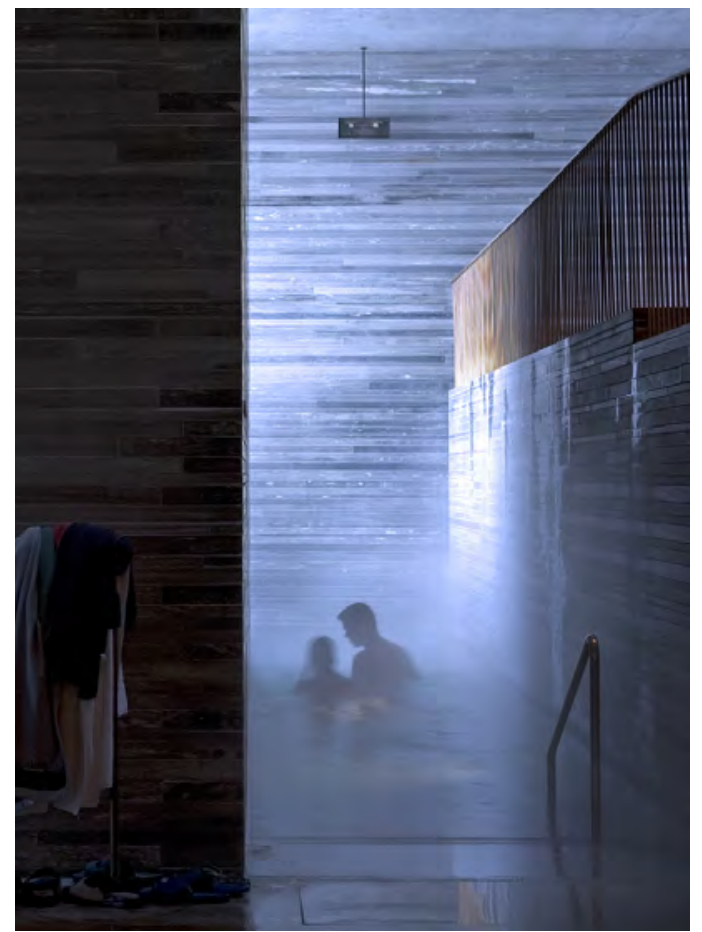

+Figure 4.26 Interior Baths.

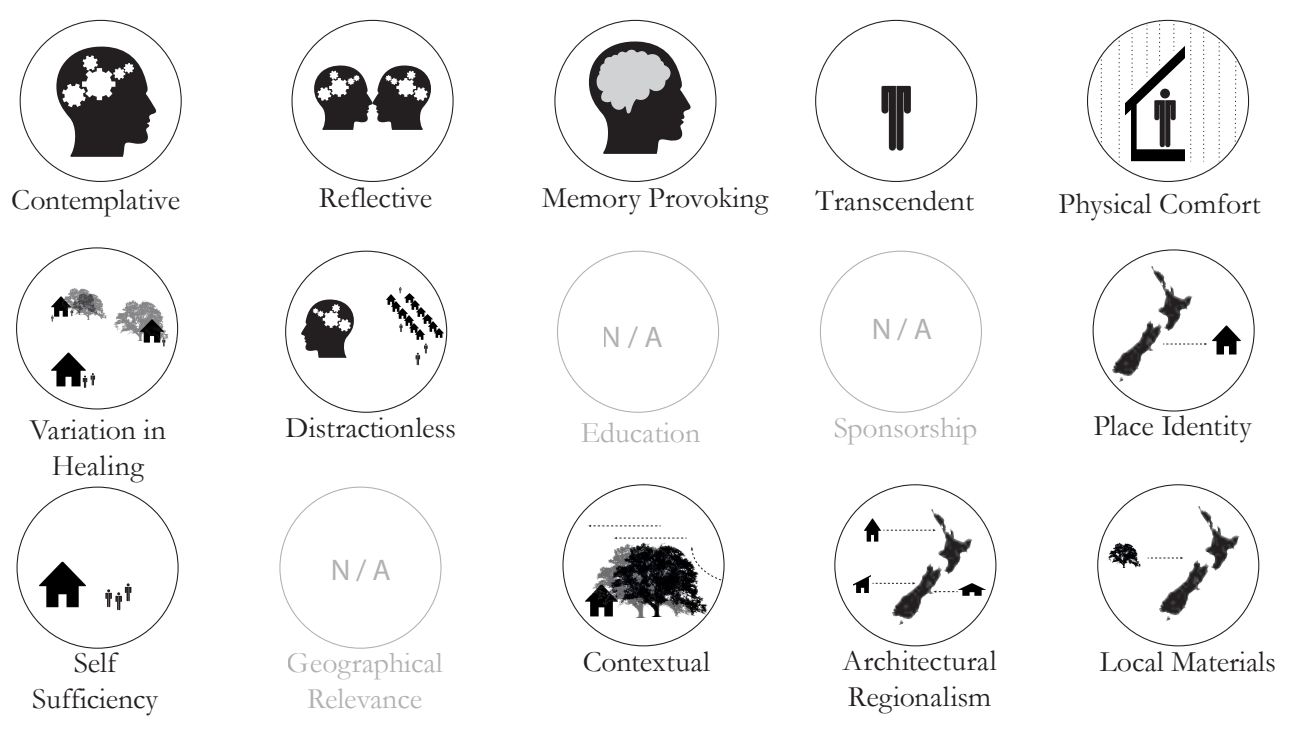




\section{CONCLUSION}

Alvaro Siza's Pools at Leça and Plischke's Abel Tasman Memorial were also analysed and their information included in the comparison.

The 'contemplation', 'reflection', 'memory provoking' and 'transcendence' criteria were all successfully exhibited throughout design in these precedents. This was achieved through careful consideration to framing in Memorial Des Martyrs and Therme Vals, through the audibility of water in Therme Vals and through the variation in lighting conditions in Therme Vals and Memorial des Martyrs.

The 'place identity' and 'architectural regionalism' criteria were poorly exhibited with only one of three demonstrating these. In both the Steilneset memorial and the Memorial Des Martyrs the architect favoured symbolism and aesthetics over vernacular references. This is not a negative observation against these memorials, it is just a different approach to memorialisation. It also must be noted that the Steilneset Memorial used education as a method of preserving place identity.

Variation in healing spaces is another common factor among some of the solution precedents. They provide various spaces for a range of people. This is important in a memorial as people heal in different ways.

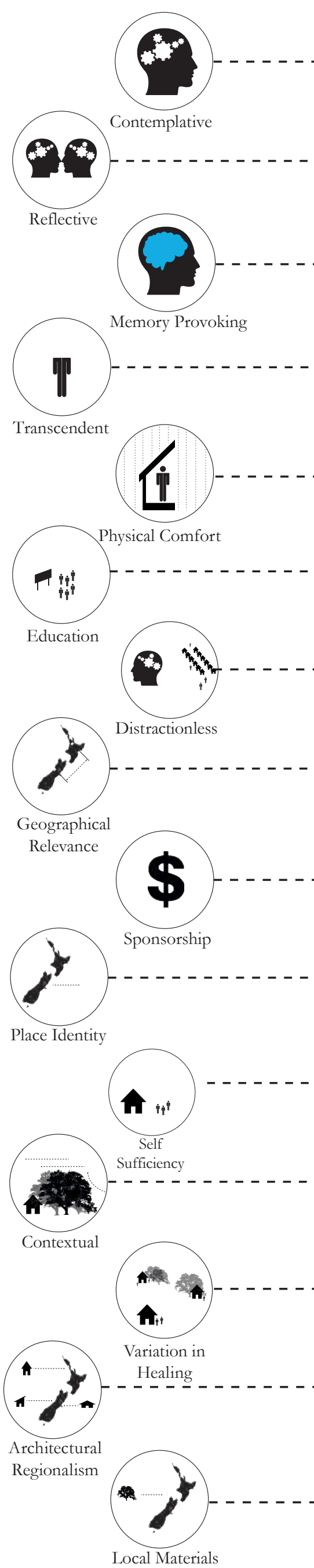




$$
\begin{aligned}
& \text { Memorial The Leça Abel Locator Sculptural Functional } \\
& \text { des Therme Steilneset Swimming Tasman Memorials Memorials Memorials } \\
& \text { Martyrs } \\
& \text { - - - - } \\
& \text { - - - - - - - - - - - - - - - - - - }
\end{aligned}
$$

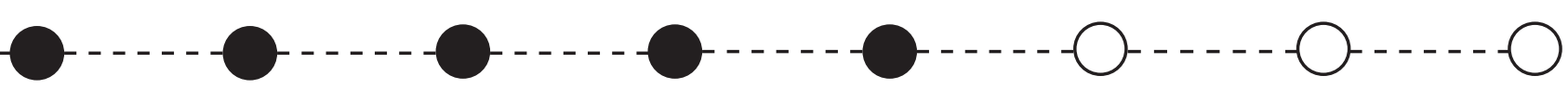

$$
\begin{aligned}
& \text { - - - - - - - - - - - - - - - - - - O- - - - }-\cdots-\cdots \\
& \text { NA- - - - - - - - NA - - - - } \\
& \text { - - - - - - - - - - - - - - - - - - - - - }-\cdots-\cdots \\
& \text { - - - - - NA- - - - - - - - -NA - - - - - - - - - - - - - - - }
\end{aligned}
$$

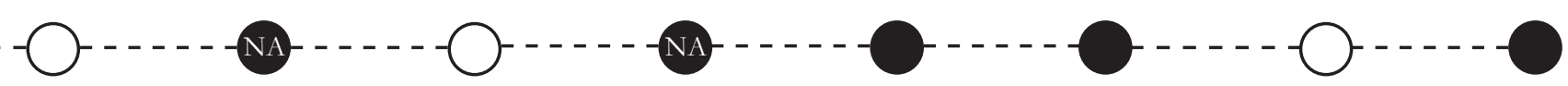

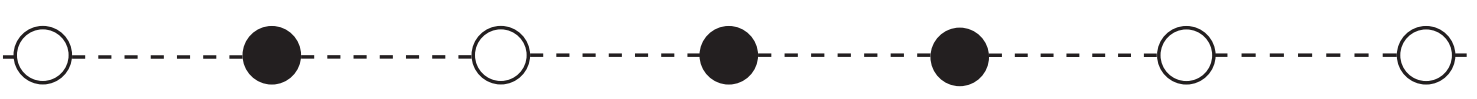

$$
\begin{aligned}
& \text { - - - - - - - - - - - } \\
& \text { - } \\
& -\bigcirc-\cdots-\cdots-\cdots-\cdots-\cdots-\cdots-\cdots-\cdots-\cdots-\cdots \\
& -\cdots-\cdots-\cdots-\cdots-\cdots-\cdots-\cdots-\cdots-\cdots
\end{aligned}
$$



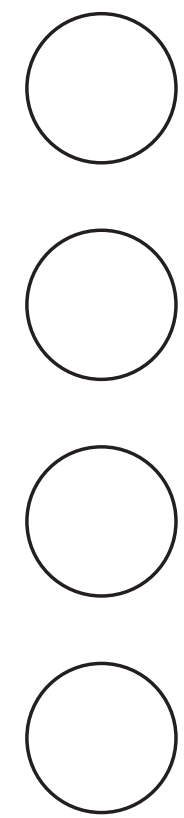

Introduction

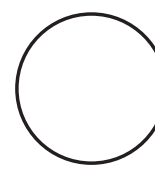

Physical Context ......」

Site Selection

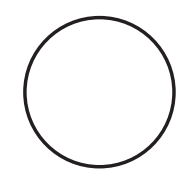

| Environmental Factors $\quad . . . .$.

Rainwater Through Site

Flooding of Wren Creek

View Points

Areas of Hot Water vs Cold Water Models of Site

\section{Conclusion}

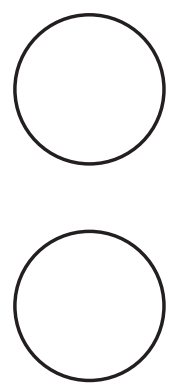




\section{PHYSICAL CONTEXT}

$$
/ / \quad 5 \quad / /
$$

The following chapter provides geographical and site information concerning the current site conditions. It identifies the site and site selection, flooding of Wren Creek, locations of hot water emergence and important view shafts. The findings from this chapter will provide information that will contribute to my architectural solution.
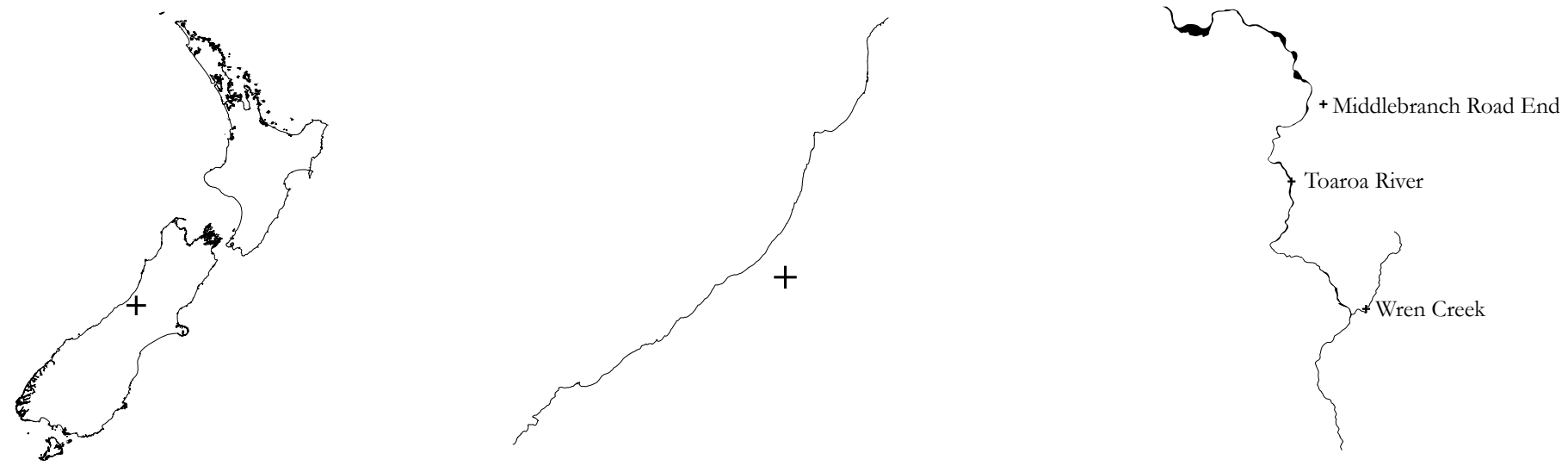

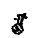

+Figure 5.01 Wren Creek. 


\section{SITE SELECTION}
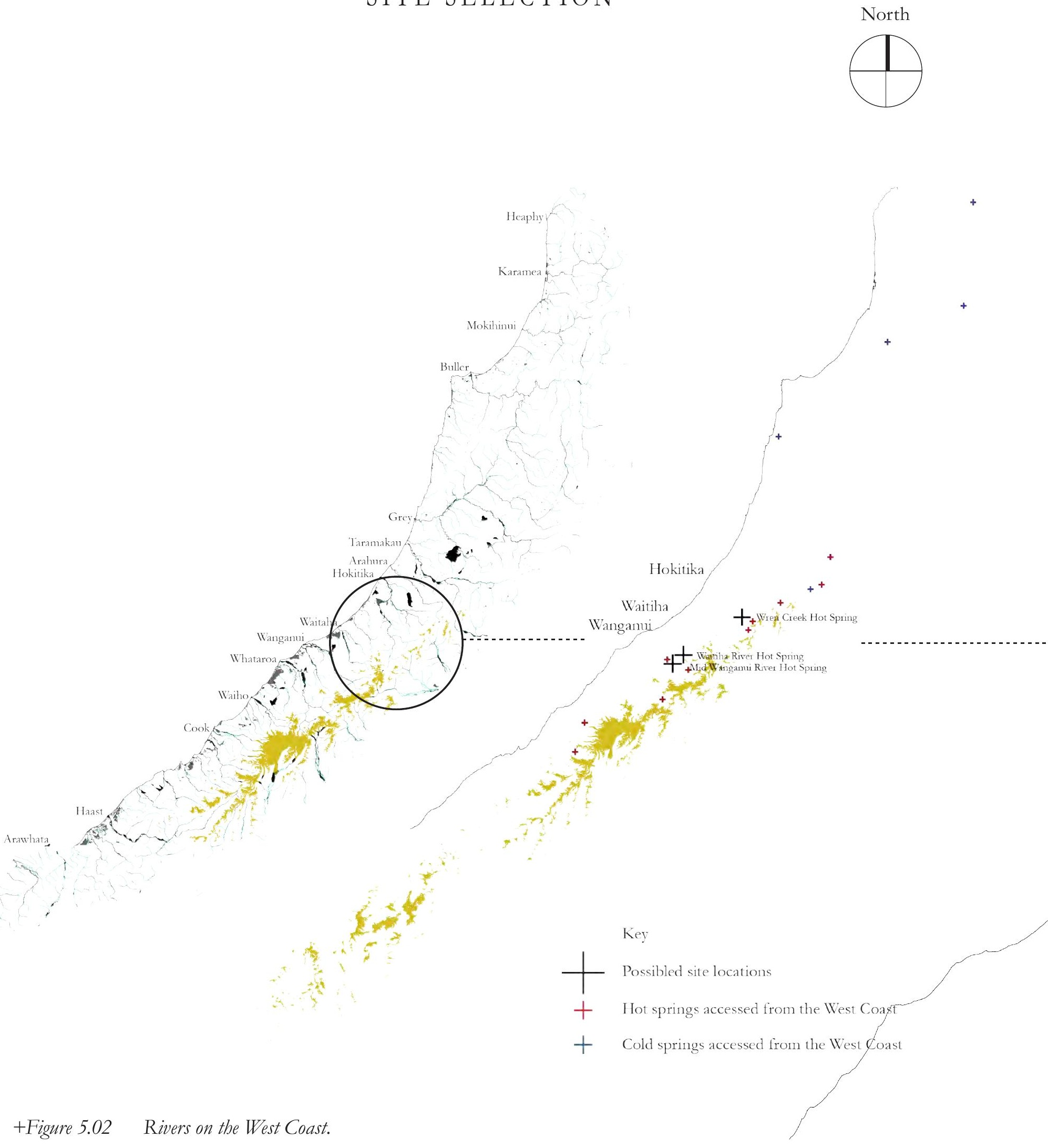

+Figure 5.03 Hot / Cold Springs in the Southern Alps, three possible sites. 



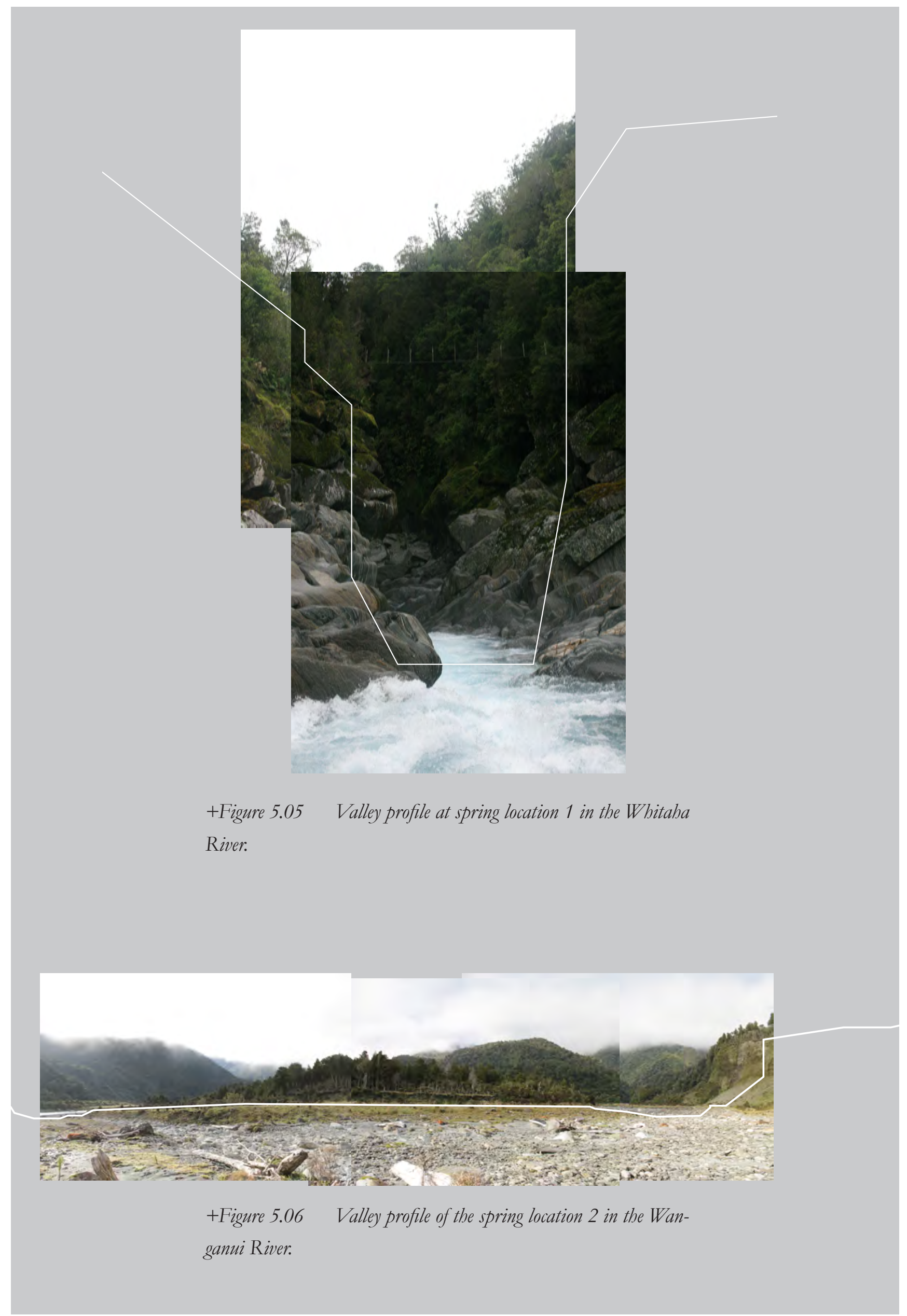




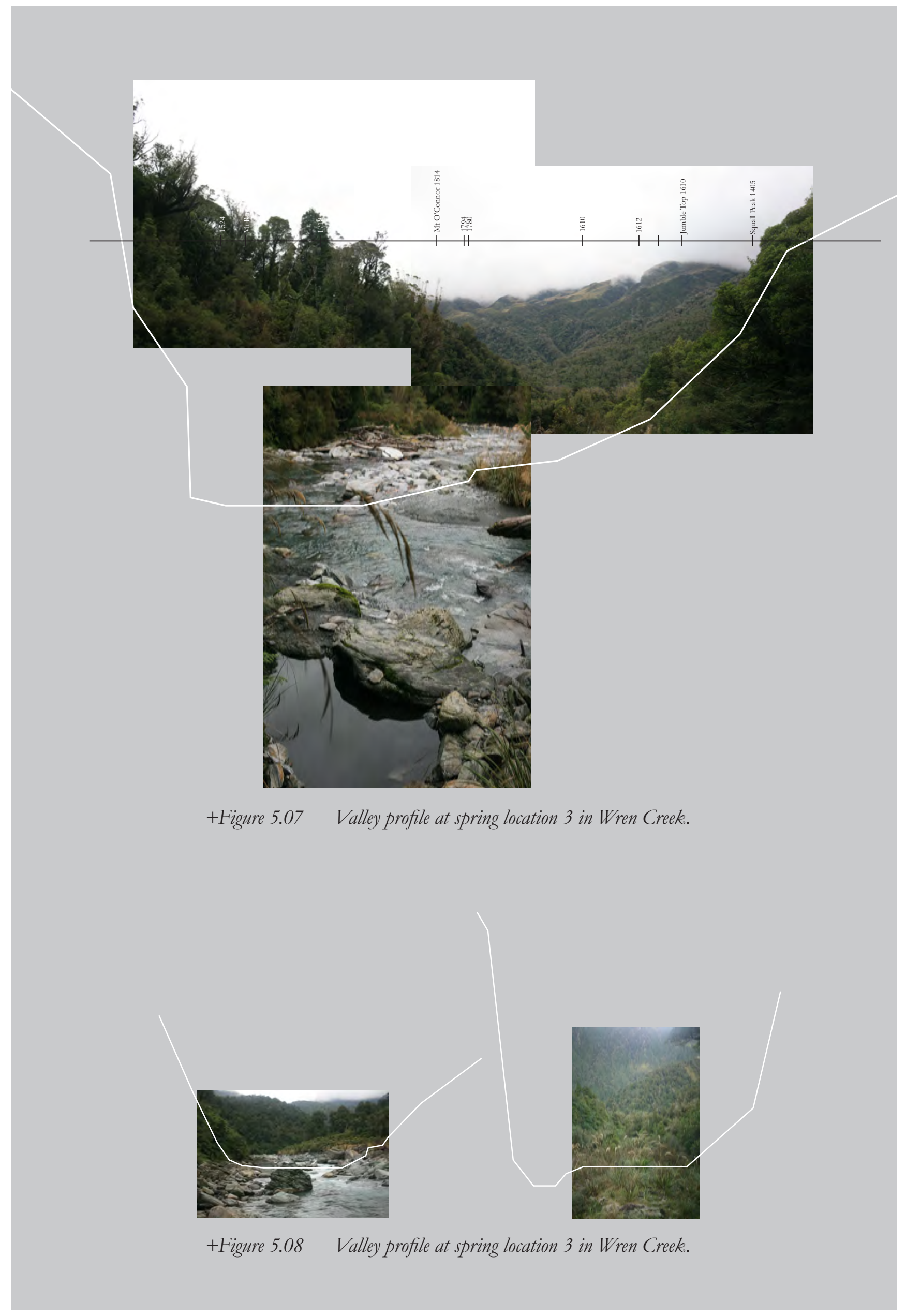




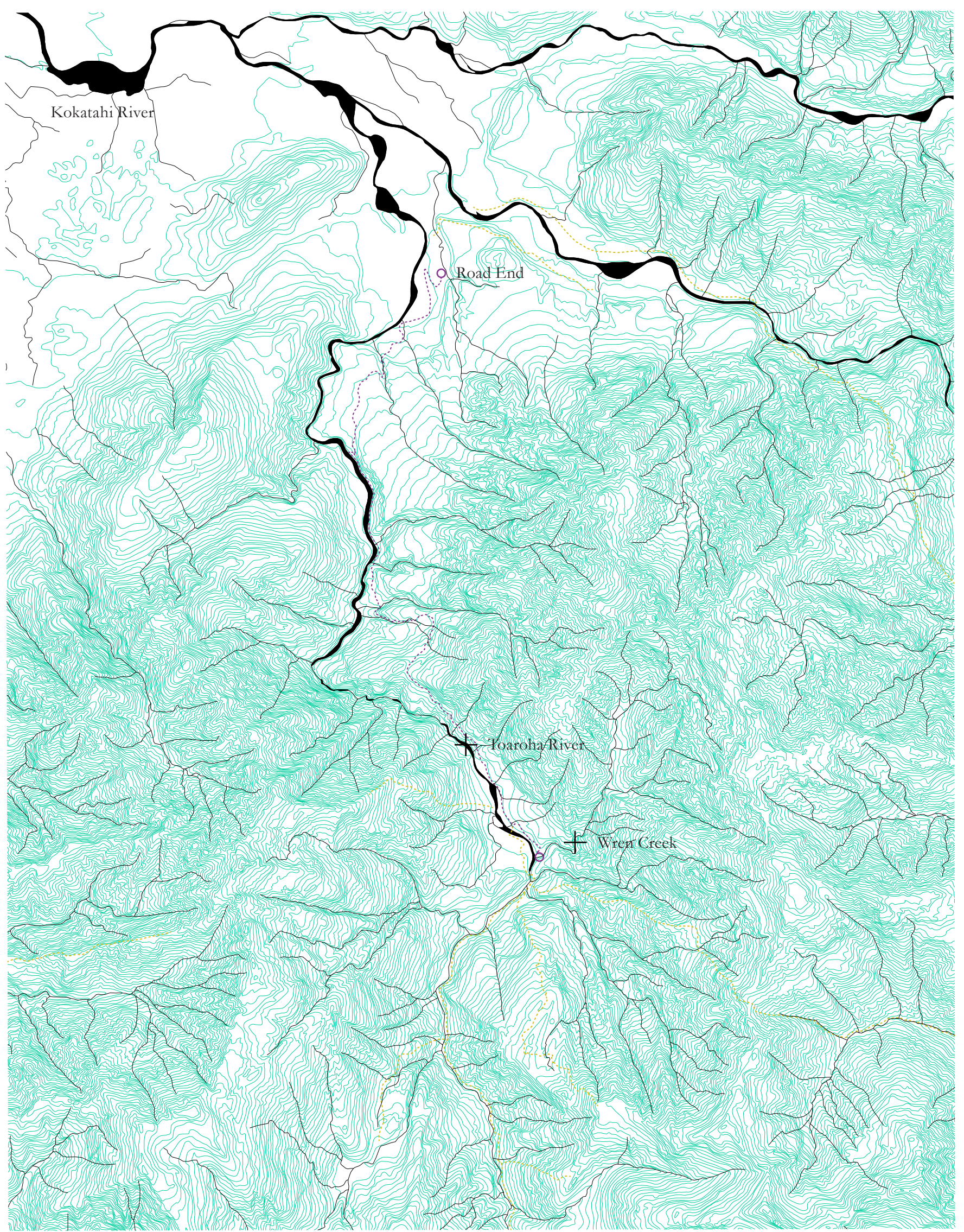

+Figure 5.09 Route into Choosen site 3, Wren Creek.

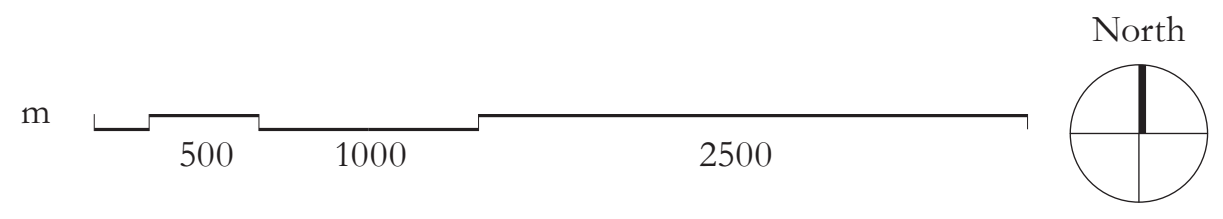


Wren Creek was chosen for the site. This was based on the disconnection from settlements, the distance from the road $(9 \mathrm{~km}$ - 4hrs walking) and to programme. A hill that separates the road from the memorial to provide more disconnection, topography of landscape, availability of thermal water, proximity to mining sites and pristine natural views.

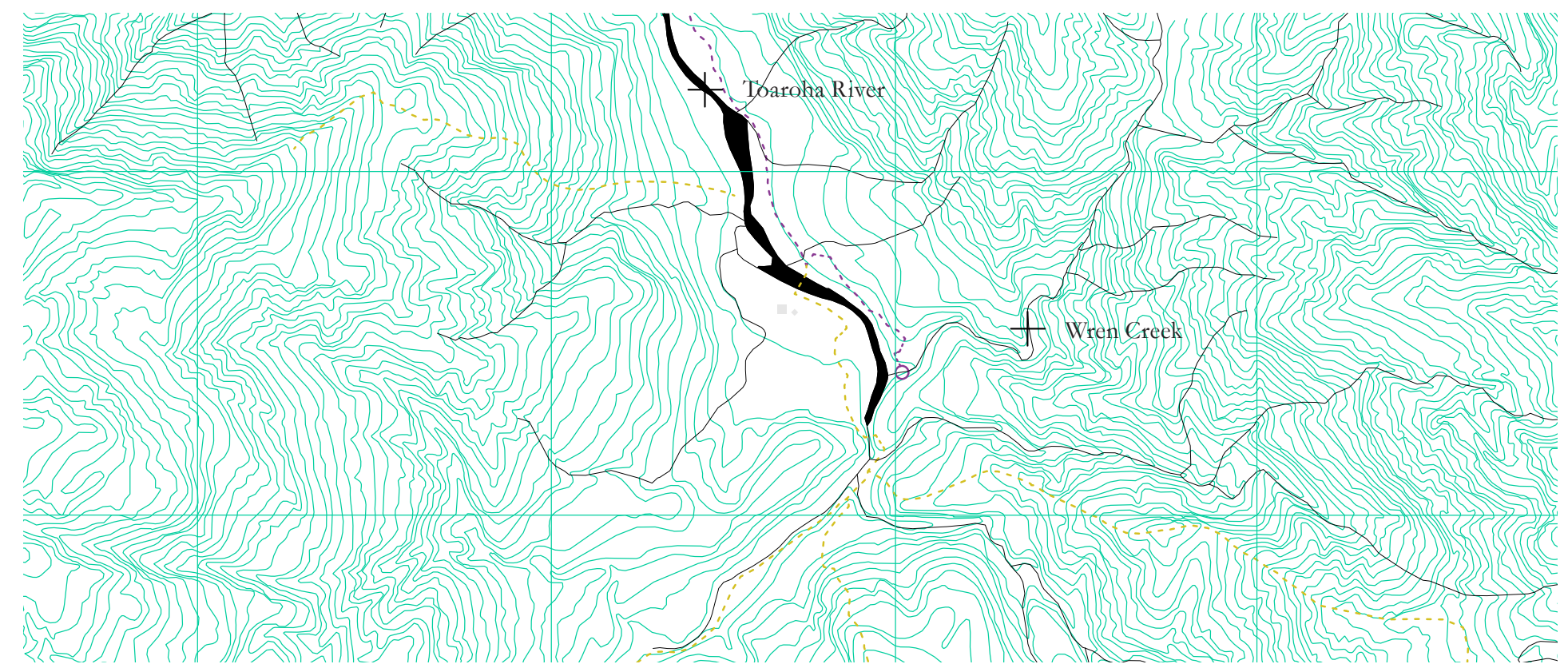

+Figure 5.10 Choosen Site, Wren Creek.

Key

$\begin{array}{lll}20 \mathrm{~m} \text { Contour lines } & \ldots \ldots . . . . & \text { Access Track } \\ \text { Rivers } & \text { Other Tracks }\end{array}$

$\mathrm{m}$

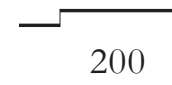

400

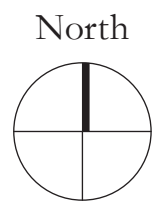




\section{ENVIRONMENTAL FACTORS}

\section{RAIN WATER THROUGH SITE}

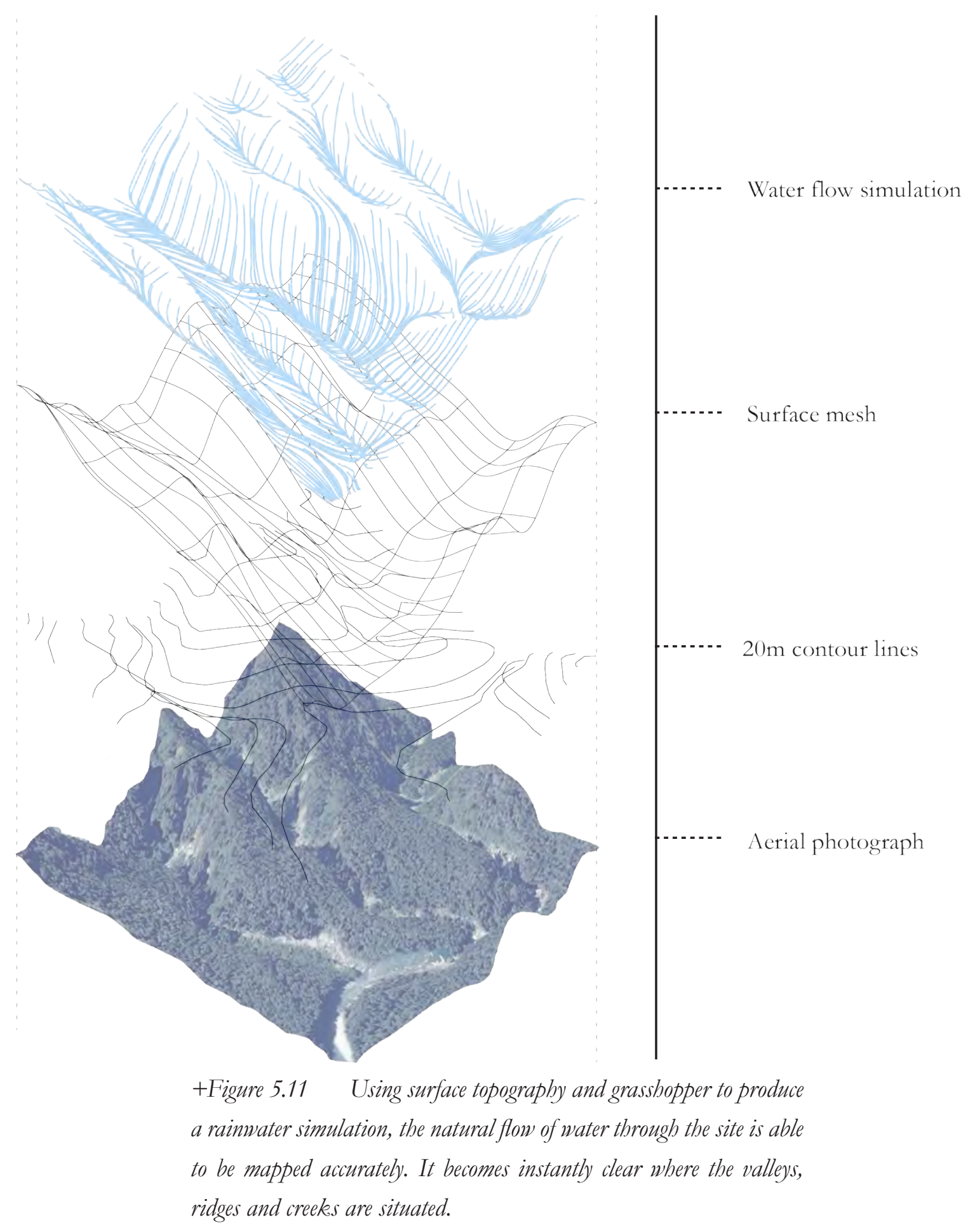




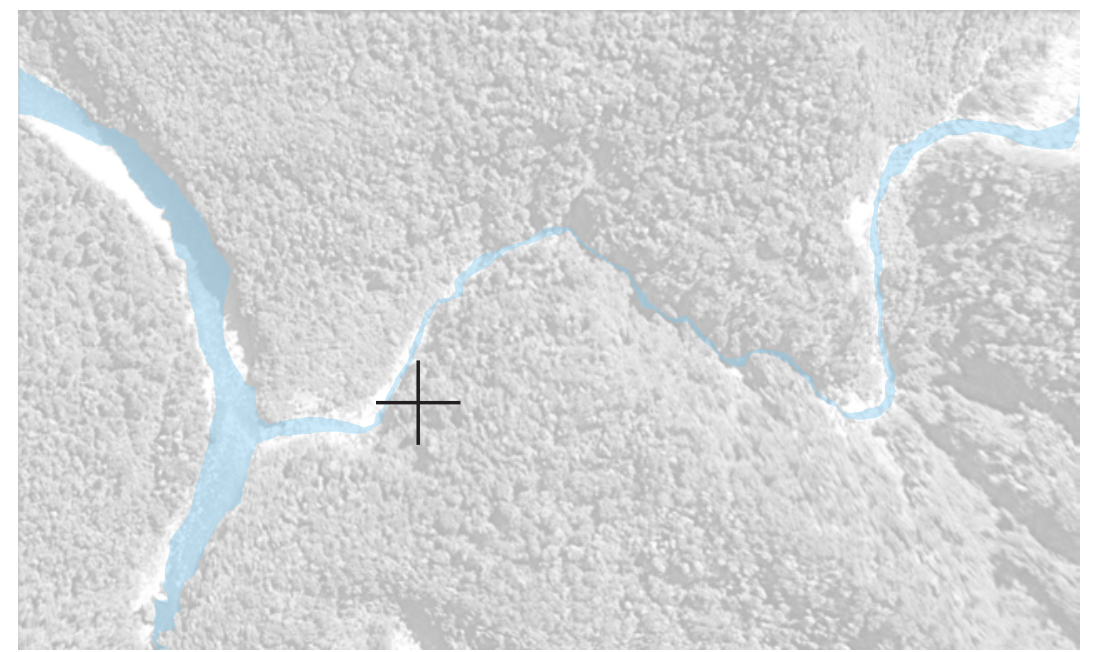

+Figure 5.12 Plan of site, no rain.

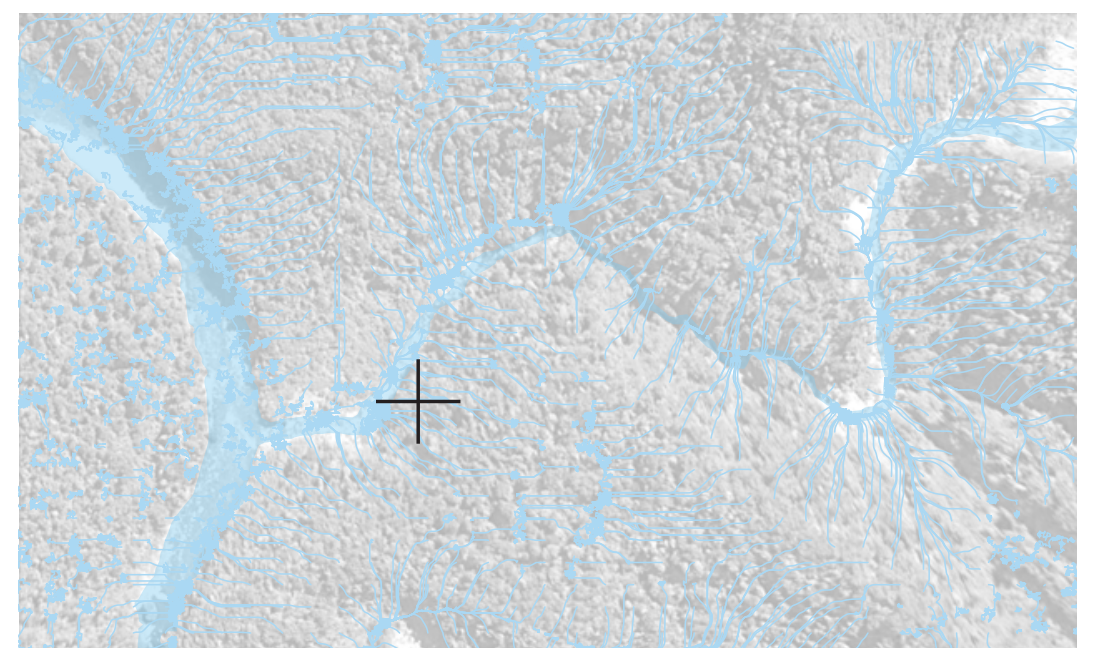

+Figure 5.13 Plan of site, medium level of rain.

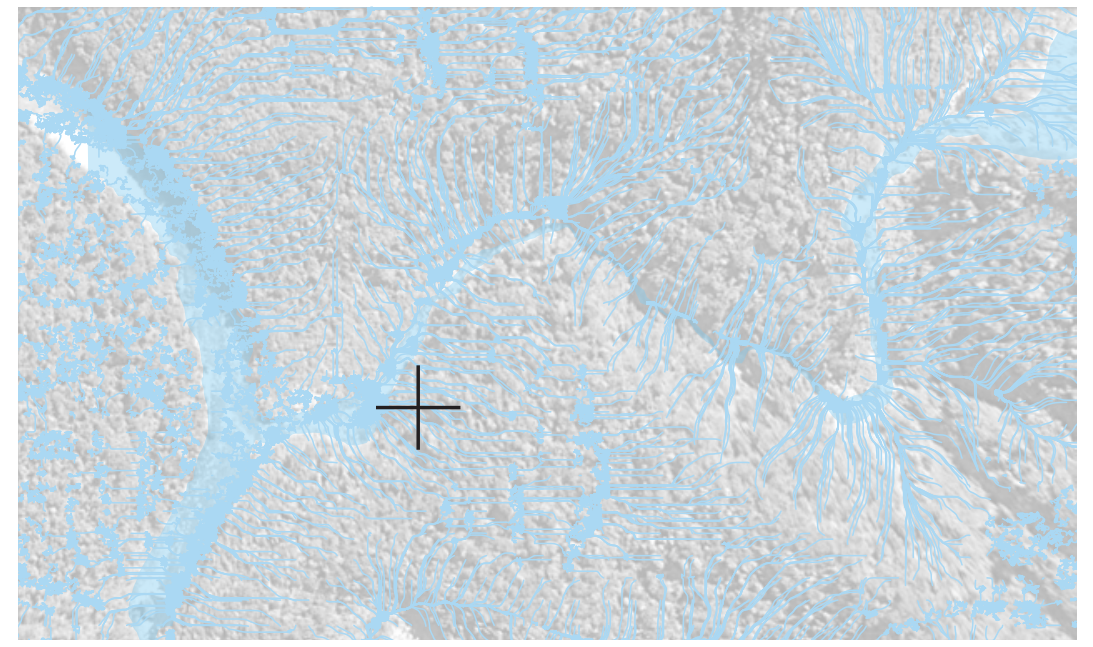

+Figure 5.14 Plan of site, high level of rain.

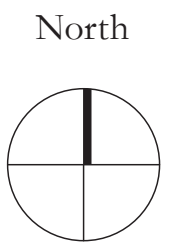




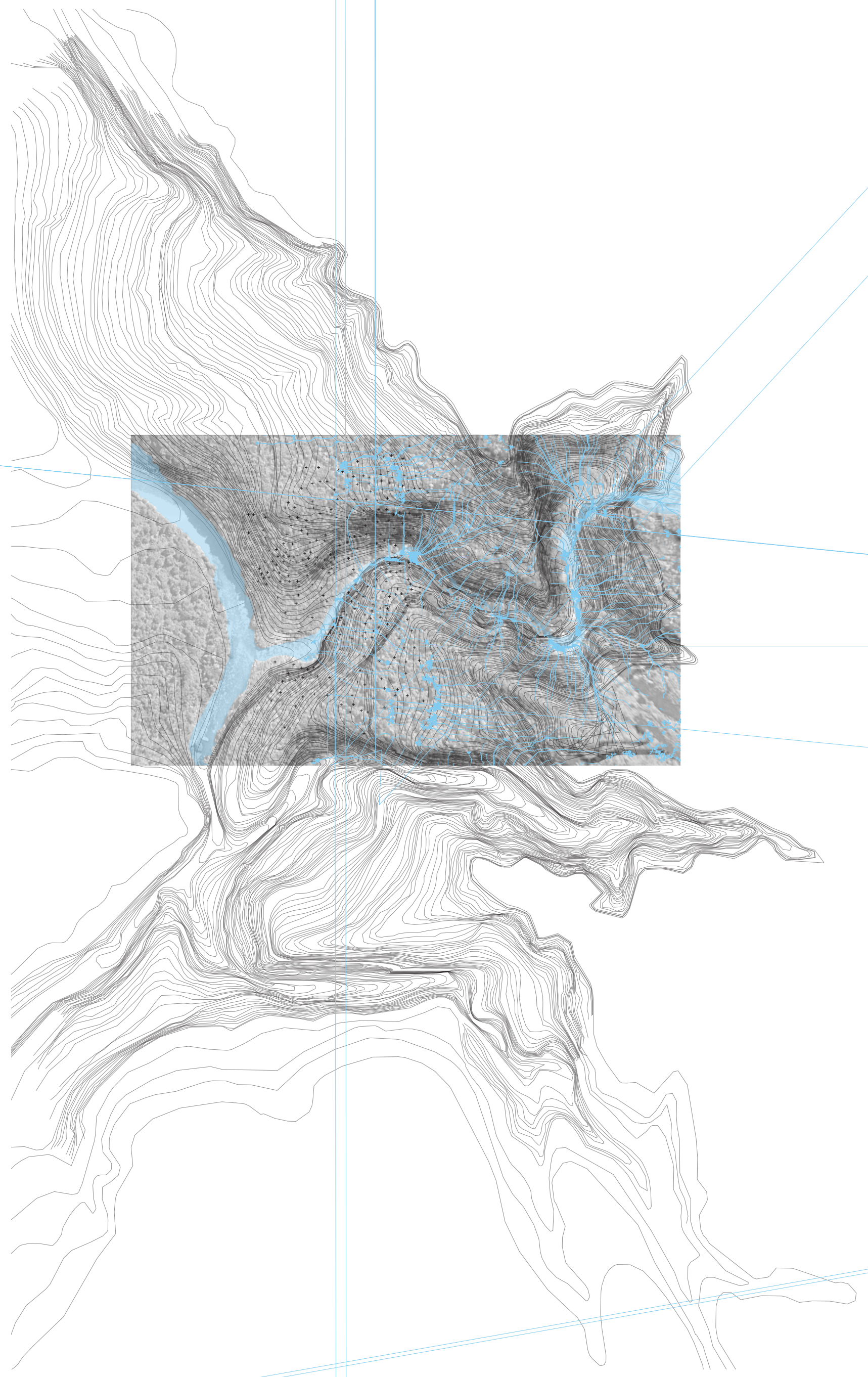




\section{FLOODING OF WREN CREEK}

The site is highly susceptible to and changeable when in flood. Wren Creek is often swollen with large trees and boulders being washed down regularly.
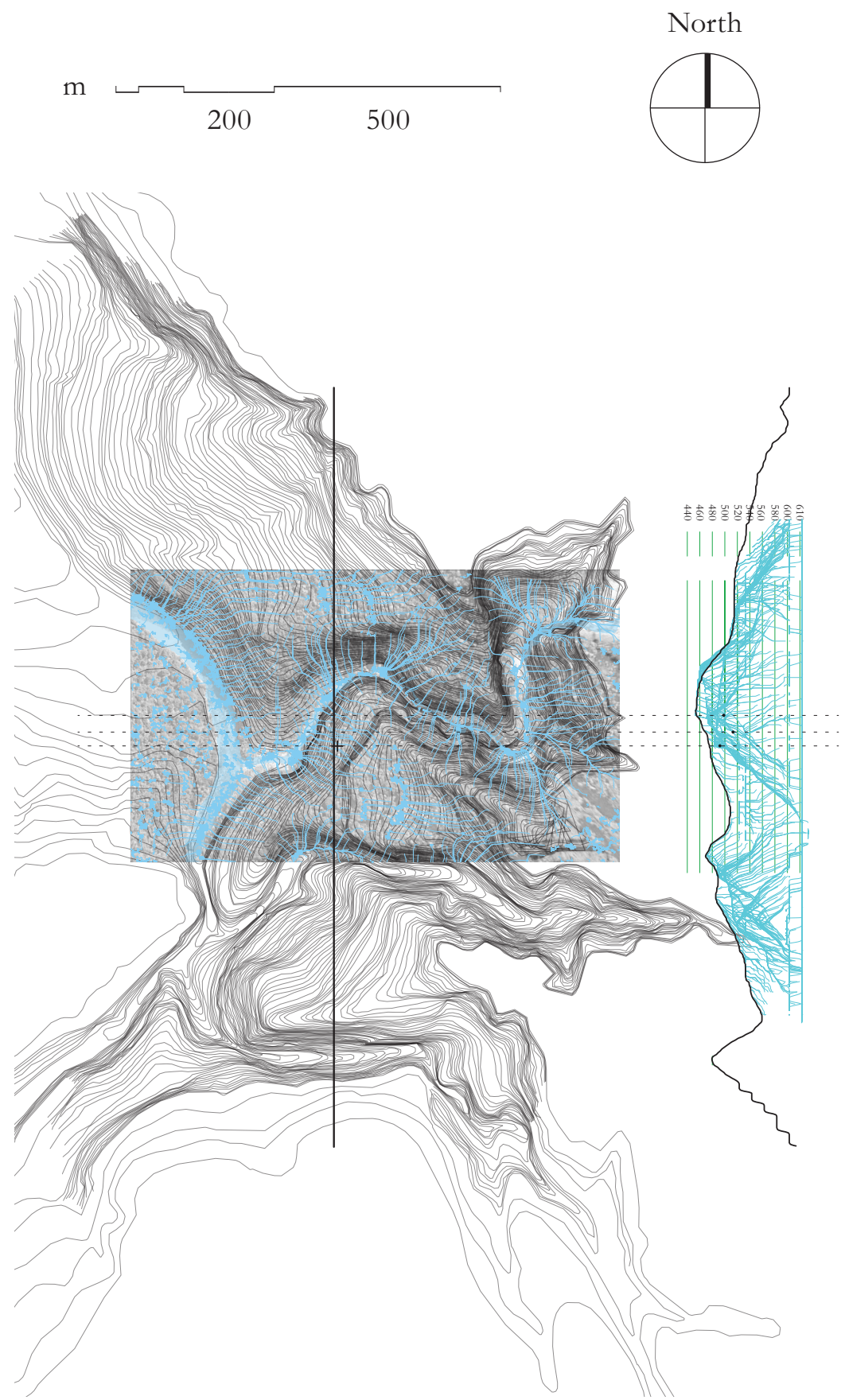

+Figure 5.16 Medium rain and river level. 


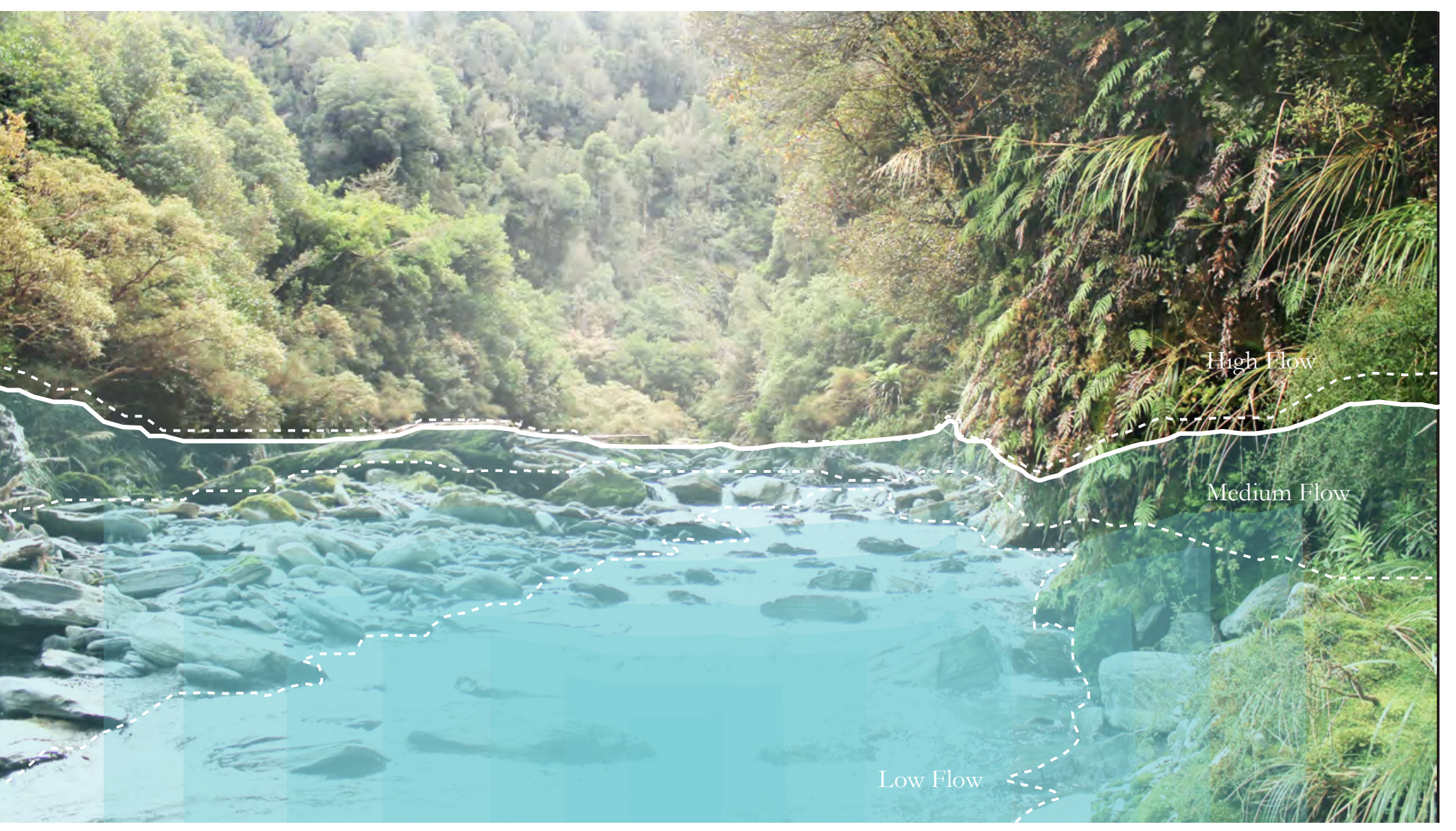

+Figure 5.17 Flood levels in Wren Creek. 


\section{AREAS OF HOT WATER VS COLD WATER}

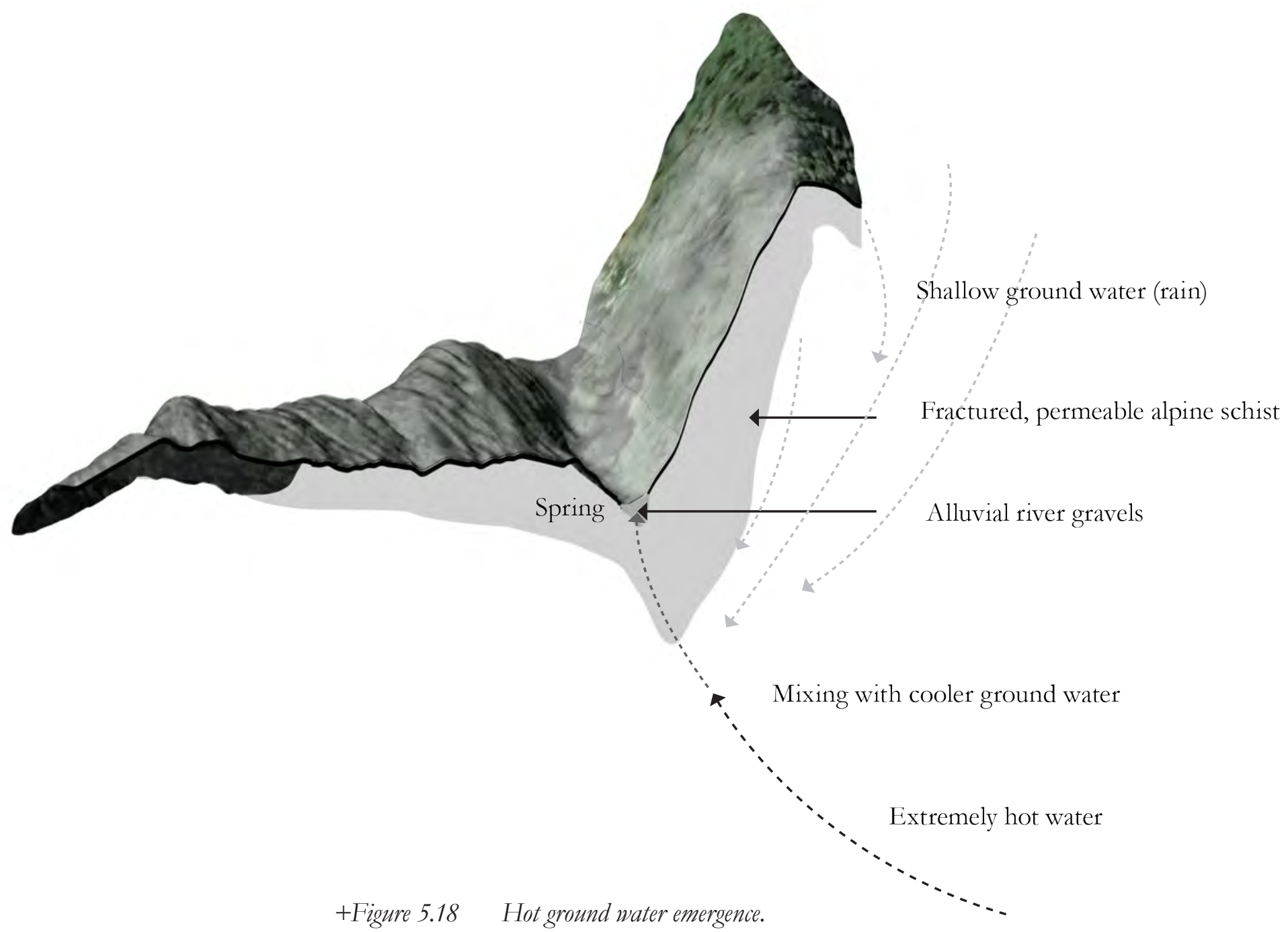



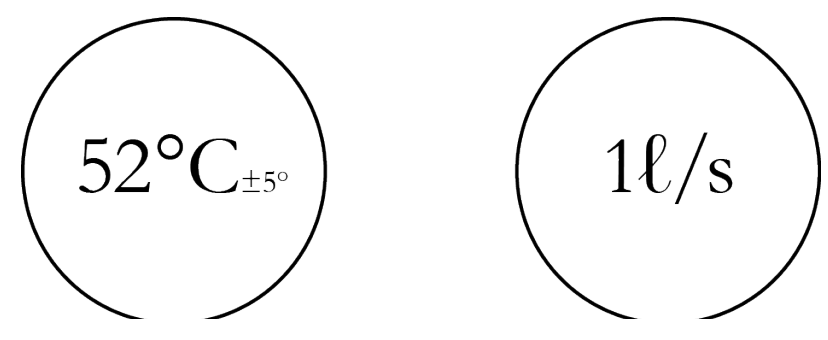

+Figure 5.20 Average flow rate and temperature output of spring. However when flow in Wren Creek is high the usual natural thermal outlets are underwater and the existing natural pools are flooded.

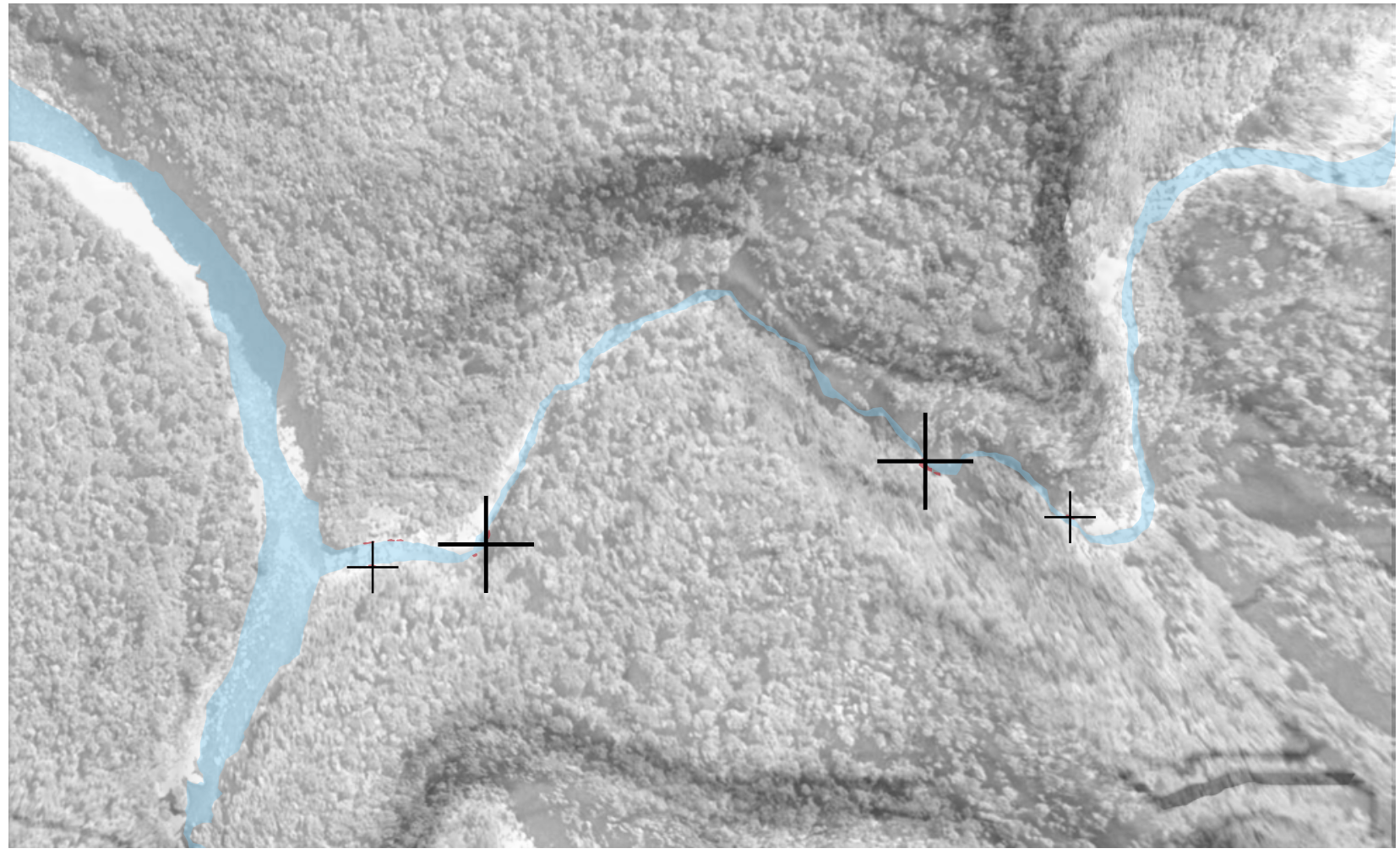

+Figure 5.19 Main locations of hot thermal water sources in Wren Creek. 

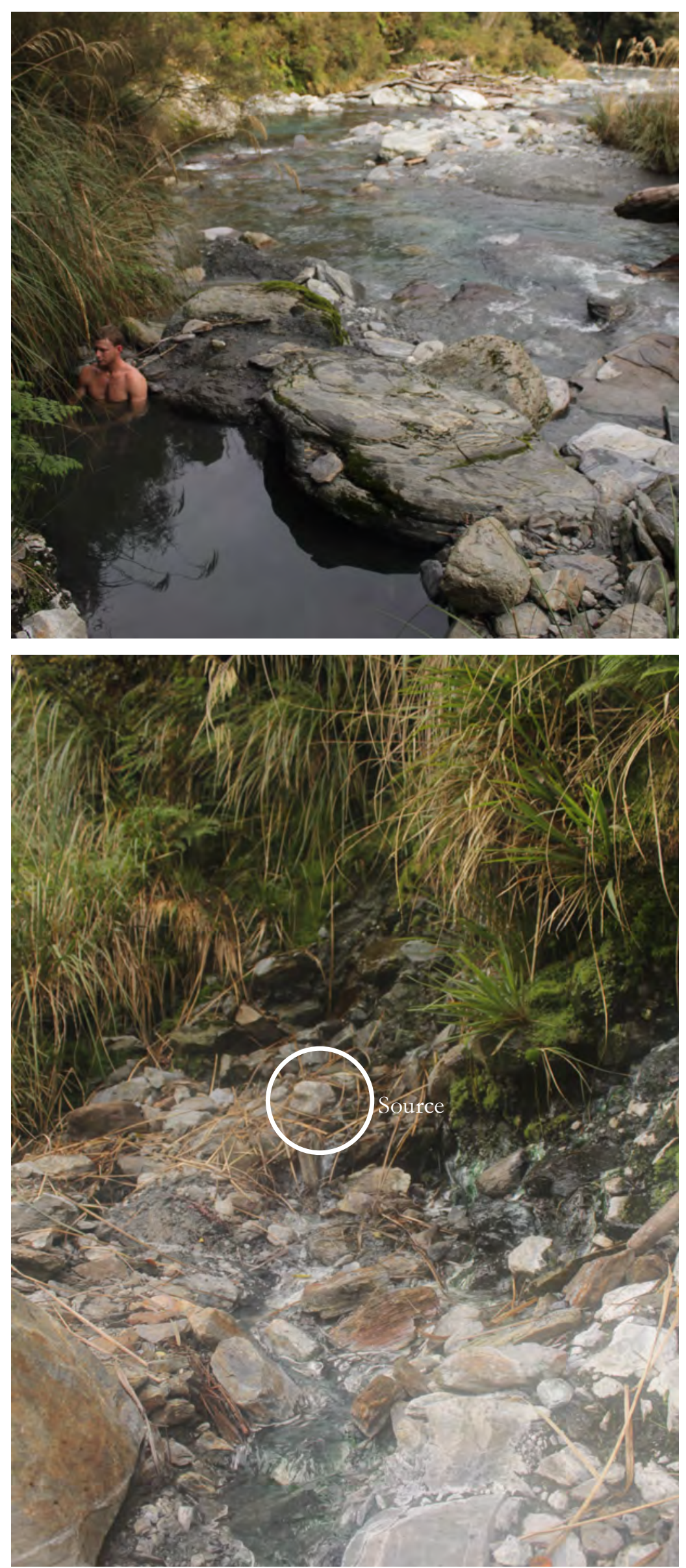

+Figure 5.21 Current natural pool and source of thermal water. 


\section{VIEW POINTS}

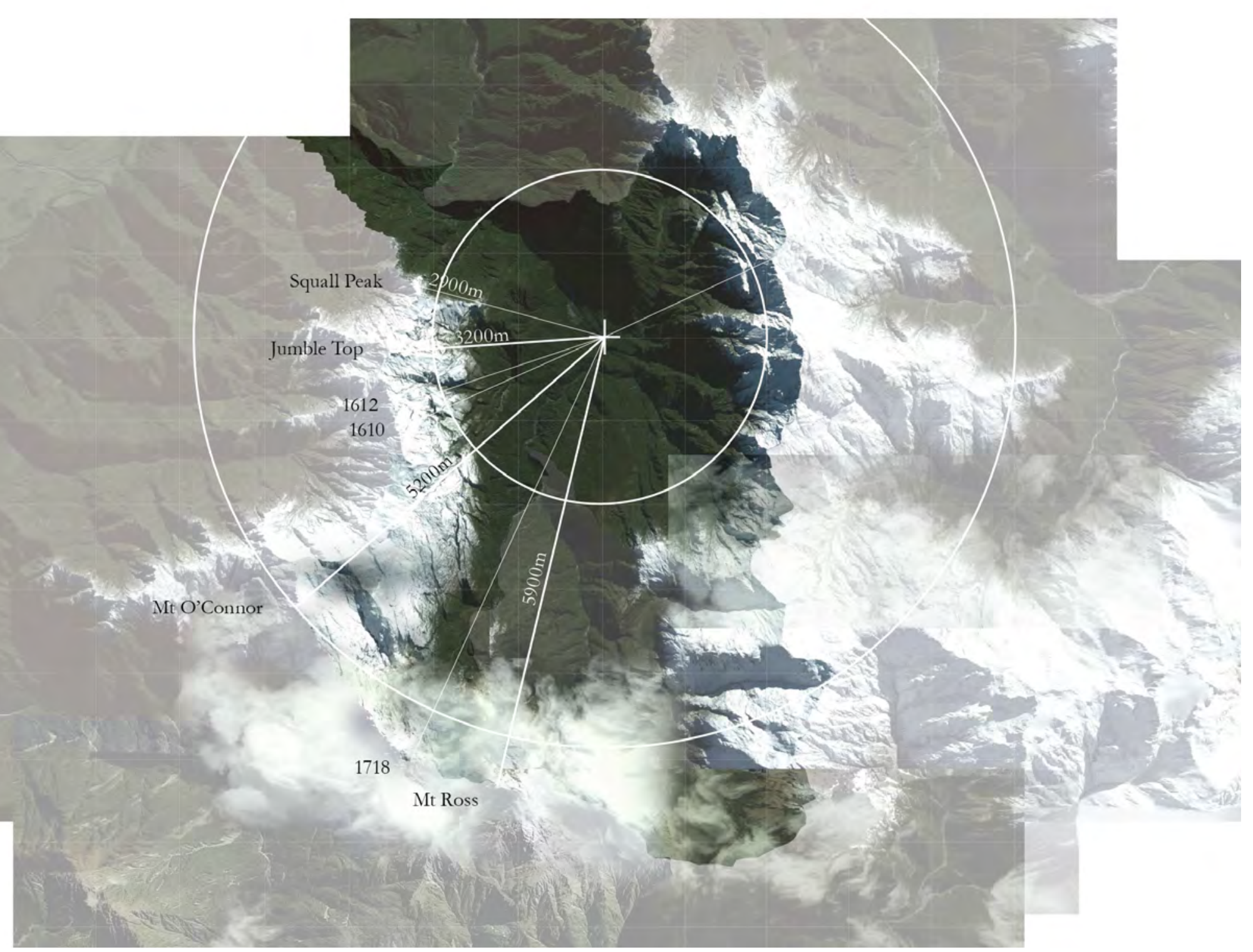

+Figure 5.22 Peaks and points around the Toaroha valley centred upon selected bath site.

North

$\mathrm{km}$

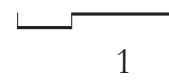

1

2

5

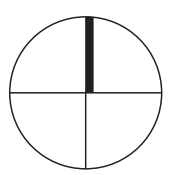




\section{MODELS OF SITE}
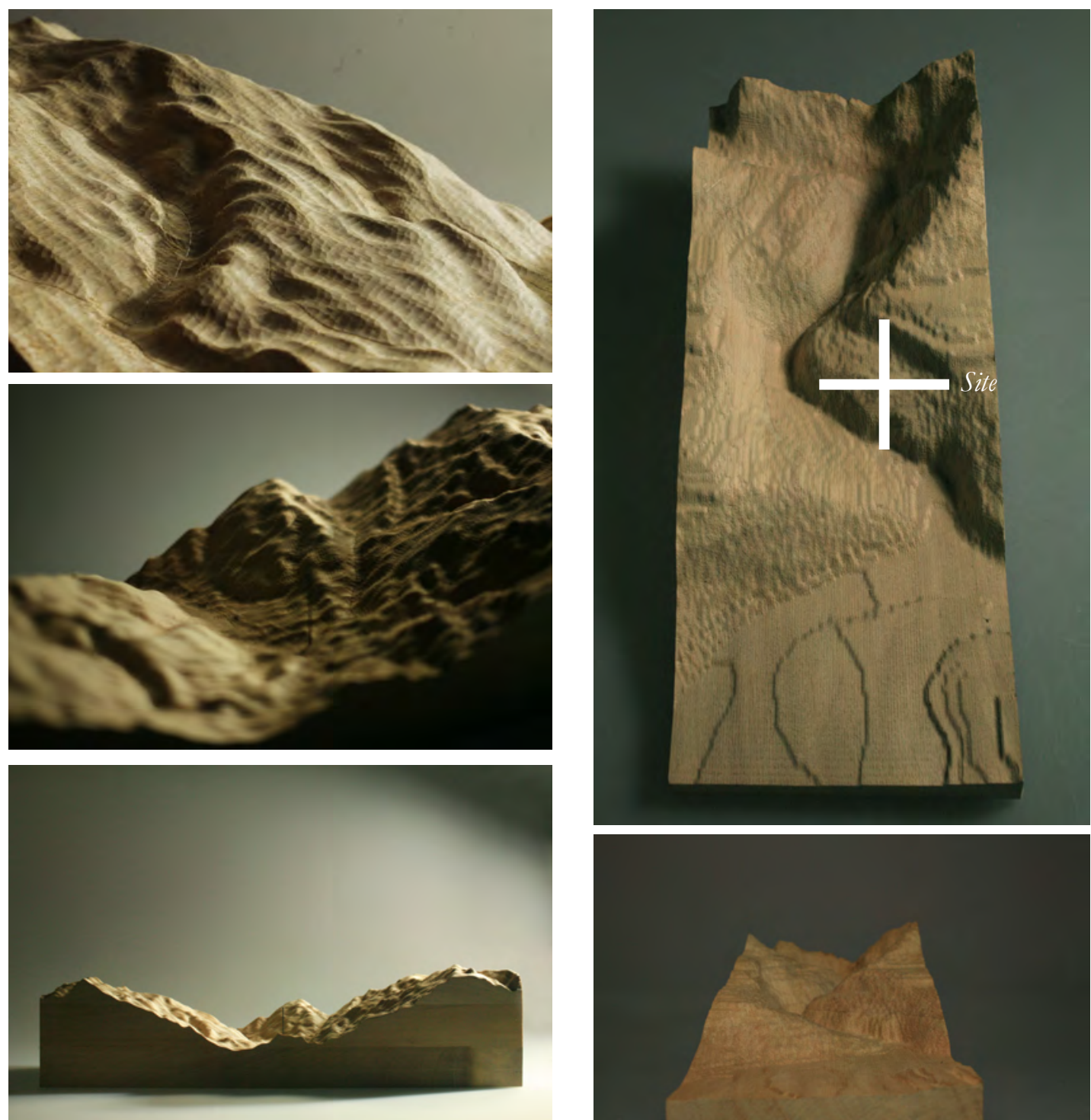

+Figure 5.24 Toaroha Valley.
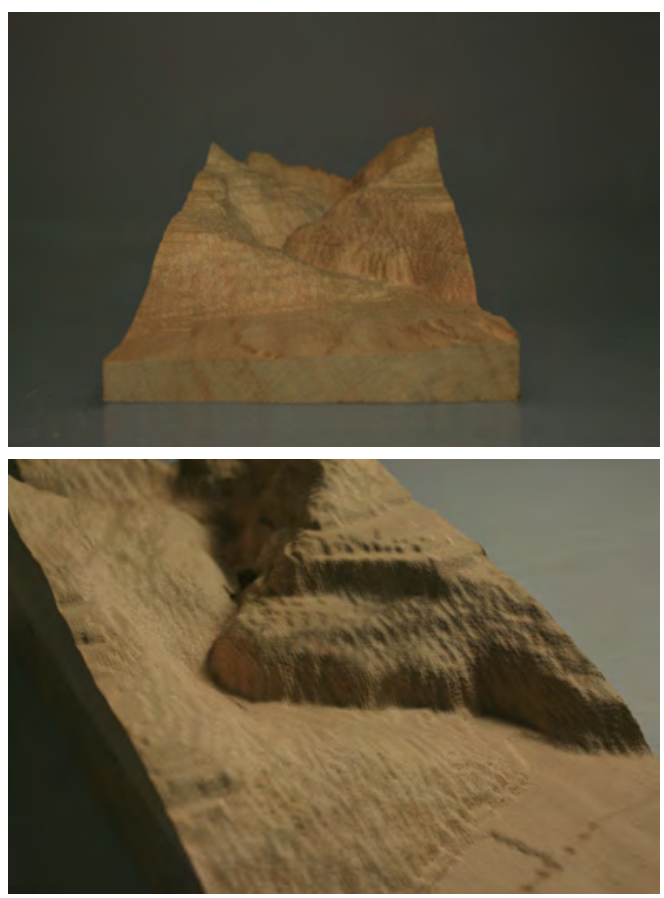

+Figure 5.23 Wren Creek. 

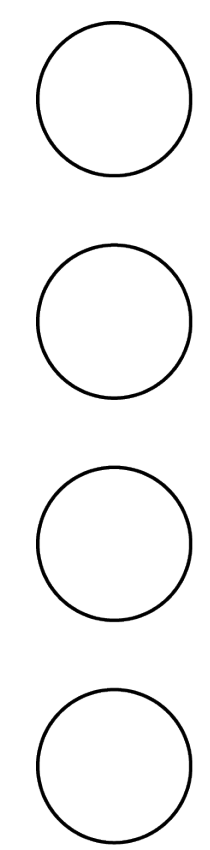

Introduction

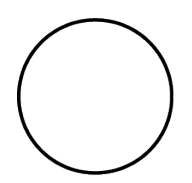

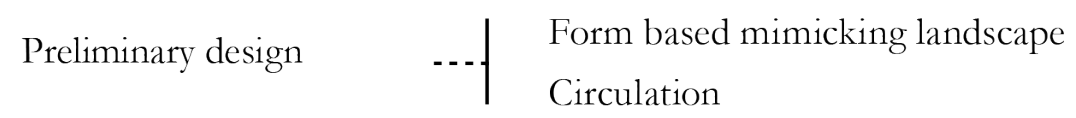
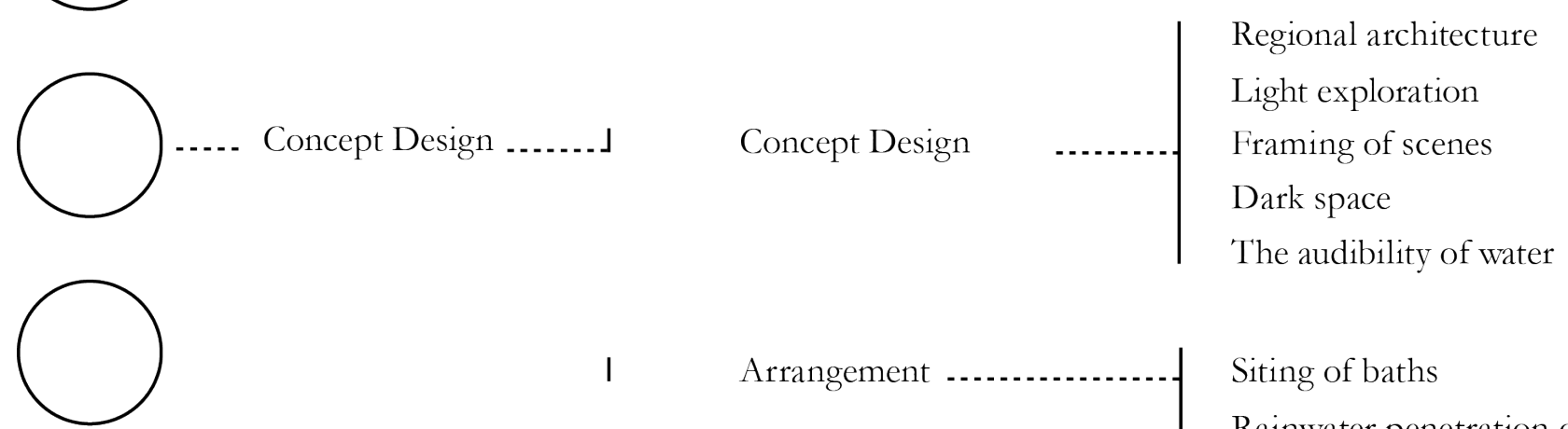

Arrangement

Siting of baths

Rainwater penetration of building Arrangement of programme

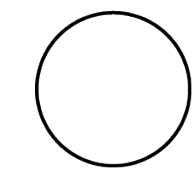

Making it Work

Bringing water around hill Electricity generation exploration Track quality

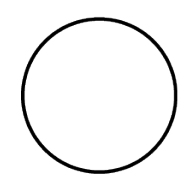

Conclusion 


\title{
CONCEPT DESIGN
}

\author{
// 6 //
}

This chapter outlines the processes and decisions that led to the developed design. It highlights: the successful and unsuccessful paths, how to design with the landscape rather than opposing it, the use of different light qualities, framing and the audibility of water. It investigates arrangement of spaces and the processional experience through space. It tests form and how to move people and water through the spaces with different circulation patterns relating to the Kessler - Kübler-Ross model. It outlines a method of retriving the hot water from upstream and finally, different methods of powering the site are explored. 


\section{PRELIMINARY DESIGN}

\section{FORM BASED MIMICKING LANDSCAPE}

Site responsive modelling responding to the underlying topography. The roof line mimics the undulating land that it sits above. Water hitting these roofs would run off in a similar way to that if it were to hit the ground.
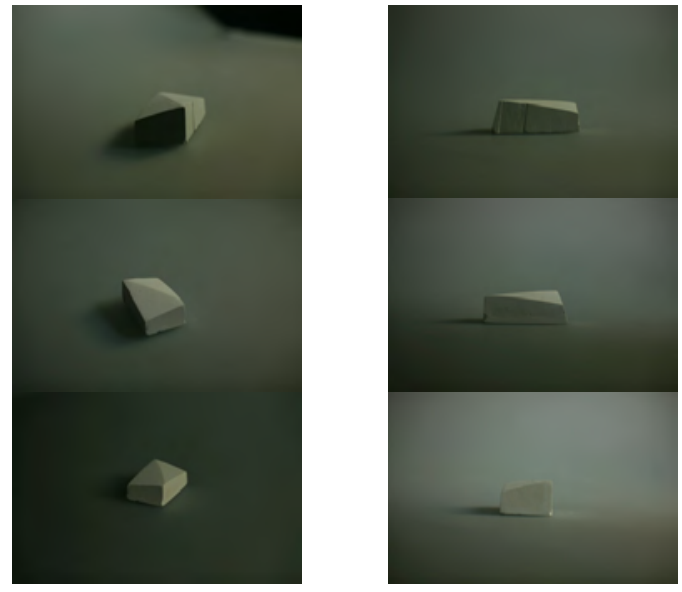

+Figure 6.01 Iterative plaster mass-model testing of roof mimicking underlying ridge.
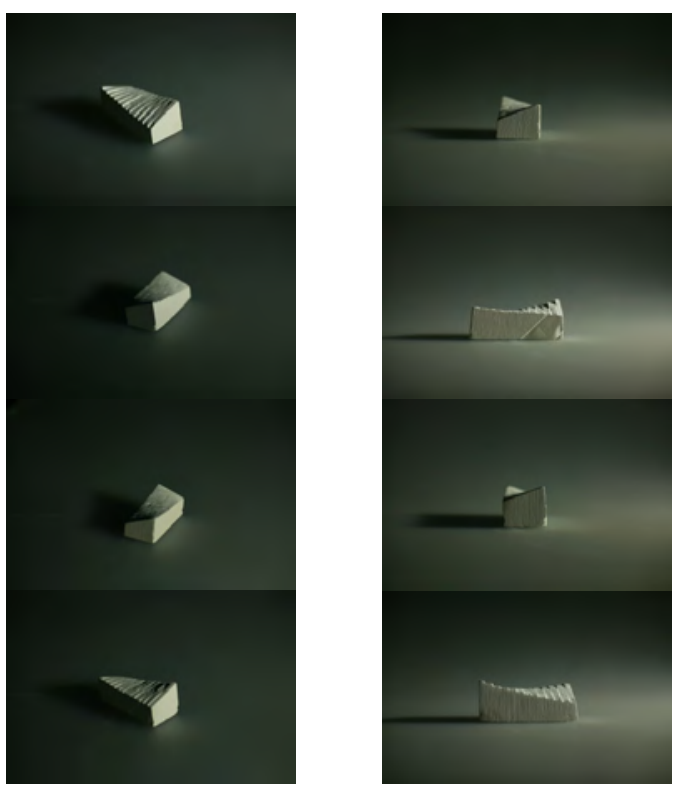

+Figure 6.02 Iterative plaster mass-model testing of roof mimicking underlying valley. 

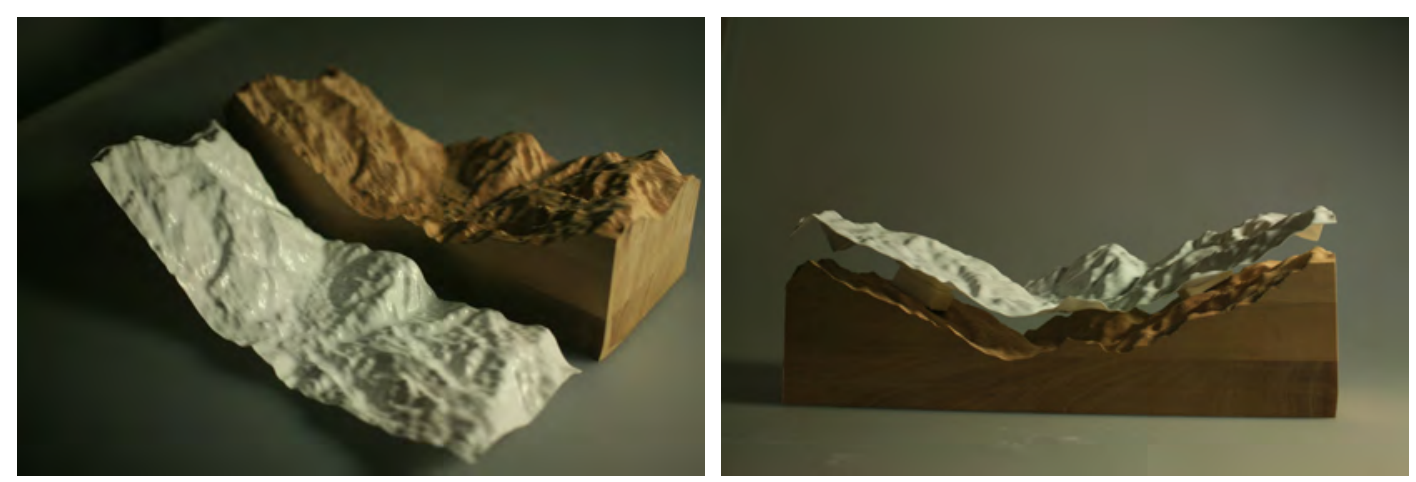

+Figure 6.03 Modelling of mimicking landscapes.

+Figure 6.04 Modelling of mimicking landscapes.

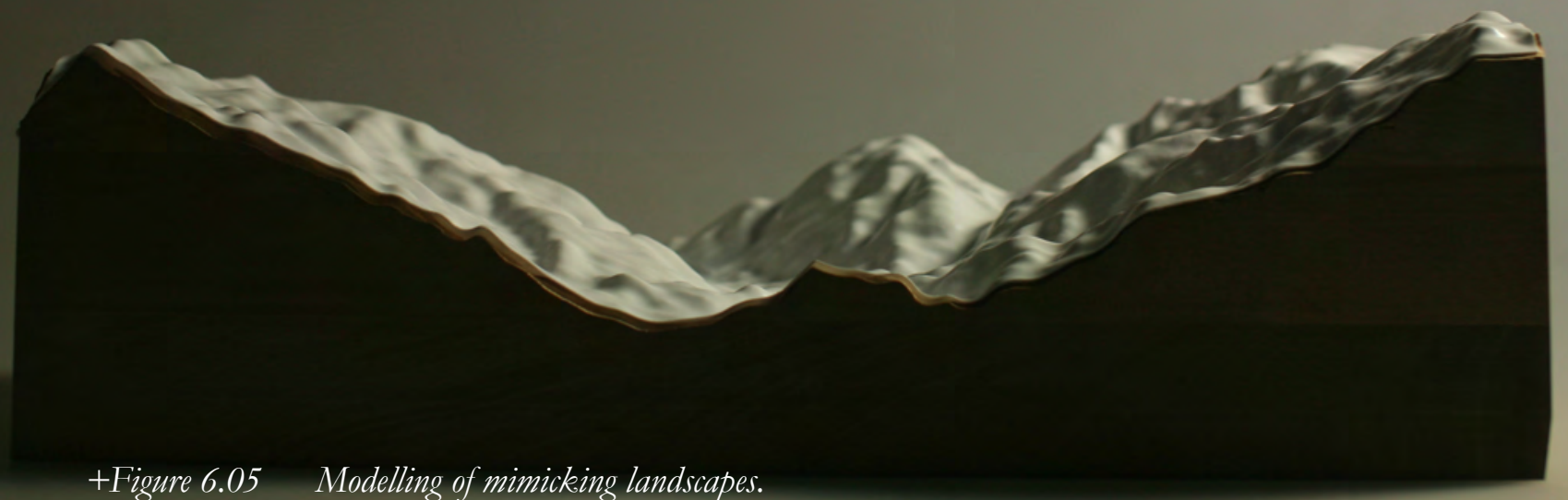

+Figure 6.05 Modelling of mimicking landscapes. 


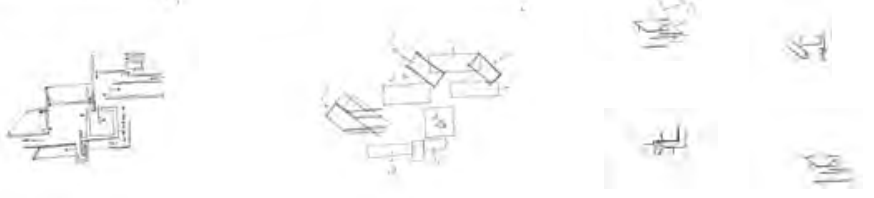

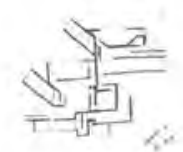

$N-15$
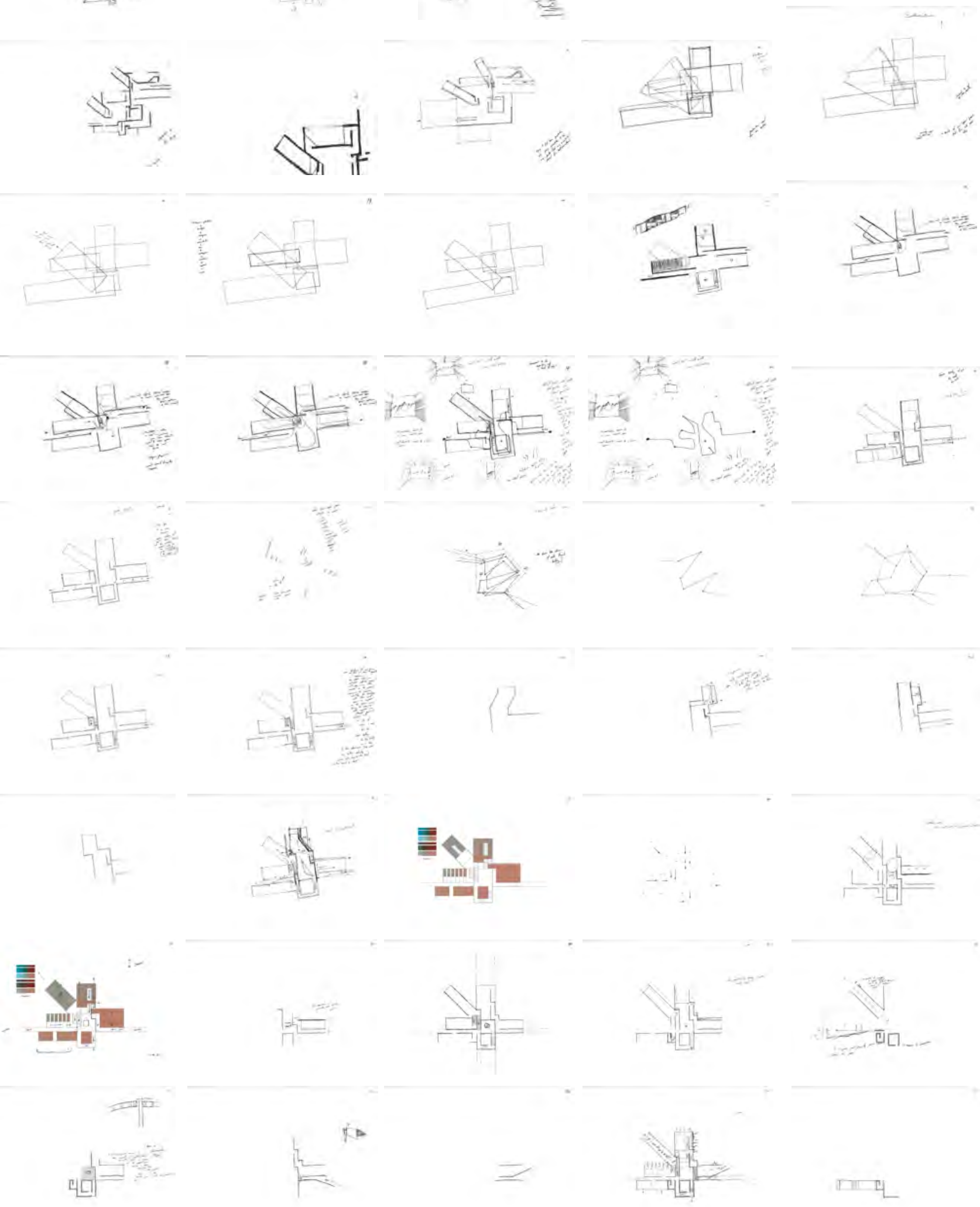

ए
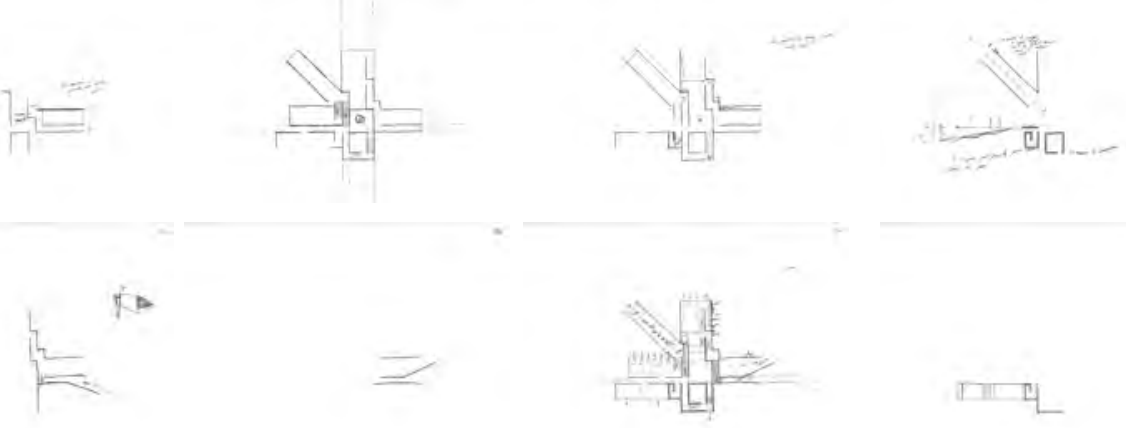

IIII 4
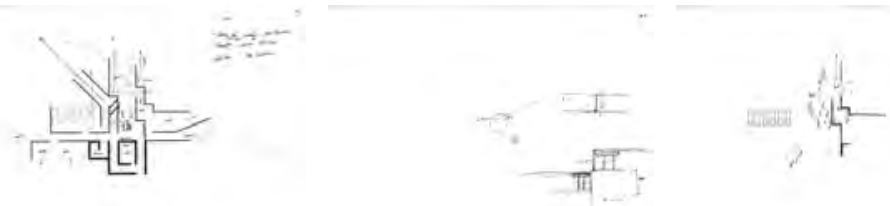

+Figure 6.06 Rapid iterative testing of circulation and 


\section{CIRCULATION}

Circulation studies helped determine an initial plan of the baths, however, these were not further developed as the scale and expansive form were not responsive to landscape or context. Nevertheless, circulation studies provided valuable knowledge regarding connections between: spaces, programmes, people, and landscape. The plan was loosely developed from this preliminary design with form and scale developed further.
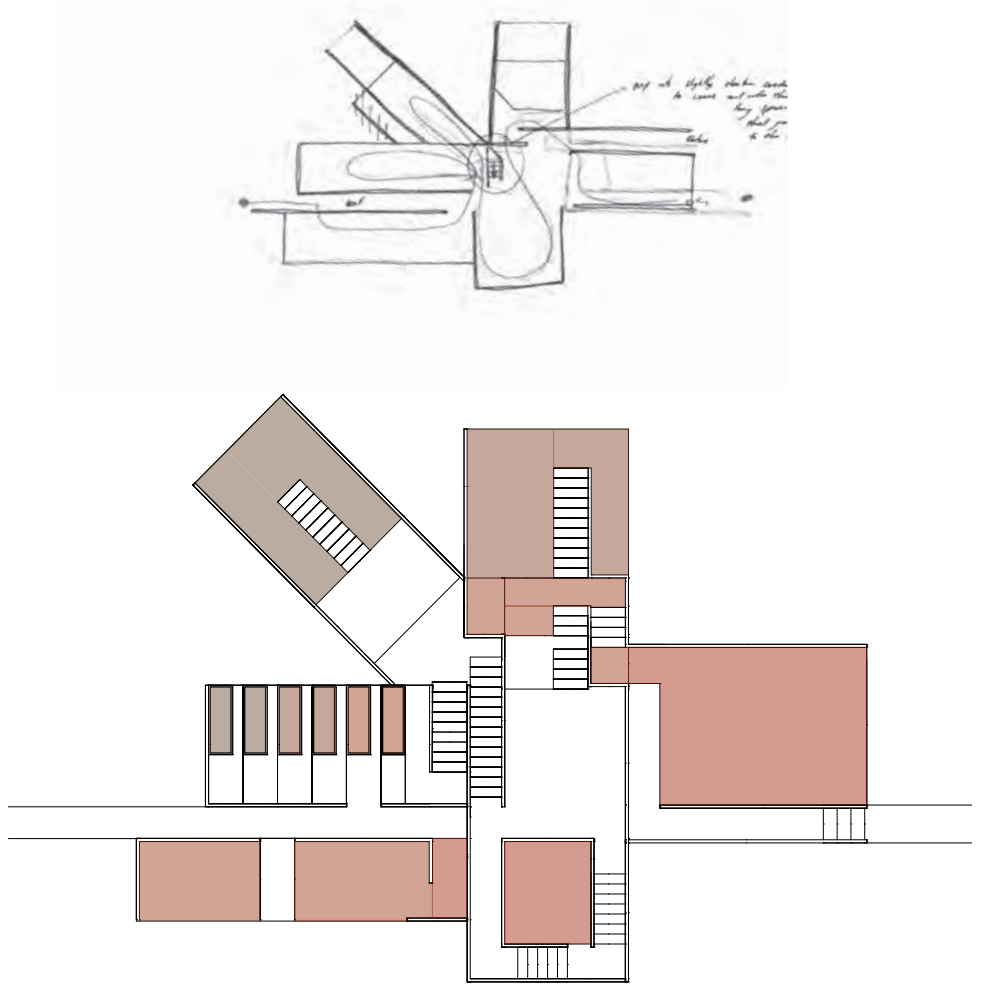

+Figure 6.07 Preliminary plan of baths based on iterative circulation studies. 


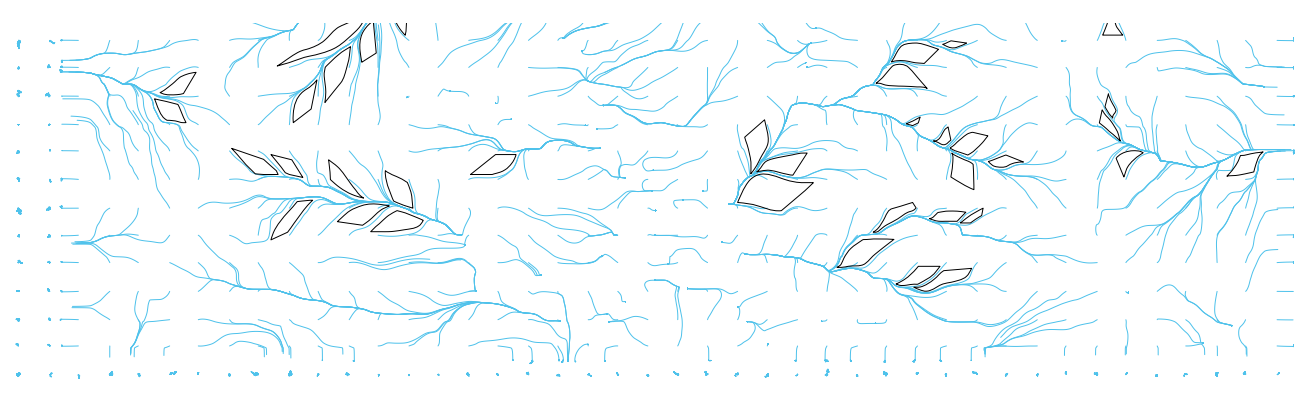

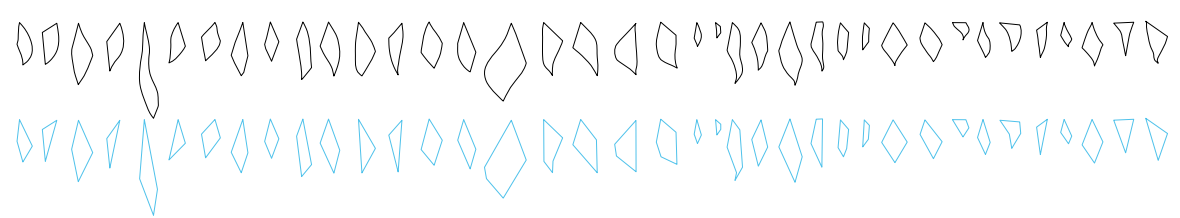

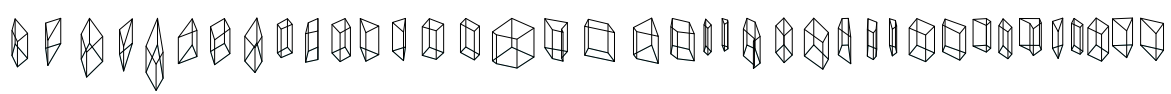

+Figure 6.08 Iterative exploration of plan driven by simulated water flow across landscape.

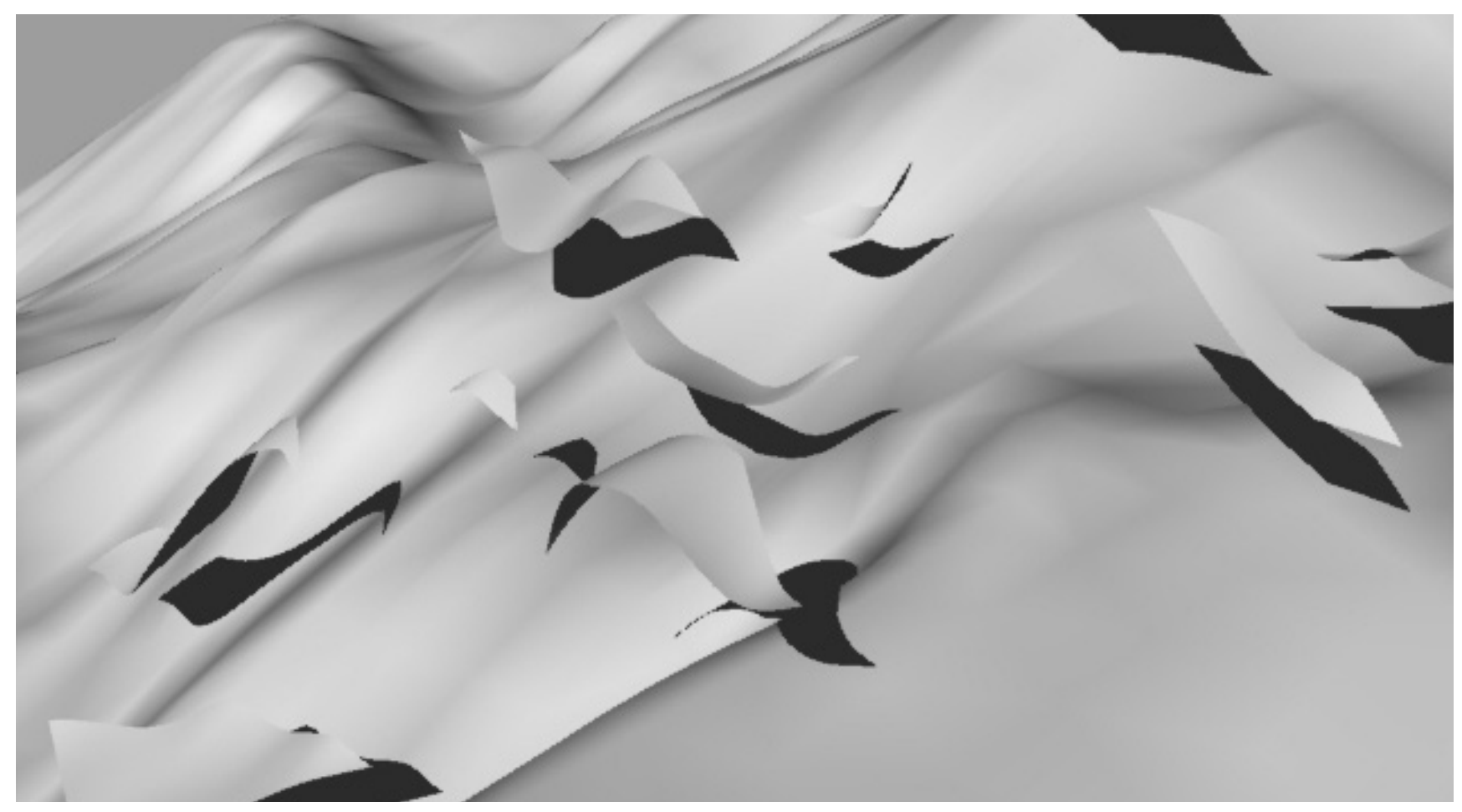

+Figure 6.09 Exploration of roof surface driven by simulated water flow. 

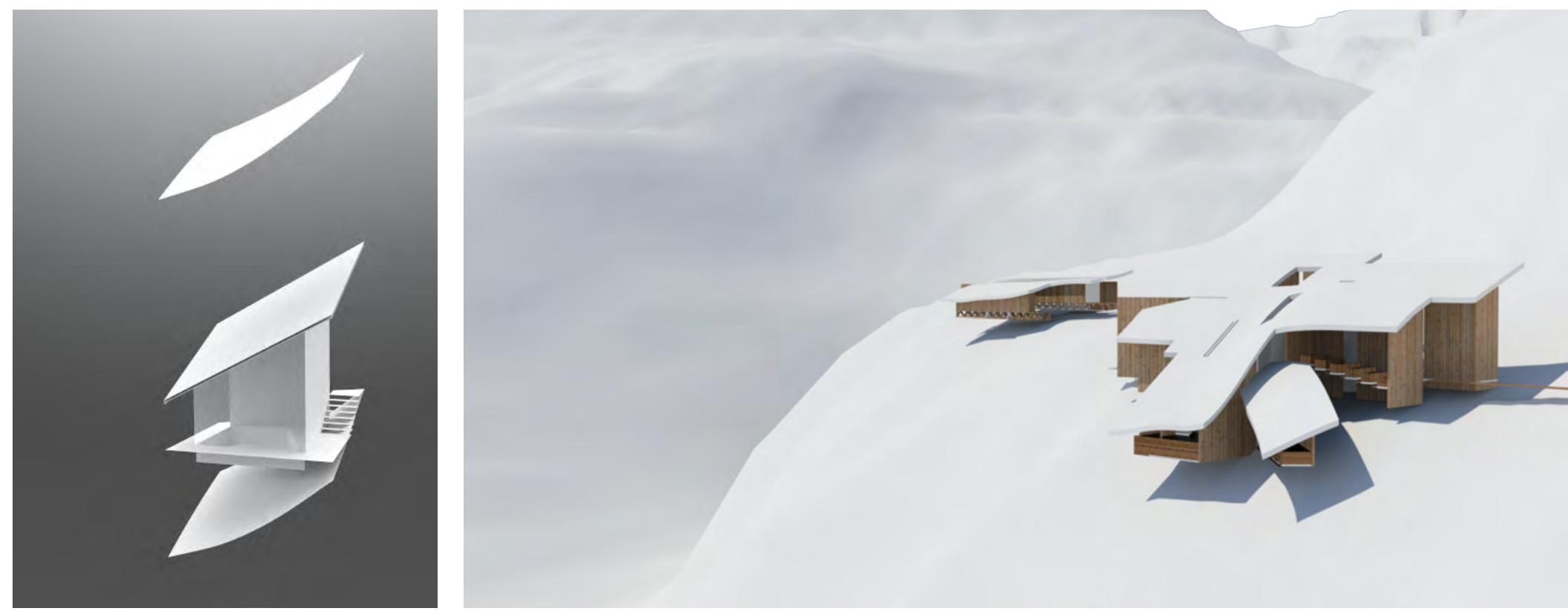

+Figure 6.10 Exploration of roof surface and form driven by simulated water flow.

This exploration used rainfall to represented regional architecture though site responsive design. However, it was a monolith that did not align with the West Coast regionalism or identity that was identified in chapter 3. The overwhelming number of baths were also a problem as the memorial became more of resort than memorial. The addition of pure contemplative spaces could change this. I also found that the plunge pool could not be central as it would become the central core to the baths and a cold plunge pool is not a central warming hearth.

I also found that a non-linear procession through the spaces and the baths relates more to the Kessler - Kübler-Ross model which is a non-linear process of recovery.

These circulation studies increased my understanding of the relationship between spaces and programme, between the entrance and the baths, the entrance and towel storage and people and the plunge pool. 

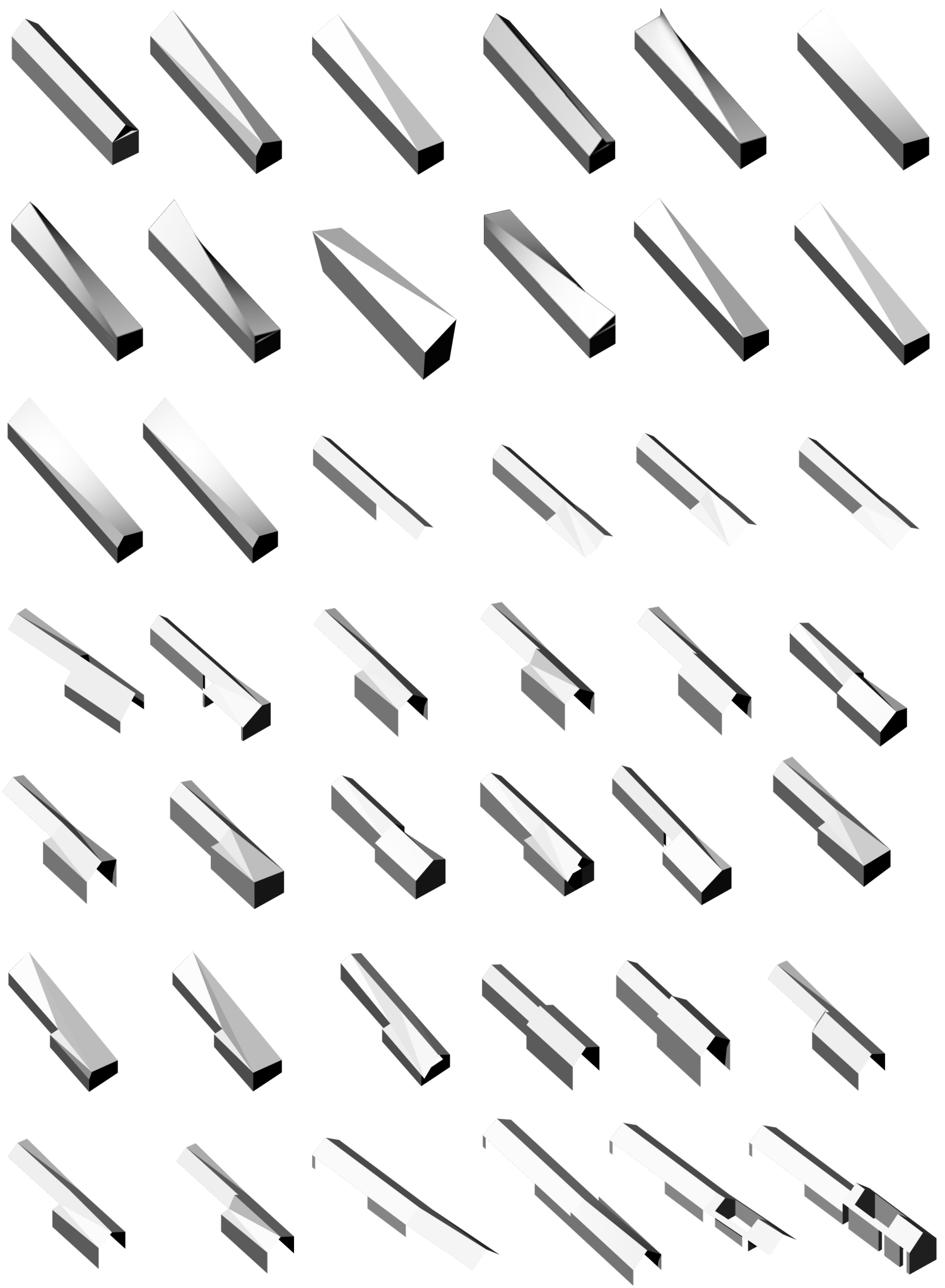

+Figure 6.11 Rapid iterative testing of vernacular form starting with a gable and finishing with a gable. 


\section{CONCEPT DESIGN}

\section{FORM BASED ON REGIONAL ARCHITECTURE}

Initially I went through a process of reinterpreting the regional architecture (the gable) as a method of preserving the architectural regionalism. After some alternative roof form exploration however, I returned to the simple gable which is readily recognisable to West Coasters. The majority of the buildings will be constructed from local Silver Pine due to its durability and locality. Silver Pine falls under durability class 1 and untreated in ground timber can last $>25$ years (NZ Wood).
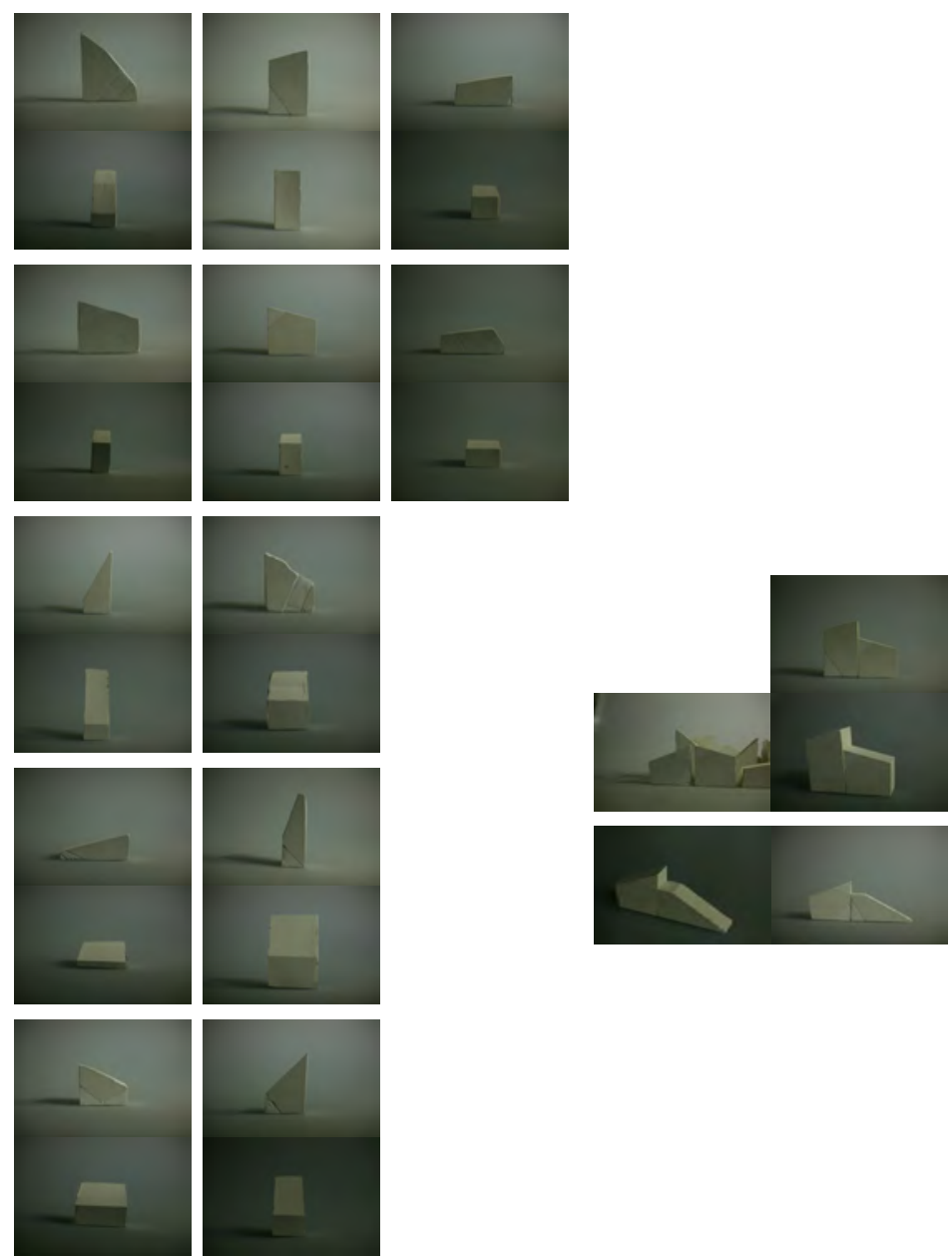

+Figure 6.12 Itterative plaster mass-model testing of vernacular forms. 

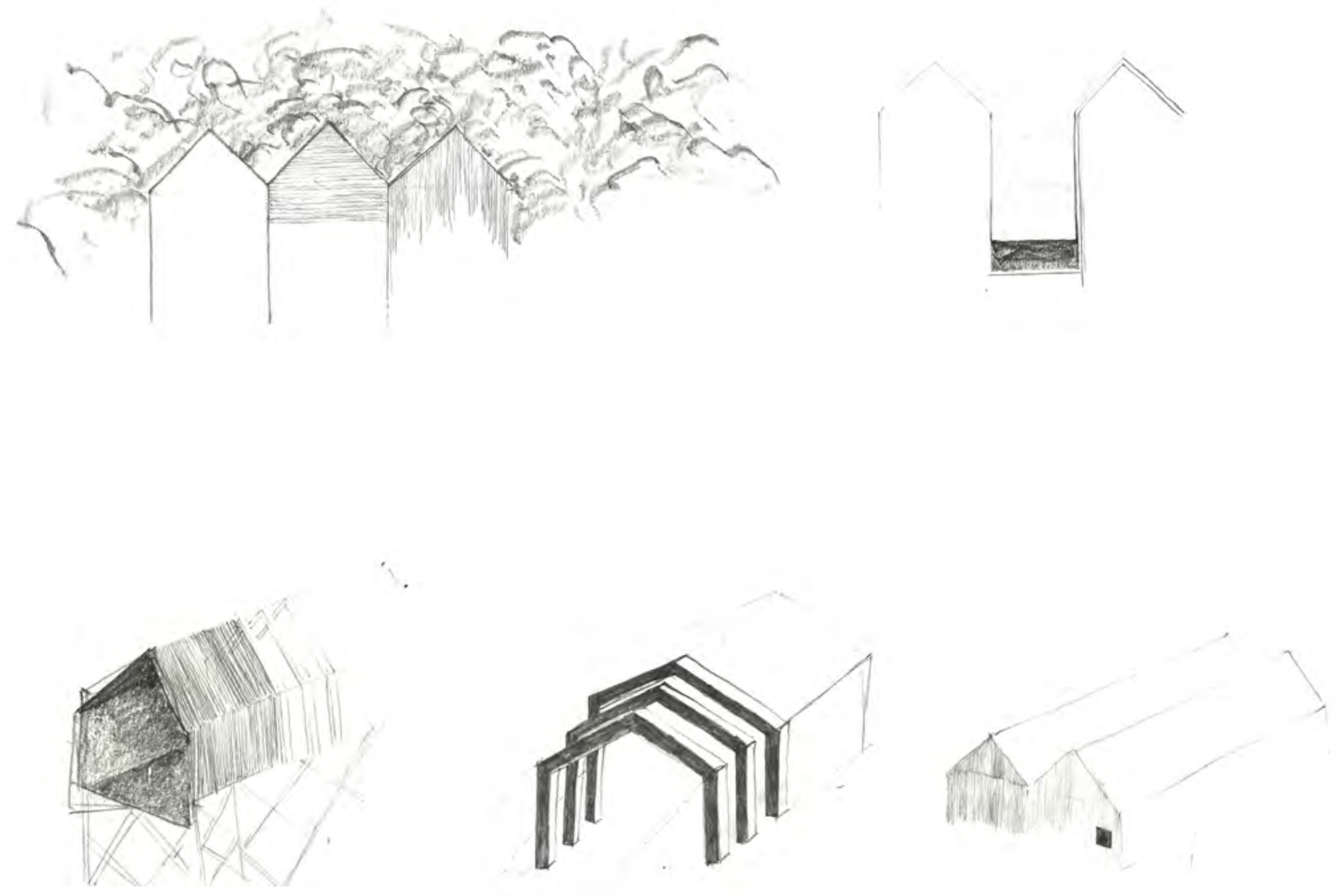

+Figure 6.13 Exploration of regional form based on the dredge and the stamping battery.
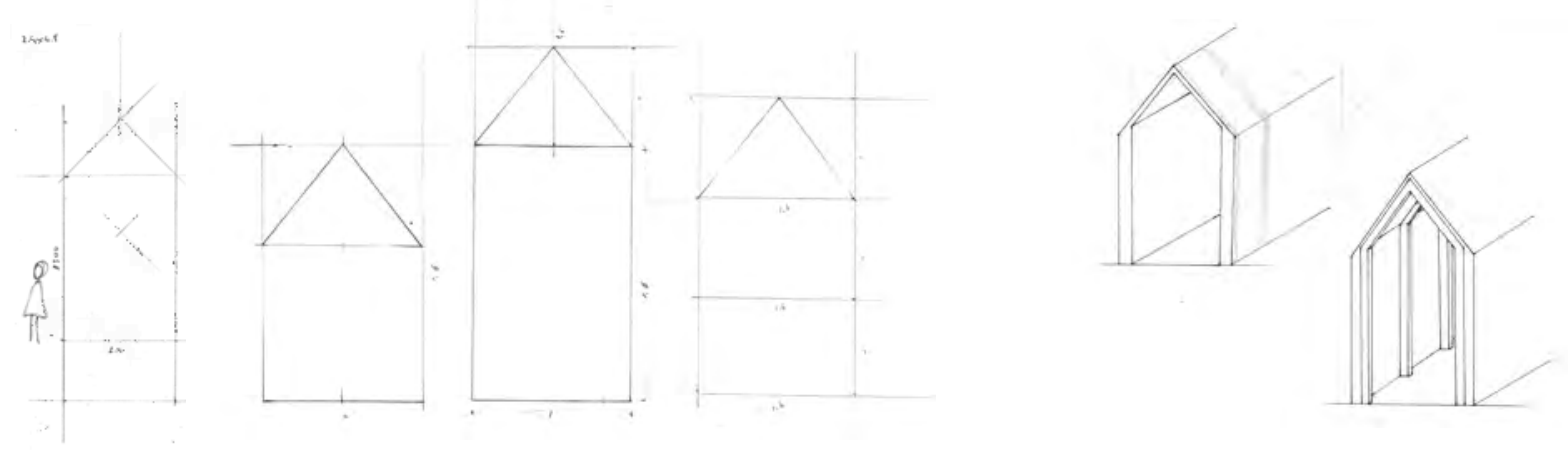

+Figure 6.14 Exploration into proportion. 


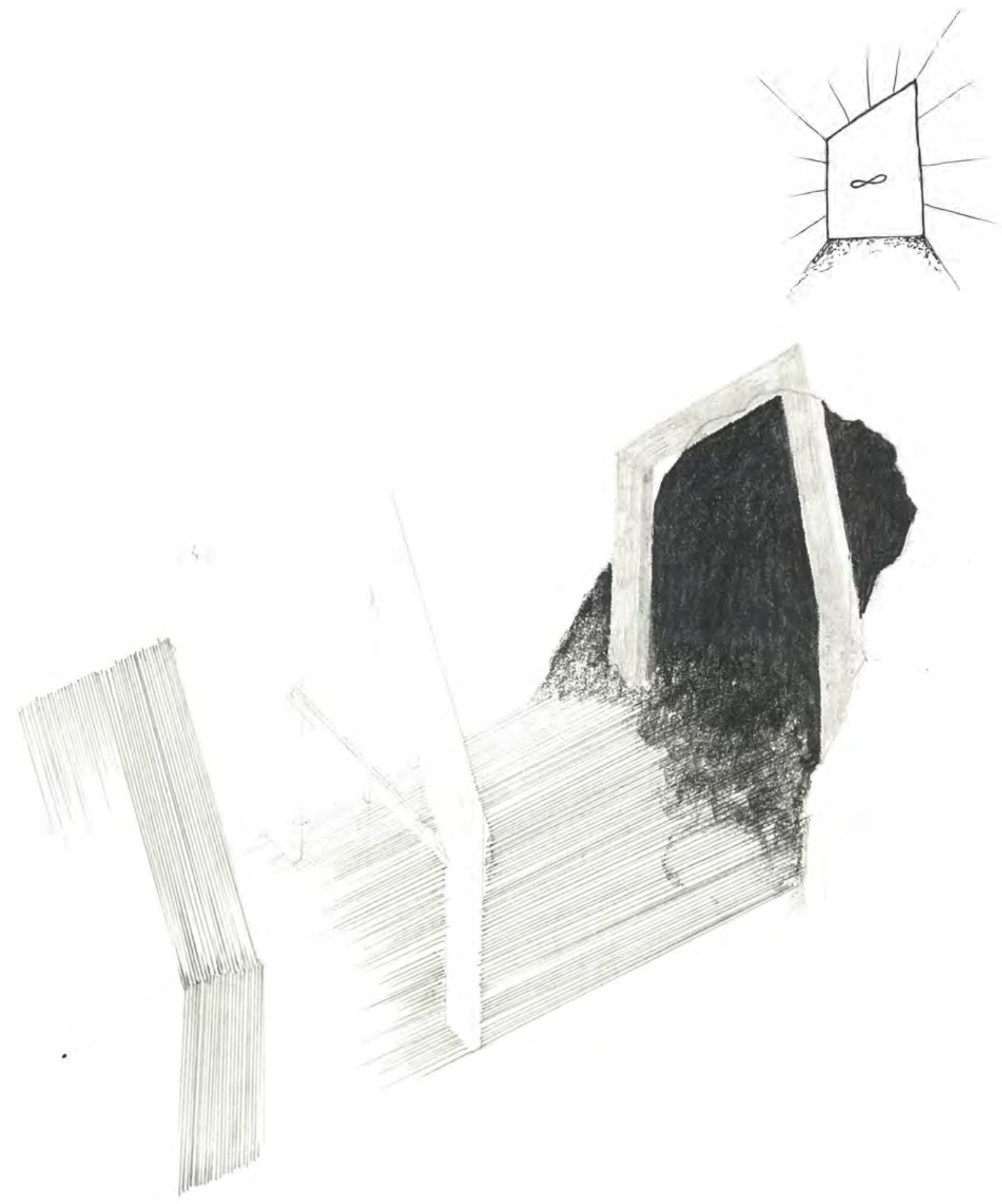

+Figure 6.15 Means of framing the distance from underground through repitition of a frame. 


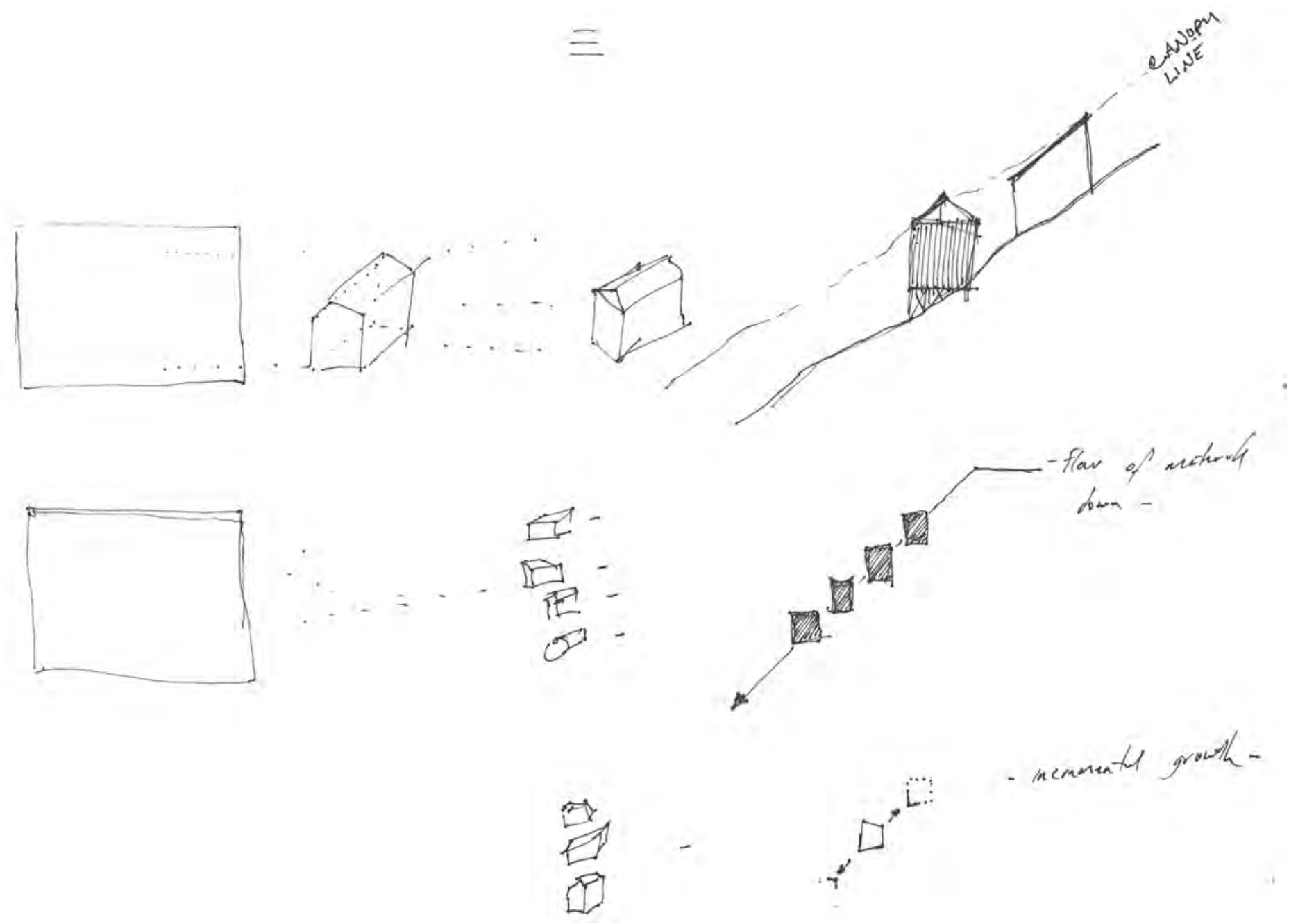

+Figure 6.16 The movement of ore and water through the stamping battery and how it defines the building-building relationship.

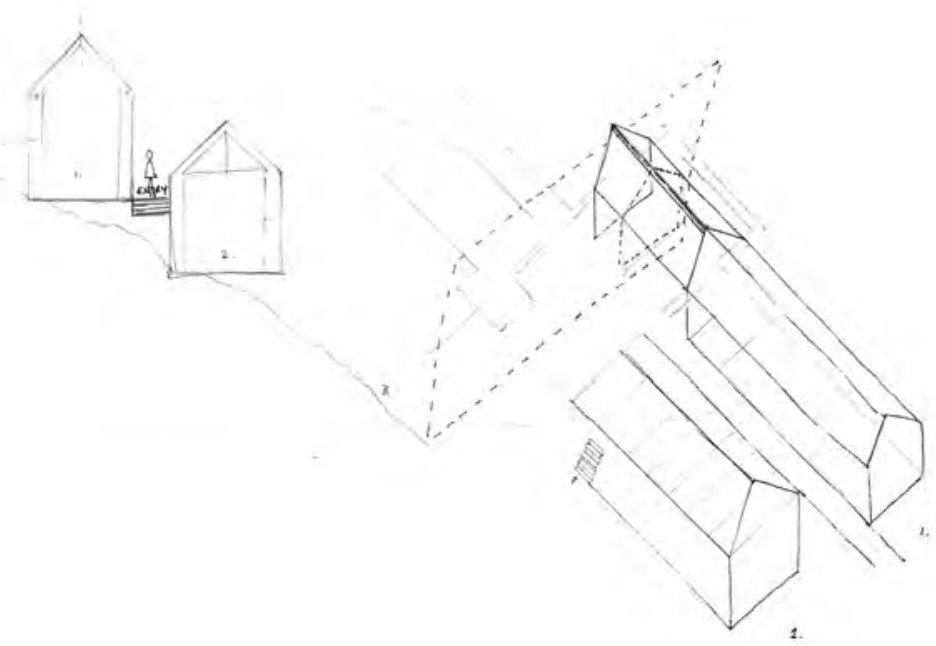

+Figure 6.17 Plan defined by preliminary design but form and arrangement of from defined by regional architecture. 


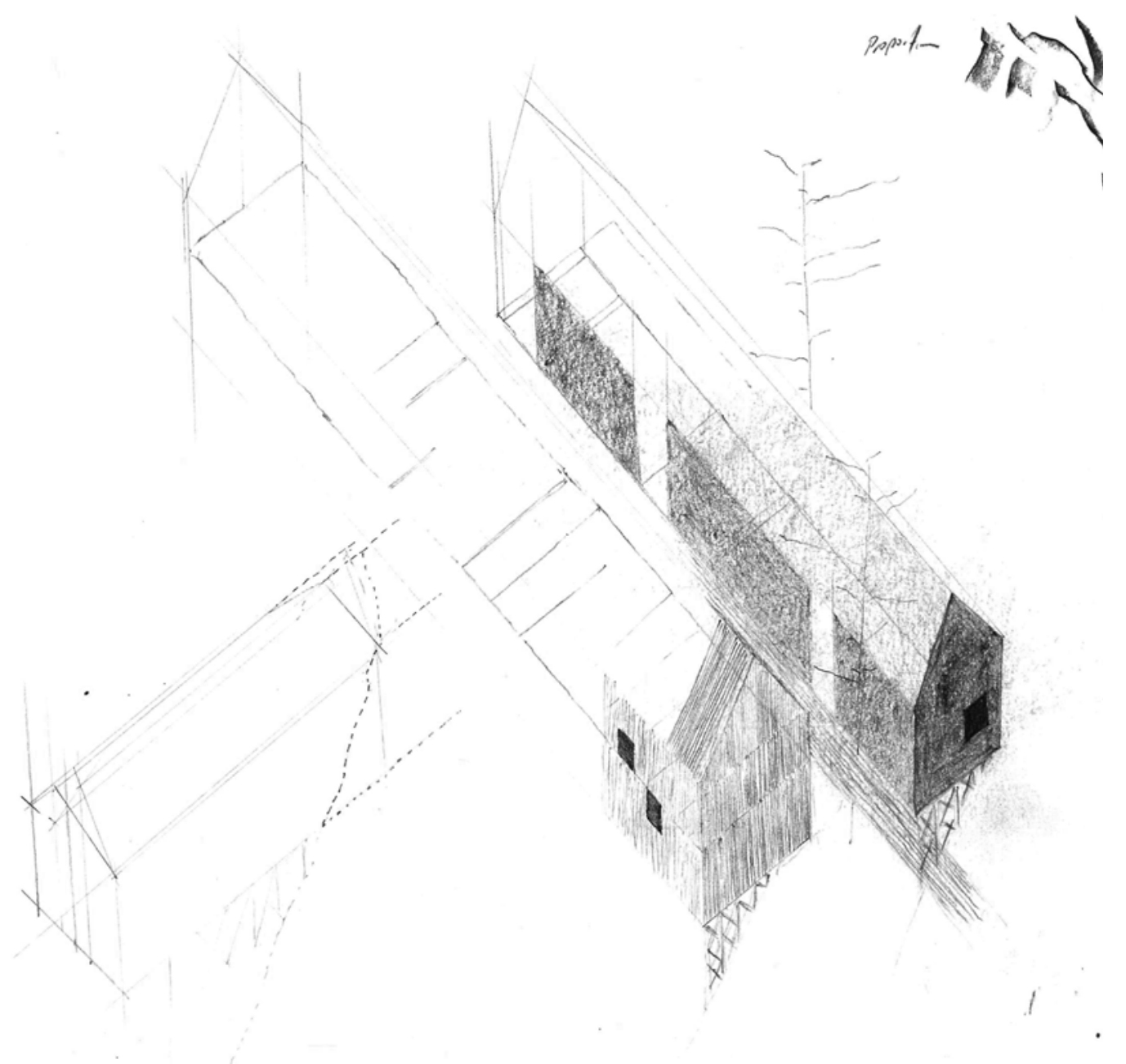

+Figure 6.18 Moving people through the building with the water to enrich, clean and refine them, similar to that of the ore in the stamping battery and dredge.

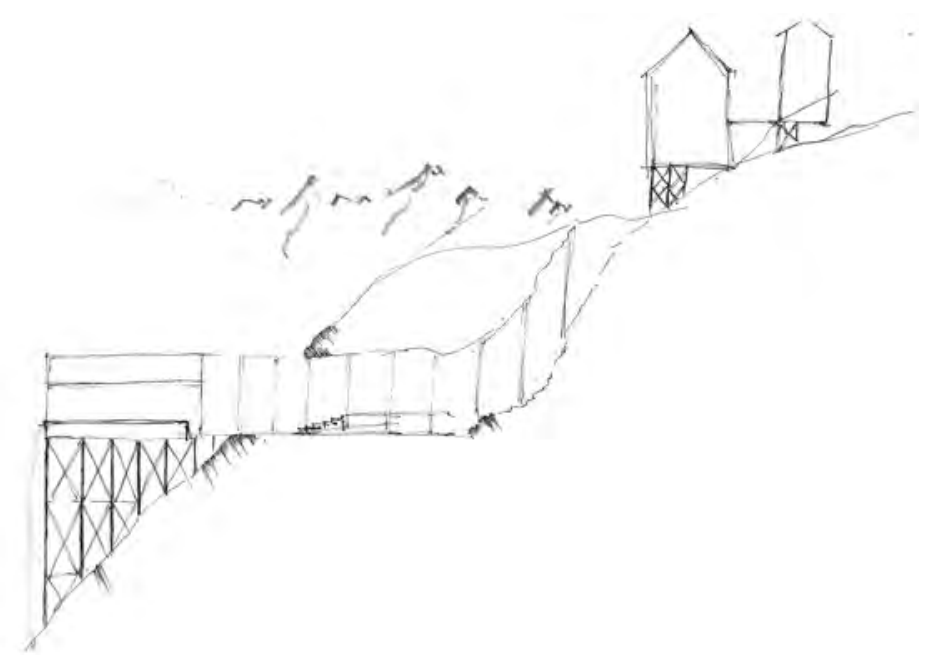

+Figure 6.19 Section through three buildings representing the bargaining depression and acceptance stages of the Kessler - KüblerRoss model. 


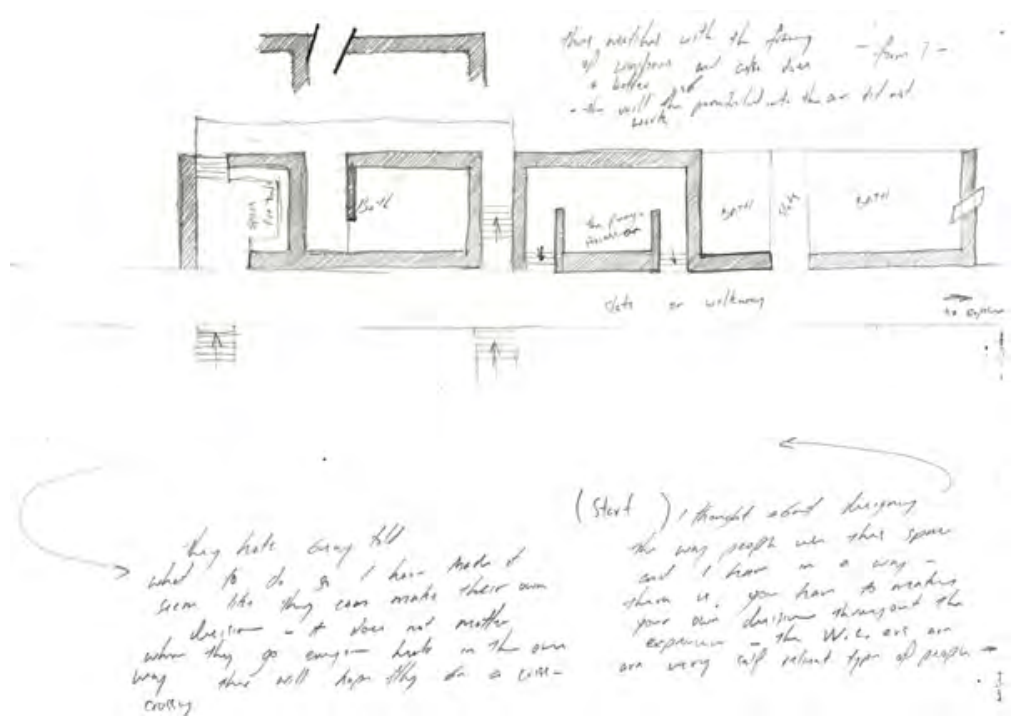

+Figure 6.20 Plan, Bargaining stage represented by building.

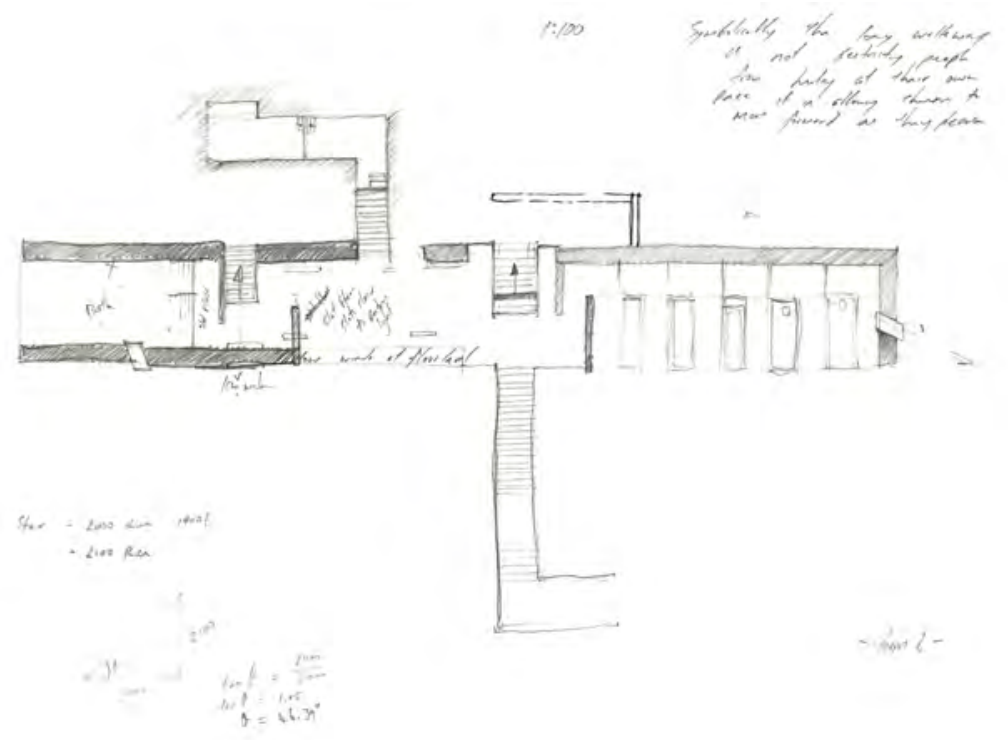

+Figure 6.21 Plan, Depression stage represented by building.

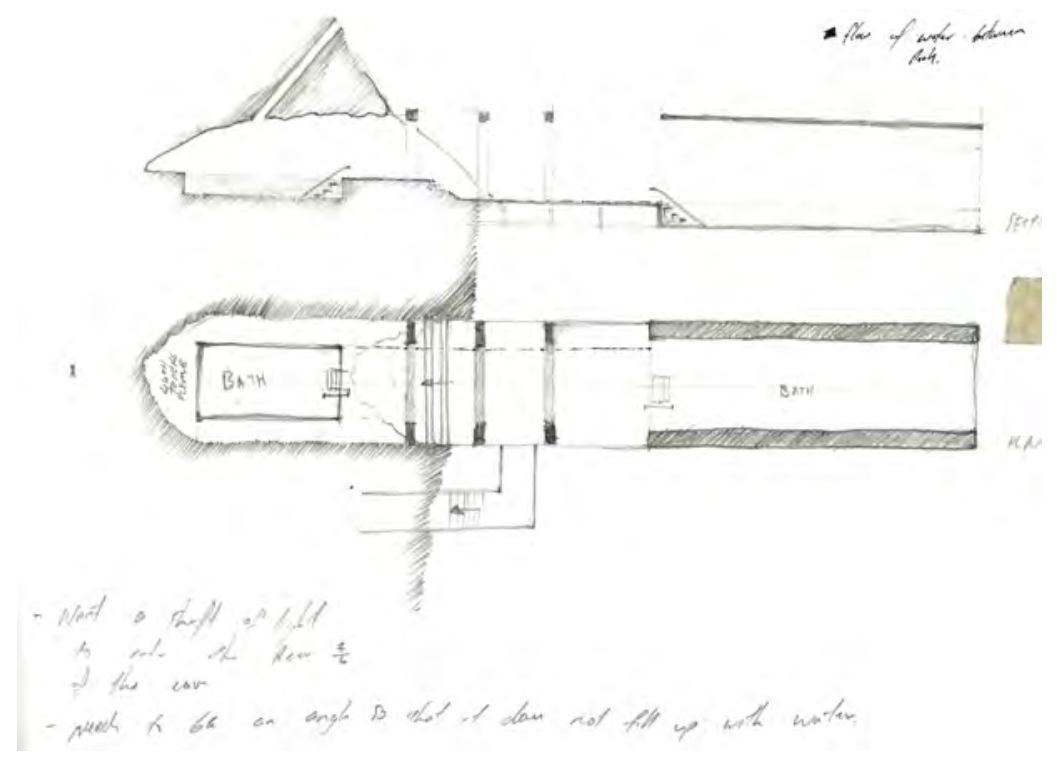

+Figure 6.22 Plan, Acceptance stage represented by building. 

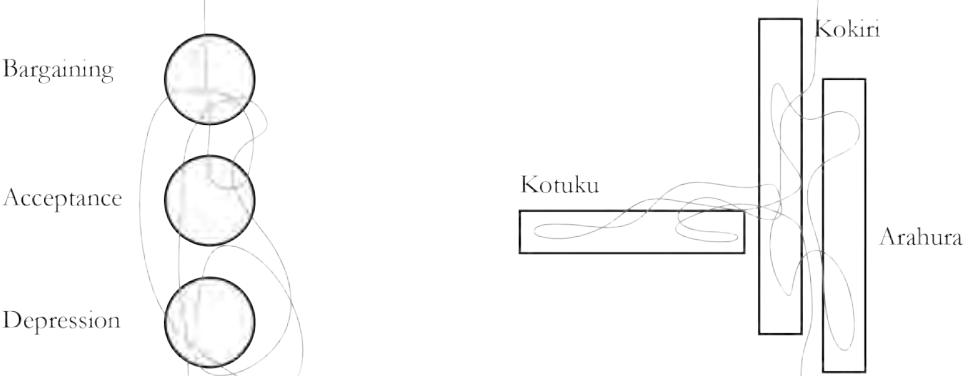

With the barganing stage being represented by the Arahura Bath, the depression stage being represented by the Kokiri Bath and the acceptance stage being represened by the Kotuku Bath.

+Figure 6.23 The Kessler - Kübler-Ross modell method of moving through the three stages vs the designed baths, their names (derived from important towns that have disappeared) and the method of experiencing them.

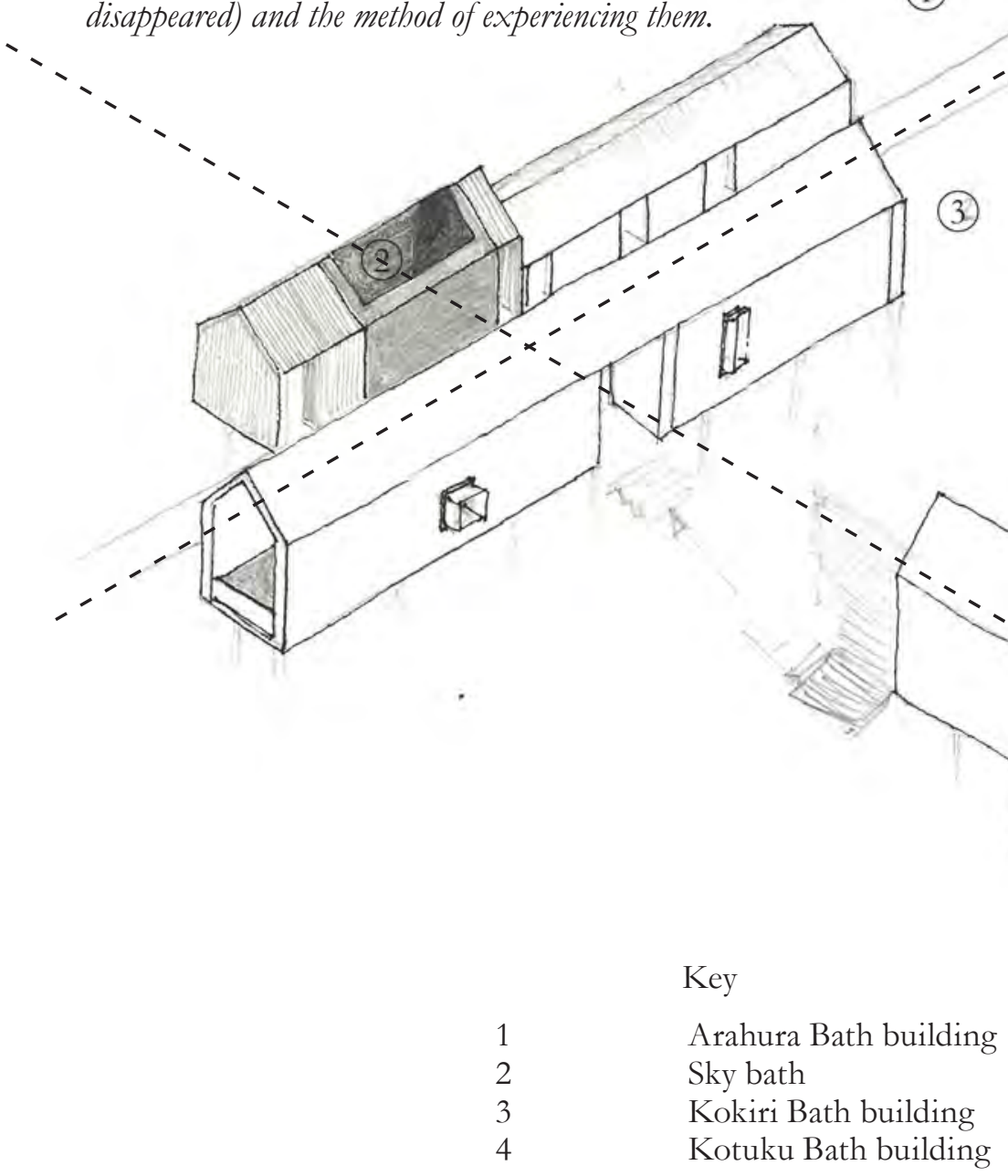

(1)

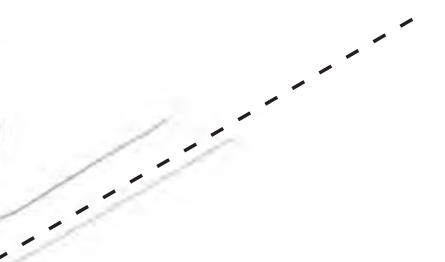

(3)

+Figure 6.24 The two axial paths that run through the main baths are referred to as the Kessler - Kübler-Ross Pathway. It is the path that represents the route someone would go on if they were working through the steps of grief. 


\section{FRAMING OF SCENES}

Utilising the writing of Kirke, framing of specific transcendent scenes can focus the senses and promote mental stimulation. An analysis of the site and important points of view was carefully undertaken. Taking into consideration of times of day and seasons of the year. This section explores framing views orientated toward these important view shafts.

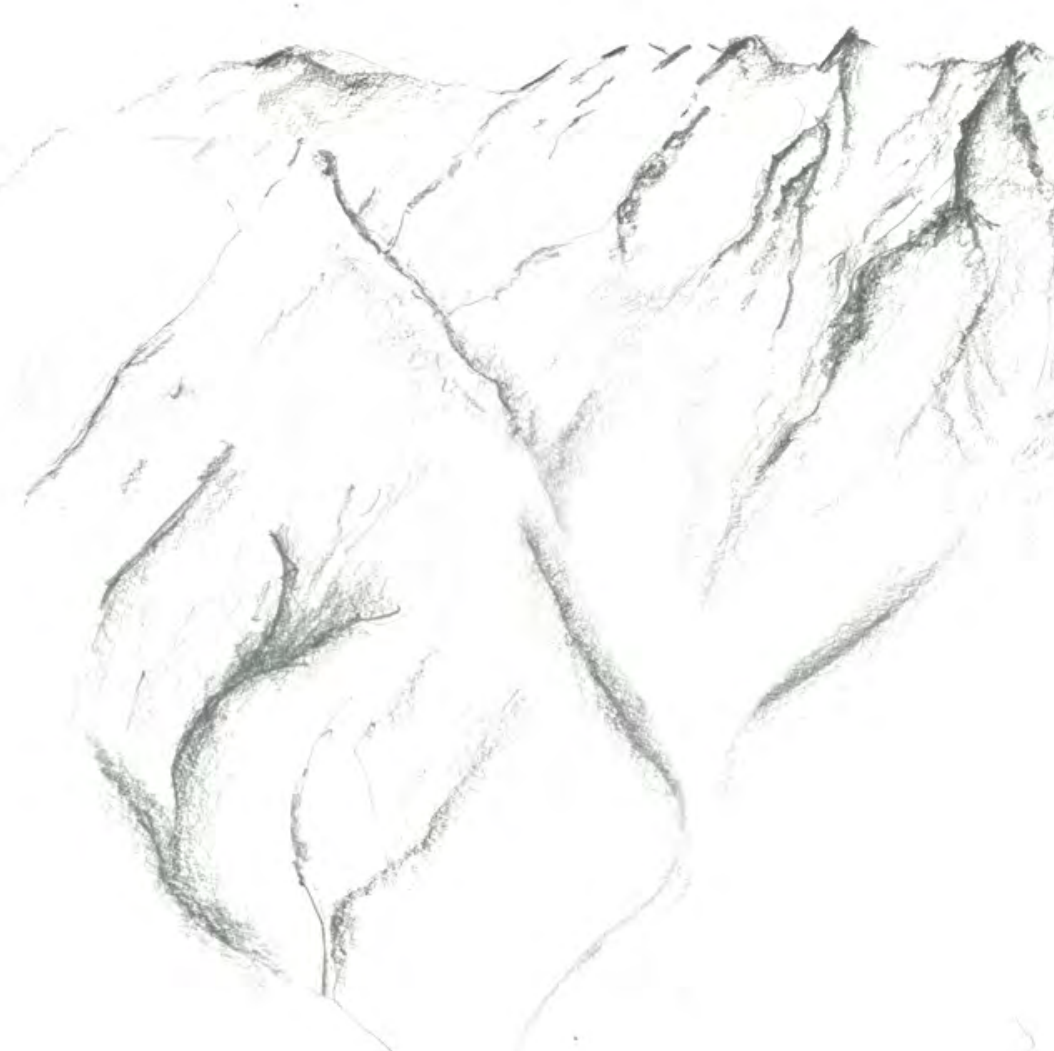

+Figure 6.25 View of Diedrichs Range from site. 


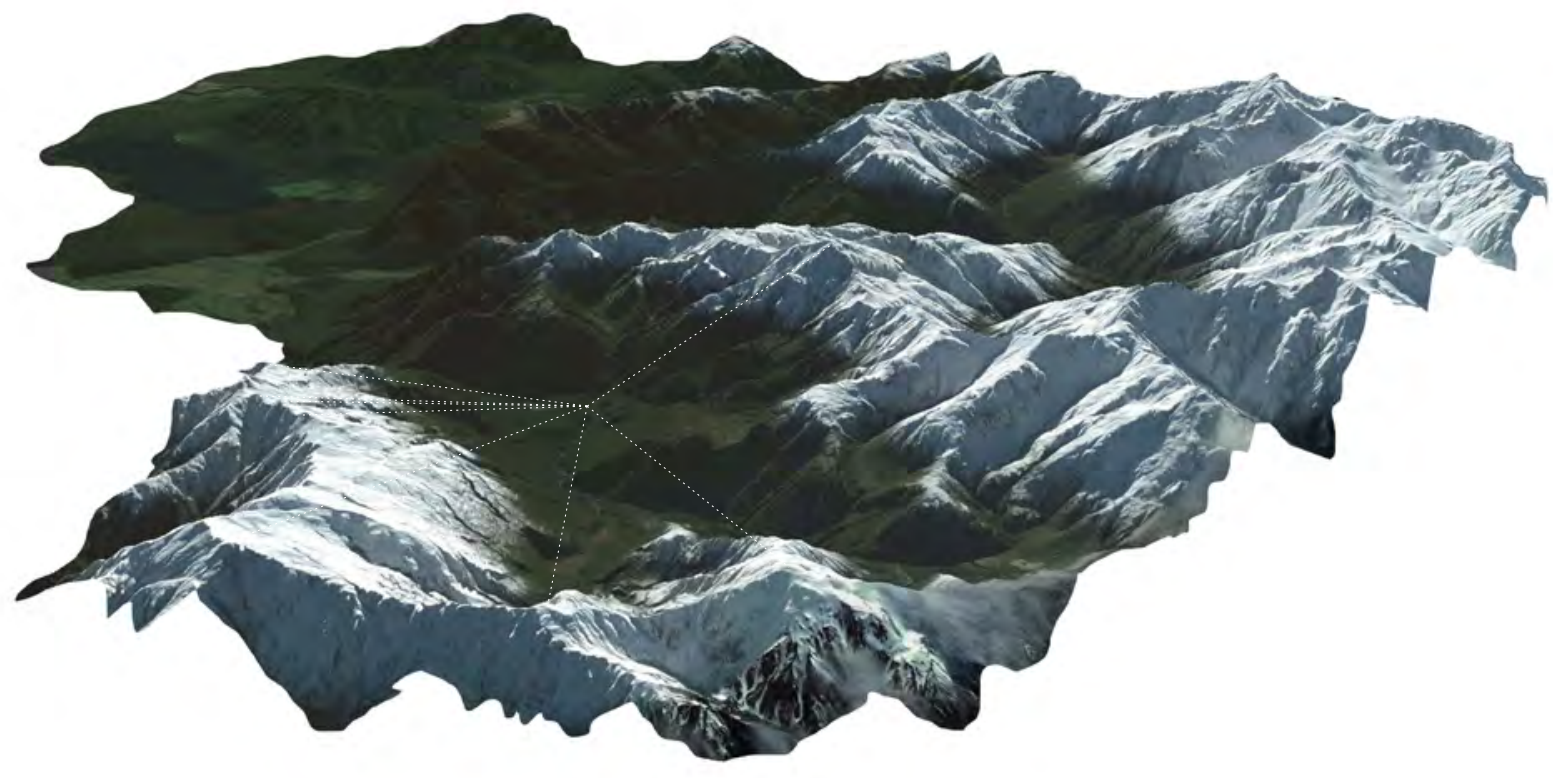

+Figure 6.26 Looking North - important view points seen from site.

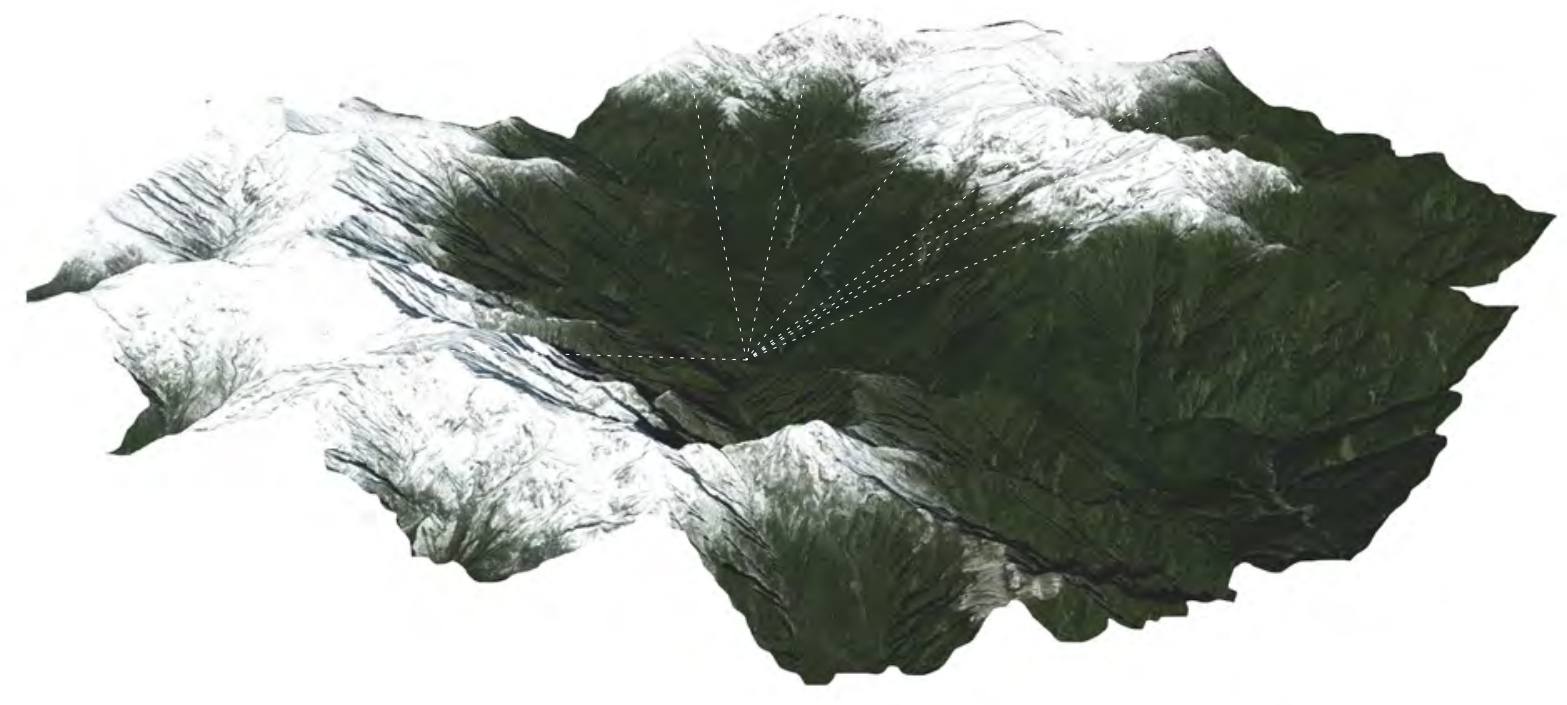

+Figure 6.27 Looking South - important view points seen from site. 
+ Figure The

point of focus.
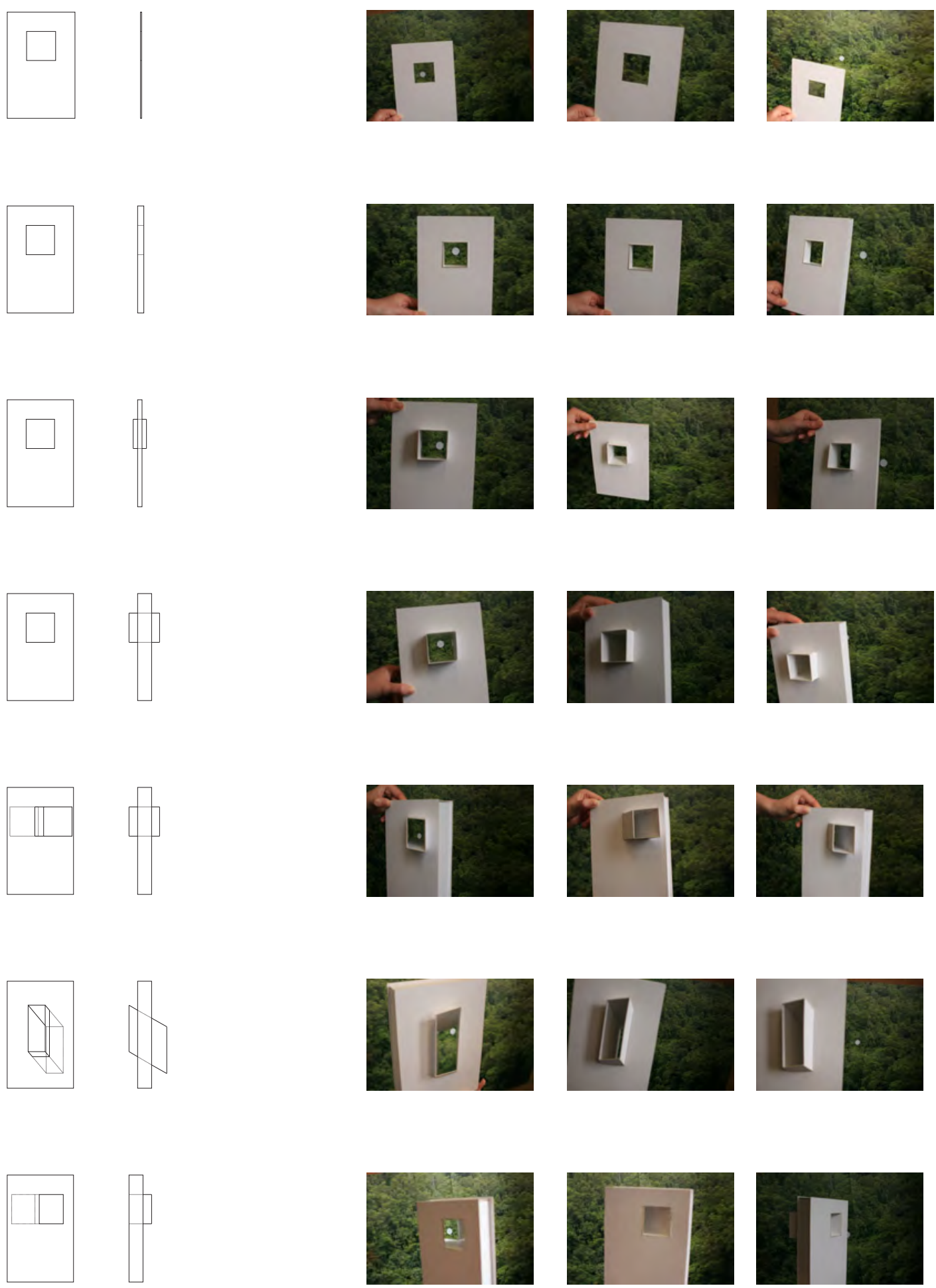

+Figure 6.28 Exploration into windows and framing methods through modelling and drawing. 

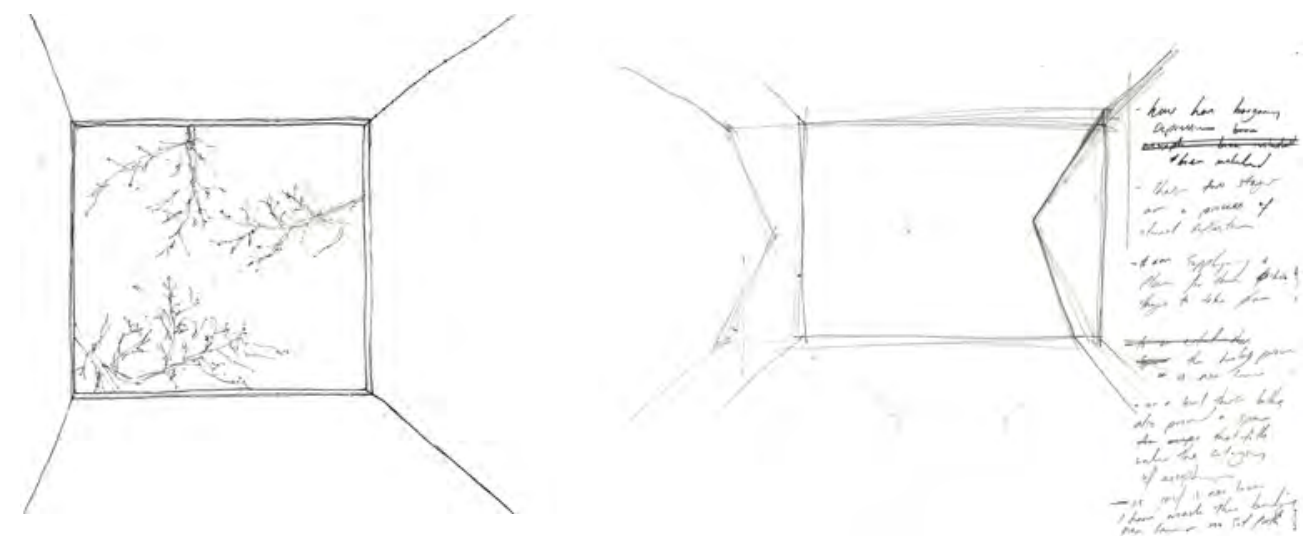

+Figure 6.29 Exploring means of framing the infinite by framing

the sky

Large windows give you an expansive view, however, they do not provide the occupant with an indervidual intimate view. The senses do not reach a level of focus and sensitivity. Visitors can become over exposed, and the contemplative spiritual sense of the space can be lost.

Physical modelling of openings tested the use of thicker wall to minimize viewers seeing through openings from oblique angles. The use of steel shafts were included in the opening detail to further maximise scene framing and to minimize oblique views. This use of of shafts extended towards the entrance of the sky baths in the Arahura Baths building is to frame the process of climbing into and out of the bath, but also to incorporate the idea of climbing into your problems. Duly it inhibits views from the bath to the entrance and provides only upward views.
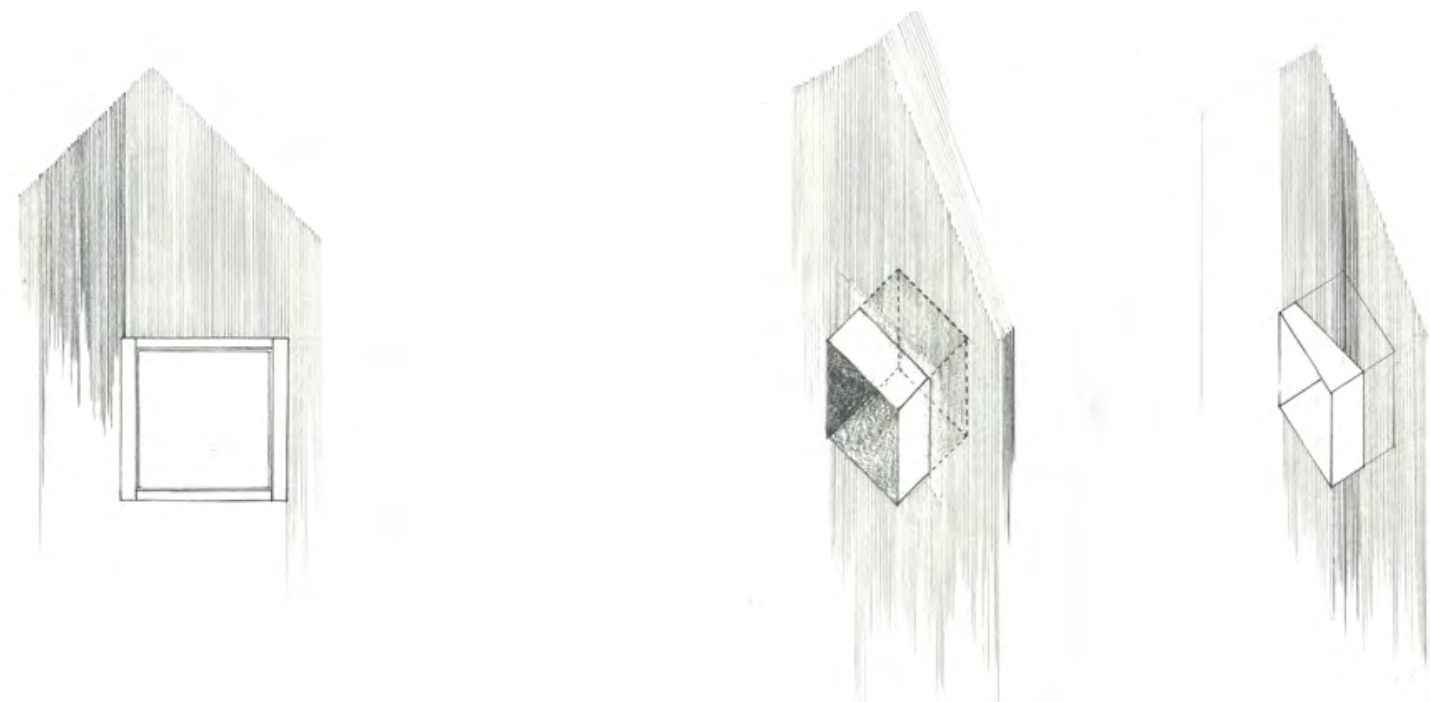

+Figure 6.30 Explorlation of windows and framing methods through drawing 


\section{DARK SPACE}

This section explores the use of dark space thorough drawing and digital modelling. Underground space was explored here as there are direct connections between mining and caves. Design that makes a person grope around in a dark cave, with wet unfinished rock for walls could invoke moments of involuntary memory, the 'Proustian Memory' described in chapter 2.
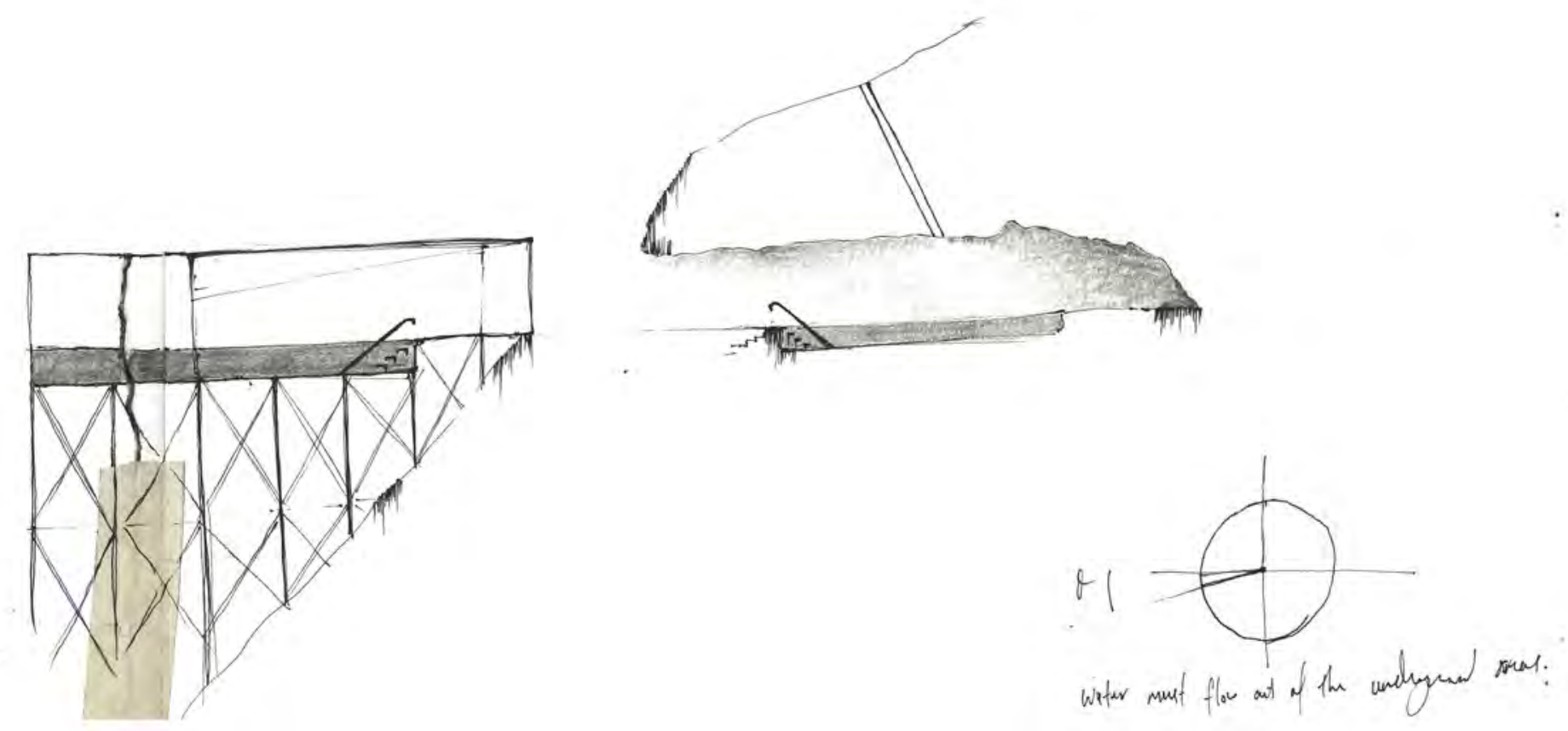

+Figure 6.31 Exploration into shafts of light penetrating space. 


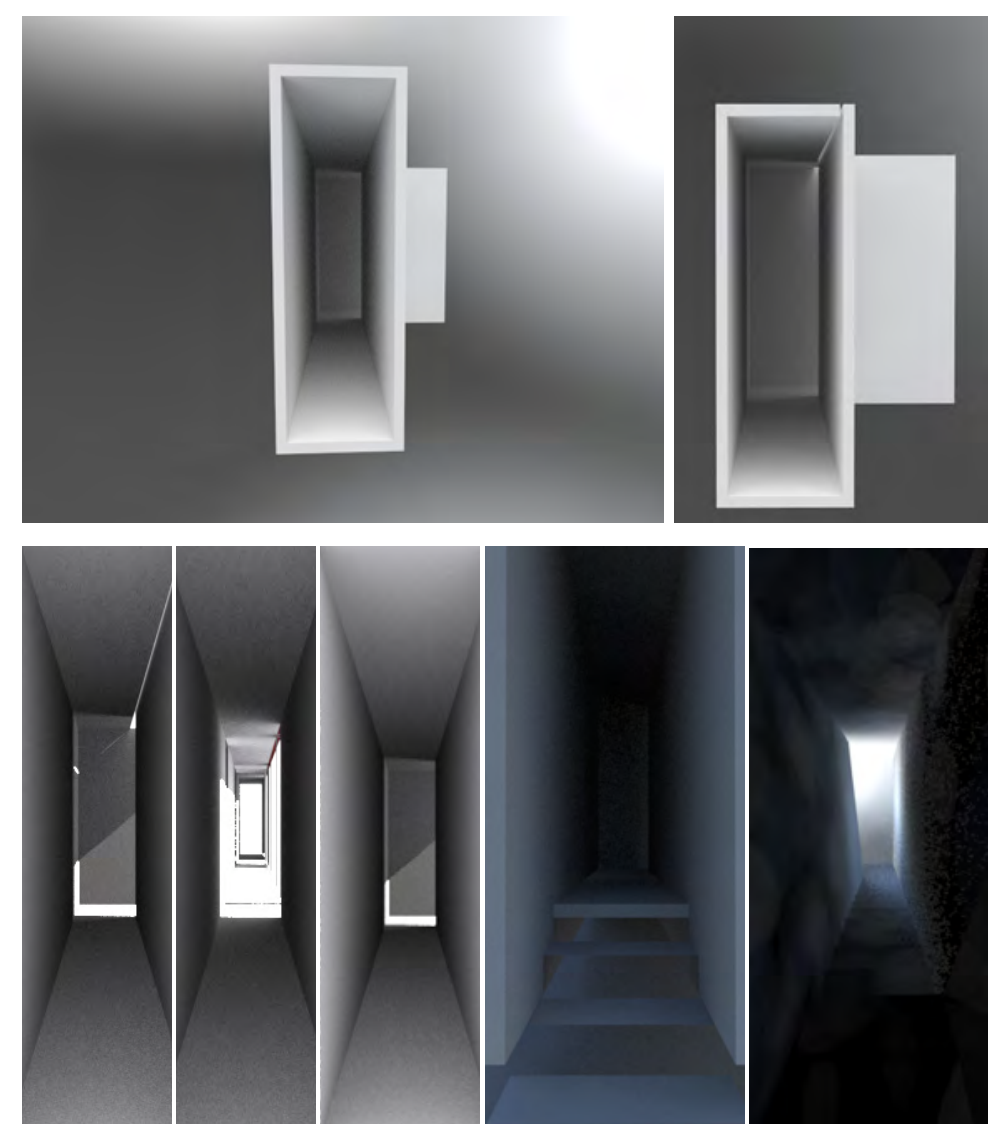

+Figure 6.32 Exploration into drawing visitors from dark to light space.

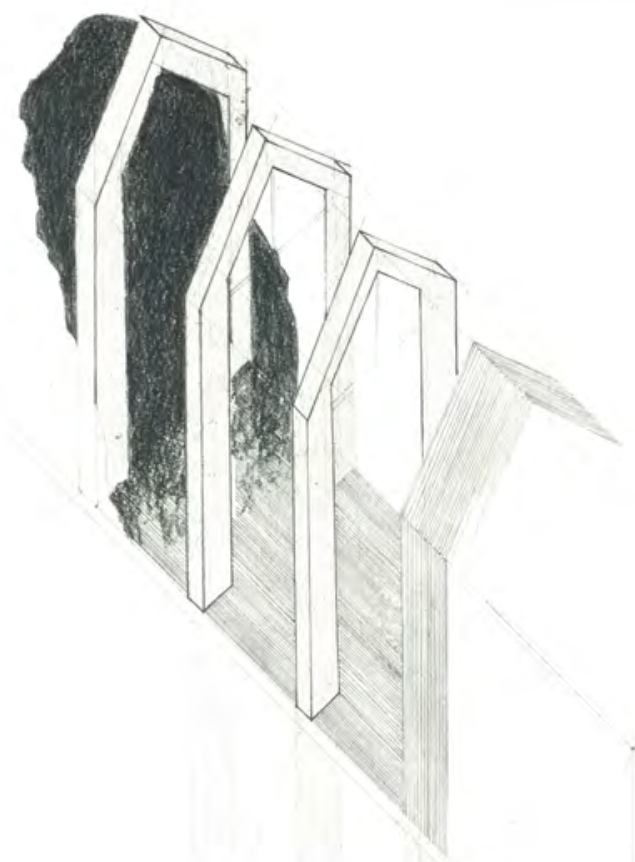

+Figure 6.33 Exploration into darker space. 


\section{THE MOVEMENT AND AUDIBILITY OF WATER}

Using the methods of water transportation as evident with the stamping battery as identified in chapter 3 , water moves via gravity throughout the baths. This provides the opportunity to introduce the sound of flowing water which will prompt contemplation. The path the water takes is defined by the hotness or coolness required of the baths. The water passes through stainless steel pipes which are unreactive to the high sulphur levels in the water. The walls of all buildings being $500 \mathrm{~mm}$ thick allow for ample room to move the water through when required. When louder zones are desired the water is dropped into the bath. Conversely when quiet zones are desired the water is fed into the bath from below the water line.
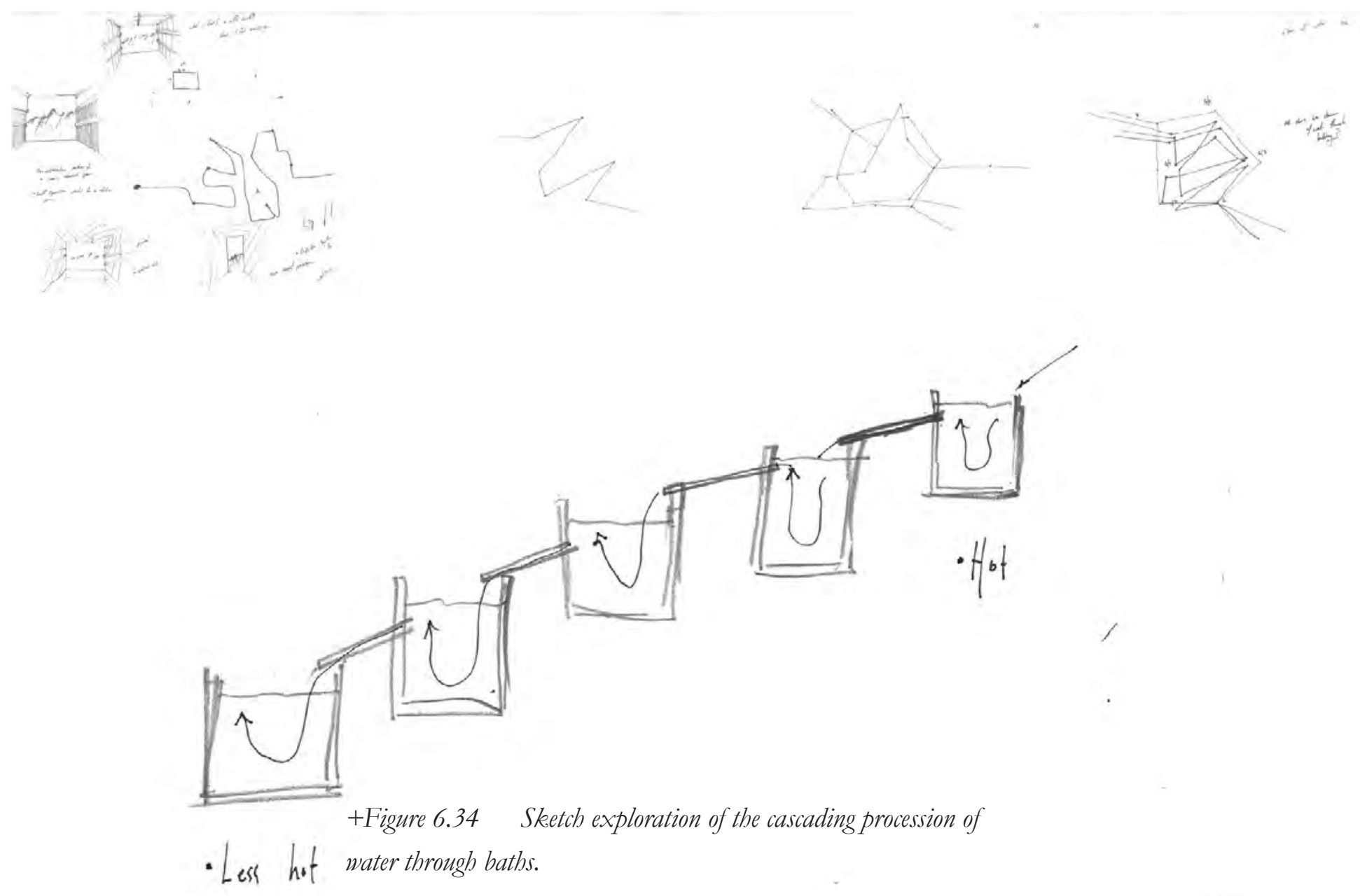


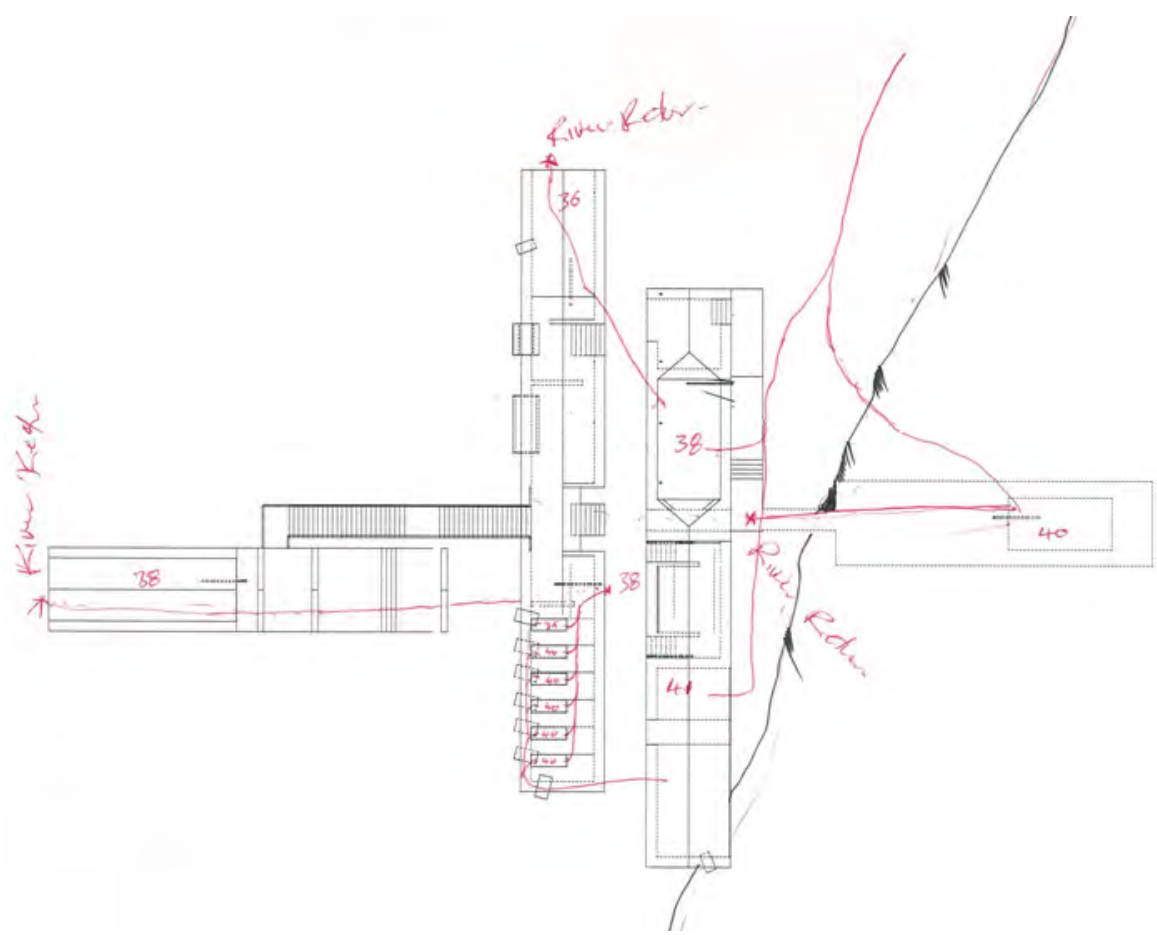

+Figure 6.35 Movement of thermal water throughout building and temperatures of baths.

$$
\begin{aligned}
& \text { B.t. the then the ity }-38^{\circ} \mathrm{C} \\
& \text { how fort and this bith lon heot? }
\end{aligned}
$$

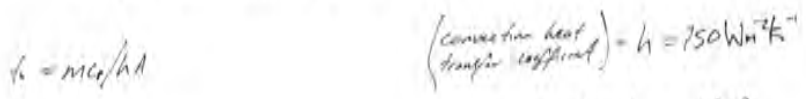

$$
\begin{aligned}
& \begin{array}{l}
(\text { suthen Axace })=A=46 \mathrm{~m}^{2} \\
(\text { mince })=m=12,760 \mathrm{k}
\end{array} \\
& \frac{12760 \times 4.187}{750 \times 406} \\
& t_{0}=3219.63
\end{aligned}
$$

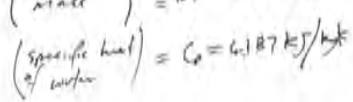

$$
\begin{aligned}
& T_{t}=T_{s}+\left(7-T_{T}\right) e^{-\lambda t}
\end{aligned}
$$

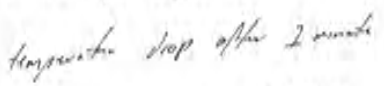

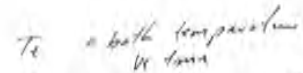

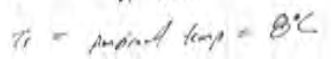

$$
\begin{aligned}
& 7 \cdot \sin 6 \pi=38^{\circ} \\
& \text { ton time }=1 \text { minate } \\
& t=t o=3214.83 \\
& T_{1}=37,91 \cdot \mathrm{C} \\
& 8+(38-8) e^{-5219.63 \times 1}
\end{aligned}
$$

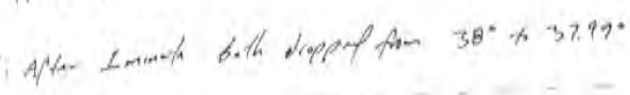

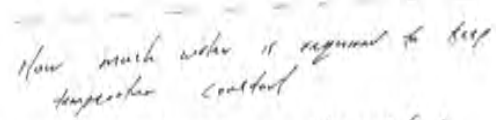

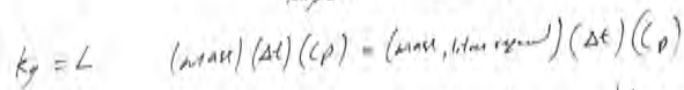

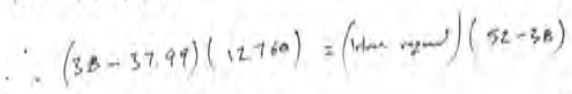

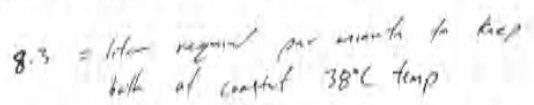

$$
\begin{aligned}
& \text { 6.3 litem of } 52^{\prime \prime C} \text { wothe form spring per minate }
\end{aligned}
$$

+Figure 6.36 Calculation of heat loss and amount of water required to keep baths at a constant temperature due to initial ground water temperature, surface area, volume, ambient air temperature and specific heat capacity of water. 


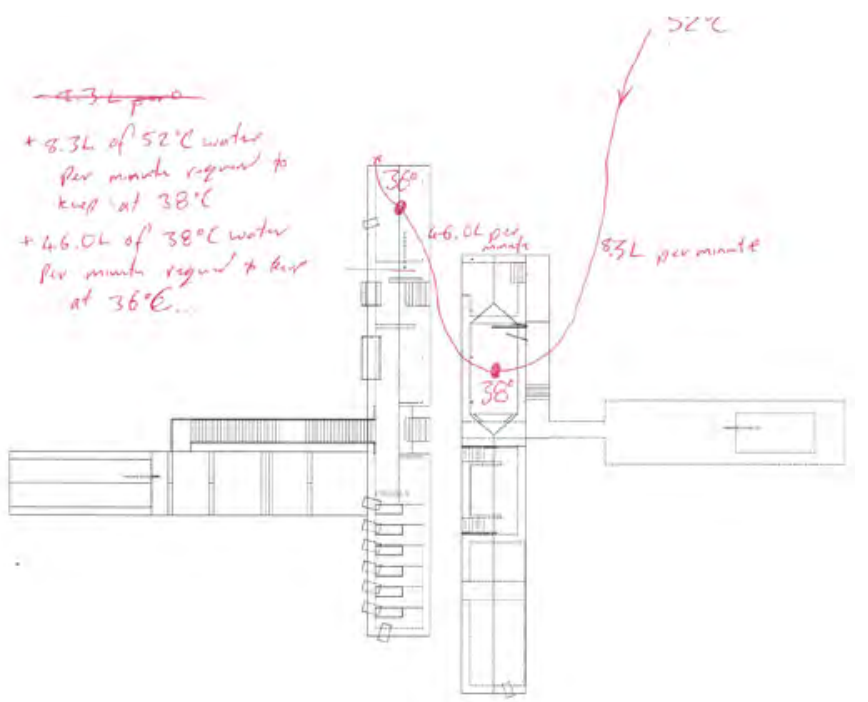

+Figure 6.37 Calculation of volumes of water required for constant temperatures.

As calculated in figure 6.35 it would take 8.31 of $52^{\circ} \mathrm{C}$ water per minute to keep the bath at a constant $38^{\circ} \mathrm{C}$, which is possible as the water emerges from the spring at 601 per minute. However, it would take 461 of $38^{\circ} \mathrm{C}$ water per minute to keep the water in the following bath at a constant $36^{\circ} \mathrm{C}$. This is impossible as it would empty the first bath, so changes in the methods of water flow had to be made, with less bath-to-bath water transfer and more direct flow from the spring.

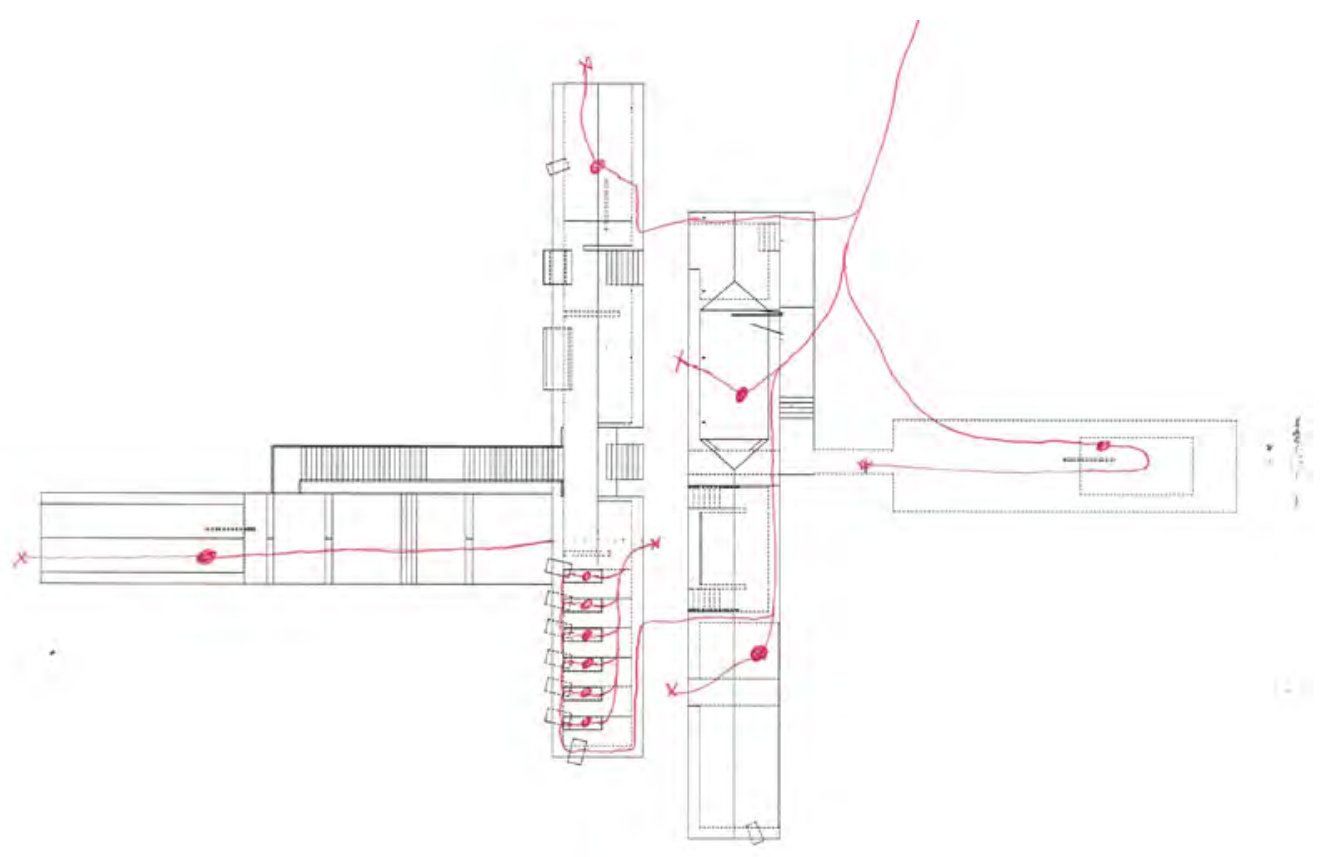

+Figure 6.38 More direct flow of water through baths with more outlets back to the river. 


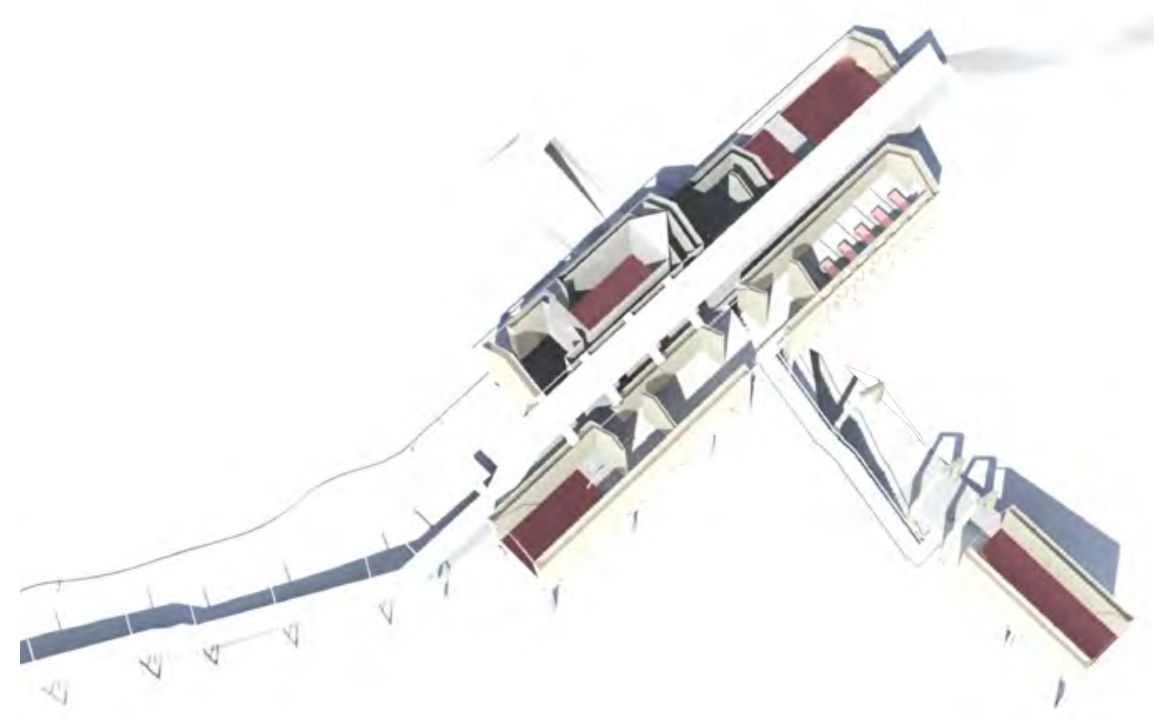

+Figure 6.39 Cold water and warm water baths.

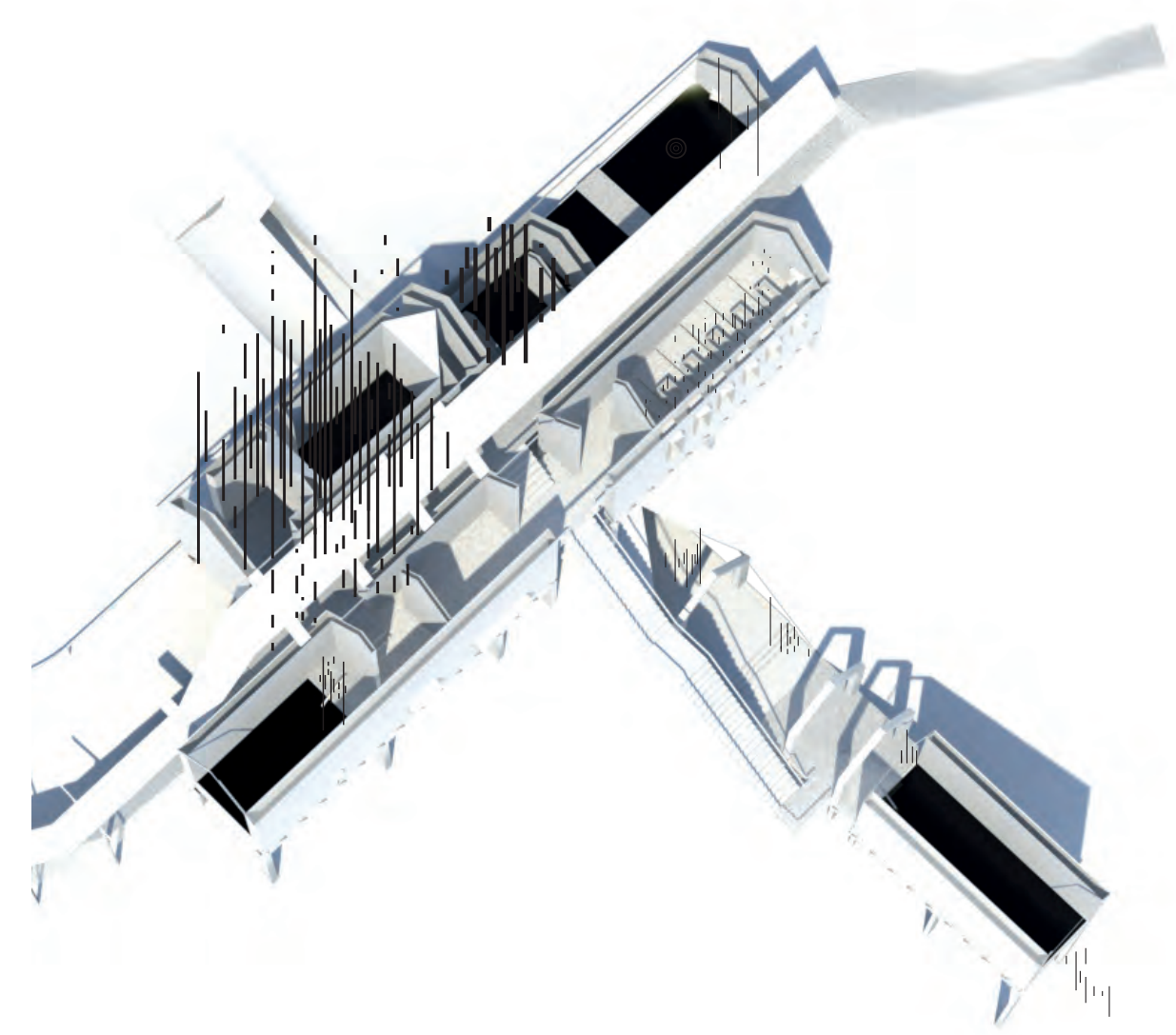

+Figure 6.40 Loudness of water throughout baths (as shown by black lines). 


\section{ARANGEMENT}

\section{SITING OF BATHS}

The exact placement of the building on site was largely driven by the water flow through the site, access to light and location of trees. This minimised impact on site and conserved as much of the natural ecology as possible. Location was determined where there was minimal water flow as evidenced by the rainfall simulation. The majority of the building is up on stilts so it is light on the ground and let's water flow under and through its structure.

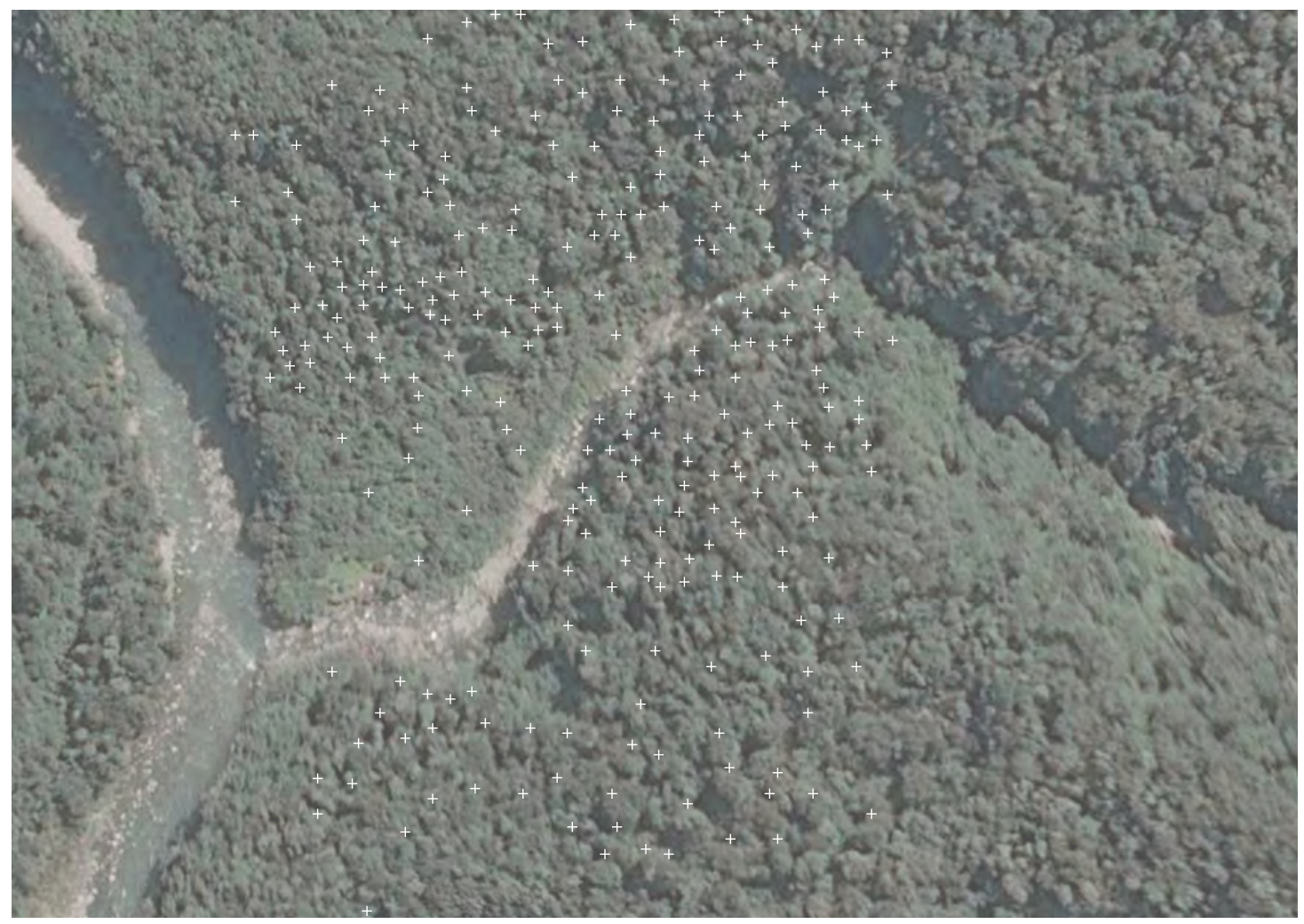

+Figure 6.41 Location of major trees, mapped on site. 


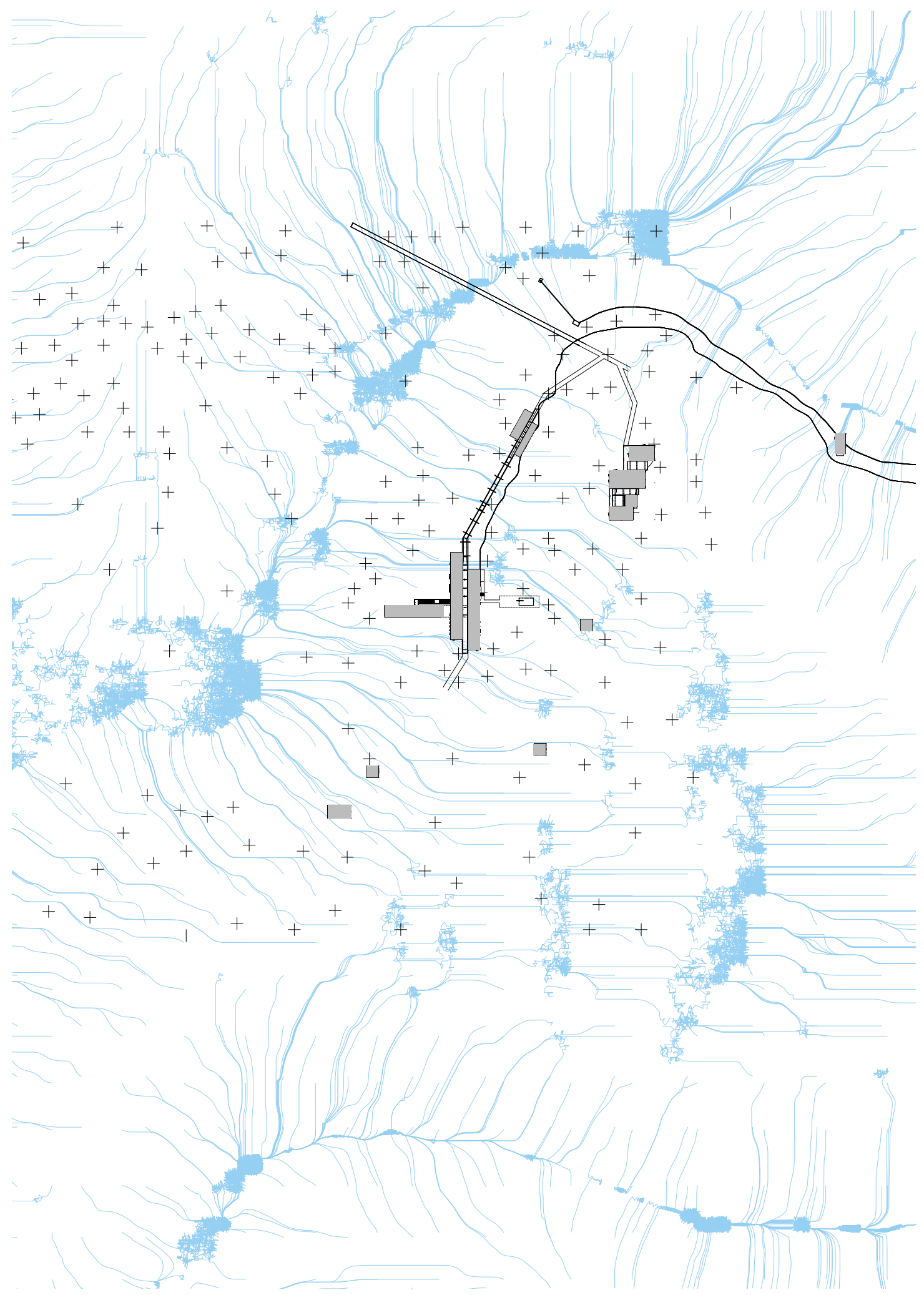

+Figure 6.42 Location of baths in relation to rainfall simulation and trees. Baths are also located on the north side of a bill to maxamise natural daylighting and to have access to the natural views. 


\section{RAIN WATER PENETRATION THROUGH BUILDING}

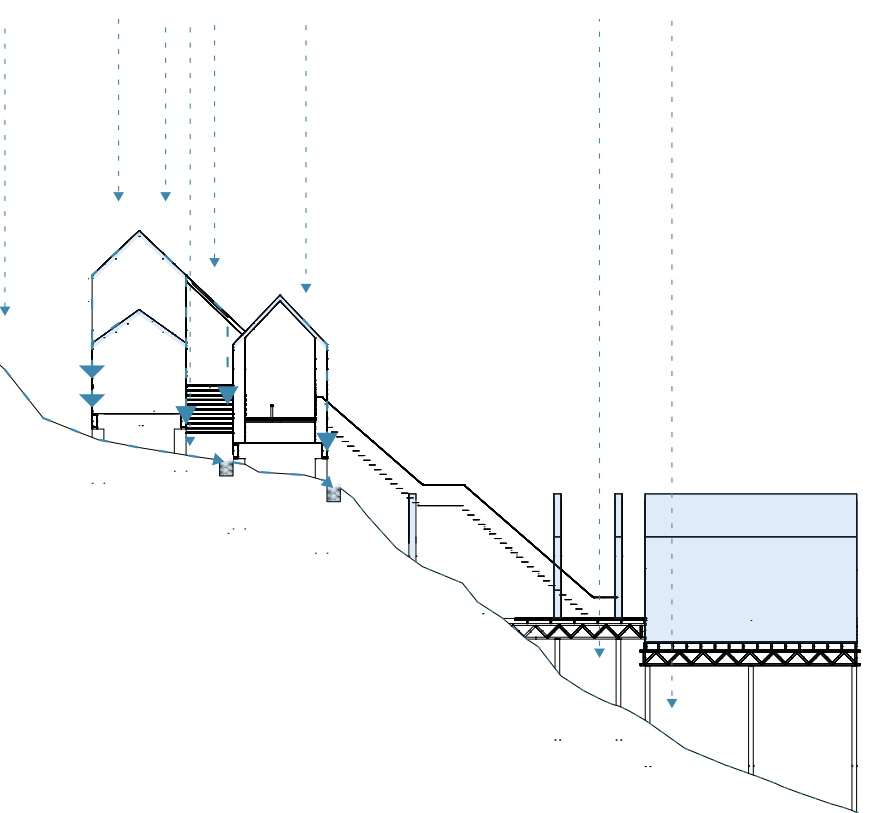

+Figure 6.43 Section showing water flow through baths and back to the river below.

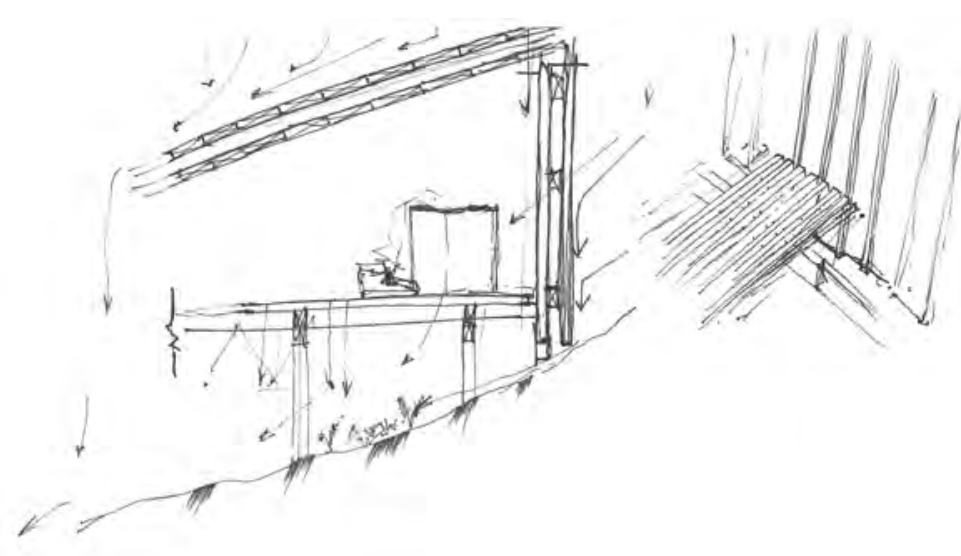

+Figure 6.44 Silver Pine wooden slat floors allow for the removal of water from dripping bathers.

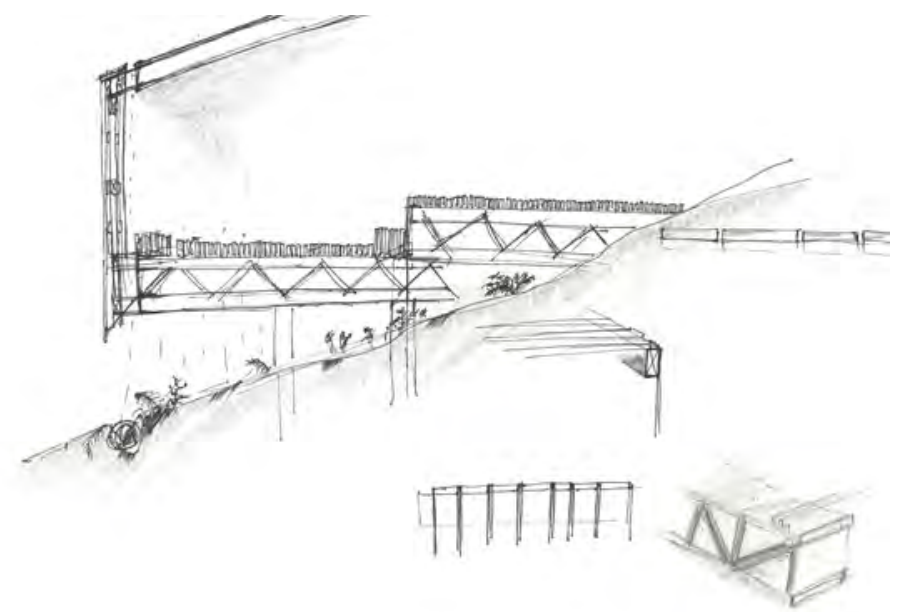

+Figure 6.45 Trussed structure is a gesture to the West Coast bridge, and allows for larger spans and therefore requires fewer foundation piles in the land. 


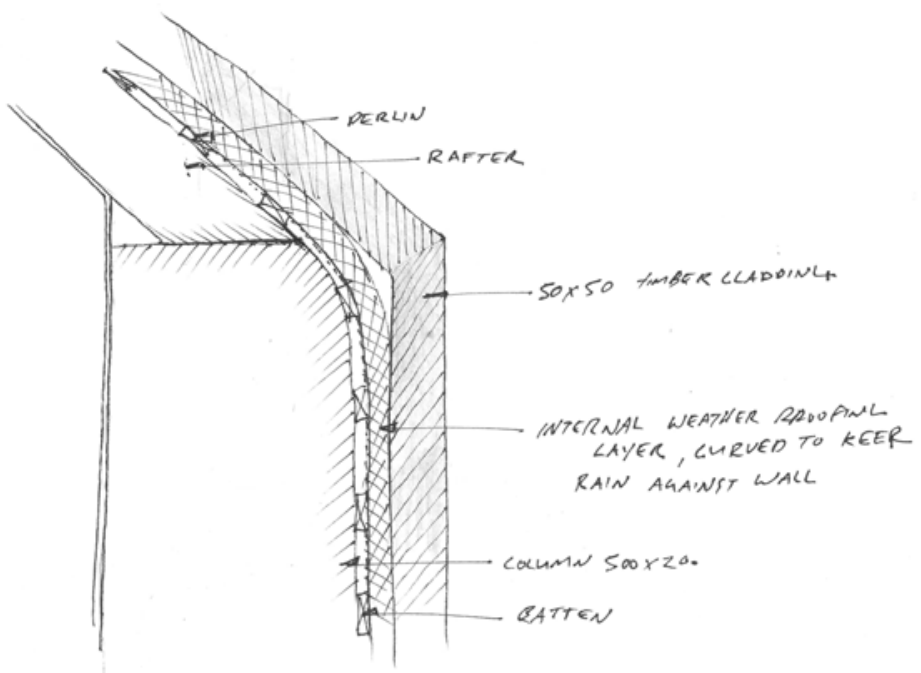

+Figure 6.46 Standard roof-wall junction detailing how the water flows over the curved surface to stay against the roof and wall to the ground. Silver Pine cladding is used for its durability and locality.

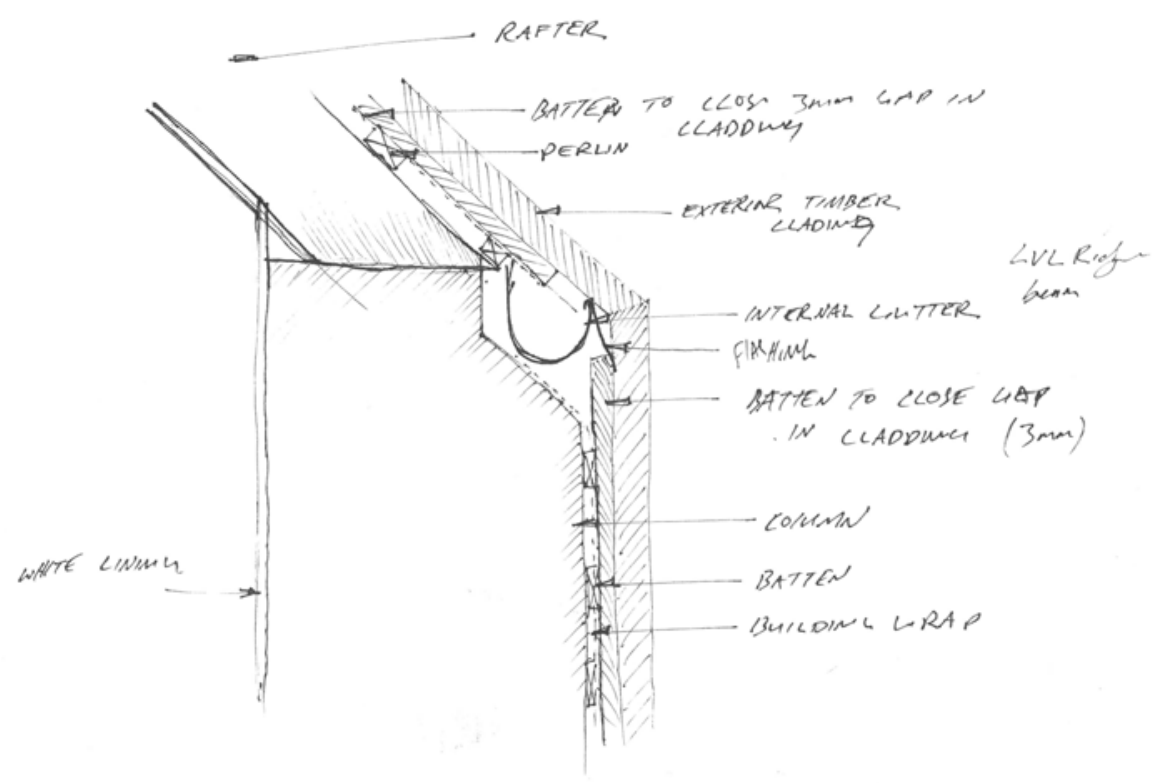

+Figure 6.47 Accommodation roof-wall junction detailing how the guttering collects water for use. 


\section{ARANGEMENT OF PROGRAMME}

Exact placement of programme and arrangement of programme on site was driven by the procession and journey through the spaces that a visitor would take in order to maximise their experience. There is a process of allowing and denying views to provide moments that prompt enlightenment.

莣
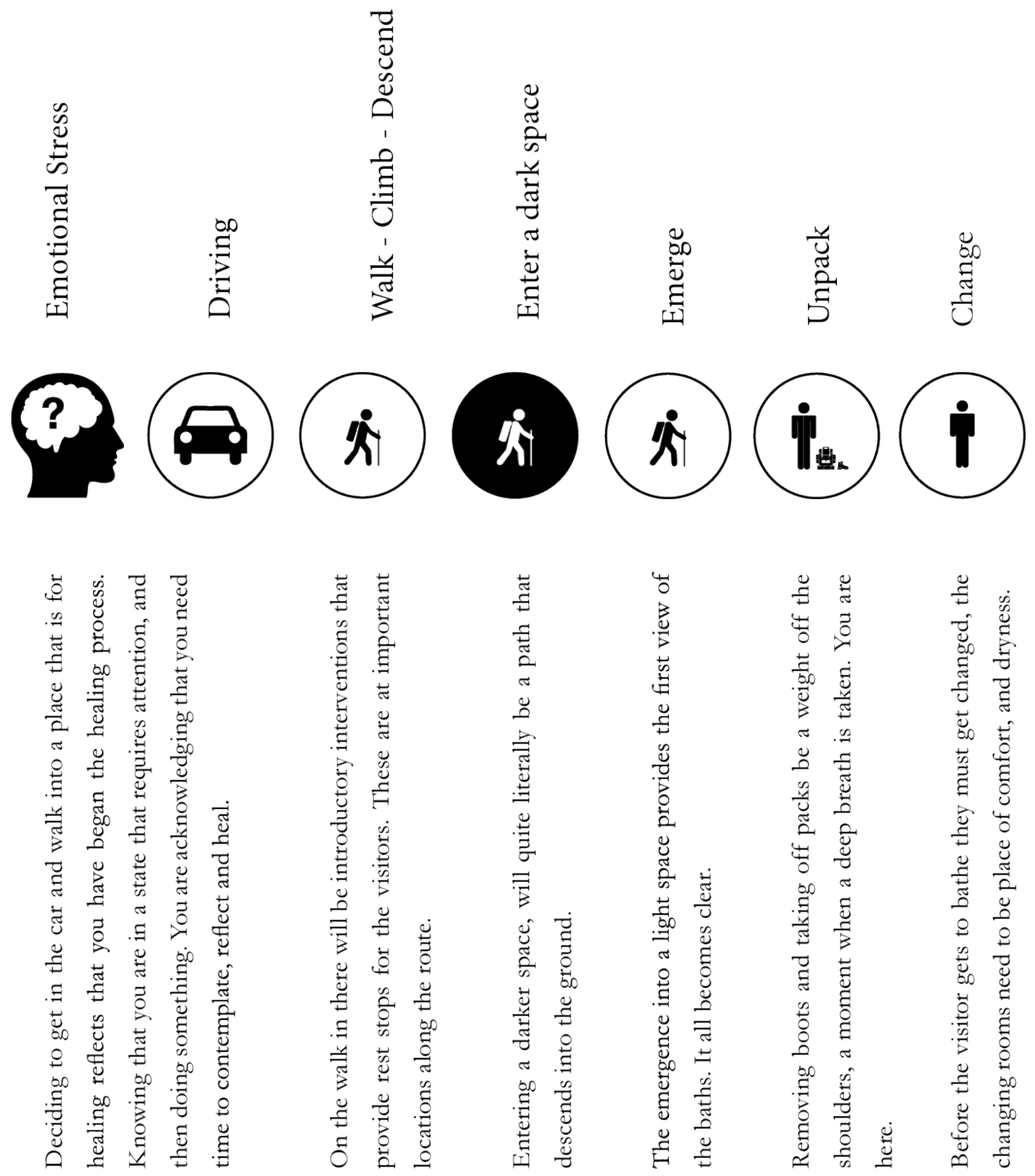


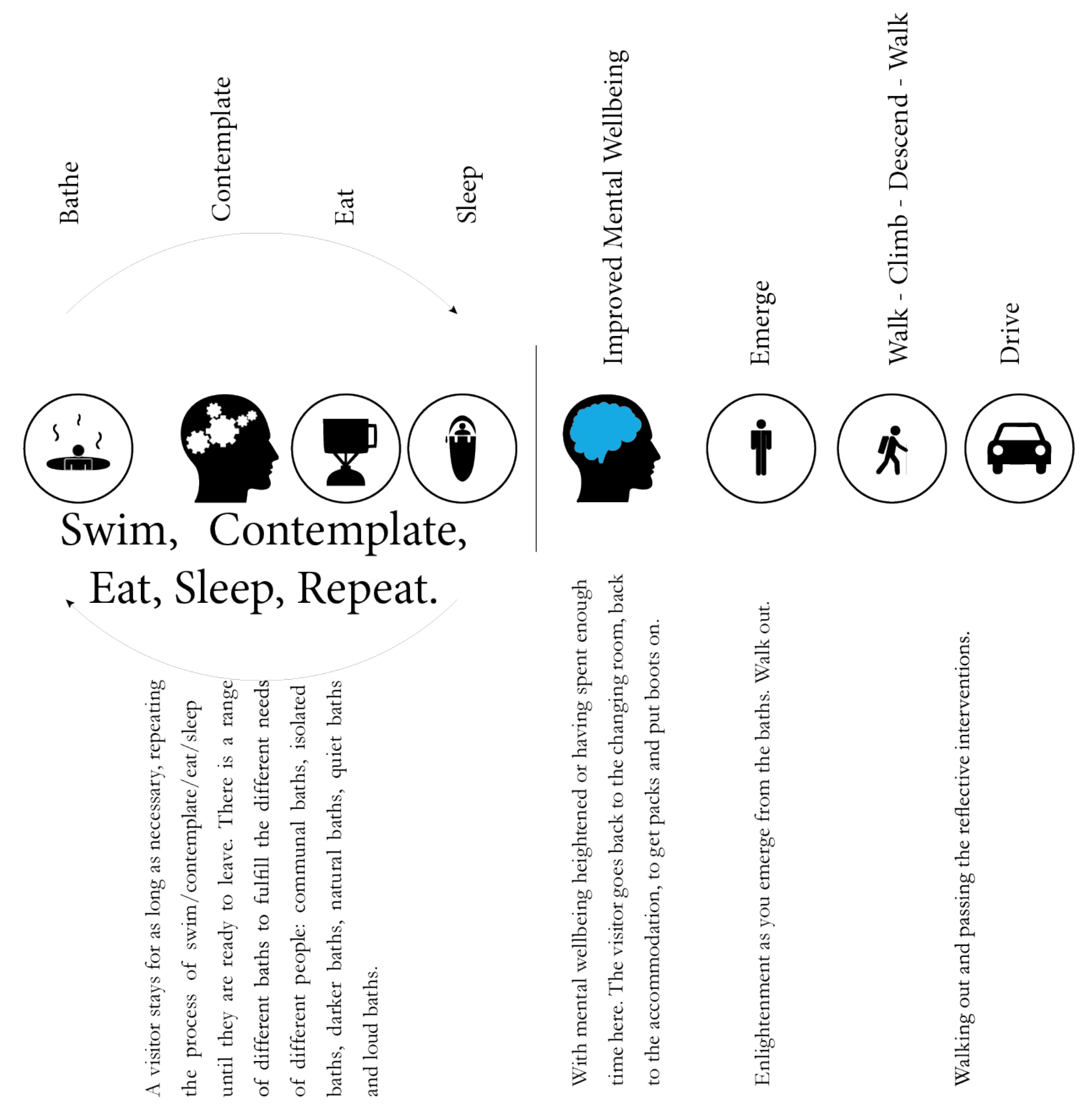




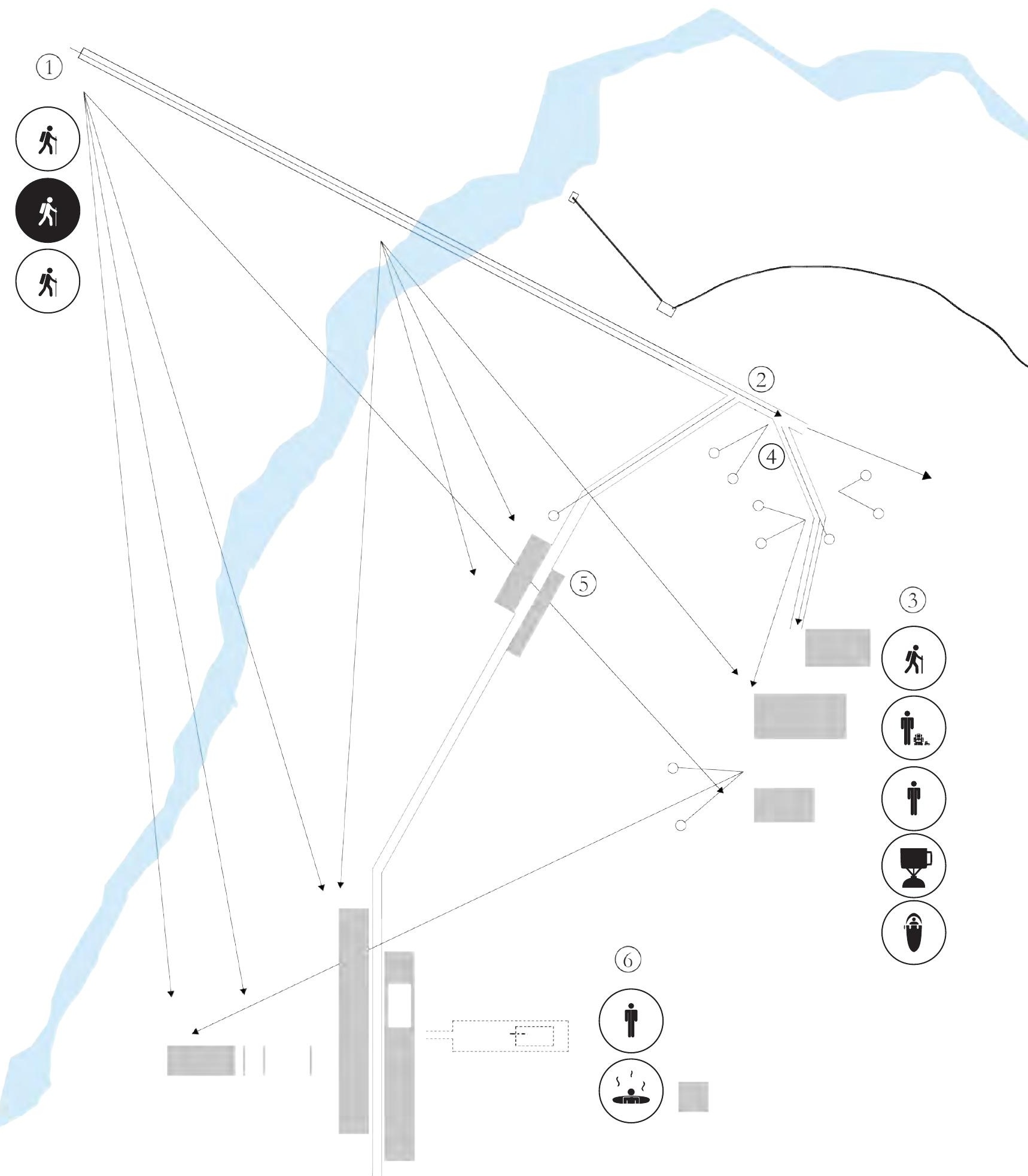

+Figure 6.49 Experiencing the baths is a processional process.

Permitted and denyed view shafts, bridge - accommodation. 


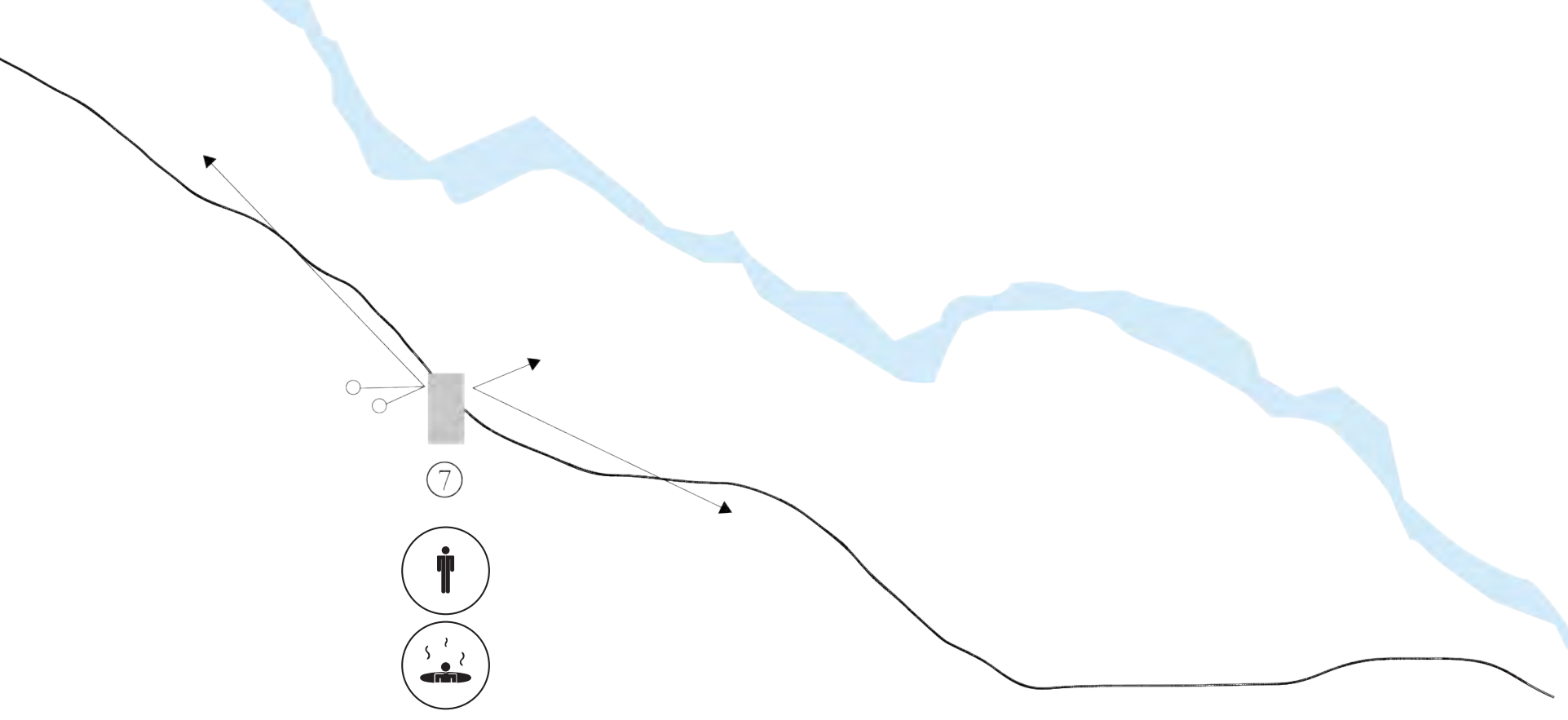

Key

1 Bridge Entry

2 The Cross Road

3 Accommodation

4 Access Walkway

m

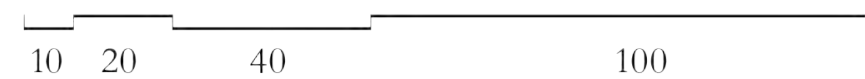

North

5 Changing Stalls

$\bigcirc$ Denied View

$\rightarrow$ Permitted View

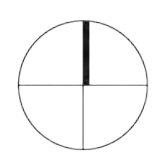



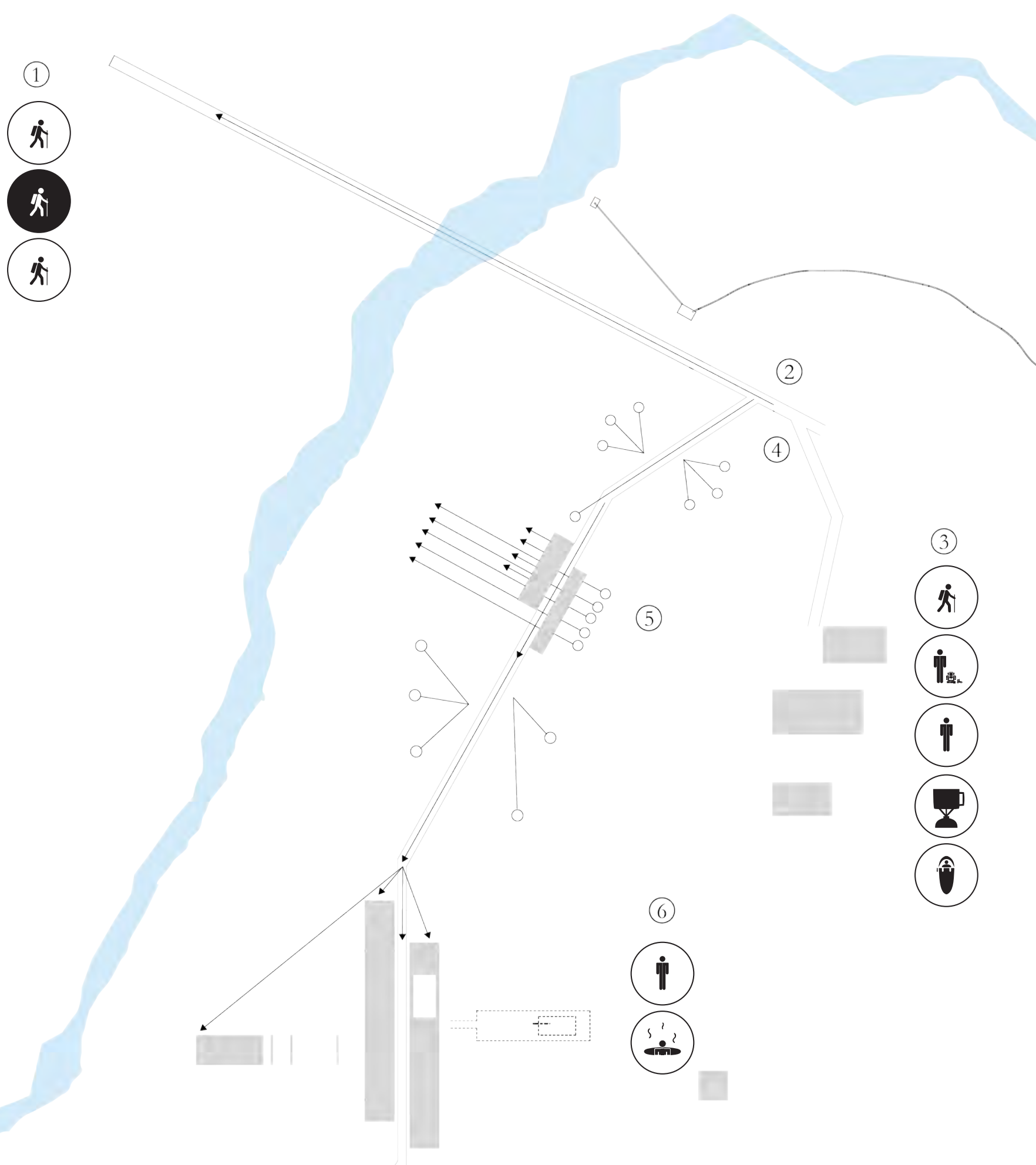

(4)

(3)

(5)

+Figure 6.50 Permitted and denyed view shafts, bridge - baths. 


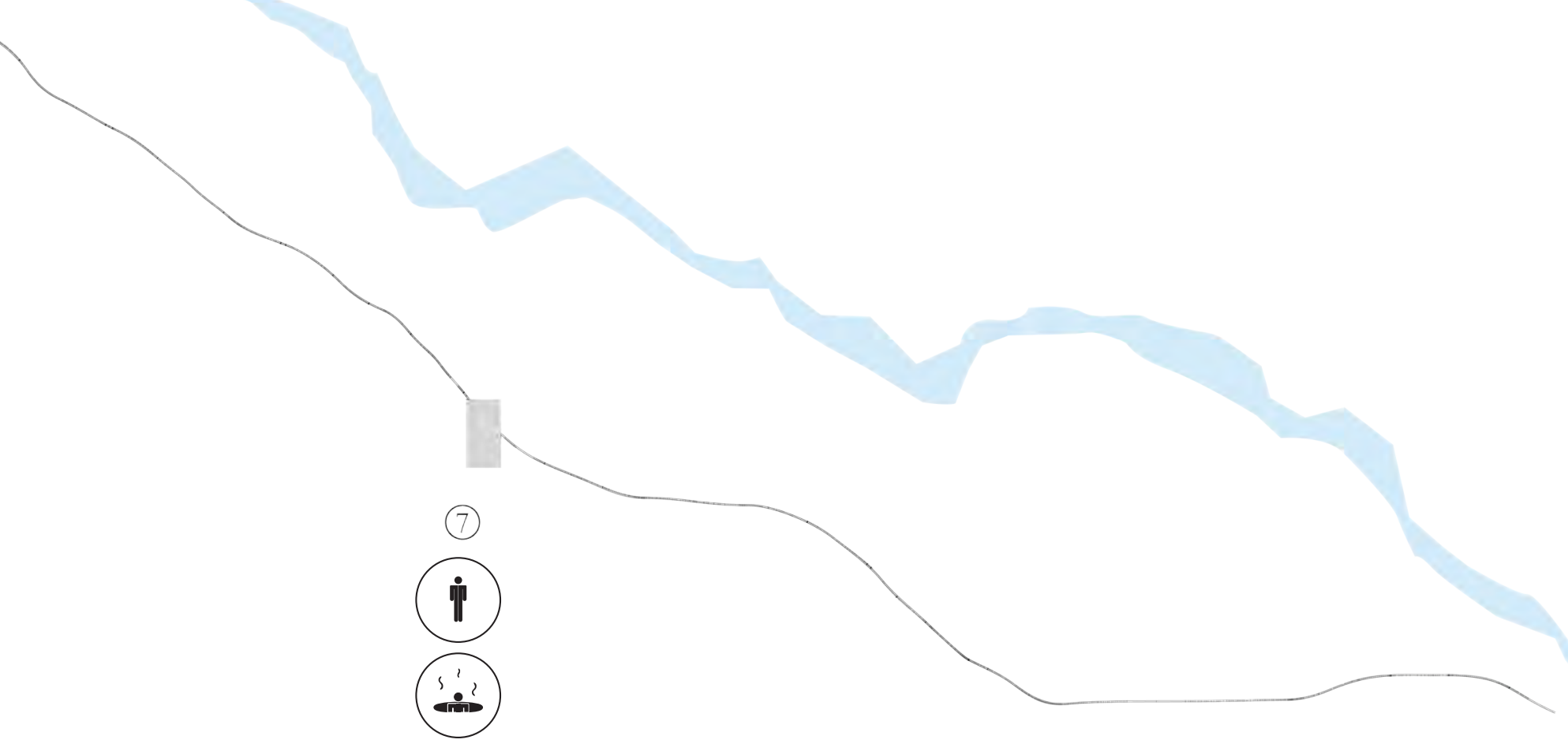

Key

$\begin{array}{llllll}1 & \text { Bridge Entry } & 5 & \text { Changing Stalls } & \text { O Denied View } \\ 2 & \text { The Cross Road } & 6 & \text { The Main Baths } \\ 3 & \text { Accommodation } & 7 & \text { The Bath of Isolation } & \rightarrow & \text { Permitted View } \\ 4 & \text { Access Walkway } & & \end{array}$




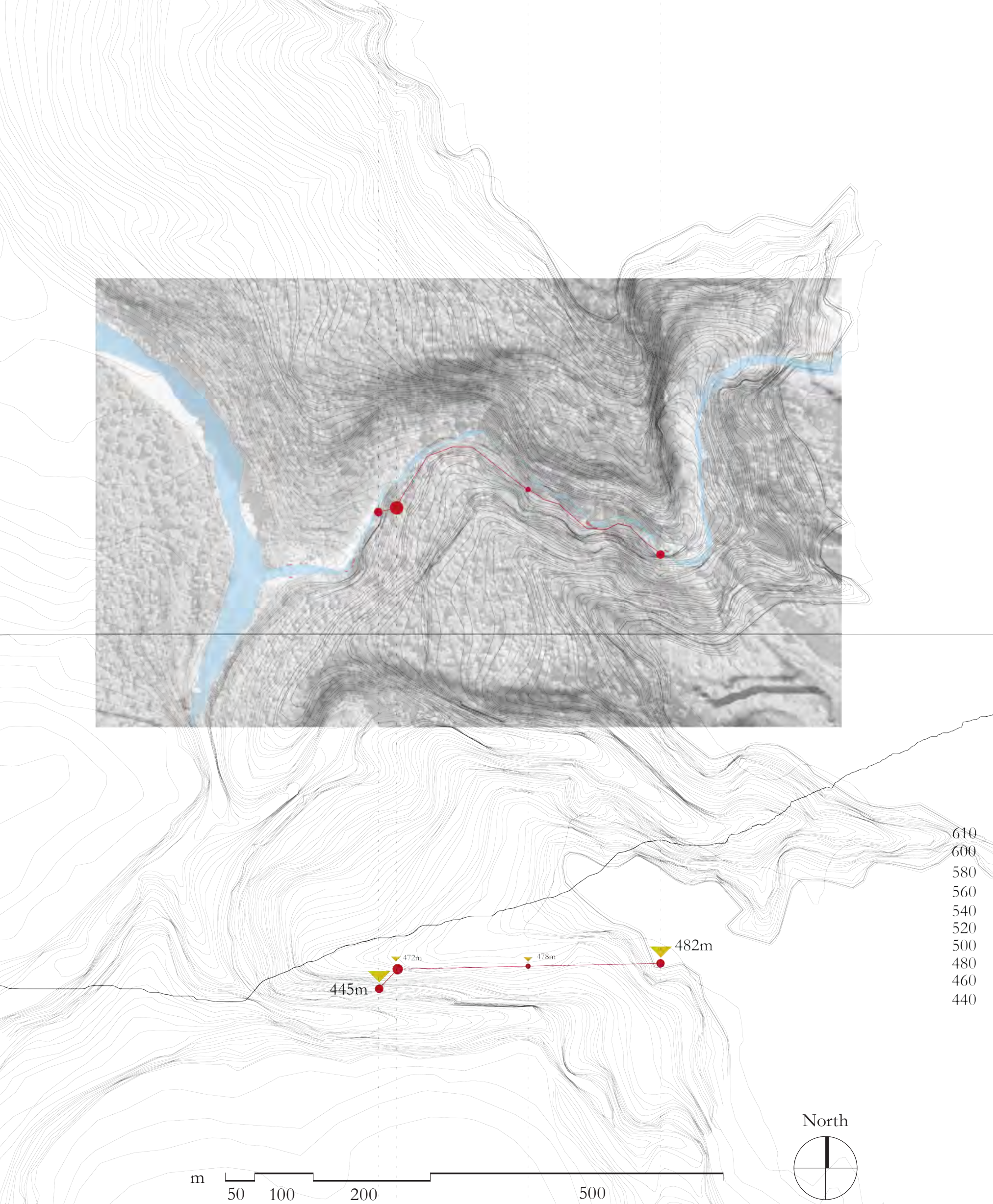

+Figure 6.51 Plan and section of gravity powered hot water retrival. 


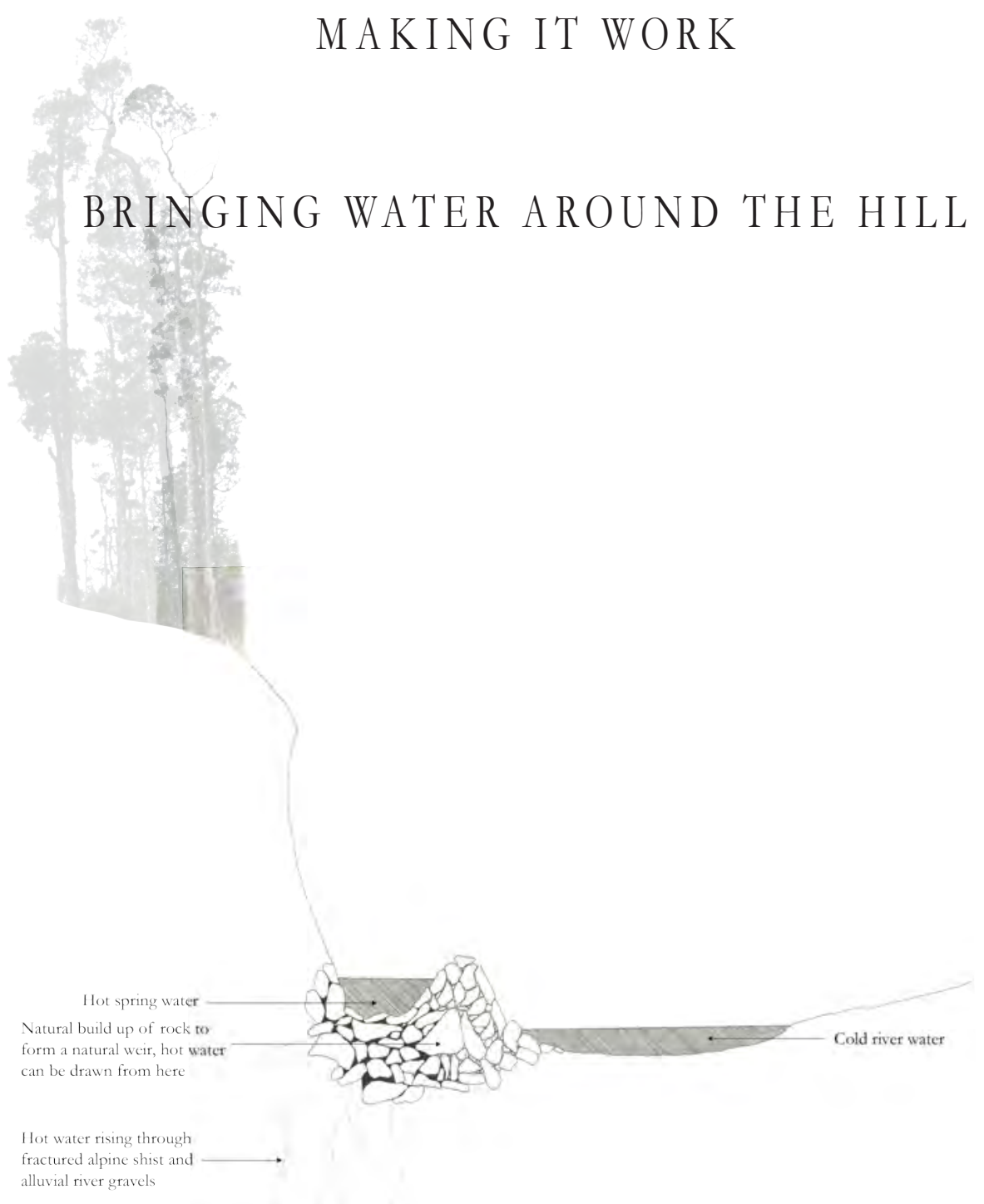

+ Figure 6.52 Section of hot water weir and river

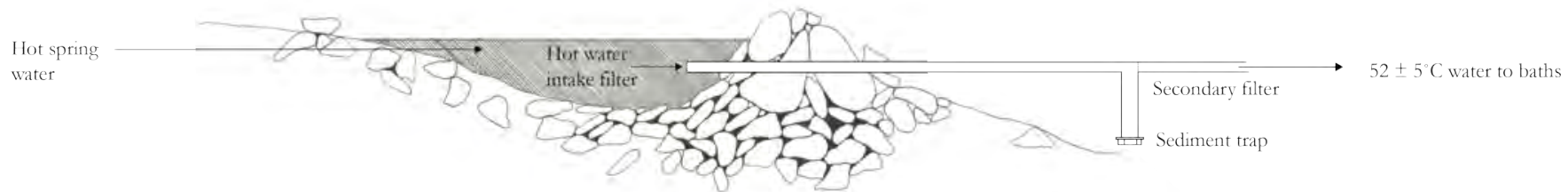

+Figure 6.53 Section of hot water intake. 


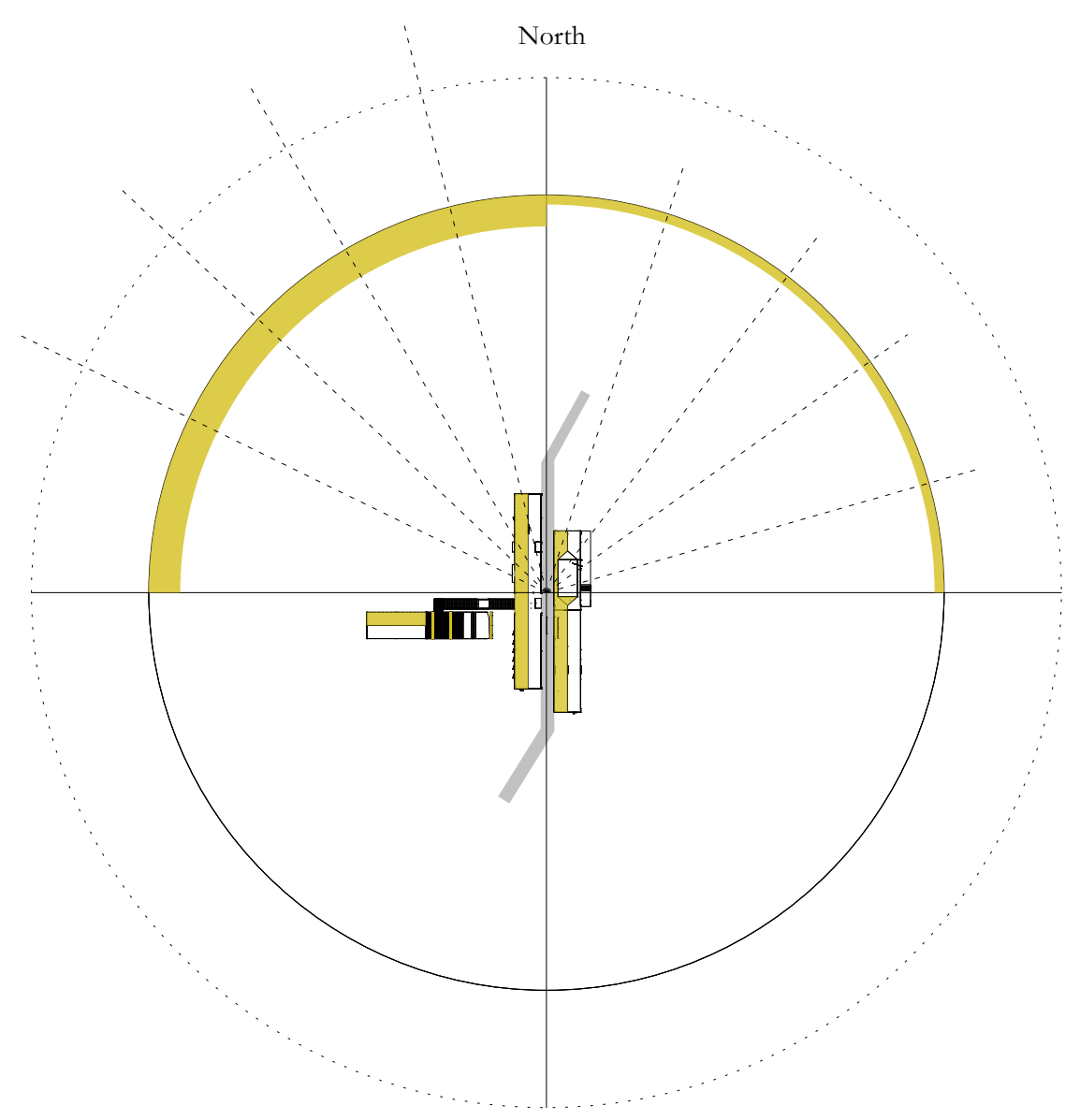

+ Figure 6.55 Relationship between orientation of building and possible PV panels.

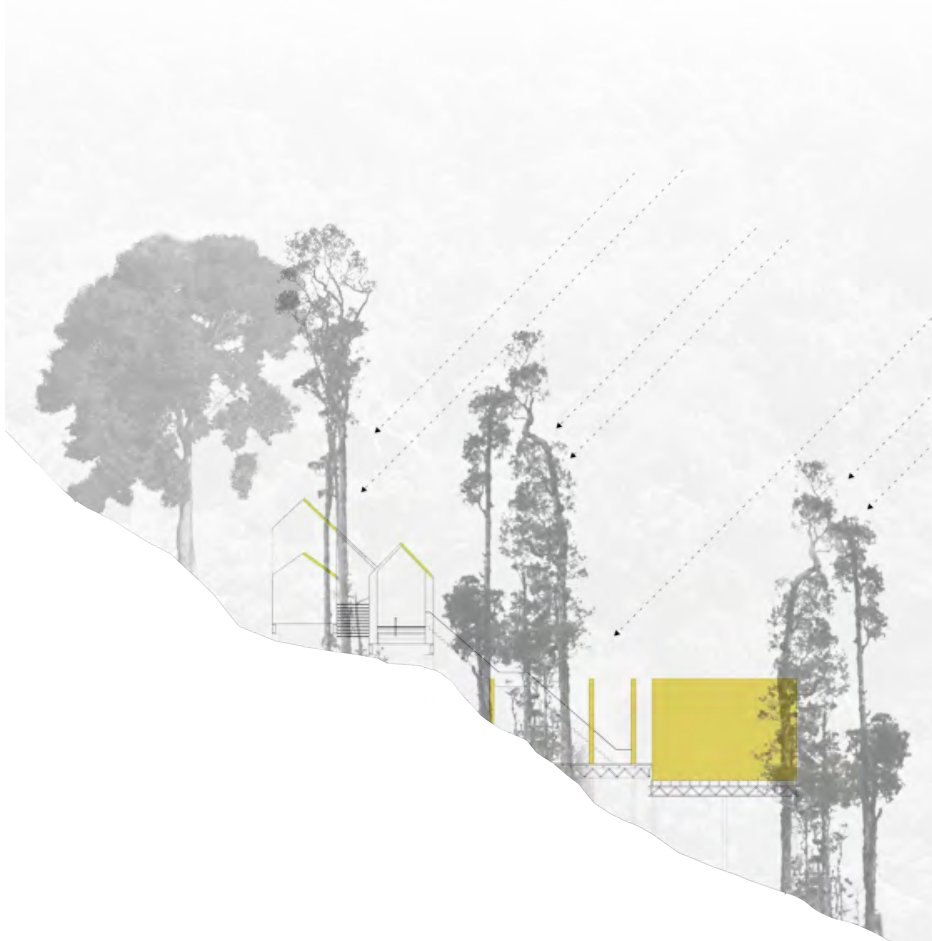

+Figure 6.54 Relationship between canopy and possible PV panels. 


\section{ELECTRICITY GENERATION EXPLORATION}

PV panels

The zero impact visually or physically on the landscape, the low maintenance and easy transportation are all positives. However, the little natural daylight in winter to power the panels, high rainfall, constant cloud cover and surrounding forest would not be conducive to PV panels.

\section{Wind turbine}

The lack of clear areas, the extremely hard if not impossible transportation and the high level of visual and physical impact onto the landscape makes this an unreasonable option for Wren Creek. 


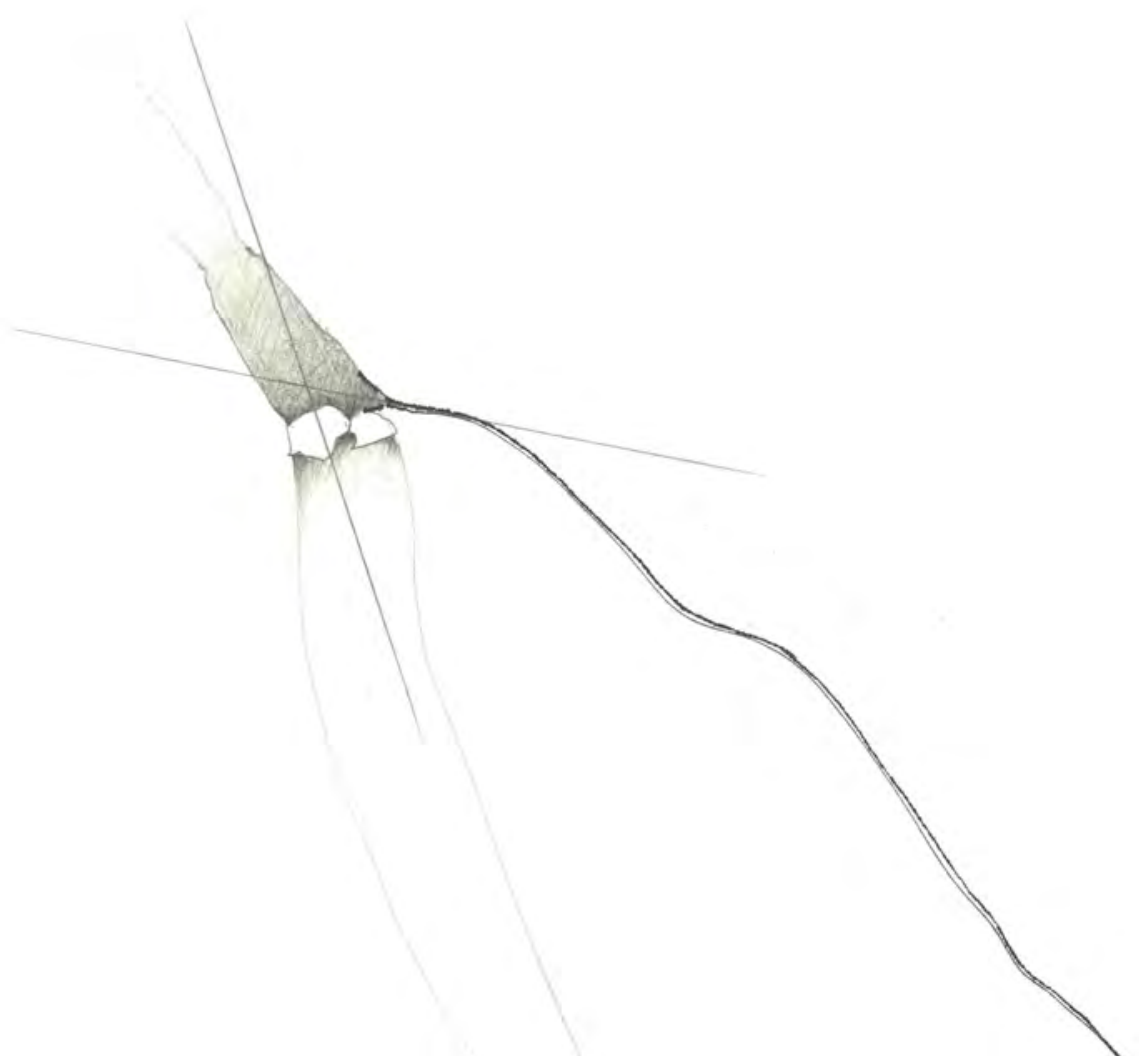

+Figure 6.56 Plan of intake of micro hydro scheme. This reticulation of water is reminiscent of the water supply (fluming) for gold sluicing.
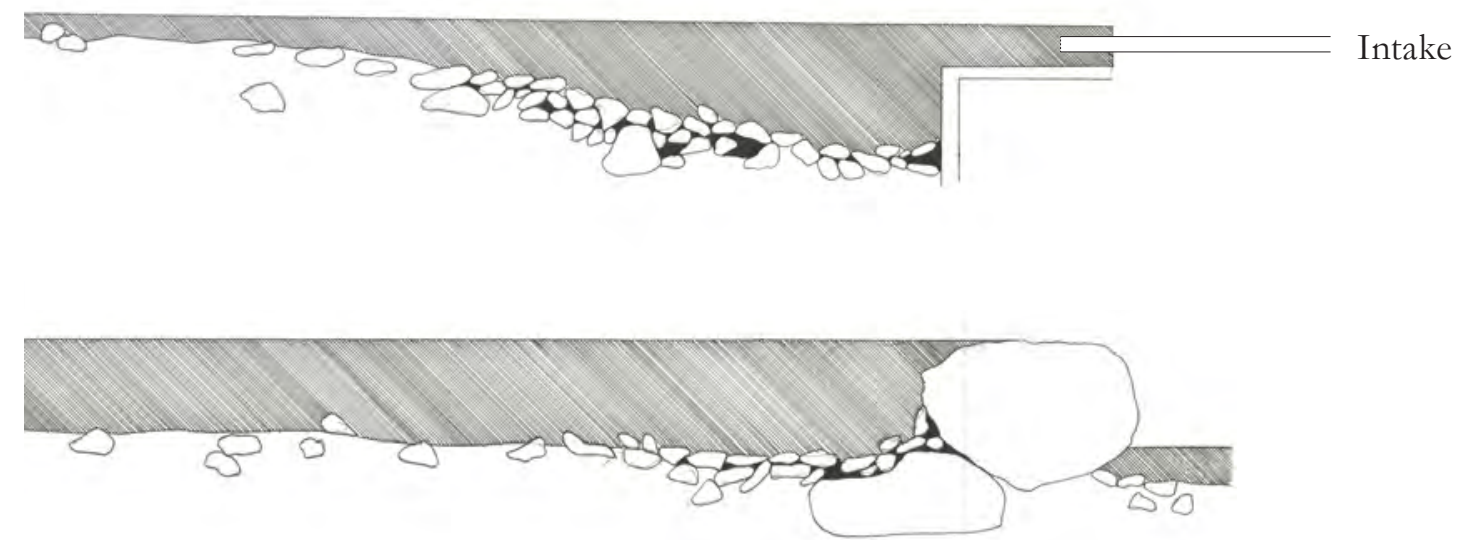

+Figure 6.57 Sections of intake of micro hydro scheme. 
Micro bydro scheme

The high flow levels in winter and spring suit the use of a micro hydro scheme as maximum power will be provided throughout the winter when required. Once in place there is little maintenance required, and on site staff can solve any problems that arise.

Any major impact on the environment can be mitigated through the incorporation of adequate passages up the weir to allow for the migration of native fish species to preserve the water ecologies. This would involve the weir design having a spillway that the juvenile Banded Kokapu and Giant Kokapu could easily climb. Any major visual impact can be mitigated through the use of natural looking features rather than smooth concrete.

The turbine would produce $>24 \mathrm{~V}$ to counteract the loss in voltage through the line to the accommodation.

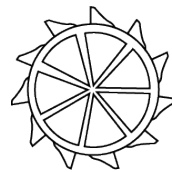

Turbine

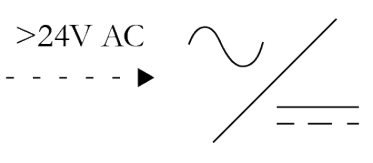

Rectifier

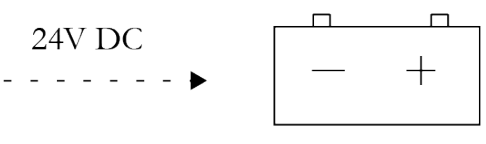

24V DC

Battery Bank 

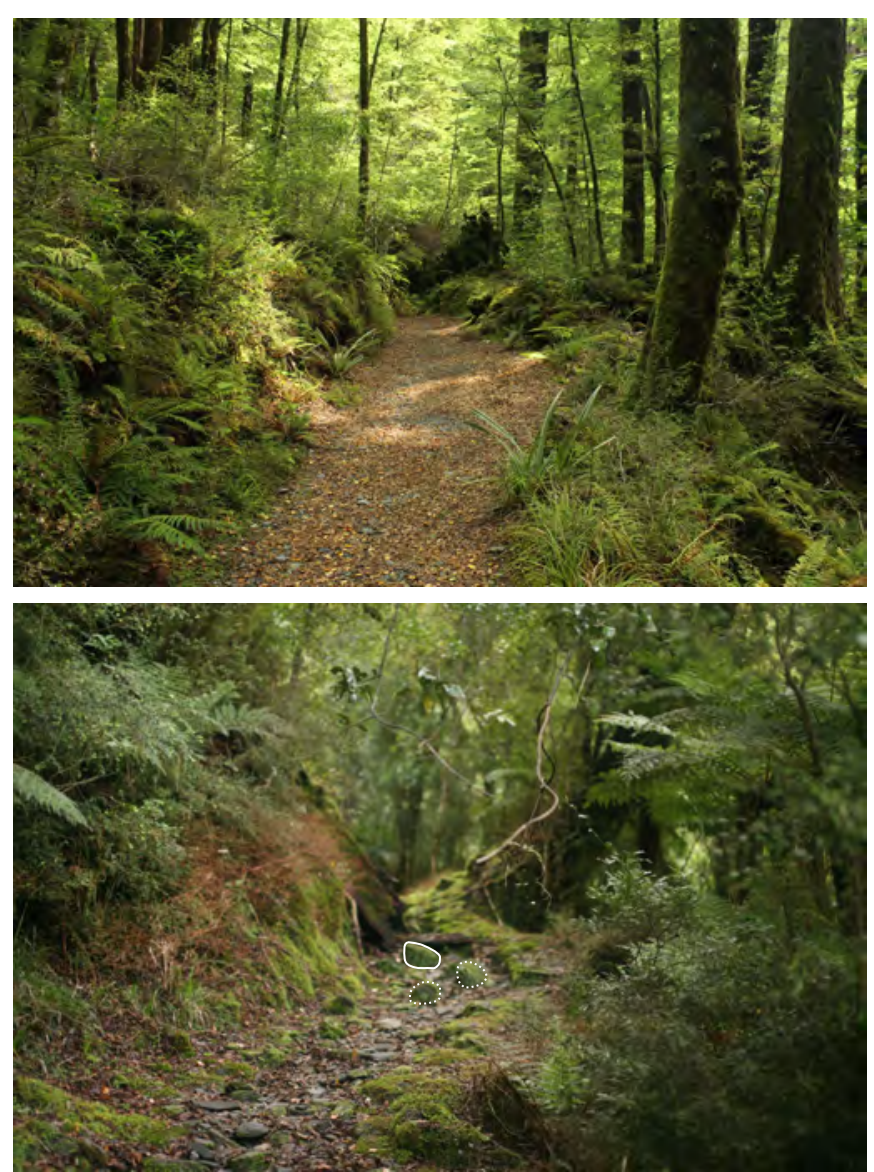

+Figure 6.58 Easy section of track.

+Figure 6.59 Rocks requiring attention on moderate section

of track.

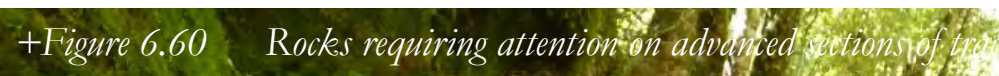

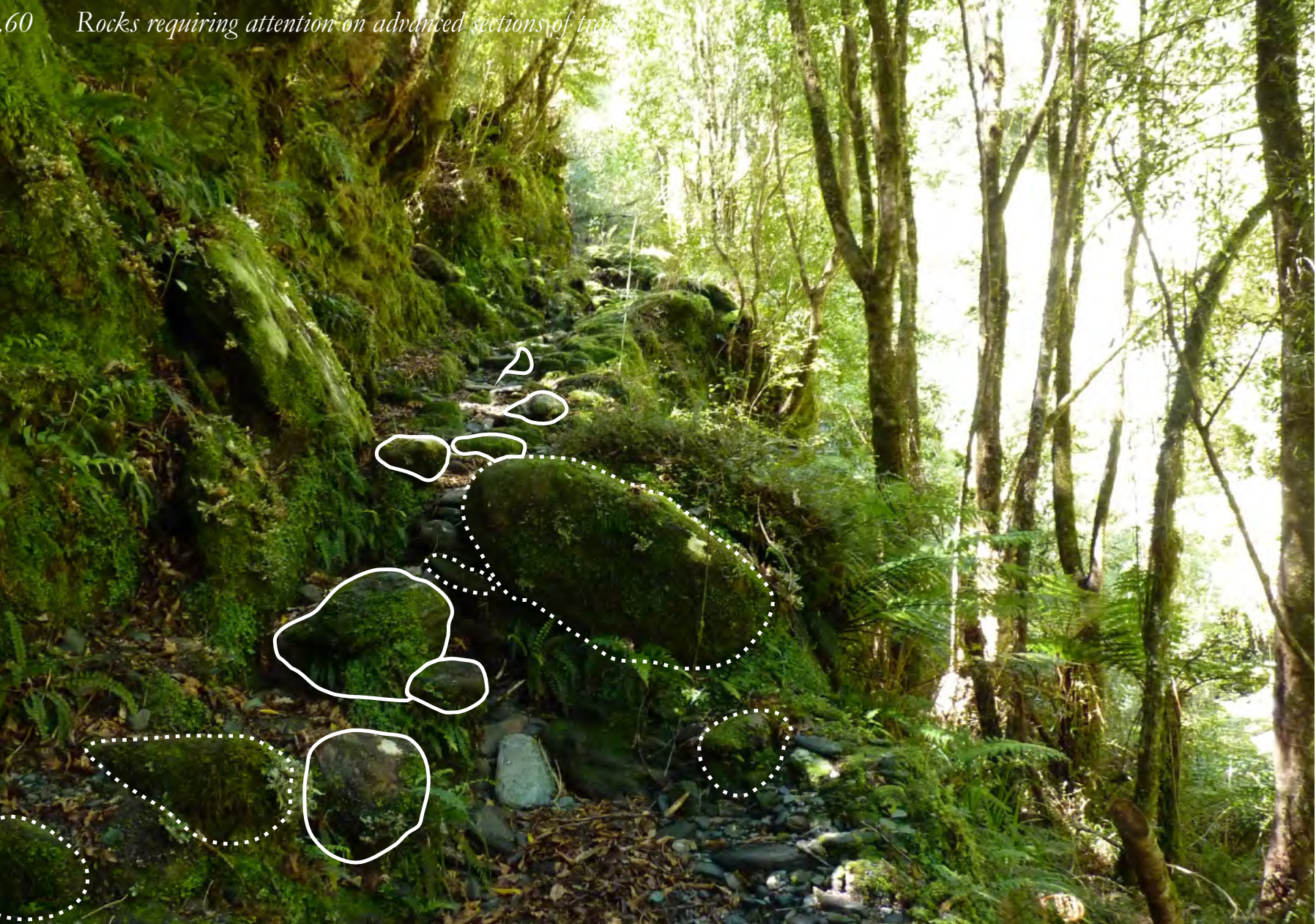




\section{TRACK QUALITY}

The quality of track ranges from a very high standard with little to trip on, to a much rougher track with many tripping hazards.

The Department of Conservation currently rates the track as advanced due to the rough conditions in its current state. With work the track difficulty can be lowered to an intermediate track by some maintenance and removal of some rocks to minimize the tripping hazard. 


\section{THE HELI-PAD}

Touchdown and lift-off areas (TALO), with diameter 1.5 times the length of the undercarrage of the served helicopter (CAA 6).

Final approach and take-off area (FATO), with diameter 1.5 times the length of the served helicopter (6).

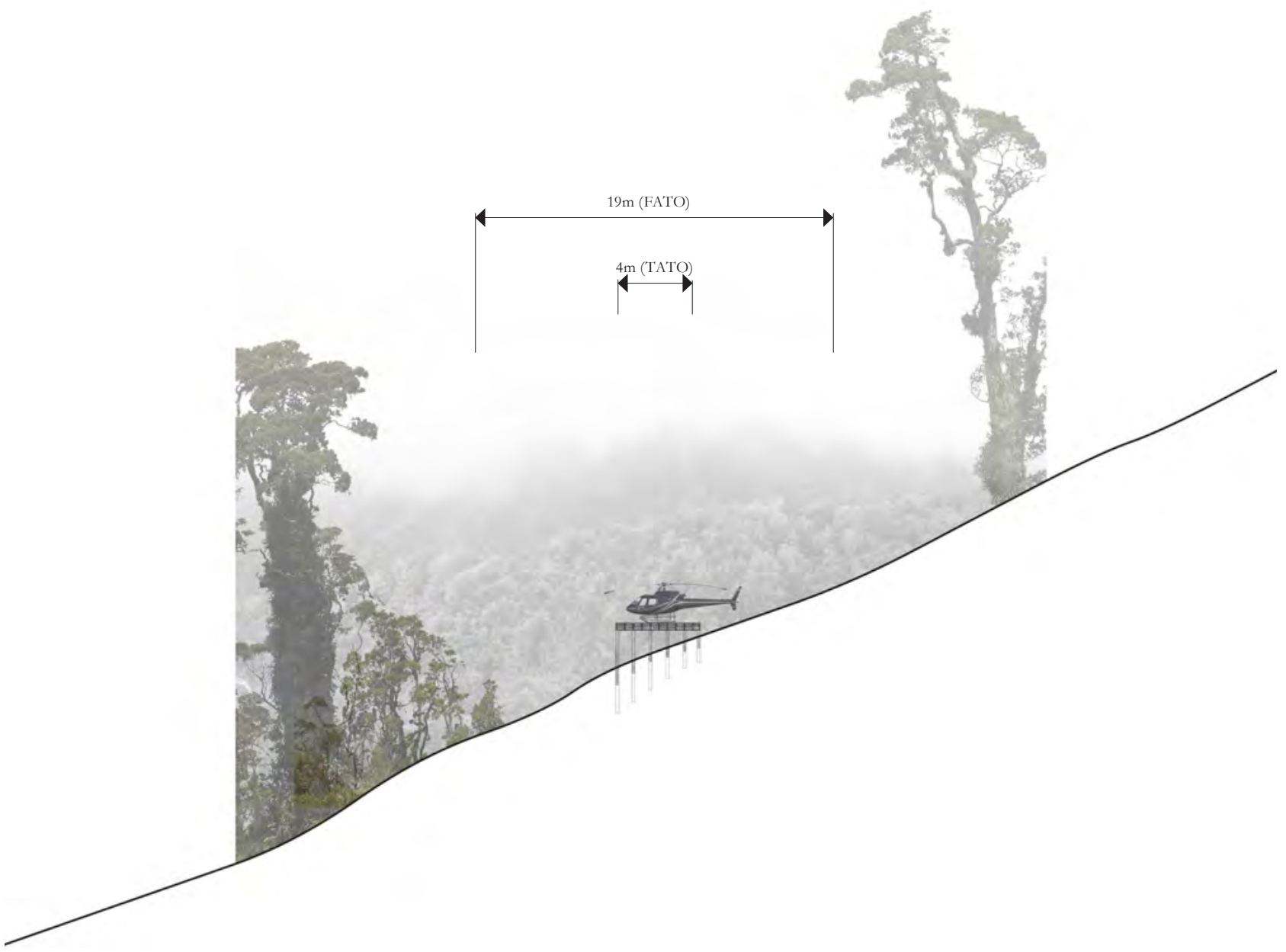

+Figure 6.61 Helicopter pad dimensions. 


\section{CONCLUSION}

The Arahura Baths are light. Where the building frames the close ground or when the baths extend underground they exhibit areas of intimacy, and when framing the sky they exhibit areas of the infinite. The larger collective spaces expected to be talked in exhibit Halbwaches' method of memory provocation emphasised with an obviously loud amount of water audibility. The underground baths surrounded by water with wet cold unfinished walls may induce a mental response, an involuntary memory recall from the bather.

The Kokiri Baths are darker spaces that frame very specific, considered scenes across the valley. Darkness is controlled through the spacing between the slats in the floor and the size of openings. This building has an individual experience where there are areas with baths for one. These have the sound of water being quieter in hope of people lowering voices but communicating between singular baths. There are also contemplative spaces that have no baths allowing for a moment of reflection out of water.

The Kotuku Baths are light. They frame one specific scene (Mt O'Connor). The water runs out the end of the building and crashes on the ground below to return to the river, thus there is a loud sound of water hitting trees and ground. This bath exhibits both Halwbaches' and Proust's methods of memory recall as there are areas underground where it is darker and the bare rock walls are wet and cold to the touch, but also larger baths that could prompt verbal communication. 

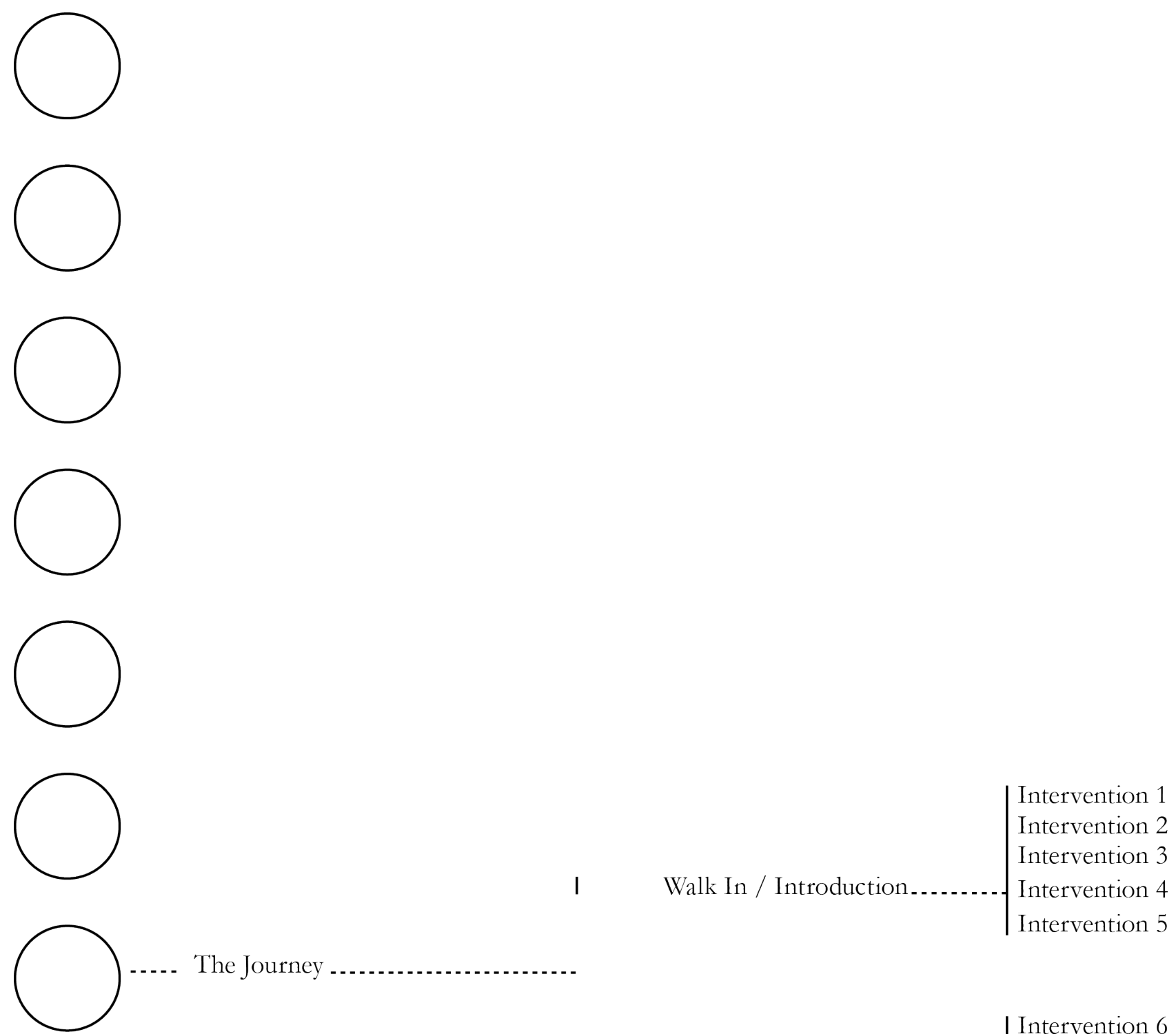

'The Journey 


\section{THE JOUR NEY}

// 7 //

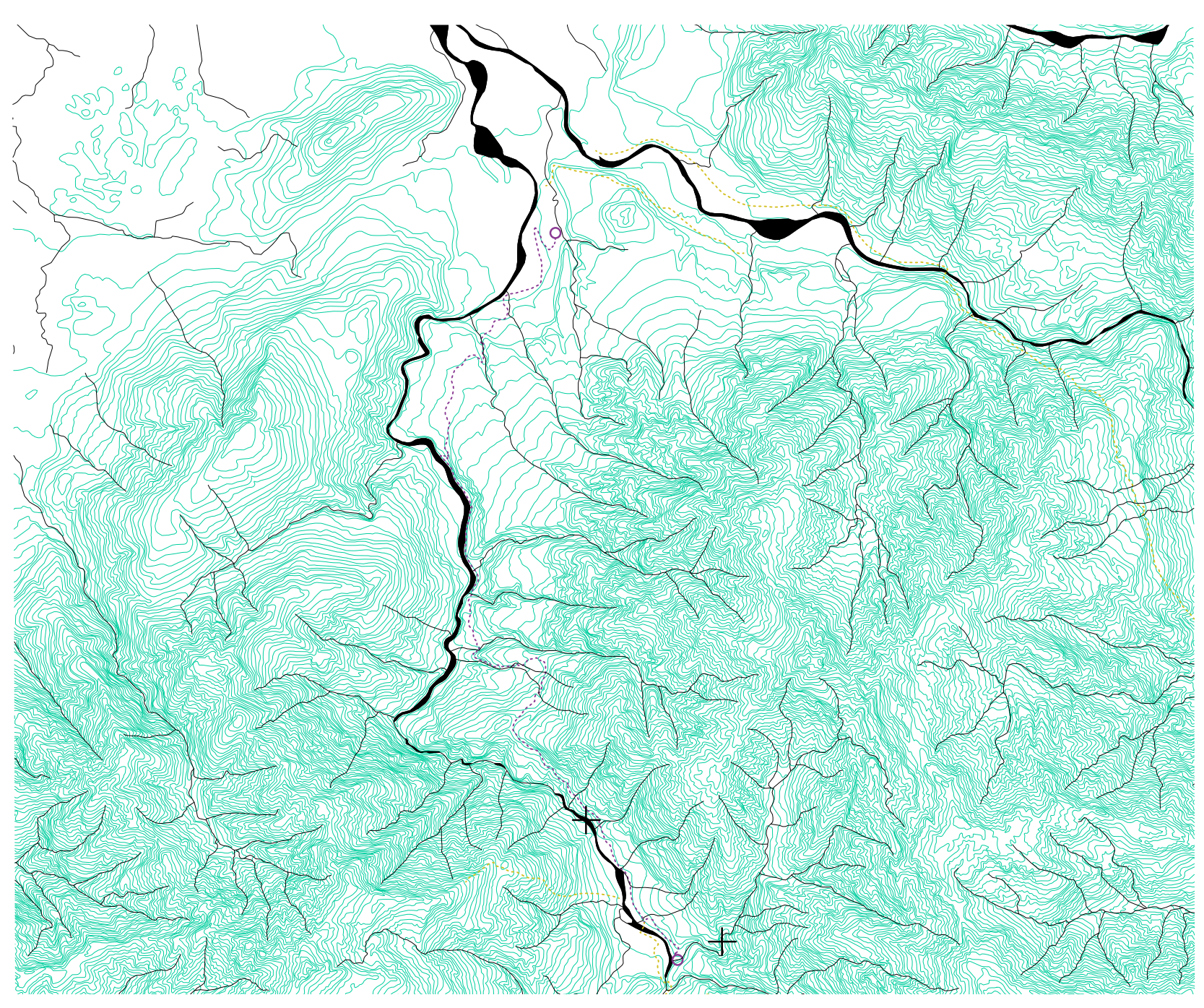



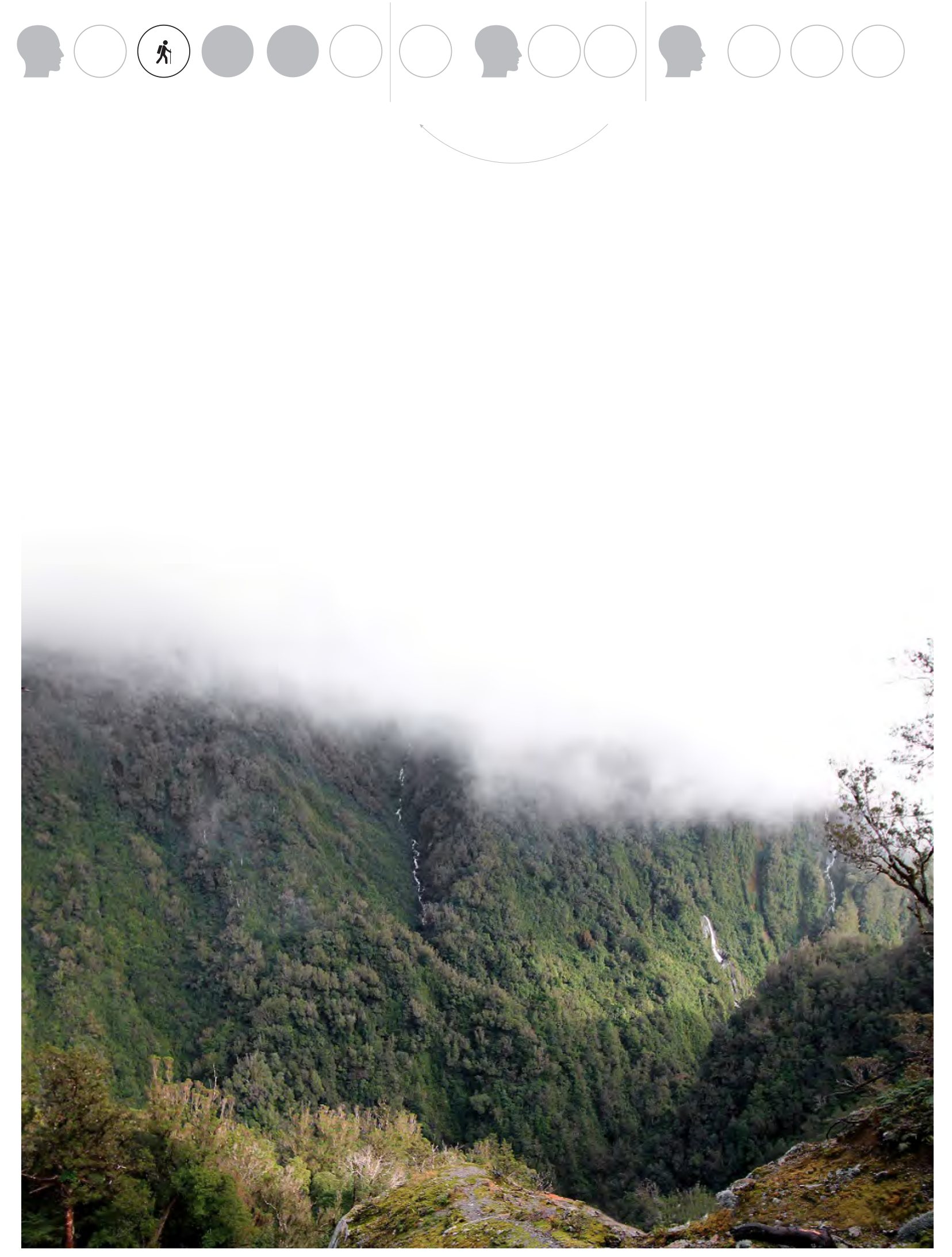

+Figure 7.01 View From Intervention 3. 


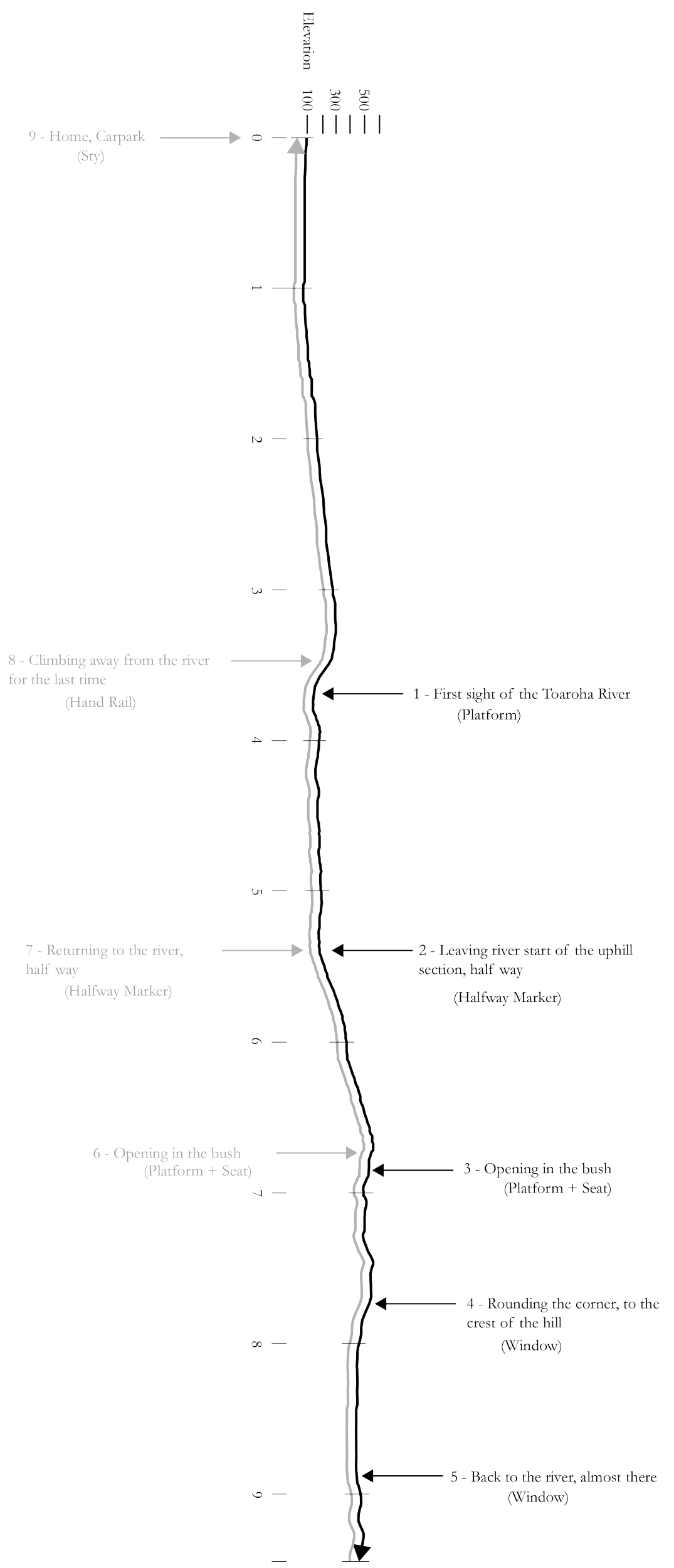

+Figure 7.02 Linear section of inwards journey with interventions. 


\section{WALK IN}

The healing process is initiated on the walk in, walking for four hours can prompt mental stimulation. A visitor will be confronted by five interventions during the walk in. The five interventions are positioned at specific geographical locations where a person would naturally stop. These provide an introduction to the memorial and play an educational role to the visitor. They give insight into the darker sides of mining in the area, providing gravitas to the memorial.

\section{INTERVENTION 1}

It is designed to educate visitors on the prevalence of drownings. On the West Coast they became so common during the mining era they were coined, 'the New Zealand death' (Pascoe 7). Providing a moment of rest, this intervention serves to warn visitors on the danger of flooded rivers.

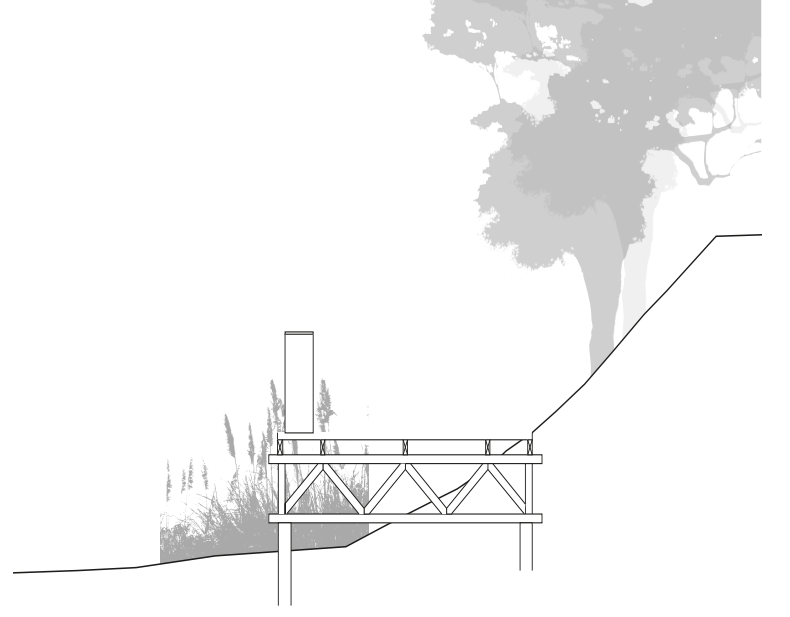

+Figure 7.03 Intervention 1 showing box to provide education.

+Figure 7.04 Intervention 1.

$\mathrm{m}$

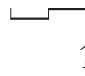

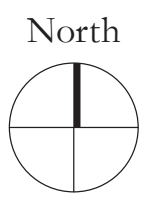




\section{INTERVENTION 2}

This point is to educate visitors on the subsequent family dynamics of a woman left at home that became common through mining disasters. As the midway point of the walk in, it will give walkers peace-of-mind knowing that they are closer to the destination than the beginning. It would comprise of some simple text.

\section{INTERVENTION 3}

Located at a slip on the accent where the bush opens up to views to face of beech forest across the valley. The platform and seat here are orientated toward the view back down the valley, providing visitors with a sense of achievement. This platform works to shed light on the felling and burning of swathes of bush native (Bishop and Walker 100) and the ruining of land that comes with dredging.

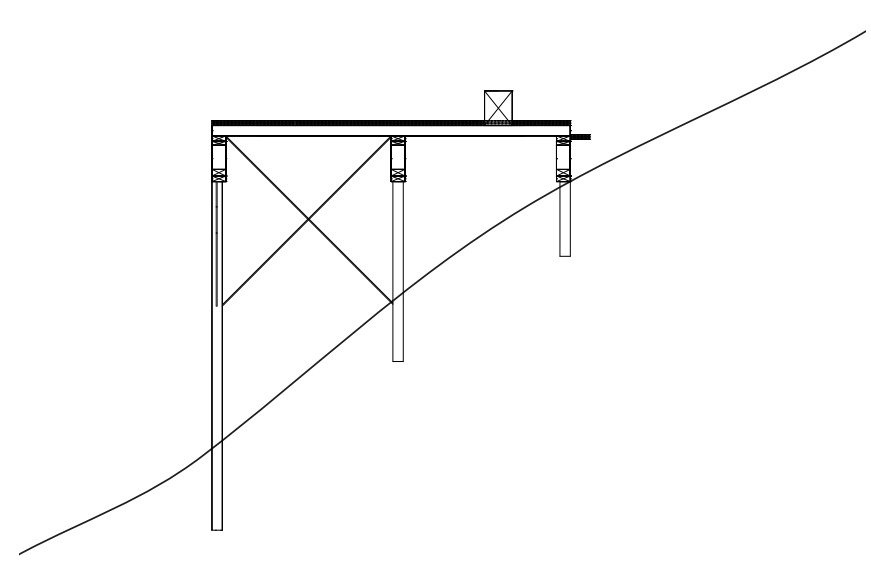

+Figure 7.05 Intervention 3.

+Figure $7.06 \quad$ Intervention 3.

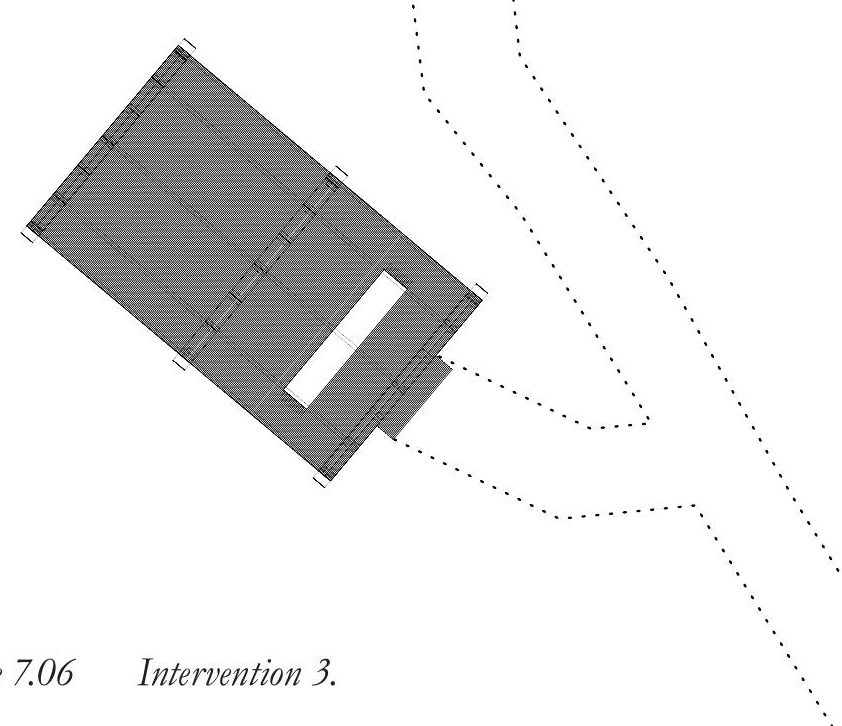

$\mathrm{m}$

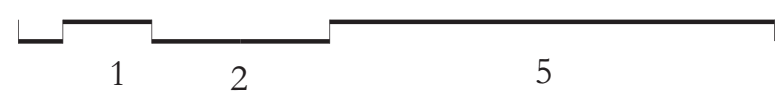

North

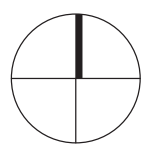




\section{INTERVENTION 4}

Atop the hill is a window framing a distant hillside. Through text it serves to give visitors an insight into the use of toxic chemicals during the gold extraction process.

\section{INTERVENTION 5}

This is a welcome sight, as it is the point where the visitors return to the river giving people the confidence that they are almost there. Also marked by a window, it describes the drinking culture associated with the West Coast and explains how the pub was a meeting place offering respite at the end of the day. It will hopefully invite visitors to make the connection that these baths can be a substitute to the historic pub for a site to resolve their problems.

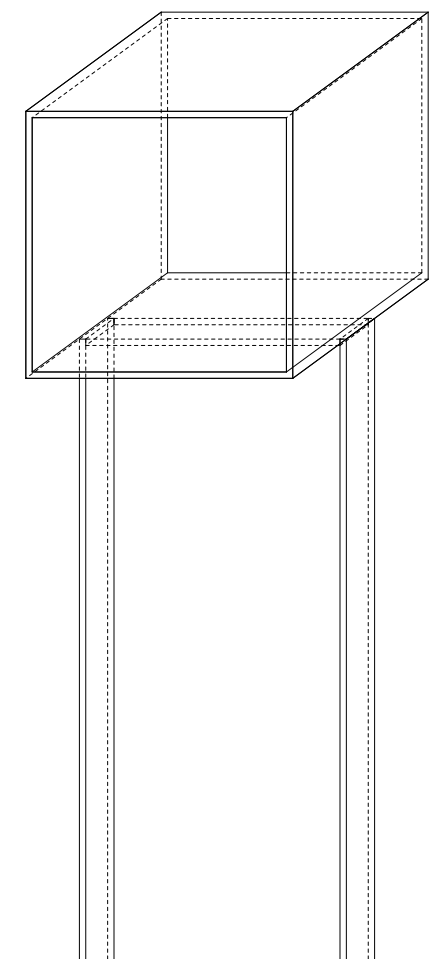

+Figure 7.07 Interventions 4 and 5 . 


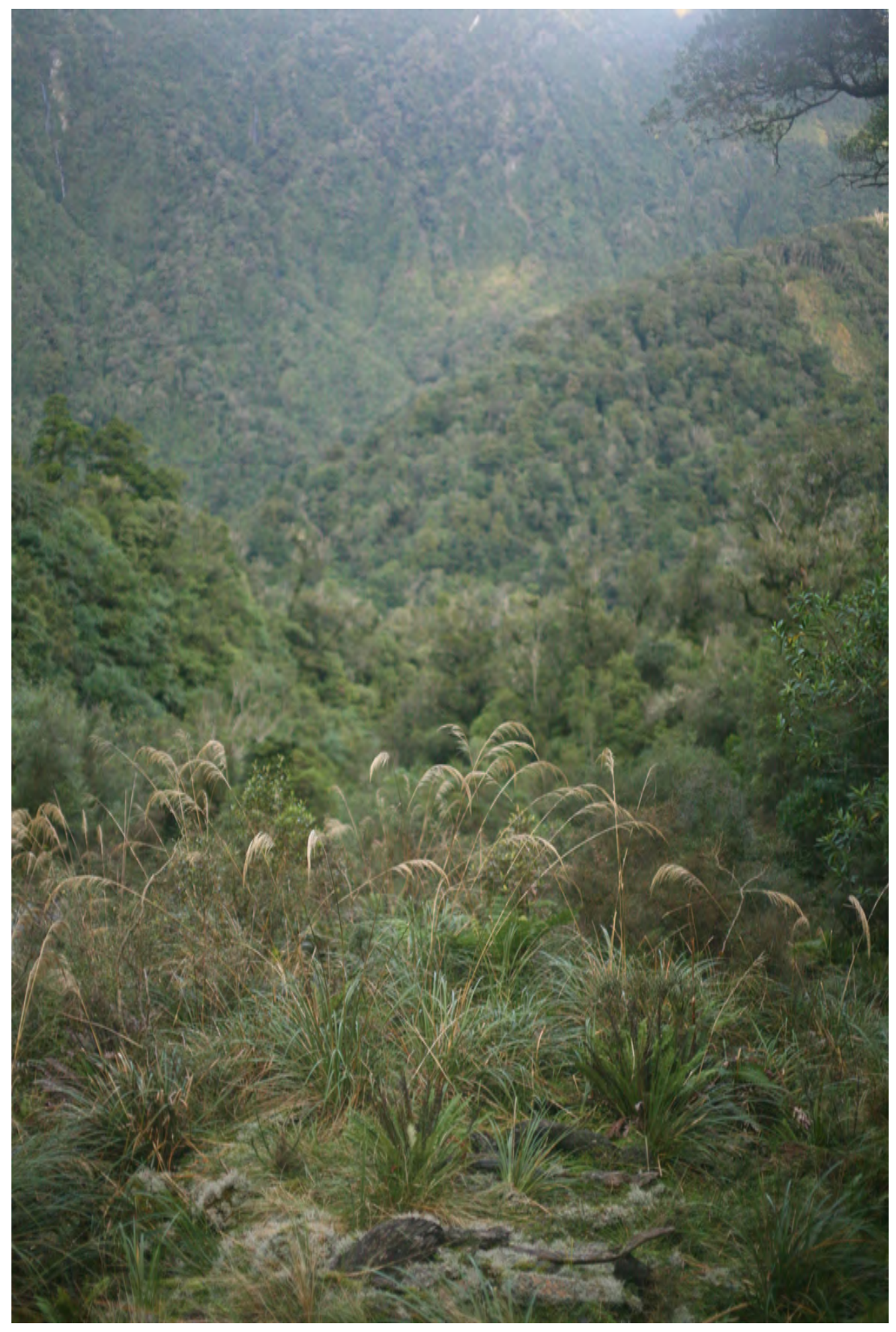




\section{0}

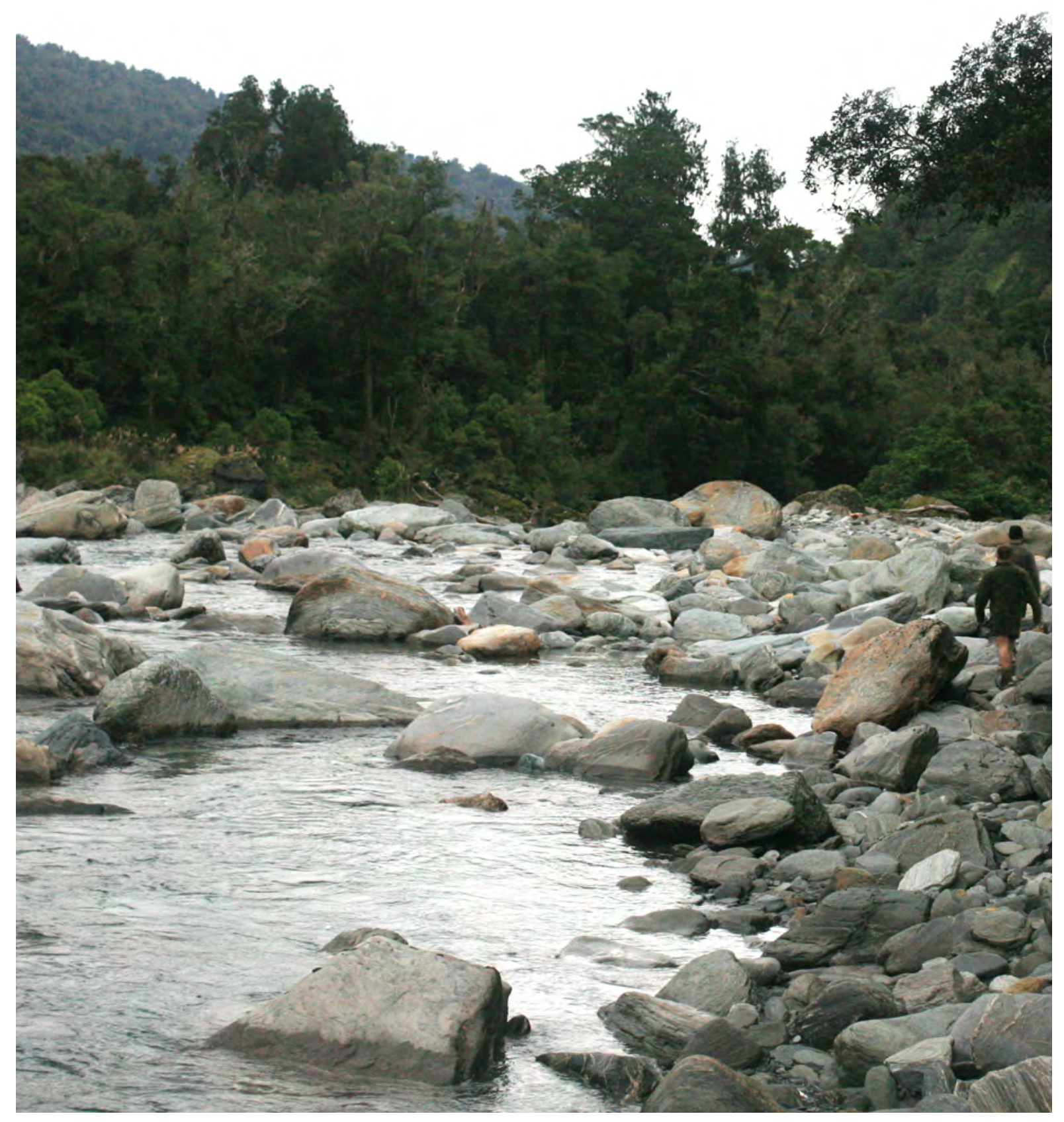




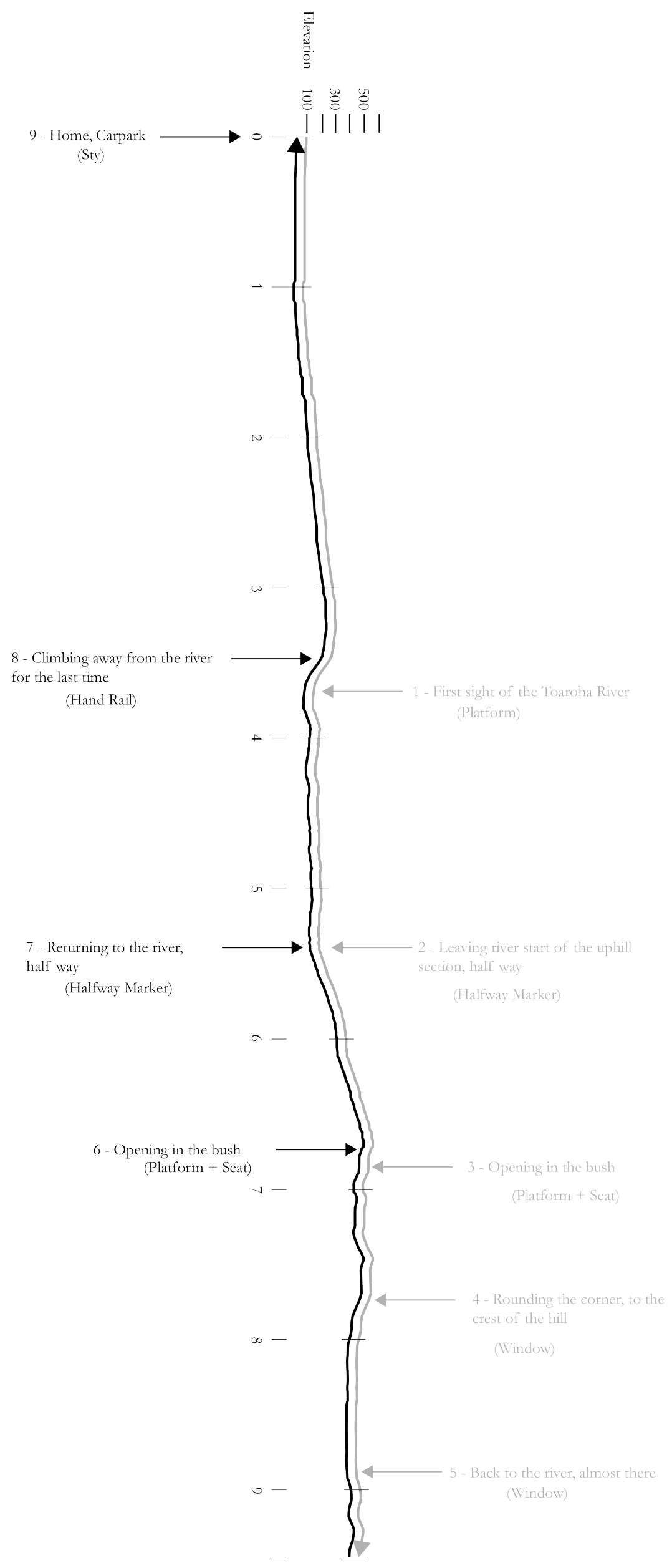

+Figure 7.10 Linear section of return journey with interventions. 


\section{WALK OUT}

On the walk out there are 4 similar interventions which provide the visitor with an opportunity to review their experience. They too are located at geographical locations a person would naturally stop. Some are at the same place as the introductory interventions and some are not. They consist of an architectural form that will provide the visitor with a sensory trigger when they interact with it or the visitor will experience conscious memory recall when they sit and look.

\section{INTERVENTION 6}

Platform and seat orientated back towards where the baths are located. Near the highest point of the journey, it gives walkers an opportunity for rest and look back to where they have come from. A moment for reflection.

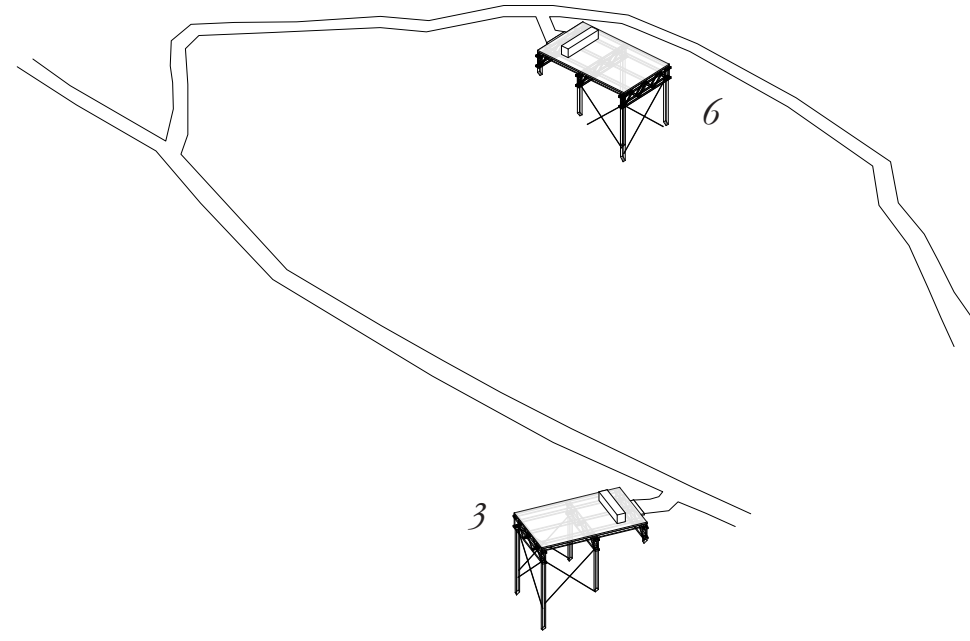

+Figure 7.11 South - West axonometric of interventions 3 and 6, designed +Figure 7.12 Intervention 6. to be hidden from each other, a visitor cannot see intervention 6 on the way in due to the landscpae and orientation of track but can be clearly seen on the way out.

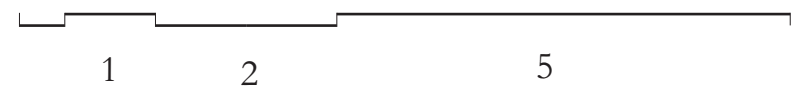

North

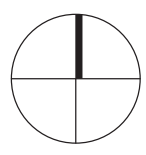




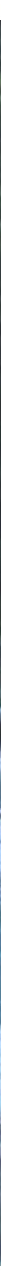




\section{INTERVENTION 7}

Located at the midway point. It is at the bottom of the hill so it is very comforting knowing that the walk out is predominantly flat.

\section{INTERVENTION 8}

A hand rail that leads you away from the river for the last time up a steep section of river bank. The hand rail is the same as the hand rails used to climb in and out of the baths. Touching it could trigger an involuntary memory of climbing into a bath earlier in the day providing a moment for reflection of those feelings.

+Figure 7.14

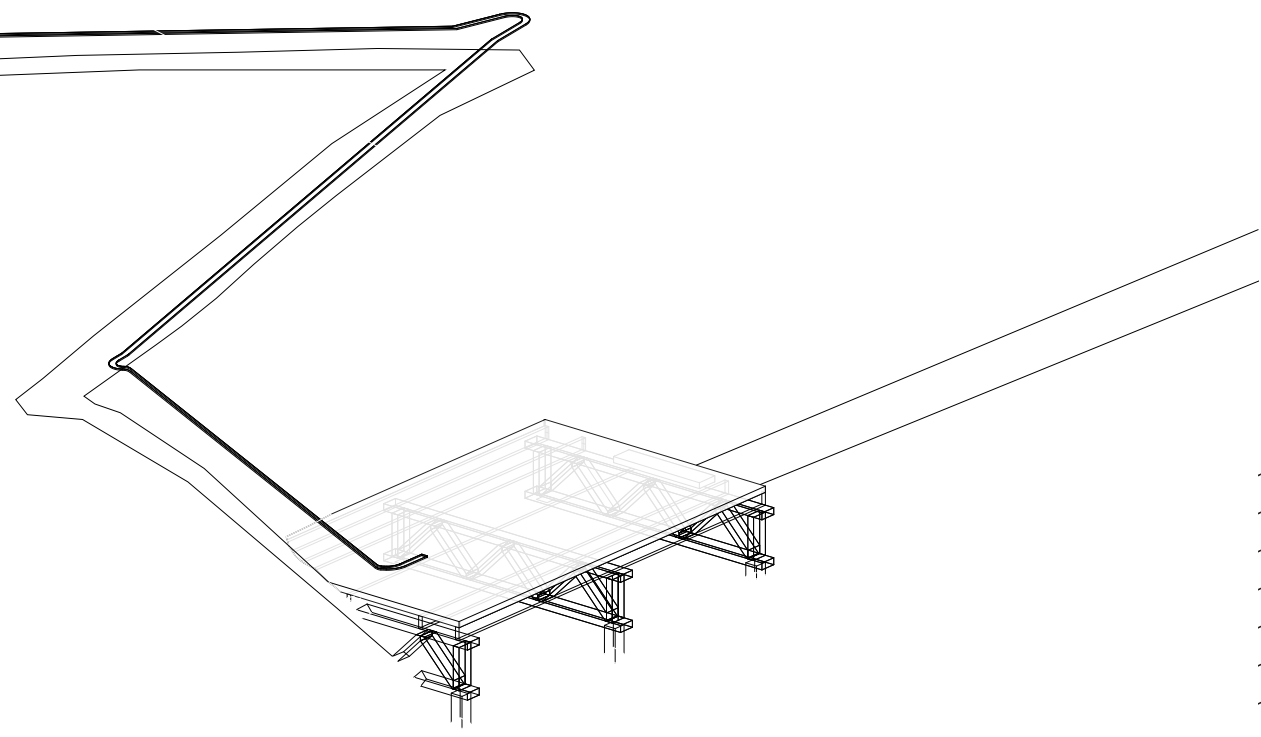

Intervention 8 .

$\mathrm{m}$

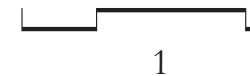




\section{INTERVENTION 9}

A sty and hand-rail climbing out of the farmer's paddock and into the carpark. Climbing the steps that were so common at the baths and holding the handrail that marked the entrance into all the pools will invite the visitor to one last recollection of the experience before they climb in their car and drive back to town.

+Figure 7.15 Sty, showing construction of steps and handrail. 


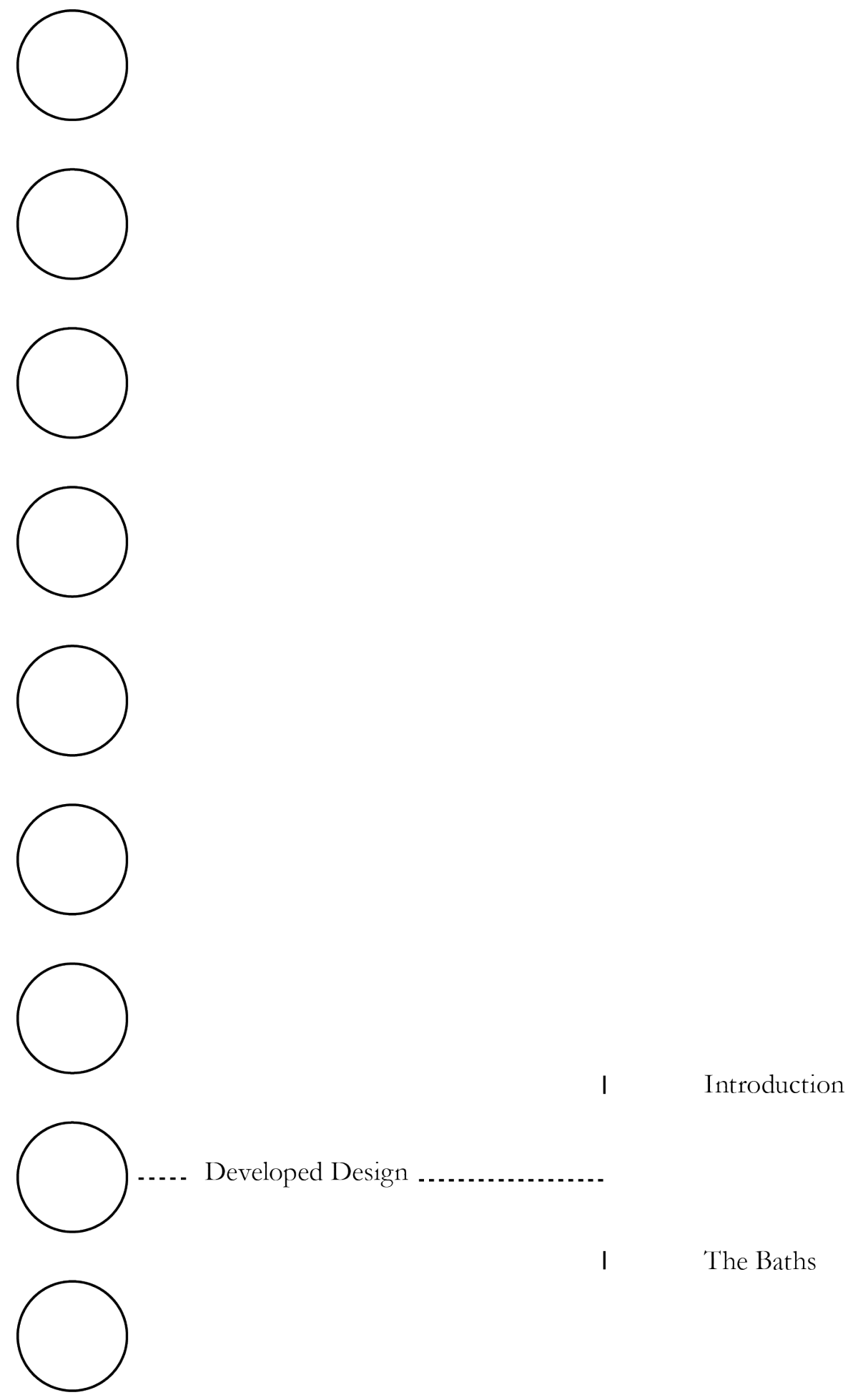




\section{DEVELOPED DESIGN}

$$
/ / 8 \quad / /
$$

The following chapter outlines the architectural solution to the problems surrounding memorialisation in New Zealand as outlined in chapter 4 while also providing a solution to the problem of declining place identity and architectural regionalism that was identified in chapter 3 . This chapter outlines a solution to these problems begining with an overall axonomteric view and site plan of the baths to provide understanding of arrangement and scale on the landscape. Following this, a series of renders that depict atmosphere shows the design in more detail. Finally plans and construction details are included for the three bath buildings. 


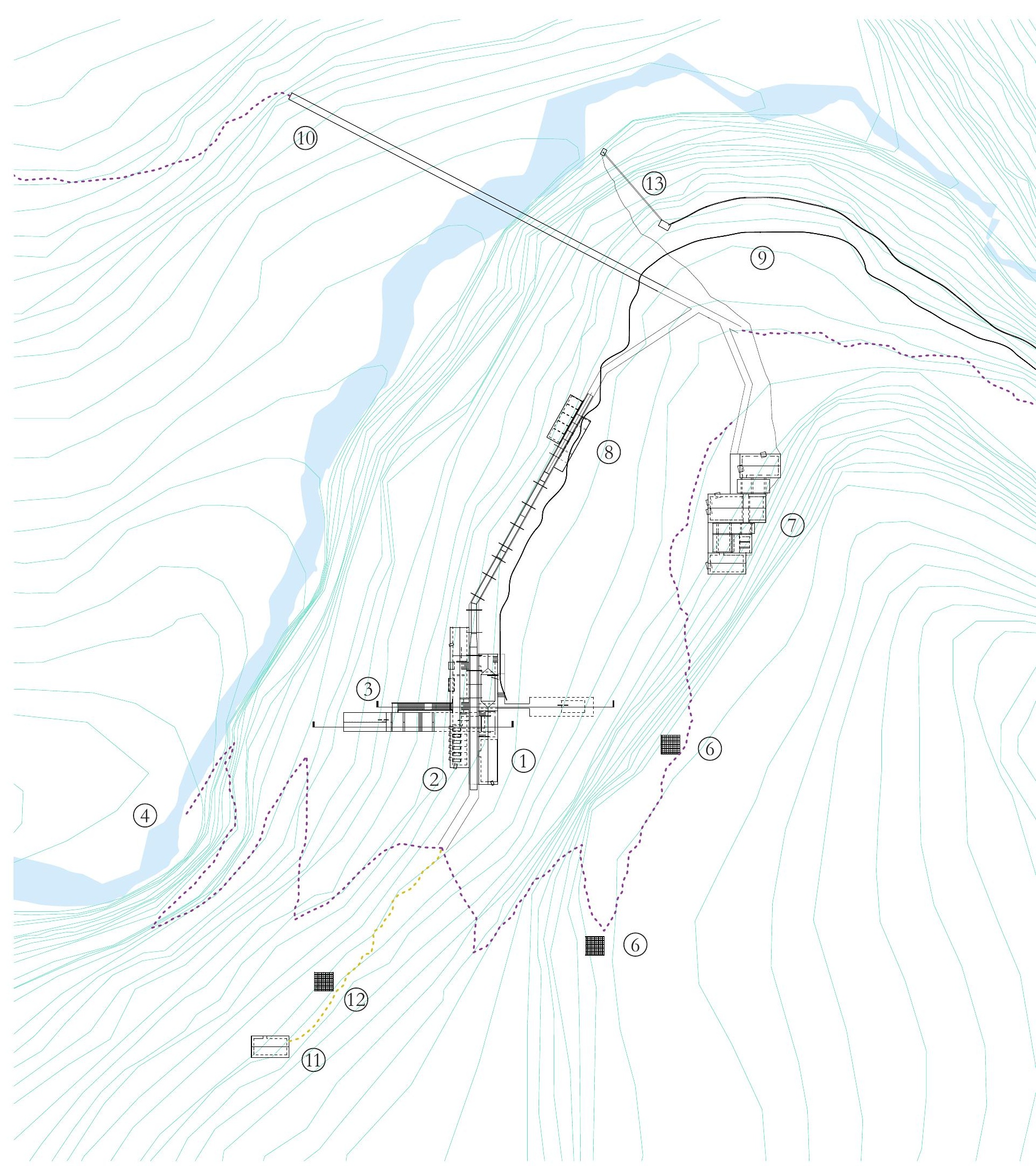

North
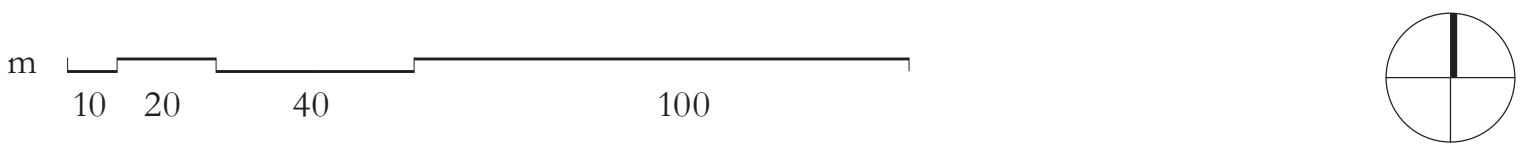

+Figure 8.01 Site plan. 


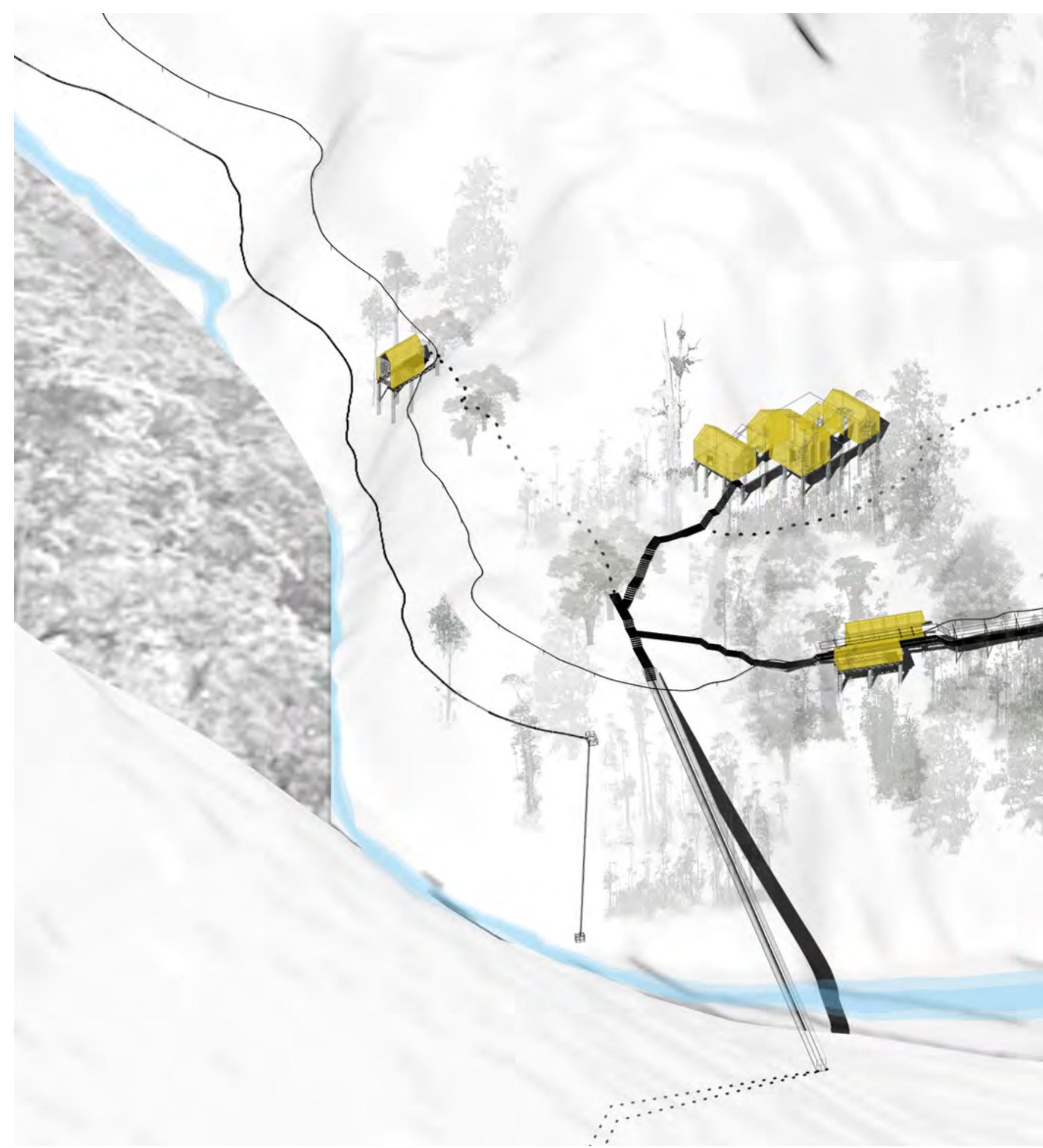





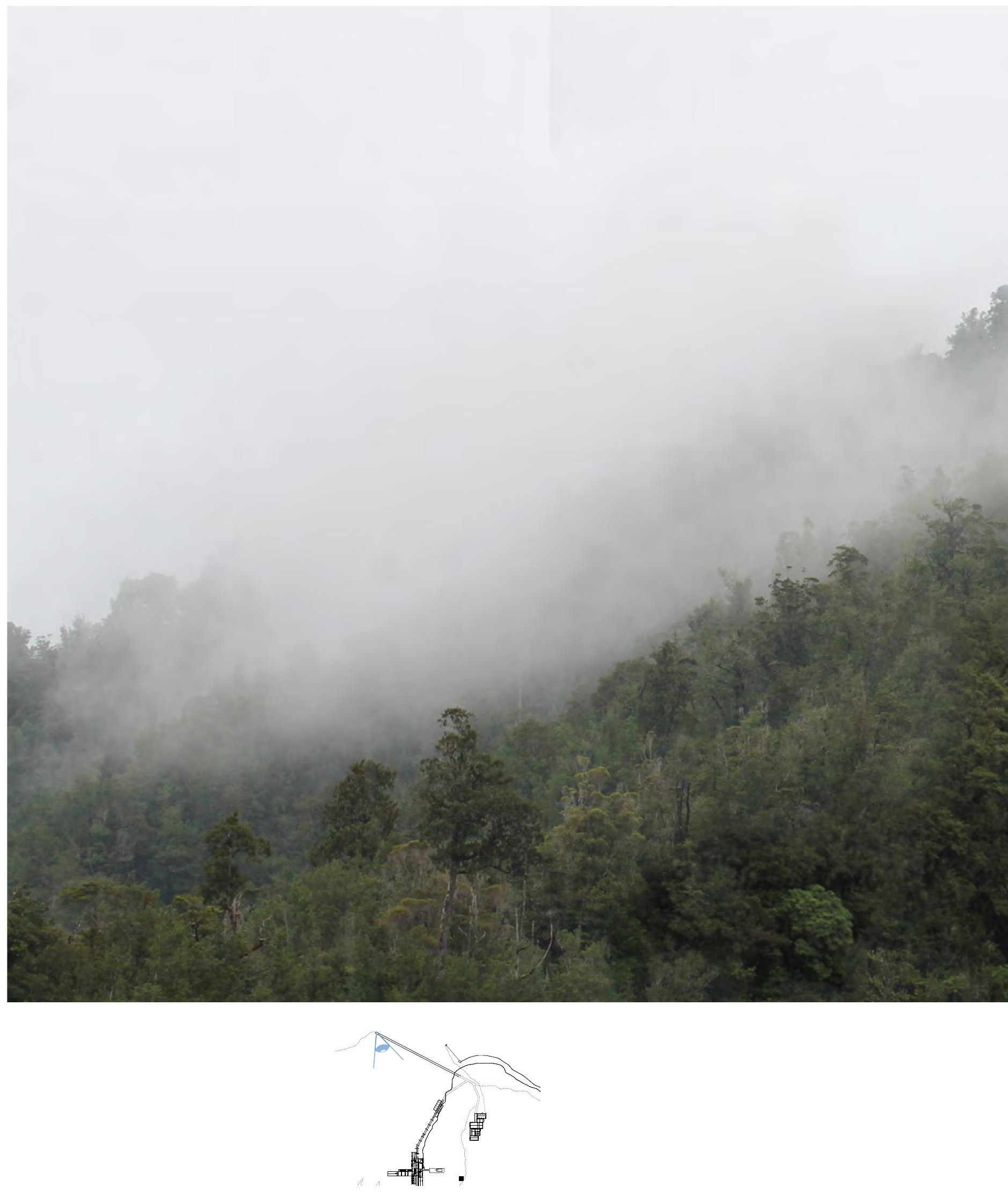




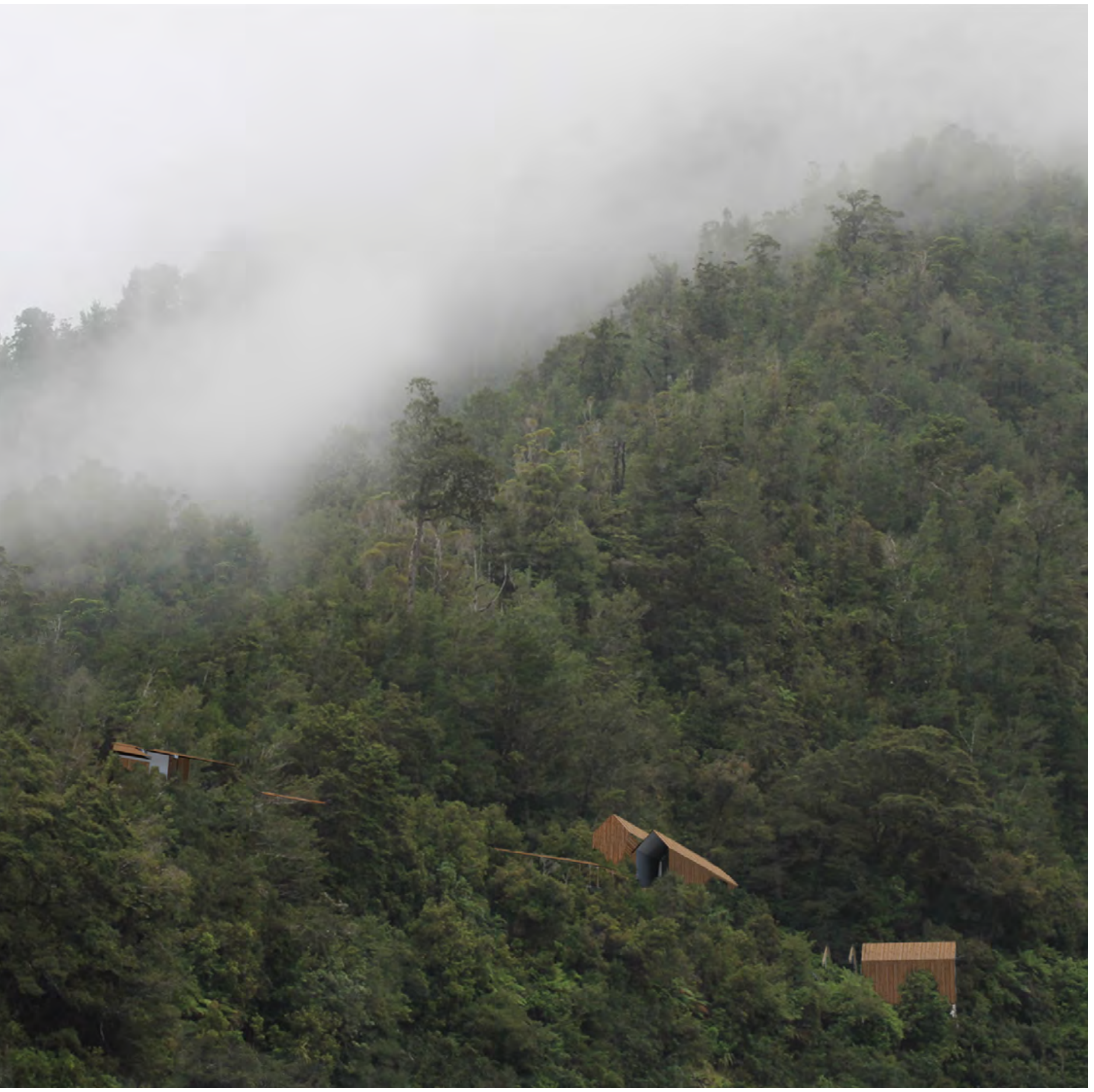



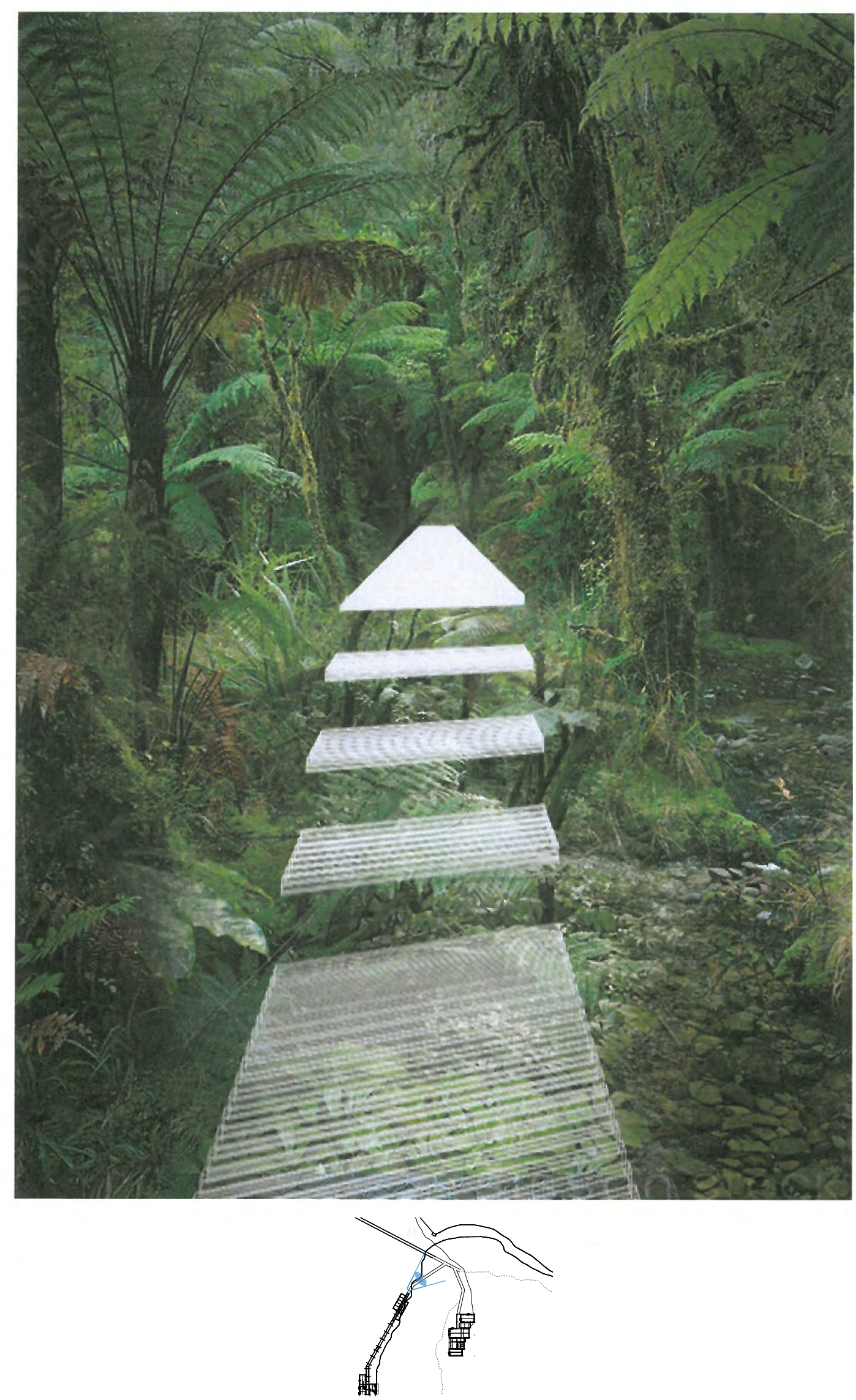

+Figure 8.04 Raised entrance walkway looking from changing stalls. 

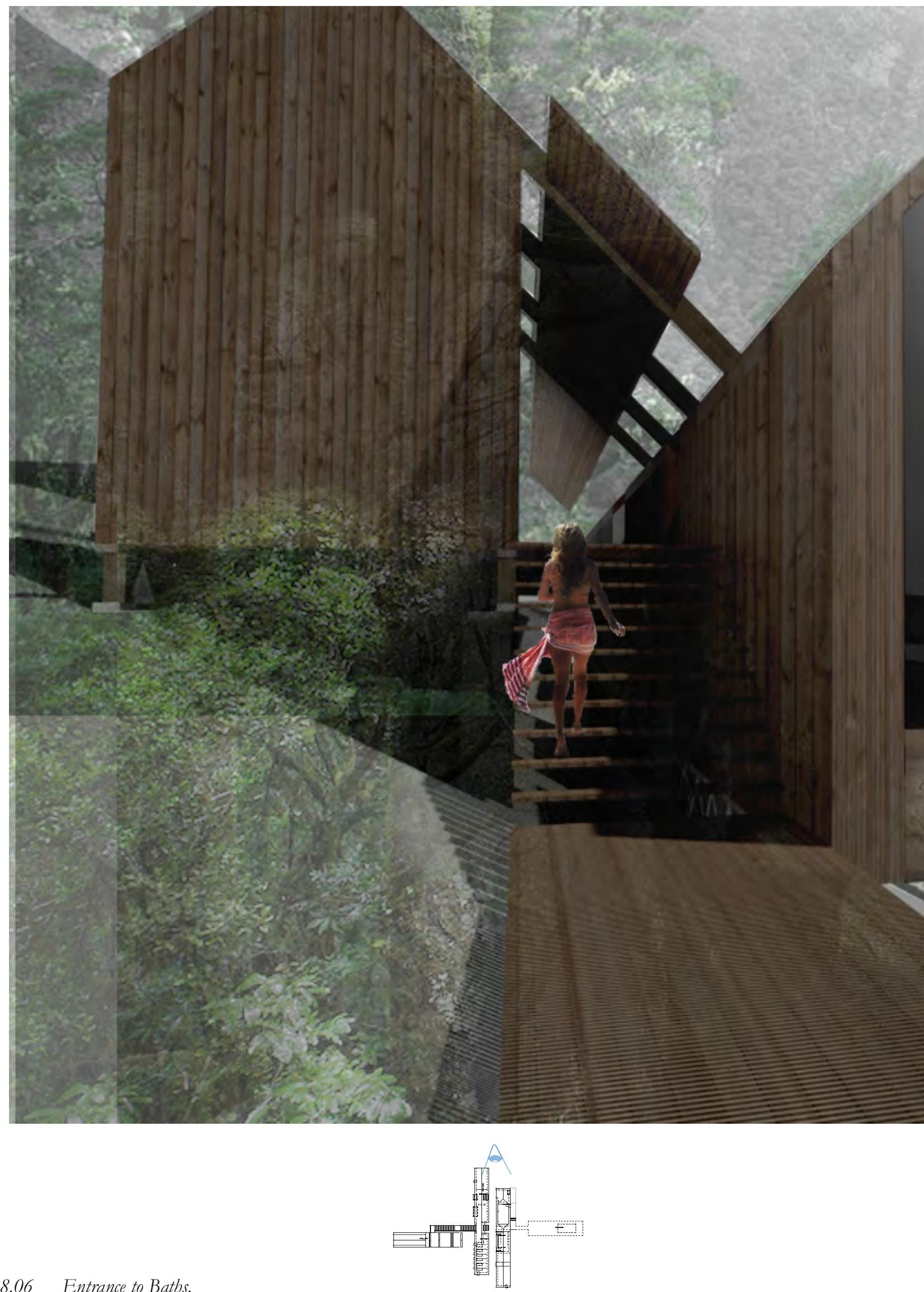


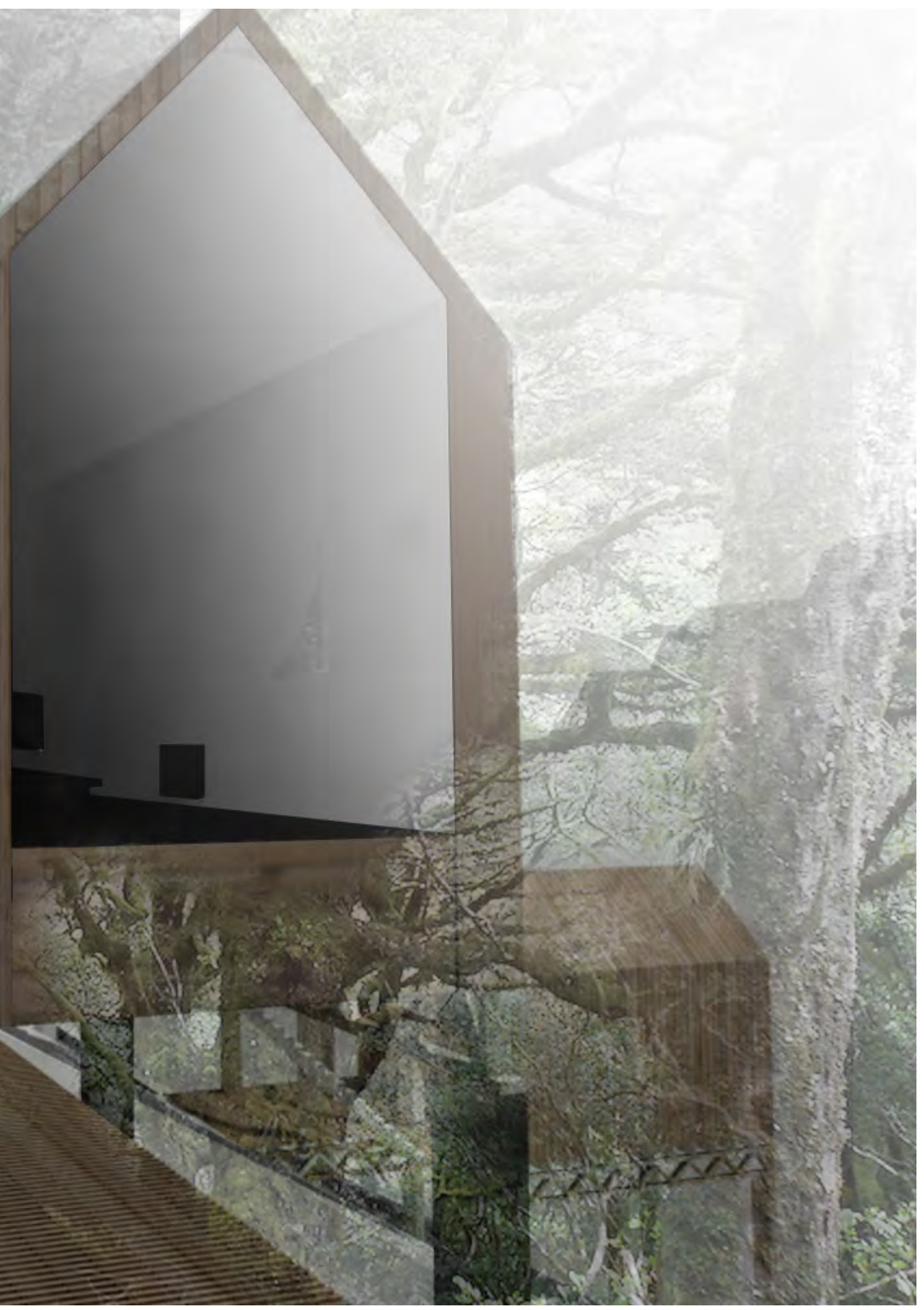



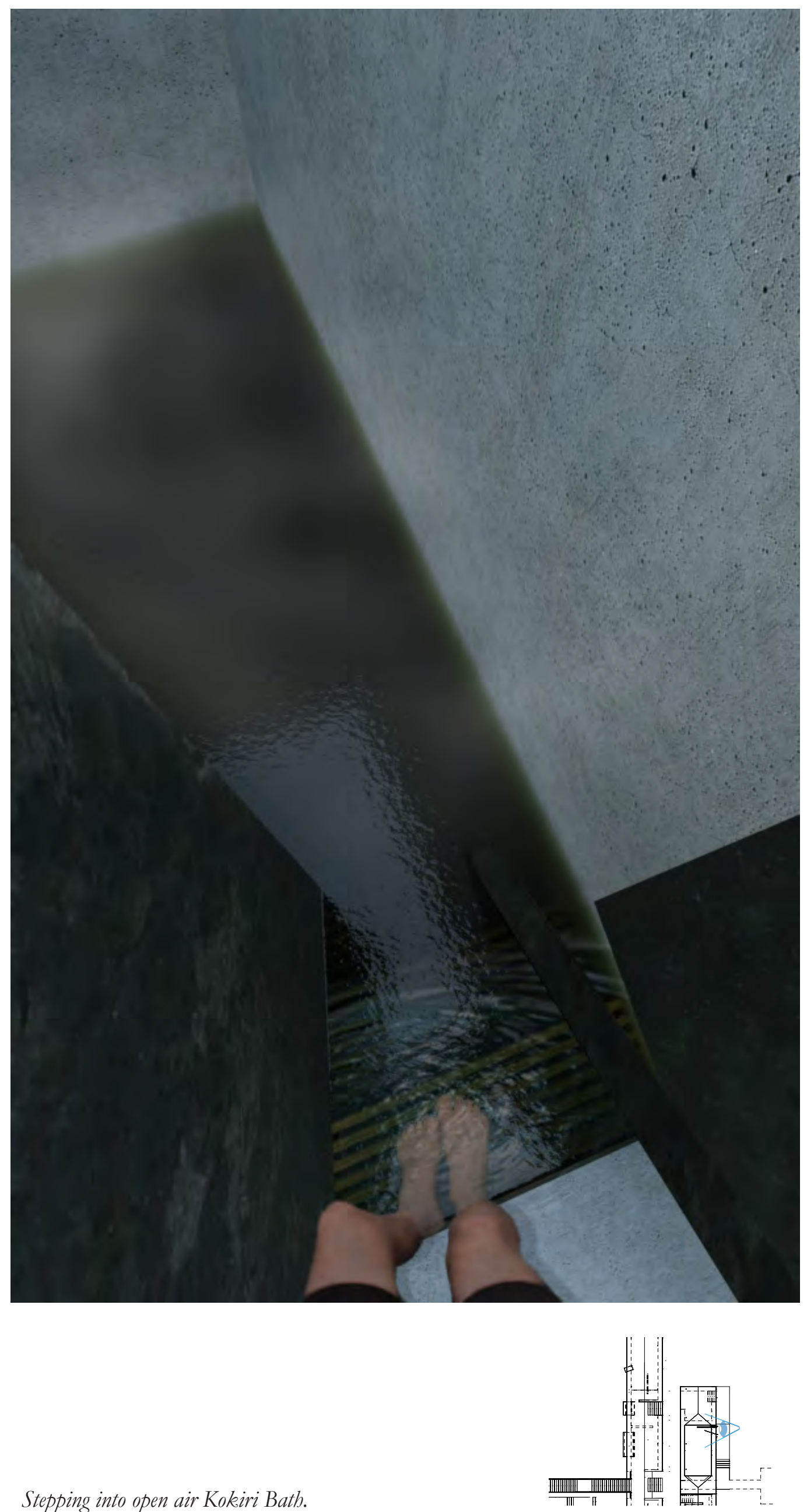

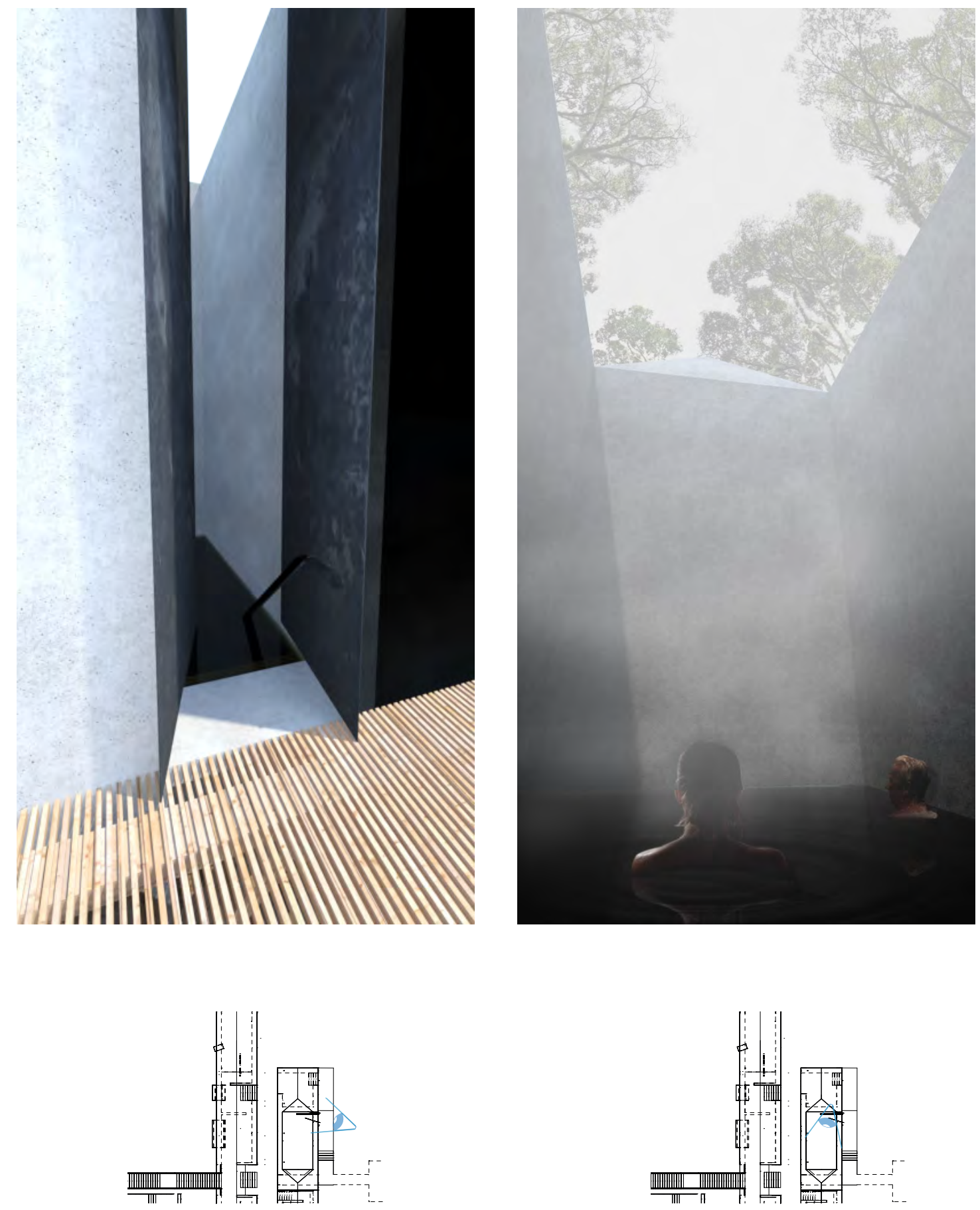

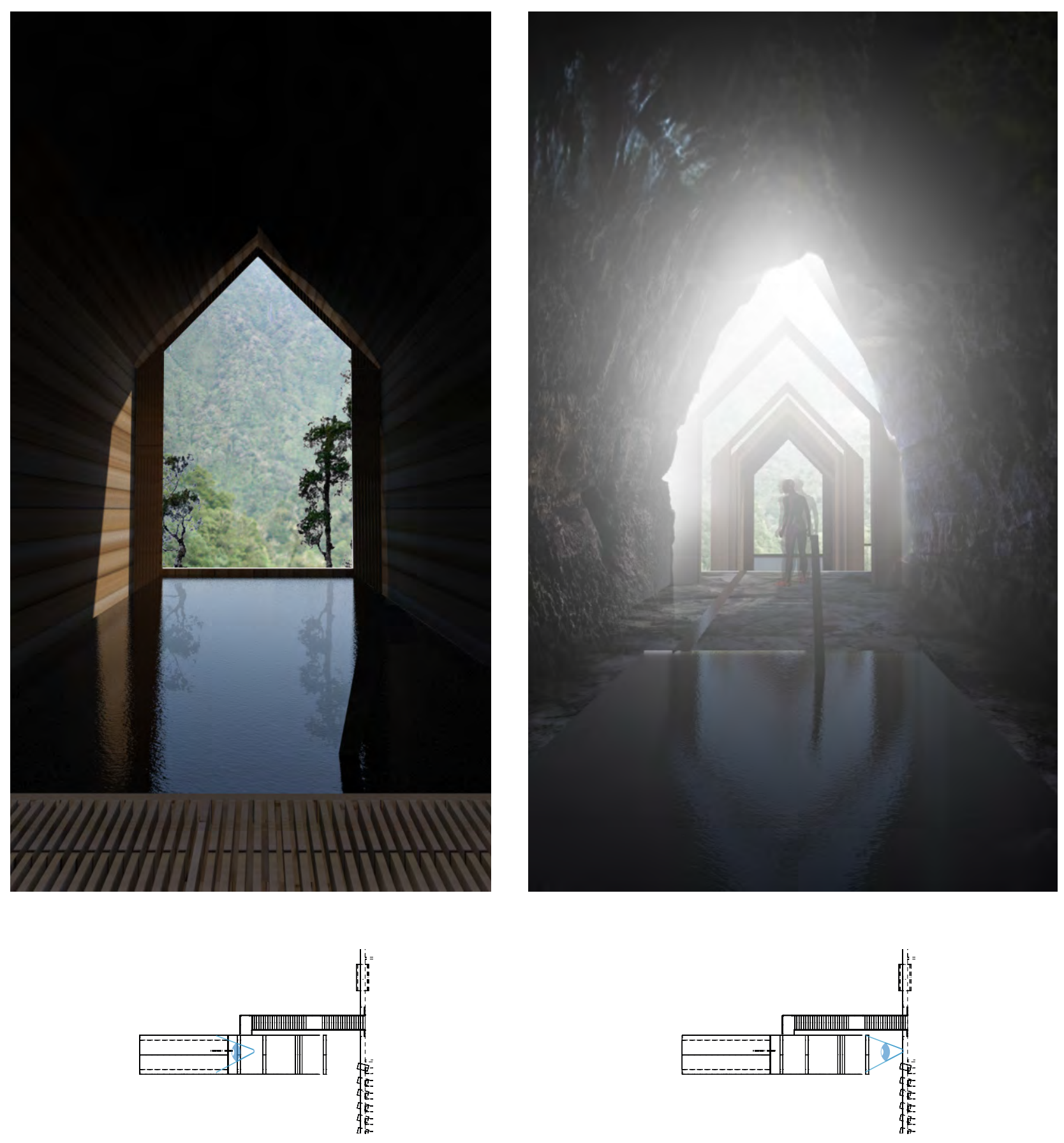

+Figure 8.09 Kotuku Bath. 


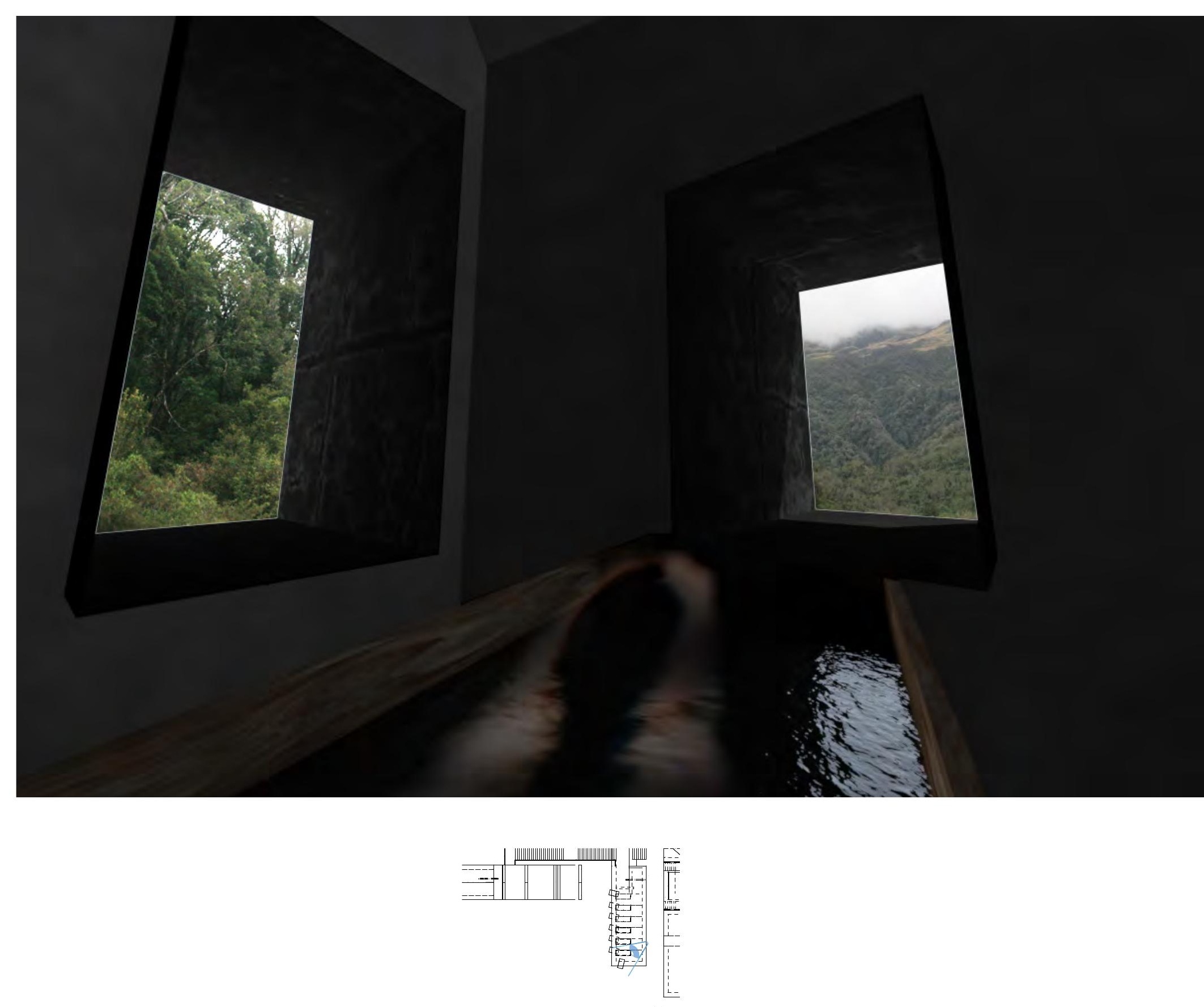



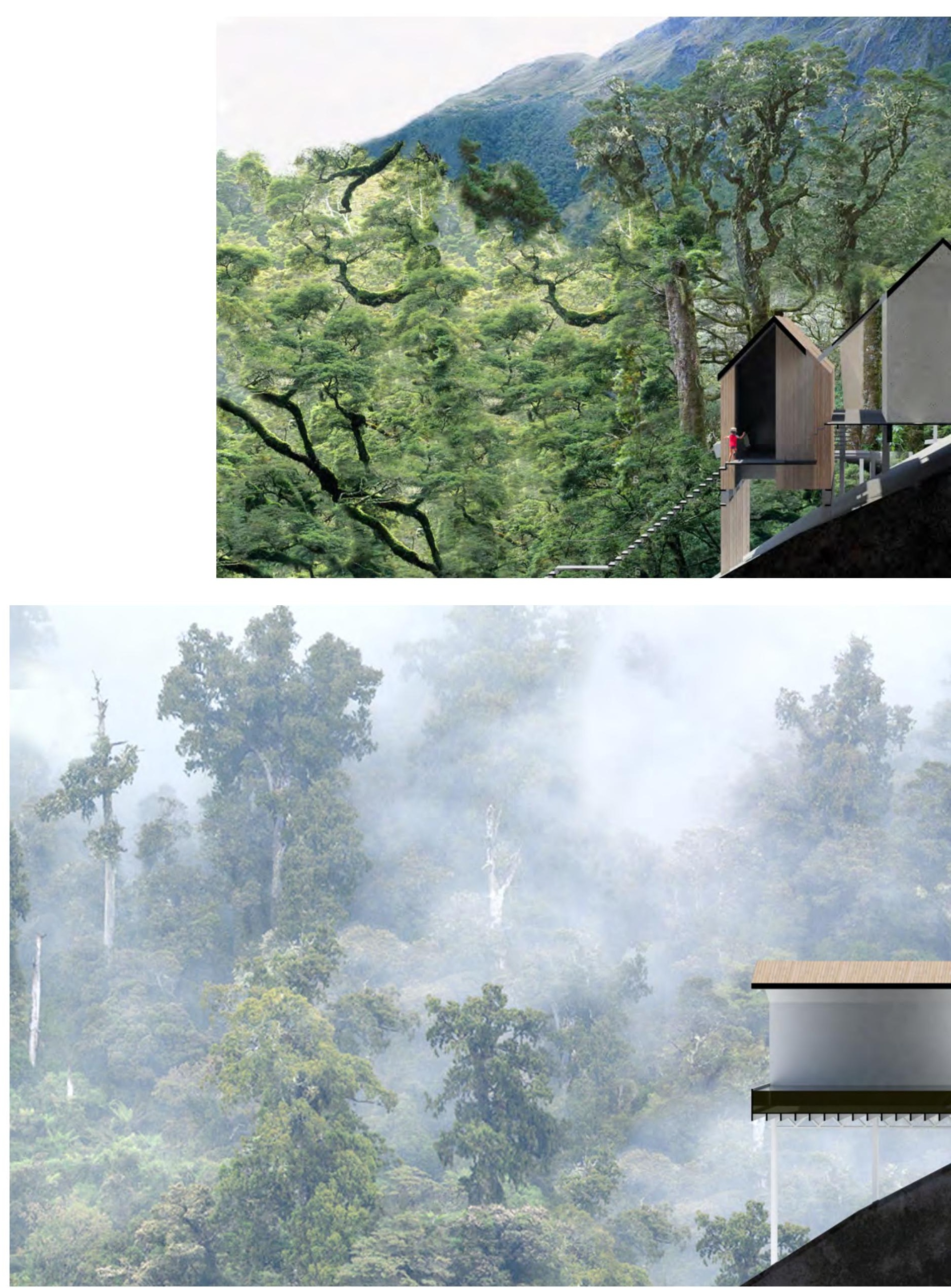


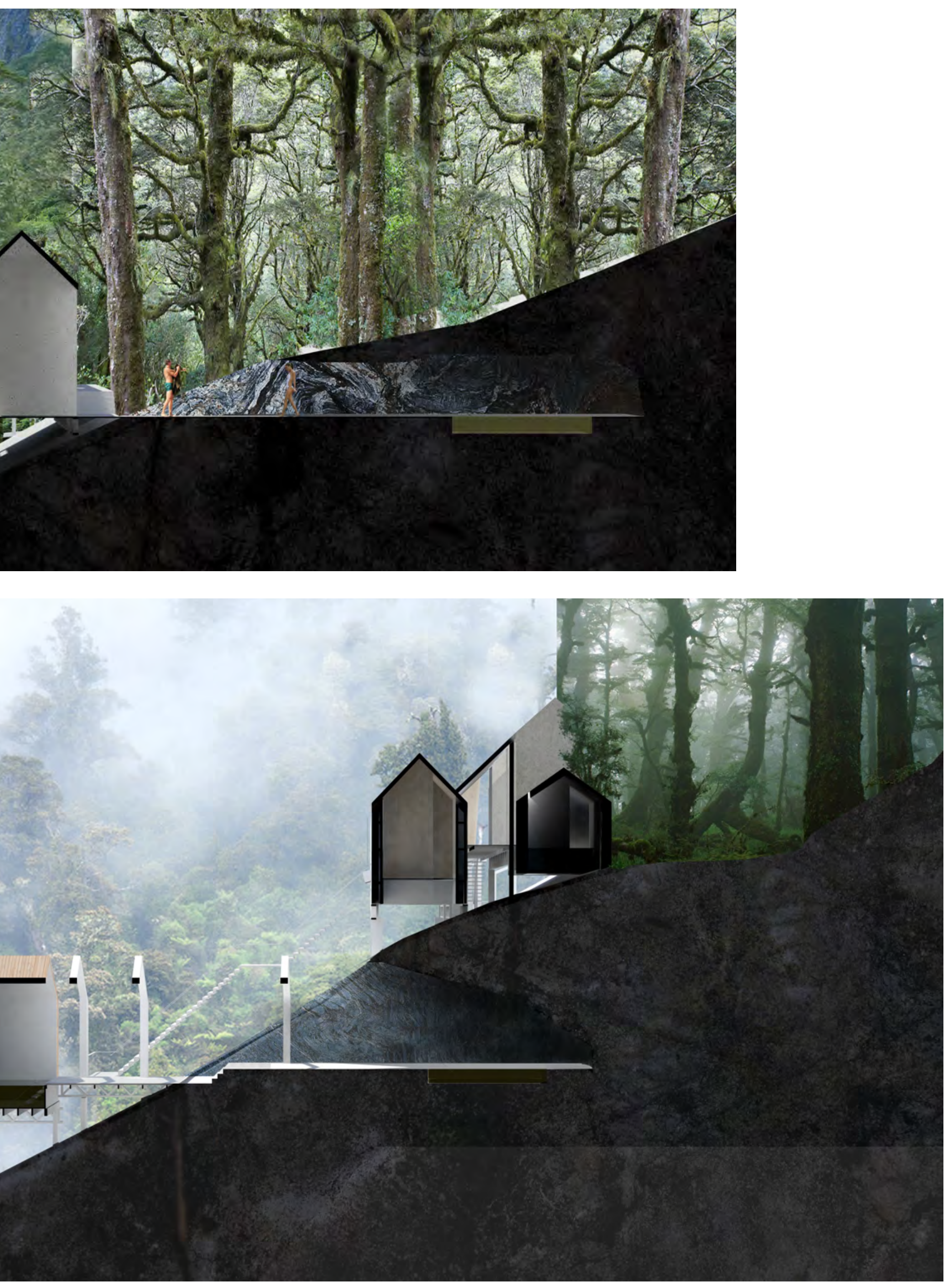




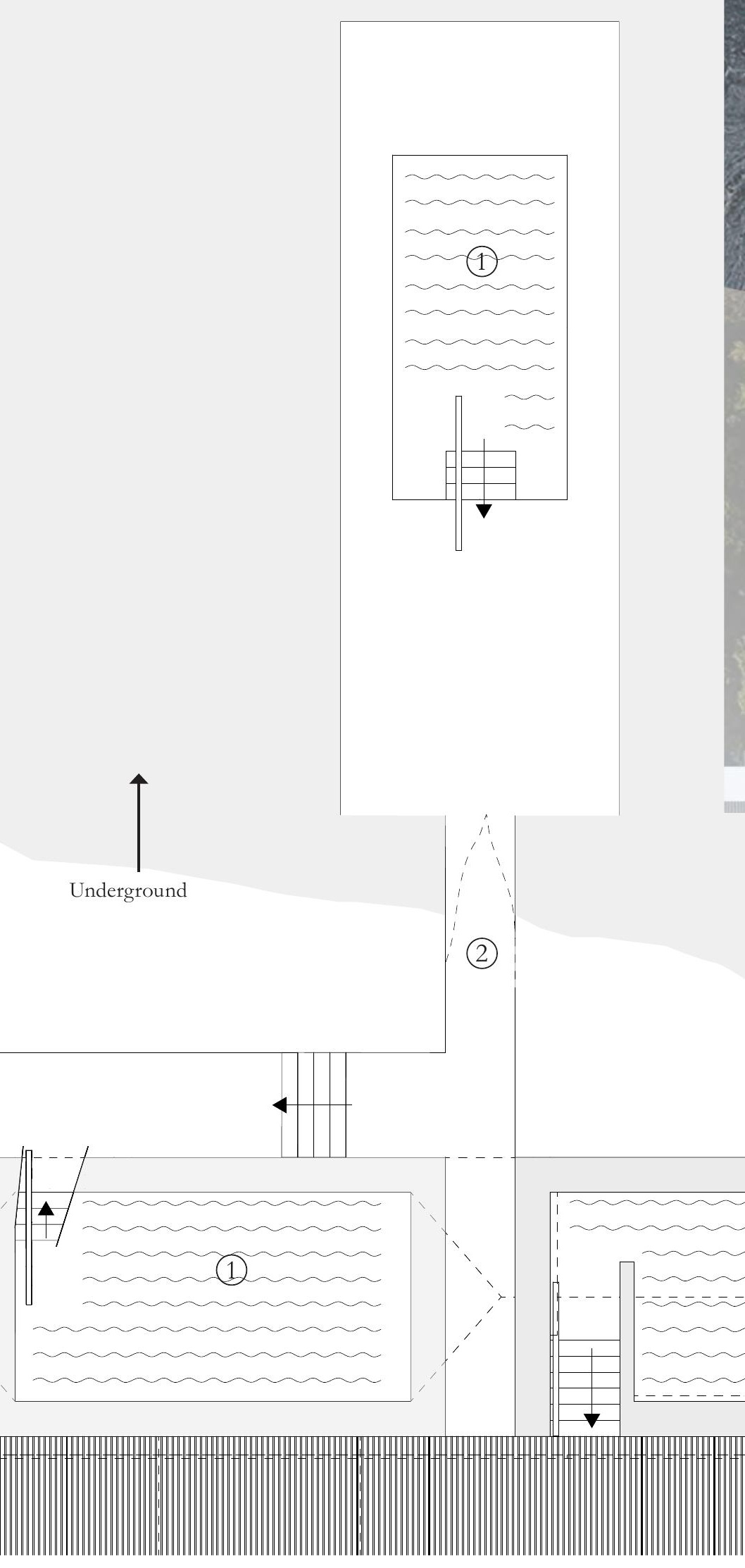

(2)

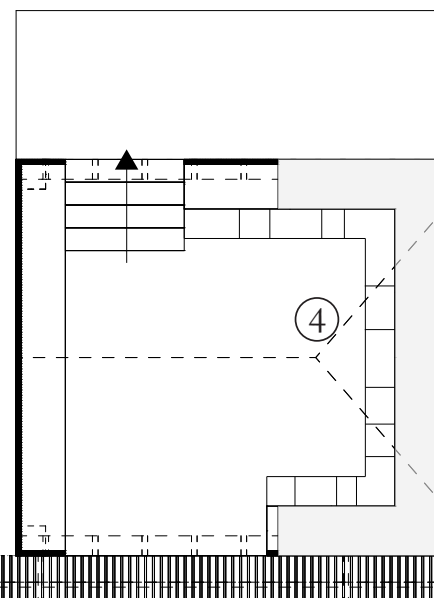




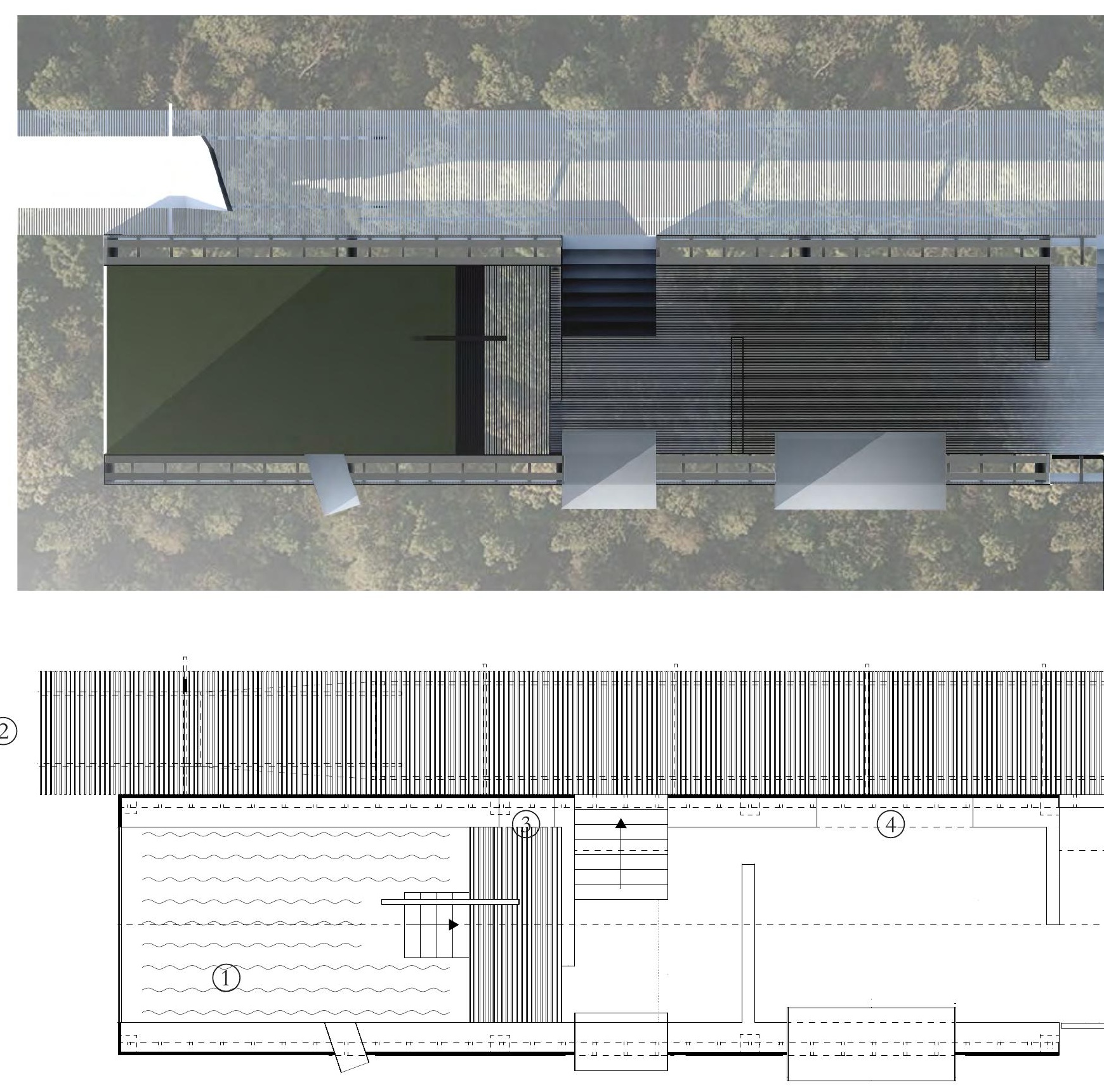




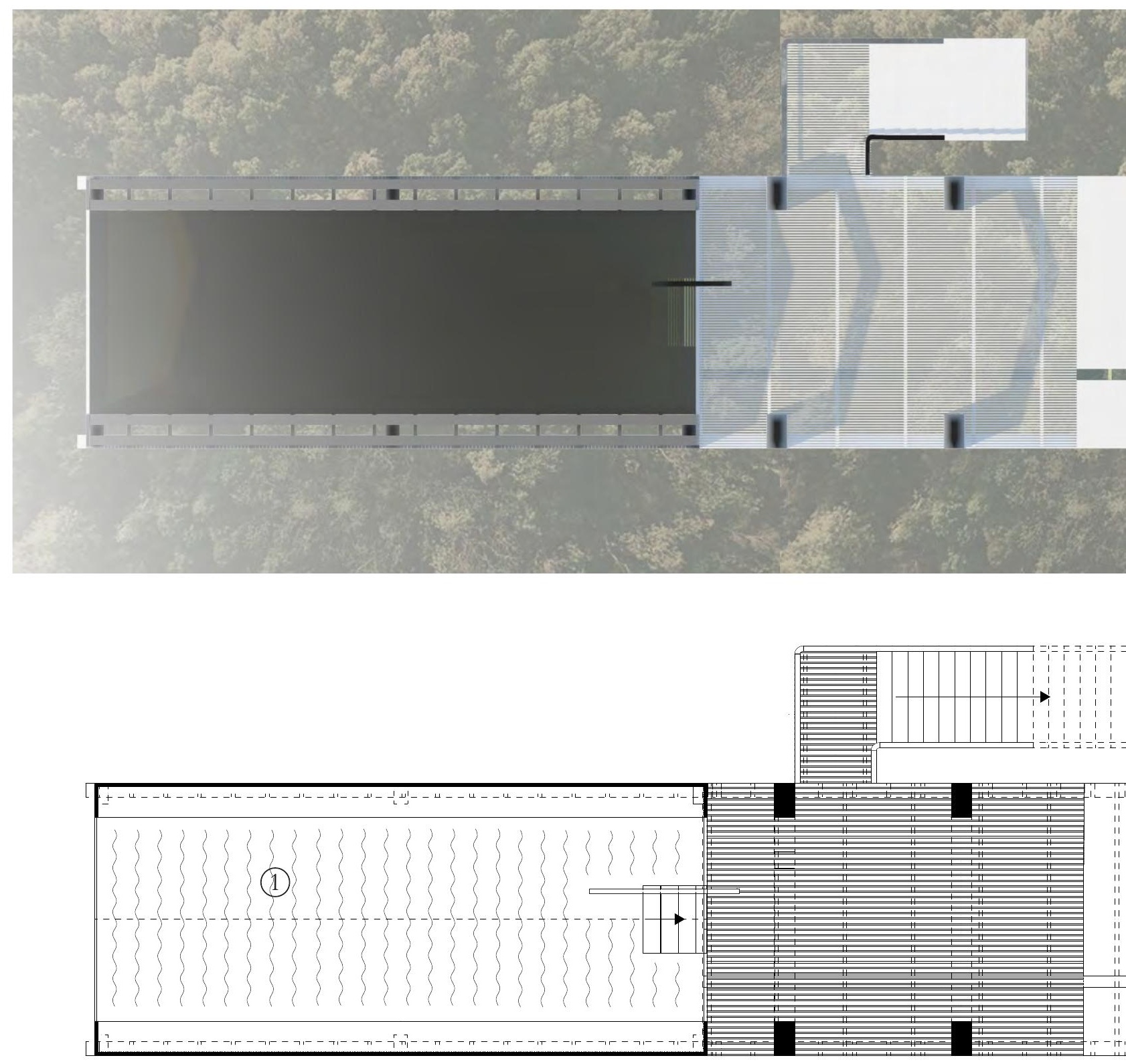

+Figure 8.16 Plan of the Kotuku Baths, rendered.

+Figure 8.17 Plan the Kotuku Baths. 


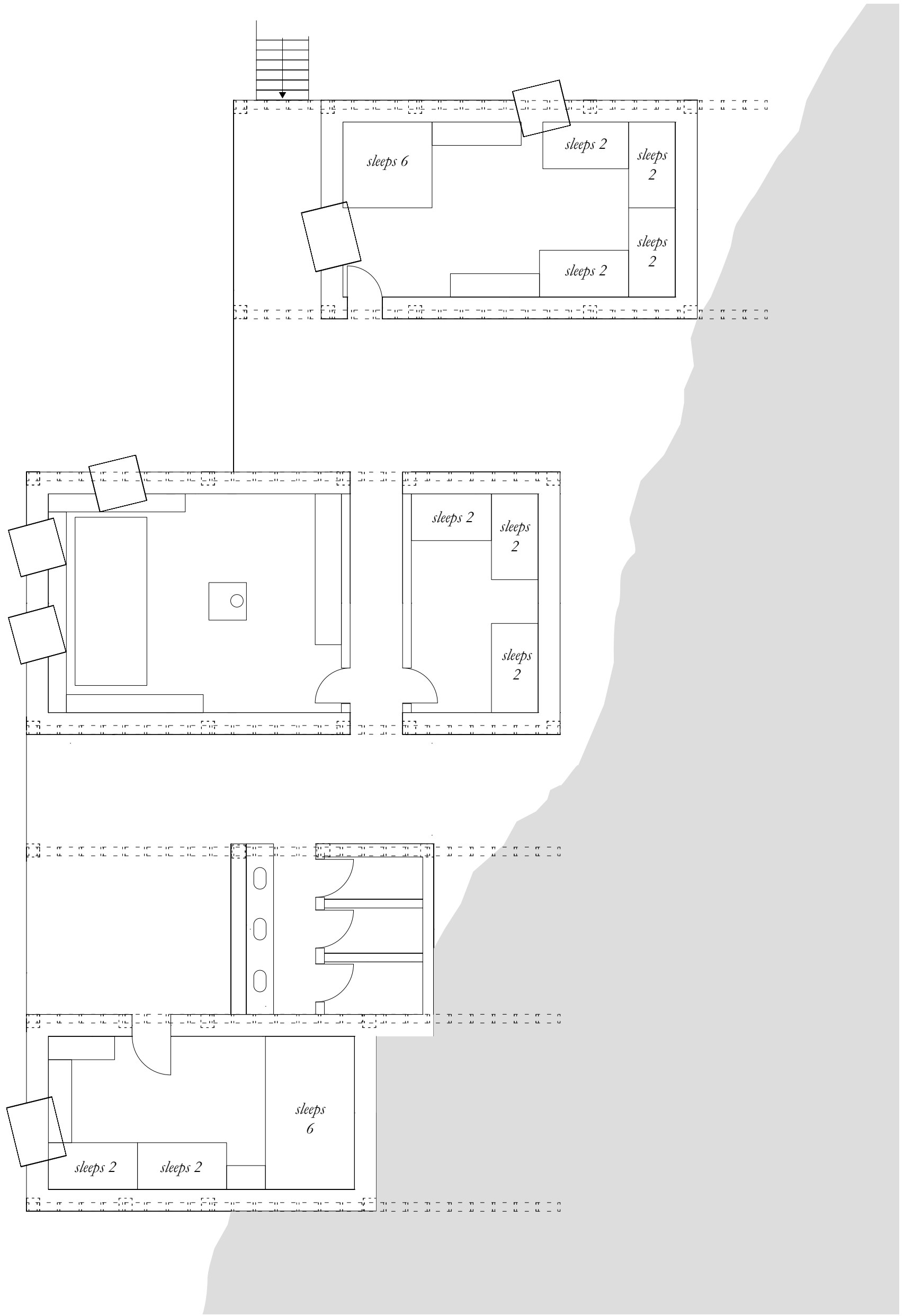

+Figure 8.18 Plan of accommodation area sleeping 30. 


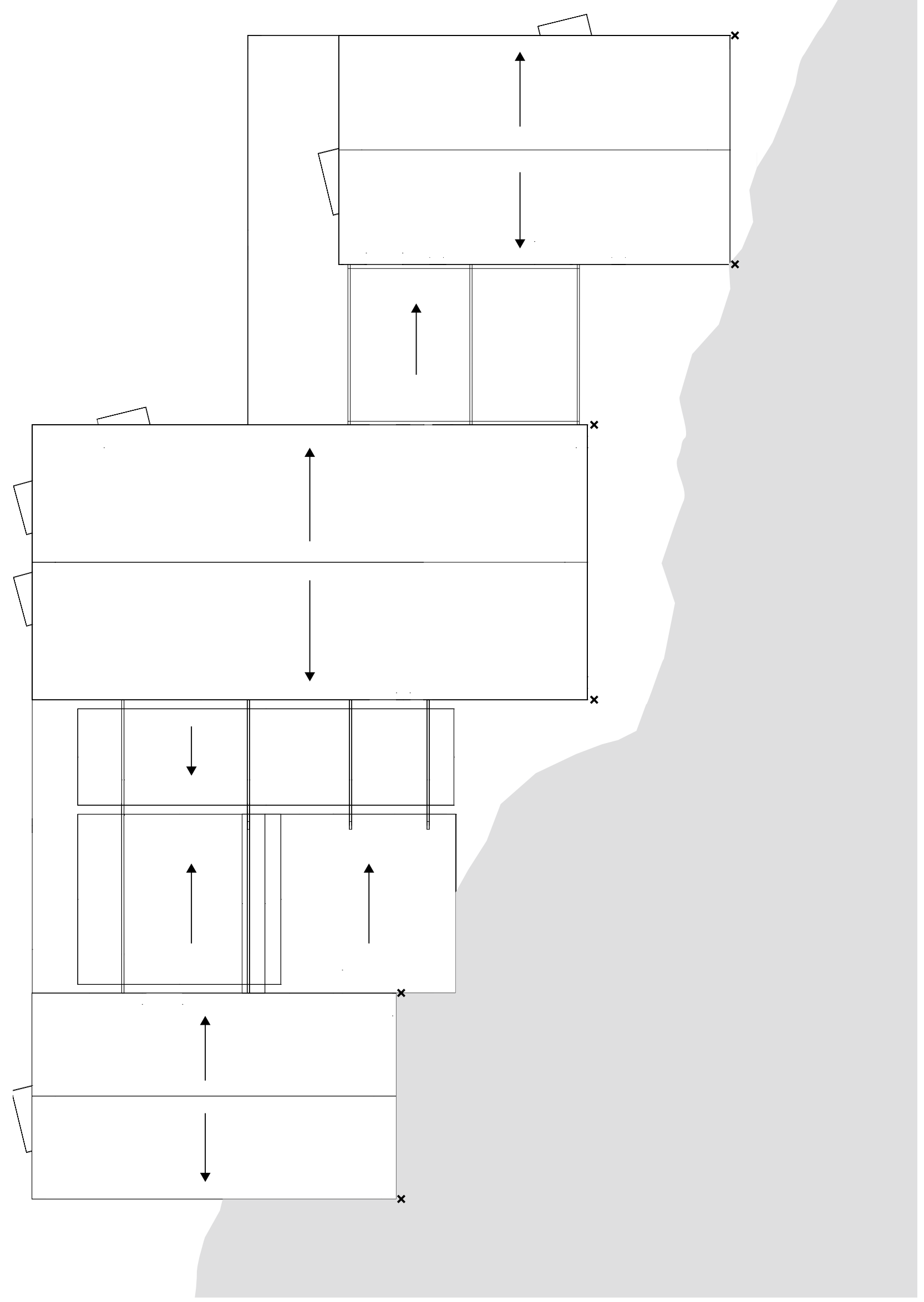

+Figure 8.19 Roof plan of accommodation areas, showing roof fall and areas of water collection. 


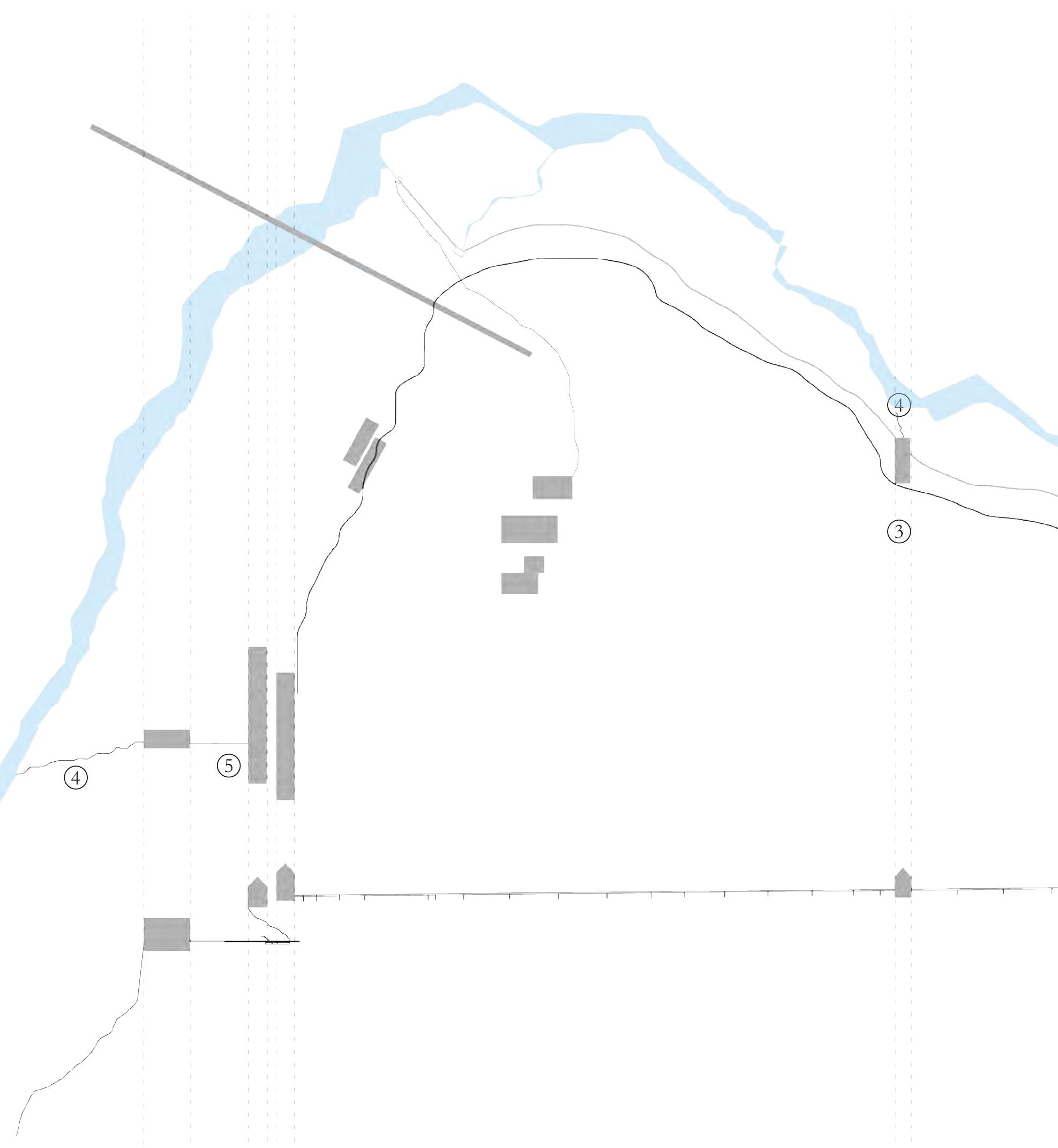

+Figure 8.20 Plan of hot thermal water reticulation. 
(2)

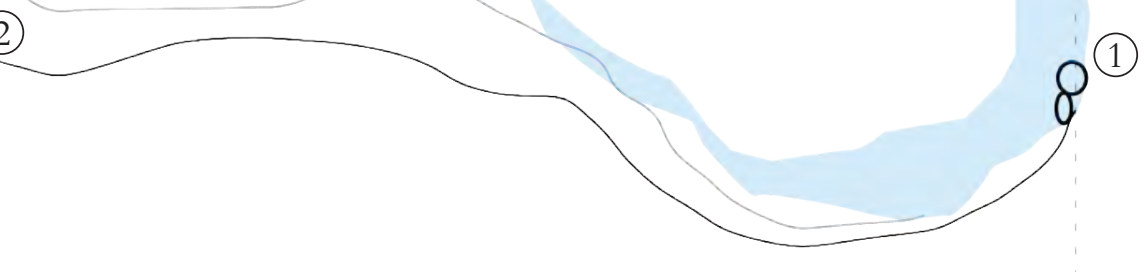

Key

1 Rock weir (intake)

North

2 Canal (pipe)

3 Outlet

4 Stream return

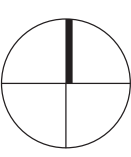

5 Baths

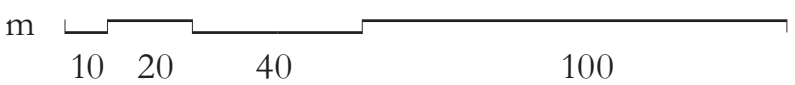




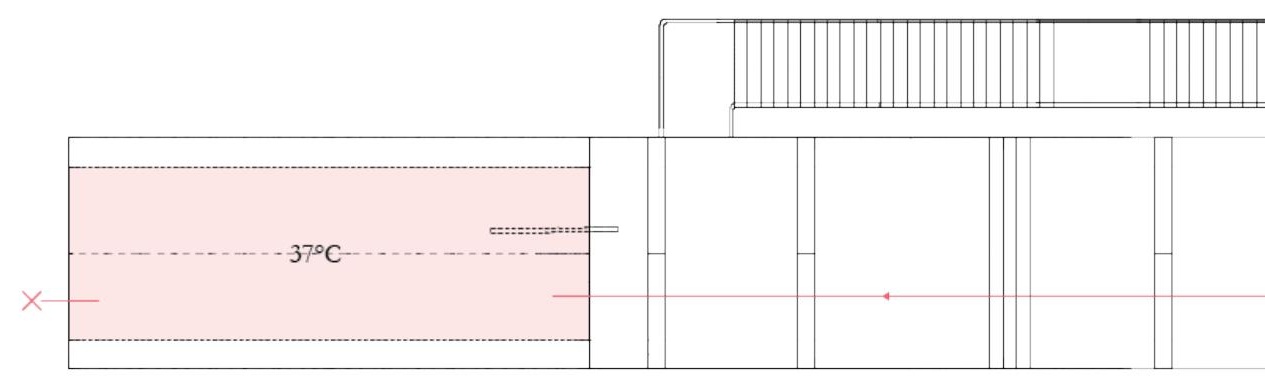

Key

Water pipe

Water returned to landscape

Water drop to lower bath

Hot bath

Plunge pool 


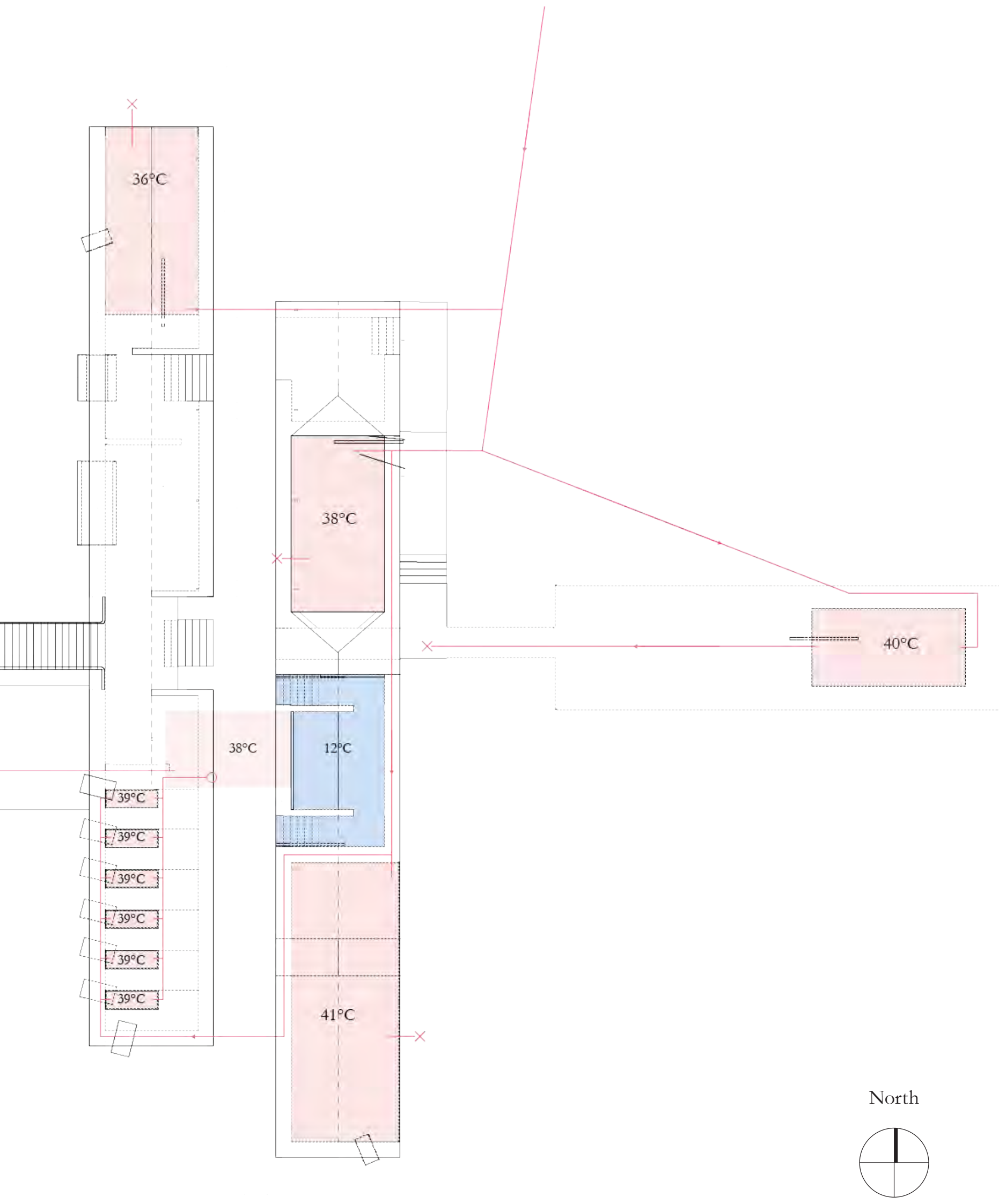




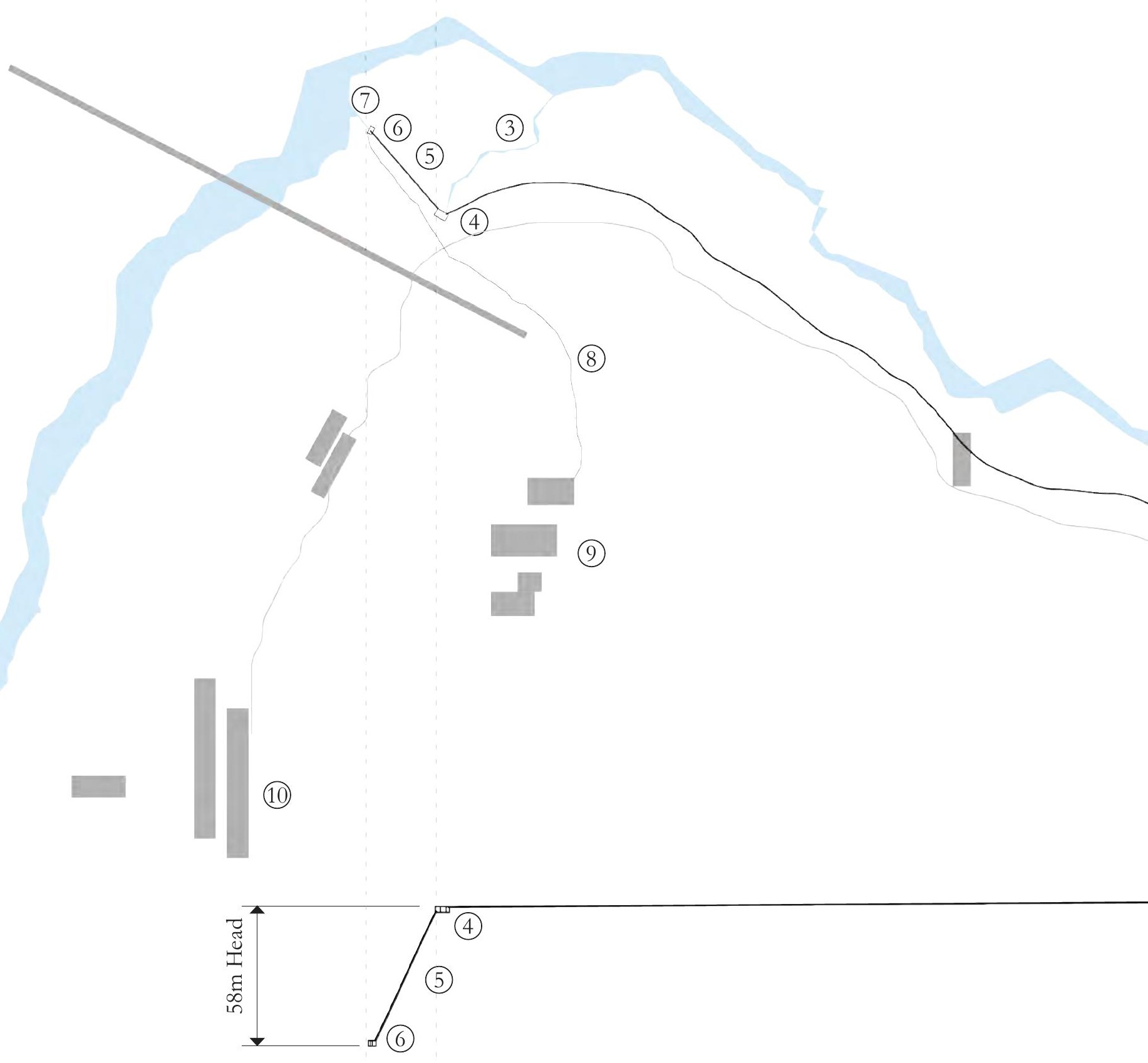


Key

1 Rock weir (intake)

2 Canal (pipe)

3 Spillway

4 Forebay

5 Penstock (pipe)
6 Turbine

7 Stream Return (outlet)

8 Transmission line

9 Accommodation + battery bank

10 Baths m

$\sqrt { 1 0 } 2 0 \longdiv { 4 0 }$
100 


\section{STRUCTURE OF BATHS}

These pages show an exploded view of the structure of the different baths.

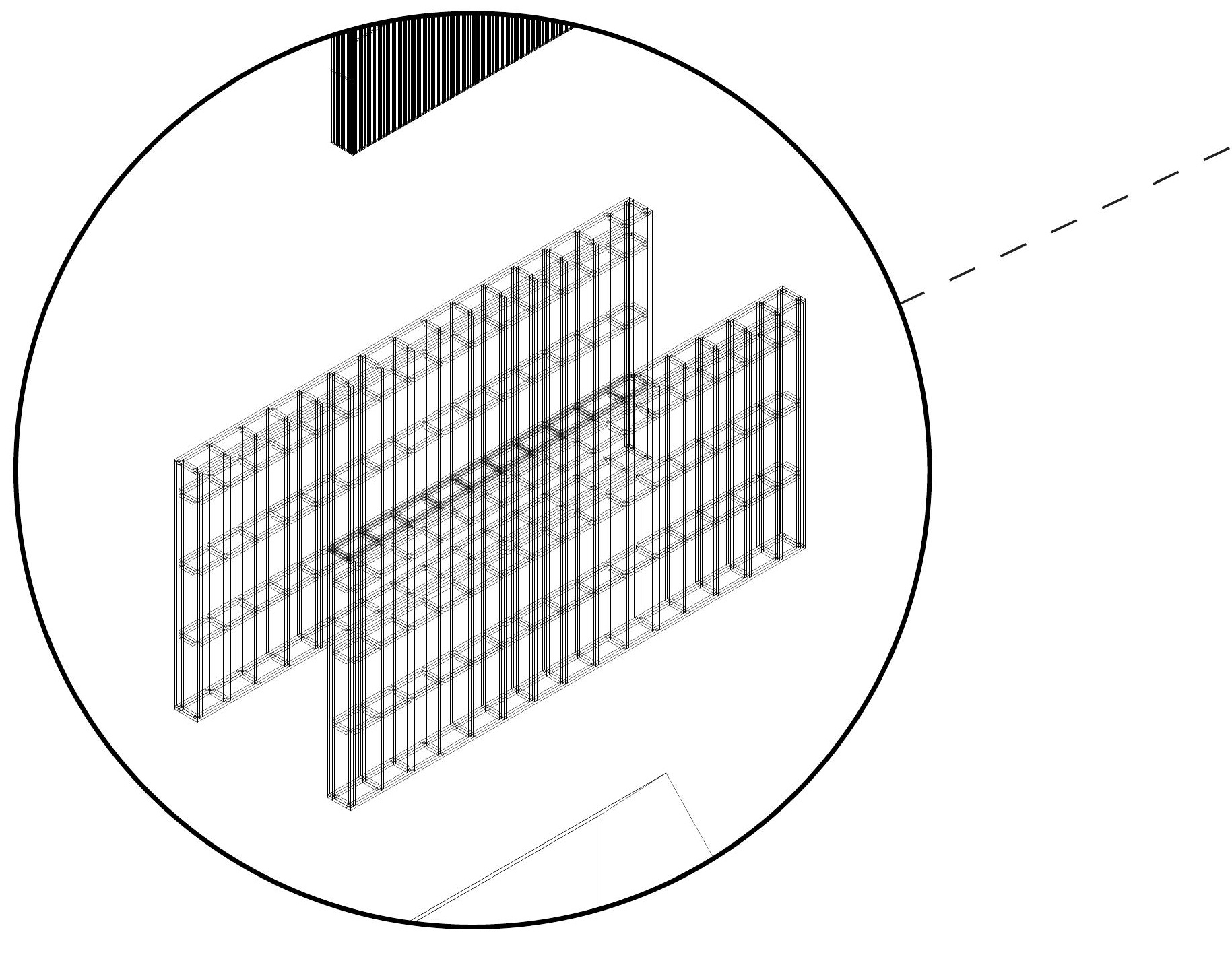

+Figure 8.23 Double stud construction to accommodate the $500 \mathrm{~mm}$ thick walls. 
500 x 200mm Silver Pine

LVL Columns

$50 \times 50 \mathrm{~mm}$ Silver Pine

slats, exterior cladding

$500 \mathrm{~mm}$ Silver Pine double

framed wall

interior lining

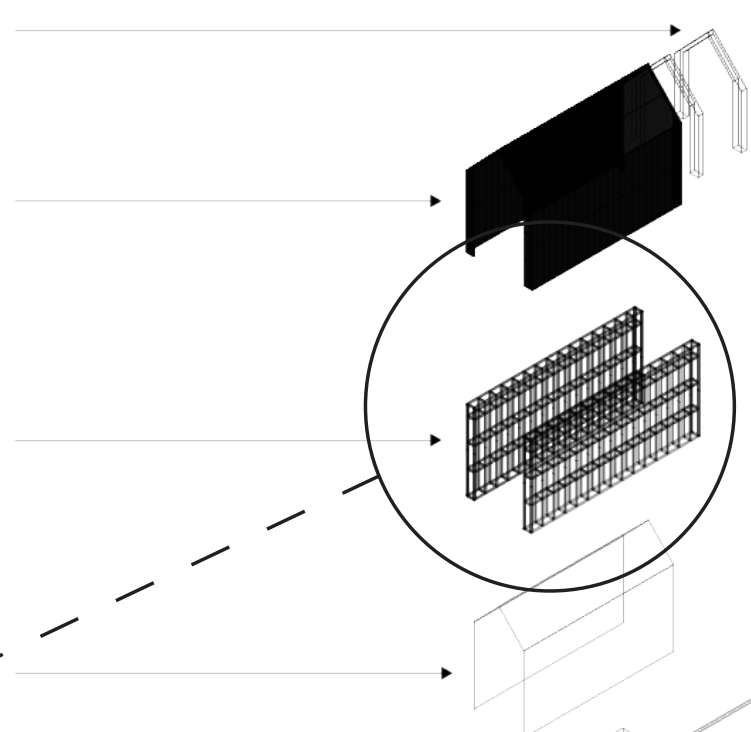

Hot Thermal Water $>$

Unfinished rock floor

Black steel handrail

$20 \times 50 \mathrm{~mm}$ Silver Pine

slats at $40 \mathrm{~mm}$ centres

$40 \mathrm{~mm}$ Silver Pine timber

boards, bath sides

$\rightarrow$

150 x 63mm Silver Pine

LVL joists at 600 centres

600 x 200mm Silver Pine

trusses

$200 \times 300 \mathrm{~mm}$ Silver Pine

piles

The Kotuku Bath

7.0 $\mathrm{kPa}$ dead load
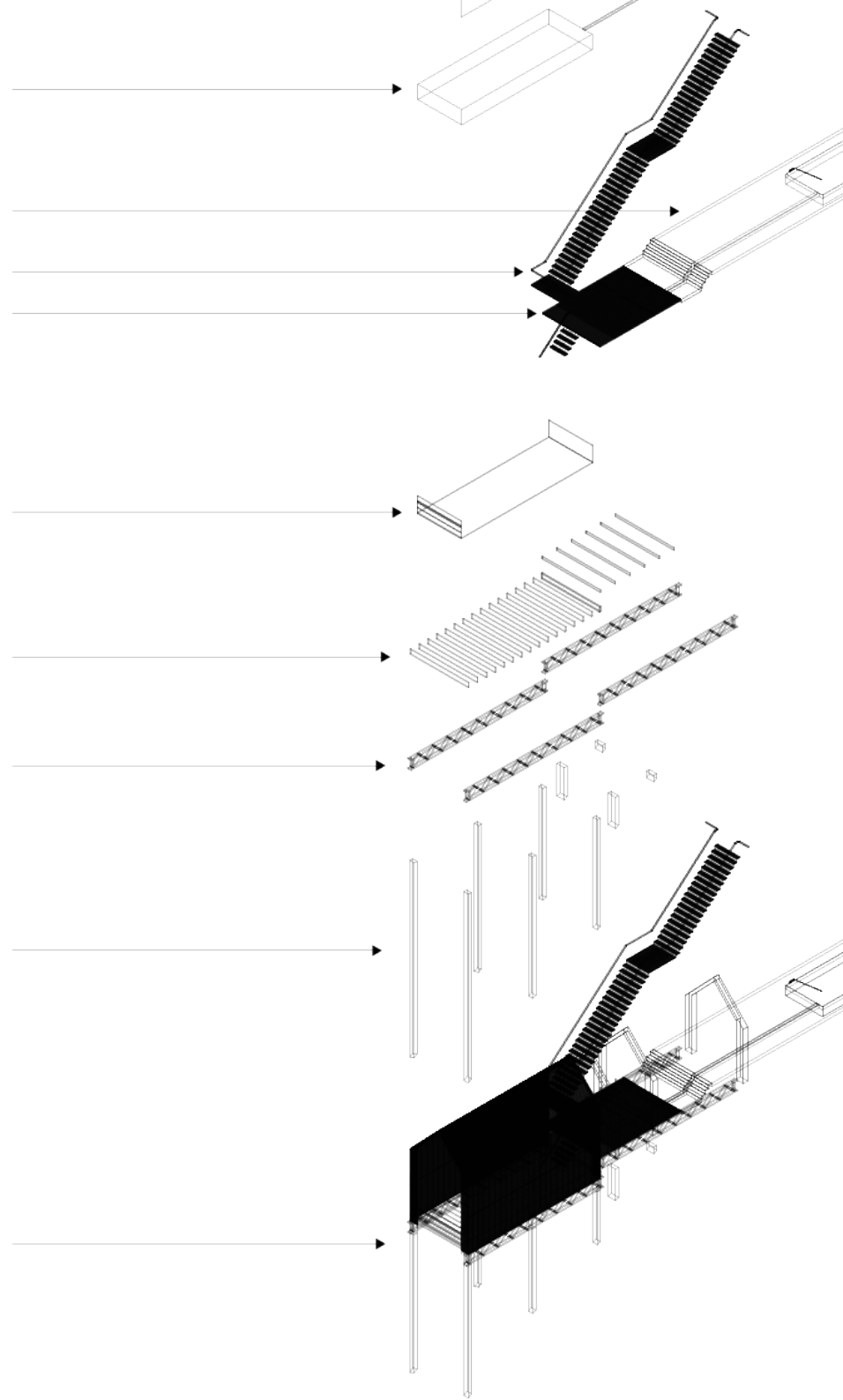
50 x 50mm Silver Pine

slats, exterior cladding

$500 \mathrm{~mm}$ Silver Pine double

framed wall

White painted Aqua ply,

interior lining

$5 \mathrm{~mm}$ black steel openings

Internal partition walls

Hot Thermal Water

$40 \mathrm{~mm}$ Silver Pine timber

boards, bath sides

$20 \times 50 \mathrm{~mm}$ Silver Pine

slats at $40 \mathrm{~mm}$ centres

150 x 63mm Silver Pine

LVL joists at 600 centres

$600 \times 200 \mathrm{~mm}$ Silver Pine

trusses

$200 \times 300 \mathrm{~mm}$ Silver Pine

piles

The Kokiri Bath

$7.0 \mathrm{kPa}$ dead load

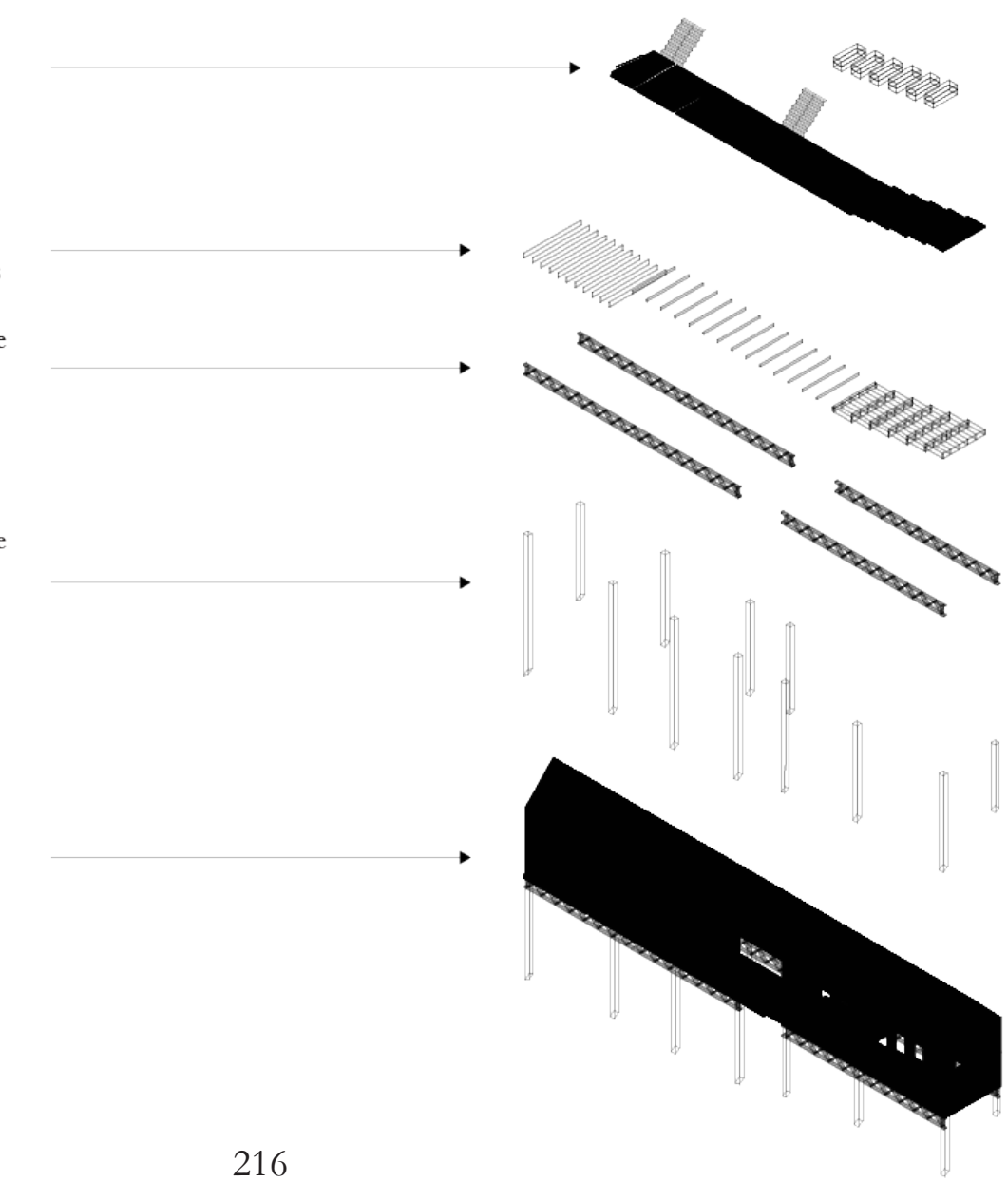


$50 \times 50 \mathrm{~mm}$ Silver Pine

slats, exterior cladding

n

$500 \mathrm{~mm}$ Silver Pine double framed wall

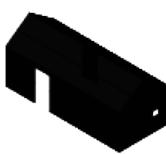

Concrete

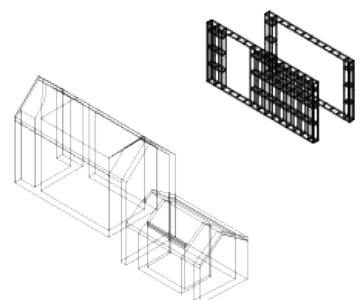

White painted Aqua ply, interior lining

Black steel handrail

$600 \times 200 \mathrm{~mm}$ Silver pine

trusses

$200 \times 300 \mathrm{~mm}$ Silver Pine piles

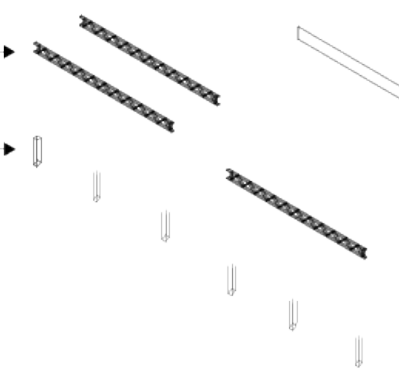

The Arahura Bath

$7.0 \mathrm{kPa}$ dead load

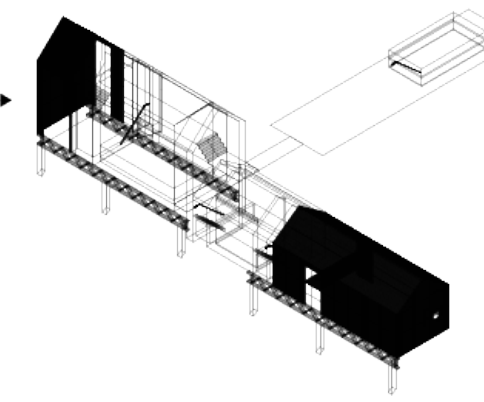


DEVELOPED DESIGN MODEL

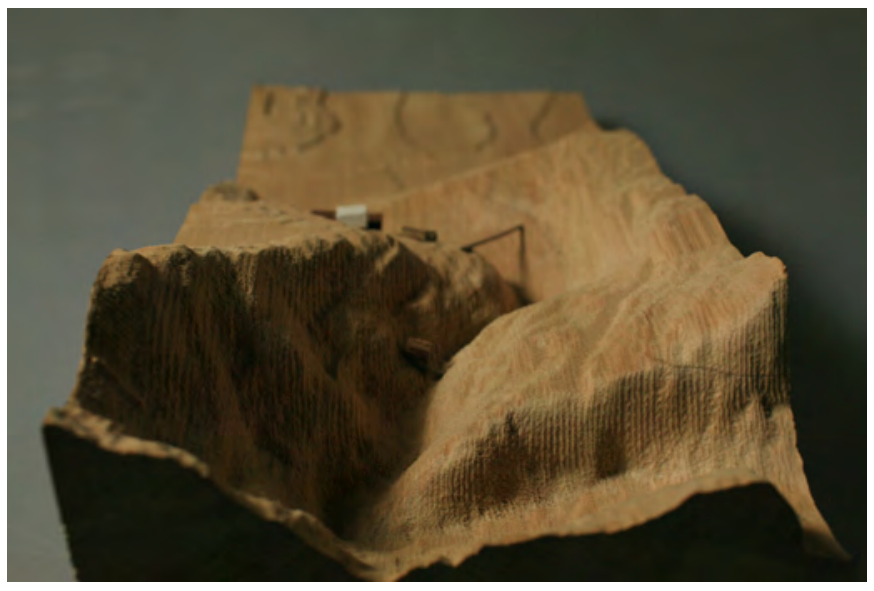



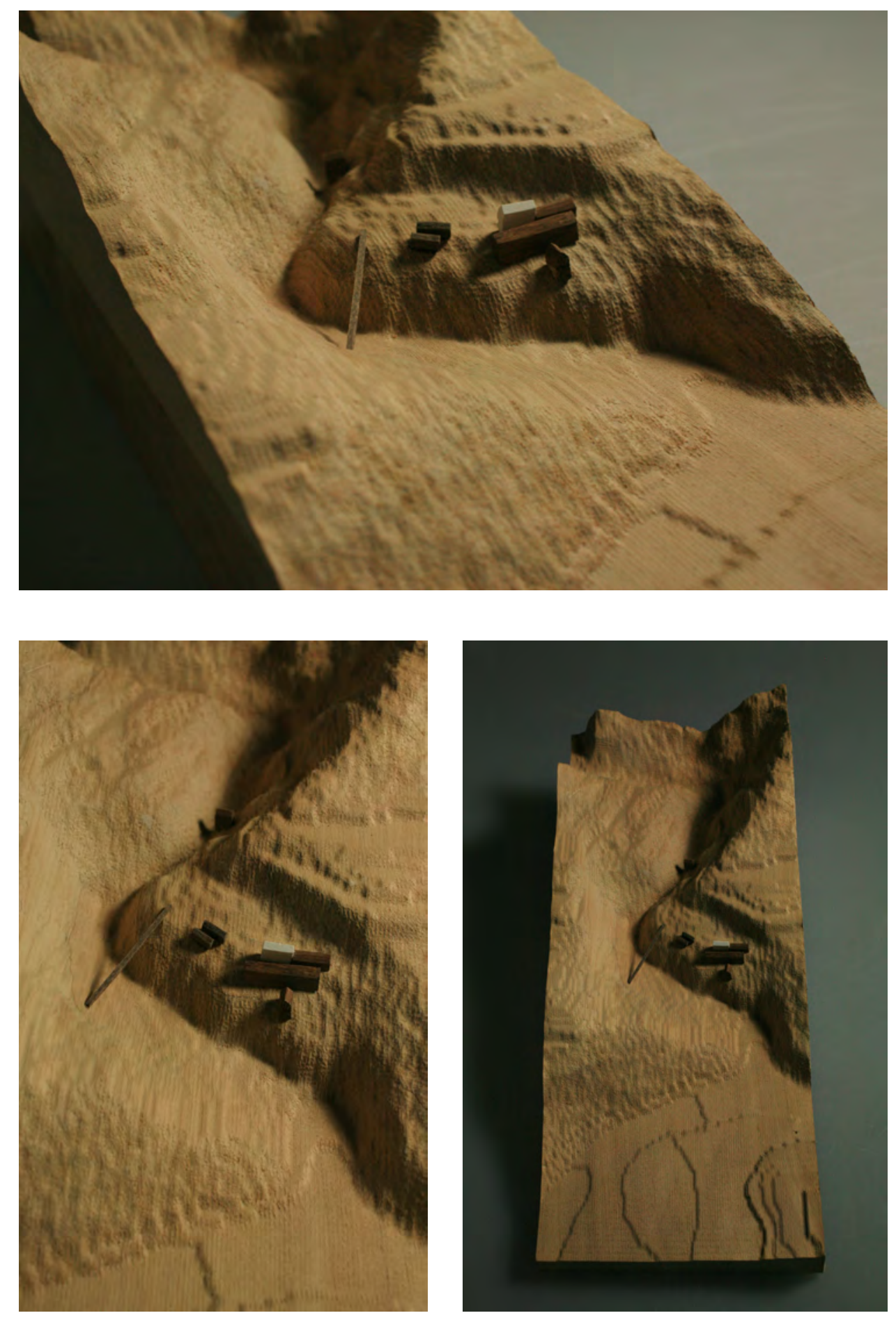

+Figure 8.25 Presentation model 


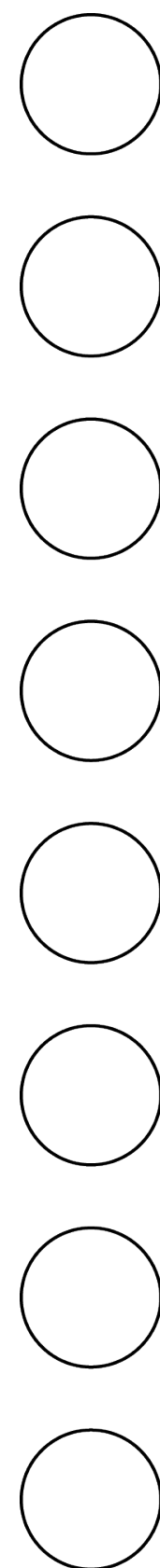

( $\ldots$ Critical Reflection ................... Critical Reflection 
CRITICAL REFLECTION

// 9 // 
The many gold miners killed in the gold rushes of the West Coast are largely unknown, unnamed people. These people, their families and their way of life are being slowly forgotten and descendants and friends of the lost have few places to remember. The primary aim of this thesis was to not only memorialise the lost gold miners and their way of life, but also to offer a model for a memorial that could provide better space for New Zealanders who are experiencing grief to remember, reflect and thereby improve their mental wellbeing.

This thesis has tested different architectural methods to overcome grief and to memorialise tragedy and loss while providing for a heightened level of mental wellbeing. This has been achieved by exploring theoretical models that both lie within the architectural realm and beyond it: the model of Kessler - Kübler-Ross was tested through circulation, spatial arrangement and individual building function. As people heal in a range of different ways the Kessler - Kübler-Ross model was expressed through the use of communal space, individual space and isolated space. Theories on memory by Halwbaches and Proust were applied via scale of space, tactility of surface and lighting levels. Writing on contemplation by Kirk, Ando and Croutier was applied through building openings, the sound of the building and lighting levels. This process has been productive as it has enabled the integration of visitors' thoughts with architectural design and providing a solution to how contemplative, memory provoking and a healing architecture can be achieved.

Through this architectural project I have investigated, interpreted and presented via architecture the historical knowledge and understanding of a life that is slowly being forgotten. The architecture itself has explored methods of memorialisation of an era through contextual design. This has led to the preservation and exhibition of architectural regionalism and place identity of the West Coast. The developed design offers a model for how 
design and building in remote, pristine landscape can be performed and suggests opportunities for future possibilities. The developed design was intended for the use of those experiencing grief after the loss of a gold miner and to also remember those who lost their lives to gold mining on the West Coast. Inevitability, this memorial will not only function to heighten the mental wellbeing of those who experience loss through a gold mining disaster, but will enrich the wellbeing of the wider community. There will be those who will visit the memorial purely for recreational purposes. It is my hope that anybody who experiences this memorial can be prompted to contemplate and thereby improve their mental wellbeing.

The main task of this project has been how to design a memorial that improves mental wellbeing without providing a depressing experience. The building needed to be comfortable enough to facilitate healing, while having the gravitas of a memorial. I did not want this place to become a resort, so it was imperative to remind people that this is a memorial. The nine segregated interventions on the journey to and from the memorial provide a heavy, weighted aspect which encourages contemplation and healing without making bathing a superficial or depressing experience.

While these baths memorialise tragedy and loss, they also celebrate a way of life as visitors see where these miners worked and lived year-round. This celebration remains the lasting legacy of the design. 


\section{WORKS CITED}

Ando, Tadao. Tadao Ando : light and water. New York: Monacelli Press, 2003. Print.

Assmann, Jan and John Czaplicka. "Collective Memory and Cultural Identity." New Ger man Critique 65 (1995): 125-133. Web. 24 November 2016.

Basden, et al. "A Comparison of Group and Individual Remembering: Does Collaboration Disrupt Retrieval Strategies?" Journal of Experimental Psychology: Learning, Memory, and Cognition 23.5 (1997): 1176-1189. Web. 20 November 2016.

Bishop, Jane and Malcolm Walker. Westland Country: a Centennial Album 1876-1976. Westland County: Pegasus, 1977. Print.

Blackwood, Michael (director). Tadao Ando. Blackwood Films, 2005. Film.

Brown, Norman. "Organization of Public Events in Long-Term Memory." Journal of Experimental Psychology: General (1990): 297-314. Web. 20 November 2016.

Brunner, Thomas. The Great Journey: an expedition to explore the interior of the Middle Island, New Zealand. Christchurch: Pegasus, 1846-1848. Print.

Carroll, Joanne. "Unique West Coast gold dredge for sale." 21 January 2016. Stuff. Web. 7 January 2017.

CAA. Aerodrome Design: Heliports. Code. Lower Hutt: Civil Aviation Authority, 2007. Web. 29 January 2017.

Collins, Catherine and Alexandra Opie. "When places have agency: Roadside shrines as traumascapes." Continuum 24.1 (2010): 107-118. Web. 25 September 2016.

Croutier, Alev Blyth. Taking the Waters: Spirit, Art, Sensuality. Singapore: Abbeville Pub lishing, 1992. Print. 
Delton, Andrew, et al. "The Psychosemantics of Free Riding: Dissecting the Architec ture of a Moral Concept.” Journal of Personality and Social Psychology (2012): 12521270. Web. 23 November 2016.

Dwyer, Owen and Derek Alderman. "Memorial Landscapes: analytic questions and metaphors.” GeoJournal (2008): 165-178. Web. 24 November 2016.

Eberhard, John. Brain Landscape: The Coexistence of Neuroscience and Architecture. Oxford University Press, 2009. Web. 21 November 2016.

Faris, Irwin. Charleston (Nelson Province, New Zealand): its rise and decline. Capper Press, 1941. Print.

Fraser, Murray. Design Research in Architecture: An Overview. Farnham: Ashgate Publishing, 2013. Print.

Grzelelwski, Derek. "Buller - The Mighty River." New Zealand Geographic 1997. Web. 7 January 2017.

Hague, Cliff and Paul Jenkins. Place Identity, Participation and Planning. Psychology Press, 2005. Print.

Halbwachs, Maurice. The Collective Memory. Trans. Francis Ditter, Jr and Vida Yazdi Ditter. New York: Harper \& Row, 1950. Print.

Hamer, David Allan. New towns in the New World. New York: Columbia University Press, 1990. Print.

Hammond, Janny. Bush Carpenters, Pioneer Homes in New Zealand. J. McIndoe, 1979. Print.

Heathcote, Edwin. Monument Builders: Modern Architecture and Death. New Jersey: Wiley, 1999. Print.

Human Rights Commission. “11. Right to Health.” 2010. Web. 22 September 2016.

(ICESCR). Human Rights for All, International Covenant on Economic, Social and Cultural Rights: A Handbook. New Delhi: PWESCR (Programme on Women's Economic, Social and Cultural Rights), 2015. Web. 21 September 2016. 
Jackson, Sally. Hot Springs of New Zealand. Auckland: Reed, 2001. Print.

Kessler, David and Elisabeth Kübler-Ross. On Grief and Grieving: Finding the meaning of Grief Through the Five Stages of Loss. Scribner, 2005. Print.

Kirke, Philip James. The Infinte and the Intimate: Notes for an Architecture of Meditative Bliss. Friend Books, 2007. Print.

Maclean, Chris and Jock Phillips. The Sorrow and the Pride: New Zealand War Memorials. Historical Branch, GP Books, 1990. Print.

Massey, Doreen. "Geographies of Responsibility." Geografiska Annaler 86.The Political Challenge of Relational Space (2004): 5-18. Web. 15 August 2016.

Massey, Lyle. Picturing Space, Displacing Bodies: Anamorphosis in Early Modern Theories of Perspective. Pennsylvania: Penn State Press, 2007. Print.

May, Philip. The West Coast Gold Rushes. Christchurch: Pegasus, 1962. Print.

McGill, David. Ghost Towns of New Zealand. Reed, 1980. Print.

Newcomb, Rexford. "Regionalism in American Architecture." Arcbitectural Regionalism: Collected Writings on Place, Identity, Modernity, and Tradition. Ed. Vincent Canizaro. New York: Princeton Architectural, 2007. 80-95. Web. 22 February 2017.

NIWA. “Climate Extremes”. 31 December 2012. Niwa. Web. 31 January 2017.

NZ Wood. "Natural durability”. NZ Wood. Web. 1 February 2017.

Pascoe, John. “The New Zealand Death.” New Zealand's Heritage. Sydney: Hamlyn house, 1971. 556-560. Print.

Pavlides, Eleftherios. "Four Approaches to Reginalism in Architecture." in Canizaro, Vincent. Architectural Regionalism. New York: Princeton Architectural, 2007. 157-167. Print.

Paulin, Robert. The Wild West Coast of New Zealand: A Summer Cruise in the "Rosa". Harvard University: Thoburn, 1889. Web. 20 February 2017. 
Proust, Marcel. In Search of Lost Time: Volume 1: The Way by Swann's. Ed. Christopher Prendergast. Trans. Lydia Davis. Vol. 1. New York: The Penguin Group, 2002. 7 vols.

Relph, Edward. Place and Placelessness. London: Pion Limited, 1976. Print.

Richardson, Len. Coal, class and community: the united mineworkers of New Zealand, 1880-1960. Auckland: Auckland University Press, 2013. Print.

—. The Denniston Miners' Union: a centennial history. Auckland: Auckland University Press, 1984. Print.

Ringelmann, Maximilen. “Recherches sur les moteurs animés: Travail de l'homme." Annales de l'Institut National Agronomique 12 (1913): 1-40.

Rockel, Ian. Taking the Waters: Early Spas in New Zealand. Wellington: Government Printing Office Publishing, 1986. Print.

Seager, Samuel Hurst. "Housing of Miners.” Wanganui Herald. 27 June 1919. Web. 7 January 2017.

Smith, Barry. "Proust, the Madeleine and Memory." Groes, Sebastian. Memory in the Twenty-First Century: New Critical Perspectives from the Arts. Hampshire: Palgrave Macmillan, 2016. 38-41. Web. 20 February 2017.

Stephens, Suzanne. "Steilneset Memorial To The Victims Of The Witch Trials Peter Zumthor And Louise Bourgeois Vardø, Norway.” Architectural Record 199.8 (2011): 36-40. Web. 27 January 2017.

Stone, Charles and William Hirst. "(Induced) Forgetting to form a collective memory." Memory Studies 7 (2014): 314-327. Web. 20 November 2016.

Sullivan, M. "Forward." Bishop, Jane and Malcolm Walker. Westland Country: A Centenial Album 1876-1976. Westland County: Pegasus, 1977. Print.

Ulrich, Roger. "View through a Window May Influence Recovery from Surgery." Science (1984): 420-421. Web. 10 November 2016. 
UNHCHR. Fact Sheet No. 31: A Right to Health. Geneva: WHO Press, 2008. Web. 21 September 2016.

Uren, Allen. "The Moaning of The Bar.” New Zealand Geographic 64 (2003). Web. 20 February 2017.

Wilson, Edward. Biophilia. London: Harvard University Press, 1986. Web. 7 December 2016.

WHO. Preamble to the Constitution of the World Health Organization as adopted by the International Health Conference. New York, 1946. Web. 22 September 2016.

Yarwood, Vaughan. "Coal on The Coast: Between a rock and a hard place." New Zealand Geographic 26 (1995). Web. 20 February 2017.

\section{FIGURE LIST}

All figures or photos not cited are authors own

Figure 1.01. "The Fern Arch 1880s, Buller Gorge". Museum of New Zealand, Te Papa Tongarewa. Photograph. 1 February 2017. <http://collections.tepapa.govt.nz/ob ject $/ 234930>$.

Figure 1.02. "Biddy of the Buller - pictured with pipe in mouth, holding her gold prospect ing equipment”. Westcoast Recollect, Reefton. Photograph. 31 January 2017. $<$ http://westcoast.recollect.co.nz/nodes/view/1160>.

Figure 1.03 “The Crystal Springs, 1920, an early pool for bathing in New Zealand”. Photograph; Rockel, Taking the Waters, p.130.

Figure 1.04. "The Fairy Bath, 1895, one of the most attractive early baths in New Zea land". Photograph; Rockel, Taking the Waters, p.126.

Figure 2.01. "European Hotel, 1868, the Original Place of Contemplation and Healing". Alexander Turnbull Library, Wellington. Photograph. 31 January 2017. <http:// natlib.govt.nz/records/22326088>.

Figure 3.01. "Franz Joseph Glacier Viewing Platform”. Westcoast Recollect. 1907. Postcard. 31 January 2017. <http://westcoast.recollect.co.nz/nodes/view/2300>. 
Figure 3.06. "1890s Fluming Construction on a Precipitous Rock Face”. Tyree Collection,

Nelson Provincial Museum. 1890. Photograph. 31 Febuary 2017. <https://collection. nelsonmuseum.co.nz/objects/P30883>.

Figure 3.10. "Fox River Bridge South Westland, Before More Permanent Infrastructure".

Westcoast Recollect. n.d. Photograph. 31 January 2017. < http://westcoast.recollect.

co.nz/nodes/view/7334>.

Figure 3.11. "Greenstone 1866". Westcoast Recollect. Photograph. 31 January 2017. <http:// westcoast.recollect.co.nz/nodes/view/13246>.

Figure 3.12. "Napoleon's Hill, about 1869”. Photograph; May, West Coast Gold Rushes, p.191.

Figure 3.13. "Kaniere, about 1869". Photograph; May, West Coast Gold Rushes, p.319. 046

Figure 3.14. Price, William, "Seddonville". Westcoast Recollect. Photograph. 31 January

2017. <http://westcoast.recollect.co.nz/nodes/view/12021>.

047

Figure 3.15. “The Road to Waiuta, 1909”. Photograph; Darrell Latham, Golden Reefs: An

Account of the great Days of Quartz-Mining at Reefton, Waiuta and the Lyell, (Pegasus, 1984) p.289.

Figure 3.16. "This is a North Island scene but similar views would have been common on the West Coast". Photograph; Nolan, Historic Gold Trails of Nelson and Marlborough, (A. H. \& A. W. Reed, 1976), p.72.

Figure 3.17. "Humphrey's Gully fluming, 1880s, the longest water race in the colony".

Photograph; Bishop \& Walker, Westland County, p.81.

Figure 3.18. “The Snowy River Battery 1908-1936”. Photograph.; Latham, The

Golden Reefs, p.320.

Figure 3.19. "Gold dredge on the Buller River". Westcoast Recollect. Photograph. 31 January

2017. <http://westcoast.recollect.co.nz/nodes/view/11982>.

051

Figure 3.20. "Rimu gold dredge and its tailings". Photograph; Bishop \& Walker, Westland County, p.85.

Figure 3.21 Sophisticated Industrial fluming extending its way through Dillmanstown.

Photograph; Bishop \& Walker, Westland County, p.9.

Figure 3.23. "Truck on Perseverence Bridge after a washout, ca early 1960s". Westcoast

Recollect. 1960. Photograph. 31 January 2017. <http://westcoast.recollect.co.nz/

nodes/view/13296>.

Figure 3.24 "Elderly gold miner outside his hut at Kirwans". Alexander Turnbull Library,

Wellington. Photograph. 31 January 2017. <http://natlib.govt.nz/re

cords/22374252>. 
Figure 3.25. "Early miners camp near Buller". Westcoast Recollect. Photograph. 31 January 2017. <http://westcoast.recollect.co.nz/nodes/view/8778>.

Figure 3.26. "Geordie Wiltshire outside his slab hut". Westcoast Recollect, Lake Kaniere.

Photograph. 31 January 2017. <http://westcoast.recollect.co.nz/nodes/view/916>.

Figure 3.27. "Goldminers hut South Westland". Westcoast Recollect, South Westland.

Photograph. 31 January 2017. <http://westcoast.recollect.co.nz/nodes/ view/4827>.

Figure 3.31. "Kaniere Dredge on the Taramakau". Westcoast Recollect, Taramakau. Photo graph. 31 January 2017. <http://westcoast.recollect.co.nz/nodes/view/ $8853>$.

Figure 3.32. "Koh-i-noor gold dredge". Photograph; Bishop \& Walker, Westland County, p.86.

Figure 3.37. "The Snowy River Battery at Waiuta”. Photograph; Latham, The

Golden Reefs, p.320.

Figure 3.40. "The stamping battery at the Snowy River Battery". Westcoast Recollect,

Photograph. 31 January 2017. <http://westcoast.recollect.co.nz/nodes/ view/15279>.

Figure 3.41. "The washroom at the Snowy River Battery". Westcoast Recollect. Photograph.

31 January 2017. <http://westcoast.recollect.co.nz/nodes/

view/15841>.

066

Figure 4.07, Phillips, Jock. "Fallen Soldiers Memorial". Te Ara - the Encyclopedia of New

Zealand. Photograph. 31 January 2017. <http://www.TeAra.govt.nz/en/photo graph/22756/war-memorial-otago-peninsula $>$.

Figure 4. 08, Hallett, David. "185 Chairs”. Stuff. Photograph. 31 January 2017. <http:// www.stuff.co.nz/the-press/news/68548793/185-earthquake-memorial-chairsface-uncertain-future>.

Figure 4. 09, Nathan, Simon. "South African War Memorial”. New Zealand History,

Westport. Photograph. 31 January 2017. <https://nzhistory.govt.nz/media/ photo/south-african-war-westport-memorial>.

Figure 4.11, Comfort, Bruce and Francis Vallance. "Kaiapoi War Memorial". New Zealand History. Photograph. 31 January 2017. < https://nzhistory.govt.nz/media/photo/ kaiapoi-war-memorial>. 
Figure 4.12. "Greymouth War Memorial Baths". Westcoast Recollect, Greymouth. Photo graph. 31 January 2017. <http://westcoast.recollect.co.nz/nodes/view/12545>.

Figure 4. 13. "Greymouth War Memorial Baths". Westcoast Recollect, Greymouth. Photo graph. 31 January 2017. <http://westcoast.recollect.co.nz/nodes/view/6883>.

Figure 4. 14. "Paihia War Memorial Hall”. Westcoast Recollect. Photograph. 31 January 2017. $<$ https://nzhistory.govt.nz/media/photo/paihia-memorial-hall>.

Figure 4. 15. "Waitawheta War Memorial Hall". Waitawheta Camp. Photograph. 31 January 2017. <http://www.waitawhetacamp.co.nz/facilities>.

Figure 4. 16, Lambert, Ron. "Memorial Baths at Manutahi School". New Zealand History. Photograph. 31 January 2017. <https://nzhistory.govt.nz/media/photo/manutahiwar-memorial>.

Figure 4. 17, Meredith, Andrew. "The Steilneset Memorial”. Archdaily. Photograph. 31 January 2017. <http://www.archdaily.com/213222/steilneset-memorial-peterzumthor-and-louise-bourgeois-photographed-by-andrew-meredith/a4544449>.

Figure 4. 18, Meredith, Andrew. "Louise Bourgeois' Piece”. Archdaily. Photograph. 31 January 2017. <http://www.archdaily.com/213222/steilneset-memorial-peterzumthor-and-louise-bourgeois-photographed-by-andrew-meredith/a4544250>.

Figure 4. 19. "Peter Zumthor's Memorial (Interior)". Arch2o. Photograph. 31 January 2017. $<$ http://www.arch2o.com/steilneset-memorial-peter-zumthor-louisebourgeois $/>$.

Figure 4. 20. "Memorial des Martyrs de la Deportation". independent travel cats. Photograph. 31 January 2017. <http://independenttravelcats.com/2013/11/03/visiting-depor tation-memorial-ile-de-la-cite-paris/>.

Figure 4. 21. "Memorial des Martyrs". Flickr. Photograph. 31 January 2017. <https://www. flickr.com/photos/ryanhadley/5898186458>.

Figure 4. 22, Bours, Lionel. "Courtyard + Entry to Crypt". Photograph. 31 january 2017. $<$ http://l.bours.free.fr/portfo-lio/index.php?showimage=131/>.

Figure 4. 23. "Framed View of Seine River". 2bdm Architecture \& Patrimone. Photograph. 31 January 2017. <http://www.2bdm.fr/projets/memorial-des-martyrs-de-ladeportation/>. 
Figure 4. 24. “The Therme Vals”. Photograph. 31 January 2017. <https://www.yahoo. $\mathrm{com} /$ news/news/poetry-space-vals-thermal-spa-switzerland-160000836.

html? ref $=$ gs>. 098

Figure 4. 25, Guerra, Fernando. "Outdoor Baths”. Archdaily. Photograph. 31 January 2017. $<$ http://www.archdaily.com/798360/peter-zumthors-therme-vals-through-the -lens-of-fernando-guerra/580fae8ce58ece64b8000030-peter-zumthors-therme -vals-through-the-lens-of-fernando-guerra-photo>.

Figure 4. 26, Guerra, Fernando. "Interior Baths”. Archdaily. Photograph. 31 January 2017. $<$ http://www.archdaily.com/798360/peter-zumthors-therme-vals-through-thelens-of-fernando-guerra/580fb5b6e58ecefd67000093-peter-zumthors-thermevals-through-the-lens-of-fernando-guerra-photo>. 
C O M F O R A B L E
CONTEMPLATION 